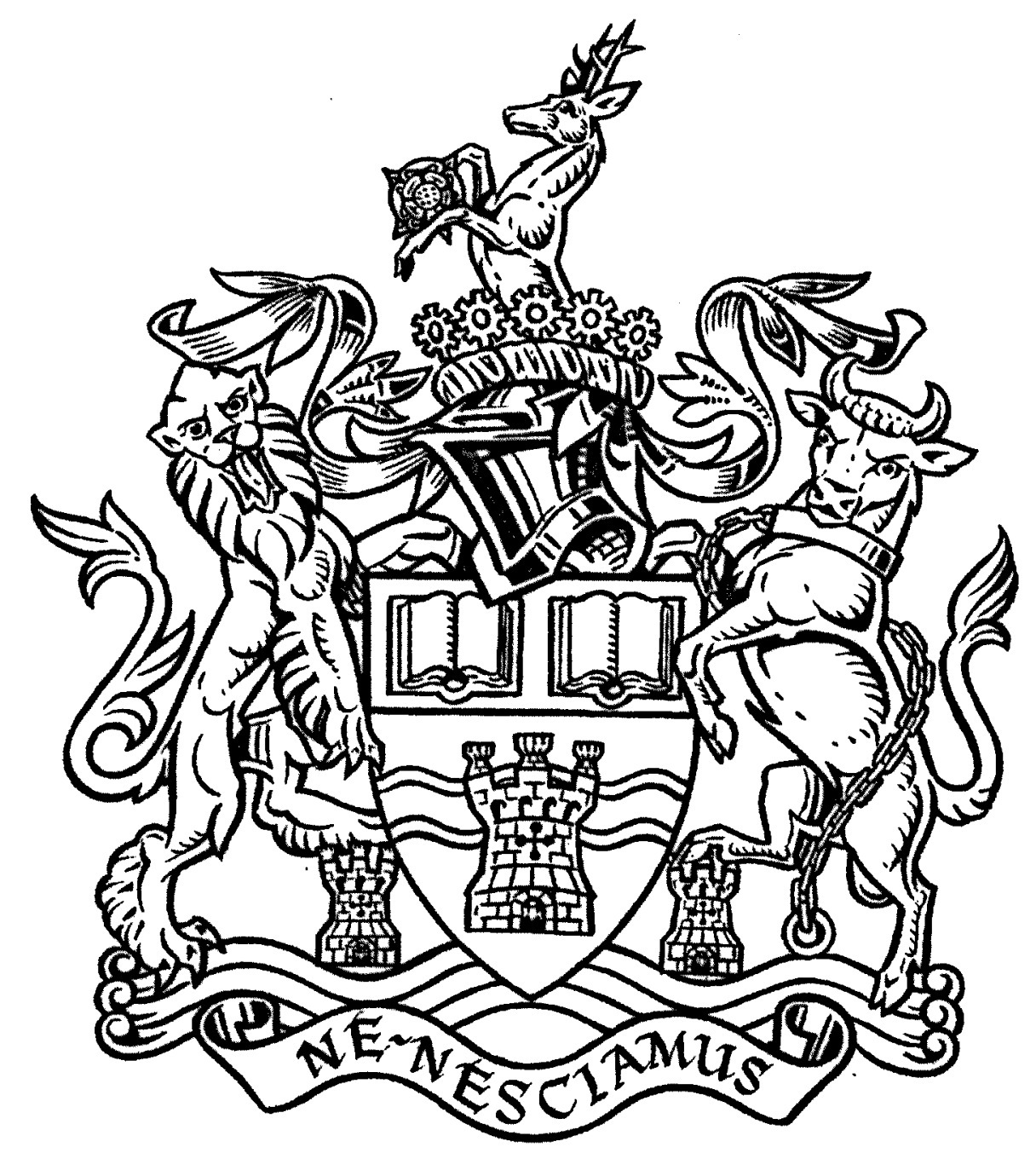

\title{
Teacher Career Motivation and Professional Development in Special and Inclusive Education in China
}

\begin{abstract}
Submitted for the Degree of Doctor of Philosophy At the University of Northampton
\end{abstract}

\section{9}

\section{FENG YAN}

This thesis is copyright material and no quotation from it may be published without proper acknowledgement

UNIVERSITY OF NORTHAMPTOY
PARK LIBRARY
ACC. NO. 10349891
CLASS NO.D371.90460951 FEN




\section{Contents}

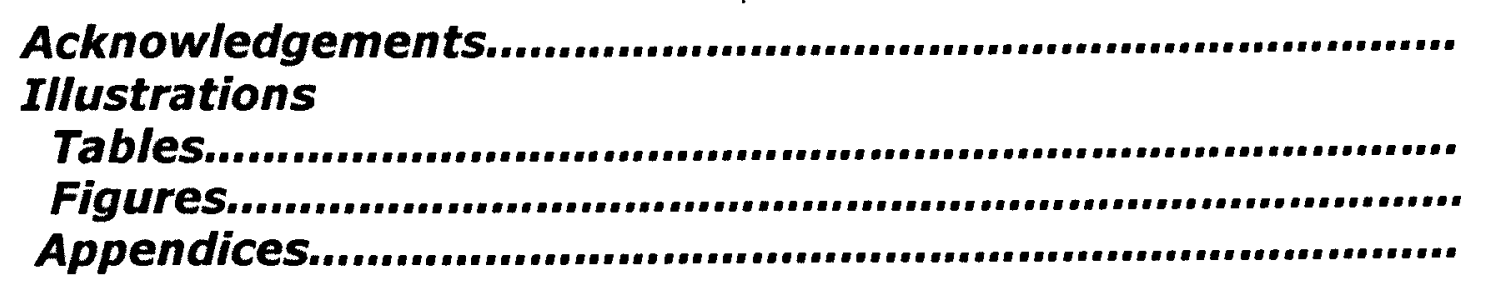

Abstract...

\section{Chapter One: Introduction.}

1.1 The topic and the context of this PhD study.

1.2 The assumptions and hypotheses.

1.3 The motivation for the study.

1.4 The research questions.

1.5 The purposes of the study.

1.6 The nature of the study...

1.7 The aims and objectives of the research.

1.8 The structure of the thesis.

Chapter Two: Research Contexts.................................... 8

2.1 The international research context............................................................................. 8

2.2 The research context in China.................................................................................. 13

Chapter Three: Literature Review (I)............................ 34

3.1 Motivation theories for researching teacher career choice................................... $\quad 35$

3.2 Teacher career motivation in special and inclusive education................................. 40

3.3 Motivation theory for the current research on teacher career motivation in special and inclusive education in China.

Chapter Four: Literature review (II) $\ldots \ldots \ldots \ldots \ldots \ldots \ldots \ldots \ldots \ldots \ldots \ldots \ldots$

4.1 Special and inclusive education............................................................................... 50

4.2 Teachers' knowledge and understanding of special and inclusive education.... $\quad 52$

4.3 Teachers' attitudes towards special and inclusive education.................................. 56

\section{Chapter Five: Literature Review (III)}

5.1 Teacher professional development in international contexts.

5.2 Demands for new models of professional development: opportunities and challenges in the Chinese context

5.3 Teacher motivation for professional development in special and inclusive education.

Chapter Six: Methodology (I).

6.1 Research design.

6.2 Research approach

6.3 Sampling 
7.1 Methods of data collection

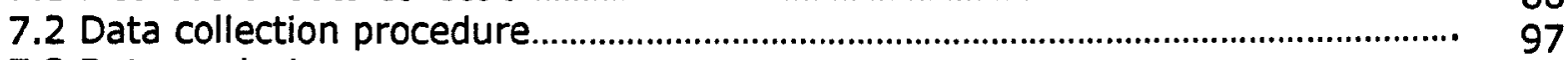

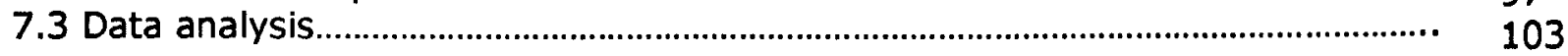

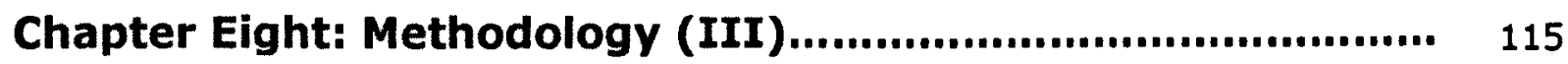

8.1 Originality of the study.

8.2 Methodological challenges.

8.3 Ethical issues in conducting the study................................................................... 118

\section{Chapter Nine: Findings}

9.1 Teacher career motivation in special and inclusive education.

9.2 Professional knowledge and understanding of and attitudes towards special and inclusive education.

9.3 Teacher professional development in special and inclusive education

Chapter Ten: Discussion (I)

10.1 Quantity and quality of teachers in special and inclusive education in the current study.

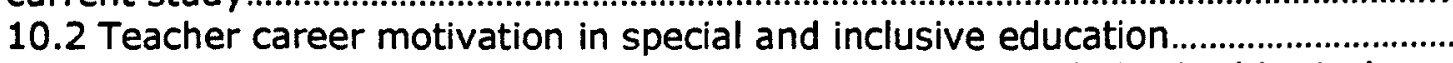

10.3 Key motivational factors contribute to teacher career choice in this study......

Chapter Eleven: Discussion (II).

11.1 Knowledge and understanding of special and inclusive education.

\section{Chapter Twelve: Discussion (III)}

12.1 Models of teacher professional development.

12.2 Teachers' awareness of and perspectives on the importance of professional development.

12.4 Factors influencing teacher motivation for professional development.................

12.5 The correlation between career motivation for, attitudes towards special and inclusive education and the motivation for professional development..

Chapter Thirteen: Conclusions.

13.1 A summary of the research and the findings.

13.2 The significance of the findings.

13.3 The limitations of the study.

13.4 The implications of the study 


\section{Acknowledgements}

I would like to acknowledge the encouragement of my friends and colleagues in the journey of my PhD study. Specifically, I would like to express my thanks to the head-teachers for their consent to research the staff in their schools and to the participants for their contribution to the evidence gathered for this study. I also highly appreciate the opportunity offered by the School of Education of the University of Northampton, which provided me with the rewarding experiences working with colleagues in the Centre for Special Needs Education and Research.

My heartfelt thanks go to Dr. Paul Bracey and Professor Sue Ralph for their advice at the later stage of my study. My special gratitude goes to Professor Richard Rose and Professor Philip Garner for their years' supervision, support as well as expectations, which have and will always have an impact on my future personal and professional development.

I would not be able to even start this PhD study without the love, understanding and support from my family, especially my husband TAO Feng and my daughter TAO Ran, whom I love and will always do. 


\section{Illustrations}

\section{Tables}

2-1: Basic statistics of the number of schools, students and teachers in China by levels of education in 1,000 unit (2007).

2-2: Basic statistics of schools, students and teachers in special education in China and Zhejiang Province (2007).

2-3: The description of the university and the schools for the research.

7-1: Survey distribution and return.

7-2: Categorising and segmenting data from special school teachers on Survey question 1: Why did you choose to be a teacher?

9-1: Percentage of questionnaire survey data (agree or strongly agree to the close statements) regarding teacher career motivation in special and inclusive education from the three cohorts.

9-2: Percentage of intrinsic motivation influencing teacher career choice from the open-ended questionnaire surveys from the three cohorts: Why did you choose to be a teacher?

9-3: Percentage of extrinsic motivation influencing teacher career choice from the open-ended questionnaire surveys from the three cohorts: Why did you choose to be a teacher?.

9-4: Data in percentage from questionnaire surveys and interviews on the factors influencing teaching in general and teaching in special schools from special school teachers.

9-5: Percentage of amotivation influencing teacher career choice from the openended questionnaire surveys: Why did you choose to be a teacher?...

9-6: Percentage of questionnaire survey data (agree or strongly agree to the close statements) regarding teachers' qualification of and attitudes towards special and inclusive education from the three cohorts.

9-7: Interview data in percentage on professional qualifications in special education from special school teachers $(N=22)$.

9-8: Survey data in percentage from the mainstream school teachers and student teachers: How do you understand special education?

9-9: Survey data in percentage from the mainstream school teachers and student teachers: How do you understand inclusive education?

9-10: Survey data in percentage from the mainstream school teachers and student teachers: Do you have any comments on special and inclusive education?.

9-11: Survey data in percentage from the three cohorts on the awareness of and motivation for professional development. 
9-12: Data in percentage of the close-ended questions from the survey to the three cohorts on teachers' perceptions on the chances and opportunities for professional development.

\section{Figures}

10-1: Self-Determination Continuum. 


\section{Appendices}

Appendix I: The motivation for the PhD study...................................................... 222

Appendix II: The research context in China: additional information.......................... 225

Appendix III: Basic Statistics on Special Education by Region (2007)..................... 229

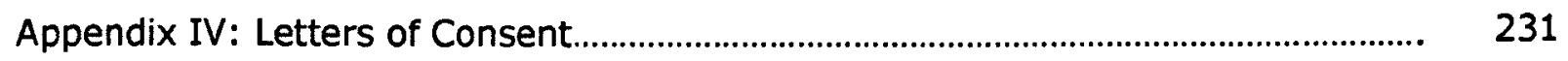

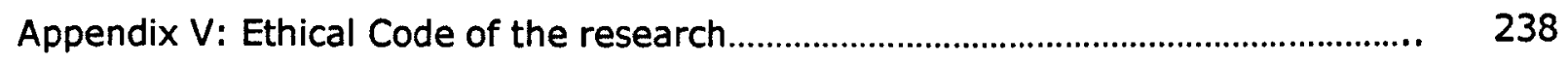

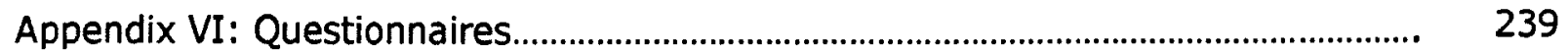

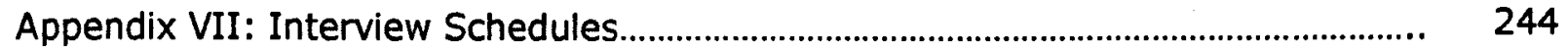

Appendix VIII: Observation schedule.................................................................... 248

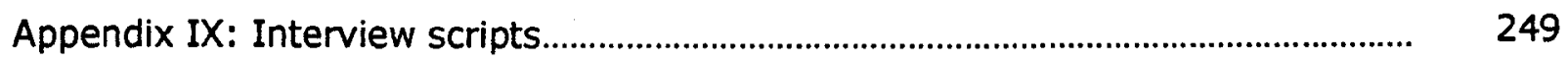

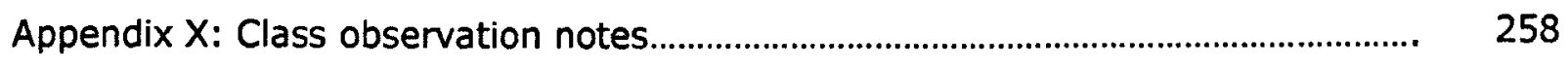

Appendix XI: Data: An example of motivational change according to the SDT

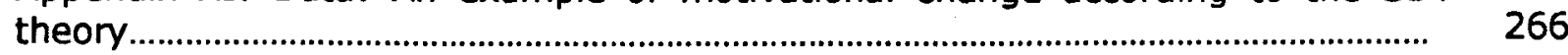

Appendix XII: The implications from the ethical issues in the current study............ 268 


\title{
Teacher career motivation and professional development in special and inclusive education in China
}

\begin{abstract}
:
Limited evidence is available from the existing literature that relates teachers' career motivation to their attitudes towards special and inclusive education and their motivation for professional development in China. A mixed-method approach was used to investigate teachers' perspectives on their professional life in this respect. A sample of teachers at seven mainstream schools $(N=326)$, two special schools $(N=37)$ and student teachers from one university $(N=565)$ in a city in China was identified. Triangulation of data collected from questionnaire surveys, interviews and observations facilitated the identification of cases for narrative enquiry. Self-Determination Theory (SDT) was applied in data analysis and discussion. The key findings are as follows:
\end{abstract}

First, teachers researched were mostly extrinsically motivated. Some were amotivated (unwilling) and were regretful of their career choice. The majority of them would have chosen other professions if possible. Second, special school teachers' extrinsic motivation for working in special schools became less controlled and more autonomous with the accumulation of knowledge and skills in teaching practice. Similarly, their initial unwillingness had altered to controlled extrinsic motivation or even autonomous motivation. Third, initial teacher education had prepared teachers with limited knowledge and understanding about special and inclusive education. This contributed to the less positive attitudes towards inclusive education. Despite a high awareness of, and motivation for professional development, most teachers were not taking an active initiative in engaging themselves in professional development.

The thesis highlights the impact of teacher recruitment policies on career motivation, models of initial and continuing teacher training on teacher attitudes, values and incentives for professional development. This study implies a correlation between the key themes and extends the discussion of the SDT model in terms of the continuum of extrinsic motivation. 


\section{Chapter One: Introduction}

\subsection{The topic and the context of this PhD study}

The PhD study reported in this thesis is on 'Teacher career motivation and professional development in special and inclusive education in China'. It was undertaken in order to investigate the current context in China which, in common with other countries, is in the process of moving towards a more inclusive education system. The study places a special focus on the trends, opportunities and challenges of teacher education in terms of teacher career motivation and professional development in special and inclusive education. Nevertheless, it was never intended to be set in the context of China as a whole. The capacity to do this in a country as vast and diverse as China is beyond a study of this nature. Practicalities only allowed me to investigate teachers from a limited number of mainstream and special schools and student teachers from a university in a single city, located about a hundred miles south of Shanghai. This more local and familiar context created an opportunity for me to develop a purposive and selective sample for the case study materials, as will be described later in this thesis.

\subsection{The assumptions and hypotheses}

The assumptions and hypotheses emanated from $\mathrm{my}$ personal learning experiences, and my direct contact through observations and discussions with people involved in special and inclusive education whilst completing my Master's degree study commencing in September, 2005 in the University of Northampton. The research for this doctoral study was conducted to collect evidence for my preliminary assumptions that, a) teachers might not have a high motivation to work in special and inclusive education; b) they might not have the expected knowledge and skills for the assurance of positive attitudes towards teaching children with special educational needs (SEN) and c) they might have varied perceptions and expectations regarding their own continuing professional development in this area of education. My overall hypotheses are that, a) the nature of and low priority attached to special and inclusive education in China demotivated teachers in their career choice; b) initial teacher education programmes failed to prepare student teachers for teaching in special and/or inclusive schools; c) teachers were not provided with the necessary support or 
incentive to actively engage themselves in continuing professional development and d) there could be correlations between the three key elements, namely, their motivation to embark on a career in education, their knowledge and understanding of, and attitudes towards special and inclusive education and their motivation for participating in continuing professional development. It is my contention that these elements impact upon each other and have influenced the current state of inclusive education in China.

\subsection{The motivation for the study}

This PhD study was based on my curiosity about teachers' career motivation in special and inclusive education and professional development in China. As a university lecturer of English language in China for 19 years, I applied to further my learning in linguistics and literature in the University of Northampton. By a fortuitous route I found myself studying modules on the Master's programme in Education which focused on special and inclusive education. At that time I could not see any reason for a change of my career life into special and inclusive education, an area in which I had no knowledge or skills. My lack of motivation for the change was due to my limited understanding about children with SEN and those teachers who were working closely with them. In addition, my attitude towards inclusive education was very much negative as I was sceptical of the practicality and feasibility of inclusive schooling in China. My professional curiosity for the aforementioned assumptions and hypotheses to be evidence based motivated me to begin this study. It was my hope that the journey to the PhD could transform me from a 'restricted' professional to an 'extended' professional (Evans, 2002: 124). A more detailed personal account of the motivation for undertaking this doctoral study is contained in Appendix I.

\subsection{The research questions}

The research questions at the heart of this study were formulated from the assumptions and hypotheses which aroused my professional curiosity. During the initial period of question formulation, I involved myself in extensive reading of the international literature and discussions with professionals and researchers in this area to clarify my own assumptions and hypotheses. I realised that there was an increasing interest in this topic internationally (e.g., Kyriacou, Hultgren and Stephens, 1999; Siniscalco, 2002; Sharma, Forlin, Loreman and Earle, 2006; Malmberg, 2006; Richardson and Watt, 2006; Cameron, Berger, Lovett and Baker, 
2007; Sinclair, 2008). By contrast, there was a singular lack of literature from China reporting research in this area, especially literature related to teachers' reflections and perceptions on their career choice of working with children with SEN. This led me to the formulation of the main research question of this study:what are the major factors affecting teachers' career motivation and their professional development in special and inclusive education in China?

Given that teachers' attitudes towards special and inclusive education and professional development have attracted considerable attention (Avramidis and Norwich, 2002; Villegas-Reimers, 2003), there is arguably a gap in researching a potential correlation between teachers' career motivation and these aspects in China. Some literature has reported issues in teacher professional development in general education (Zhou and Reed, 2005; Paine and Fang, 2007). However, the perspectives of teacher motivation for a career focused upon marginalized learners or attitudes towards special and inclusive education and their professional development (Wang, Gu and Chen, 2004; Deng and Holdsworth, 2007) have been the subject of relatively little scrutiny. This provided me with an added incentive to explore what was clearly, within a Chinese context, an under researched phenomenon. This situation also assisted greatly in clarifying my main research question. Further probing of the issue indicated the need to look at other related aspects of the research focus. In particular a consideration of teachers' values, attitudes and perspectives on special and inclusive education which influenced those choices and their subsequent professional development. The sub-questions which emerged from the subsequent investigation. were shaped and refined on the basis of a limited body of literature with this regard. The following are the guiding questions which influenced the development of the data collection process:

1) What are the motivations of teachers in special and inclusive education in China?

2) What is the impact of teachers' professional knowledge and skills of and attitudes towards special and inclusive education on their career motivation?

3) What is the impact of teacher career motivation and their perspectives on special and inclusive education on their motivation for professional development? 


\subsection{The purposes of the study}

It is increasingly recognised that teachers are key stakeholders in the process of developing inclusive education (Davies and Garner, 1997; Deng and Holdsworth, 2007; Ainscow, 2008; Forlin, 2008). Yet, teachers' voices are often unheard (Shevlin and Rose, 2003) among the planning and decision making for reaching the ambitious global targets established in Education for All Global Action Plan (UNESCO, 2007). As such, I was particularly interested in listening to the perspectives of teachers working in special and inclusive education to examine the contradictory pressures on schools that seek to include and value students in a competitive educational climate which create economic and social pressures to devalue and exclude students' (Booth, Ainscow and Dyson, 1998: 193). Through this process I hoped to enhance my knowledge about teachers' professional lives in special and inclusive education. More specifically, by empowering teachers to articulate their perceptions and perspectives as well as by investigating the multiple interpretations surrounding this complex issue, I attempted to construct 'reality' regarding teachers' professional aspirations in special and inclusive education. It was hoped that the findings of the study would provide new evidence-based knowledge to inform policy, practice and further research (BERA 2004) in teacher career motivation and professional development in special and inclusive education in China and possibly beyond.

\subsection{The nature of the study}

This study was primarily exploratory in that it investigated motivation for career choices of student teachers, mainstream and special school teachers and their subsequent professional development. It was also descriptive as the purpose of the research was to collect data using a mixed or combined-method approach (Gorard and Taylor, 2004; Creswell, 2008) including narrative inquiries based on teachers' stories about their professional lives, which were then developed as case studies. In particular, the study focused upon an interpretive understanding of a complex phenomenon and real-life contexts in the research area. I deployed the data in a way which enabled me to collate factors that impacted on teachers' career knowledge and expertise in special and inclusive education and their perspectives on their professional development experiences. The data collected were aimed at deepening my own understanding of the topic. Moreover, the data provided me with evidence which assisted in the interpretation and construction of a 'reality' as opposed to being solely based on my assumptions and 
hypotheses. More importantly, this study set out to draw an overall picture and raise the awareness of the problems and issues with regard to special and inclusive teacher education and professional development in China.

\subsection{The aims and objectives of the research}

The aims of this research were to investigate the current situation in and the potential future direction of special and inclusive teacher education in China. To some extent influenced by time, funding and resources available, the research questions were designed to seek answers related to the motivation of teacher career choice and their professional development specifically in special and inclusive education in China. This, as anticipated would be achieved by investigating teacher voices on the motivation of their career choice, perspectives on working with children with SEN in mainstream and special schools and their professional development. This arguably is innovative within China where teachers have had limited opportunities to either express their ideas or to offer any critique of educational policy or practices within the country.

The objectives of the research were, first, to enquire into various aspects of teachers' attitudes and motives for taking up their teaching career; second, to identify their career concerns, and their change in motives with the acquisition of greater teaching experience; third, to encourage teachers to articulate their perceptions of professional development; and finally to use the information to promote change where appropriate in culture, policy and practice. In so doing, the research addressed some critical issues in special needs educational provision in China by reflectively comparing this with the provision in the wider world. The necessity to recognise historical, socio-political, economic and cultural differences between the countries formed a paramount consideration for this research (Mitchell, 2005). A critique is provided based on the Chinese government's educational policies in terms of special and inclusive education and research on special needs teacher education and professional development. I belleve these to be the most critical factors for developing an understanding of and further promoting special and inclusive education in the context of China.

It was my hope that the research could add to the limited body of literature through an analysis of the hidden voices of teachers on their experiences in special and inclusive education in a Chinese context. Additionally, evidence-based findings could be used as indicators to illuminate policy and practice in this area 
for a paradigm shift when China moves towards more inclusive education. More importantly, the implications drawn from the research could contribute to the international comparative studies of this nature. Eventually, better understanding of teachers may be reached, diverse educational needs of children may be addressed and above all, there may be a greater likelihood that educational inclusion will be achieved.

\subsection{The structure of the thesis}

The study is reported in the thesis in 13 chapters. I will first give an overview of the global and local research contexts. A brief account of the research context in a wider world aims to reflect the current situation and the position where China is in terms of special and inclusive education. This is followed by an analytical review of the literature, which played a prominent role in the design of the research, in particular, the formulation of research questions. The review is arranged into three chapters according to the key research themes, namely, a) teacher career motivation in special and inclusive education; b) teachers' knowledge and skills of and attitudes towards special and inclusive education and c) teacher professional development in special and inclusive education. Each of the chapters is further separated into the international literature and that of China for a better understanding of the research area In China within an international context.

The issues related to methodology are detailed in three sub-chapters, these providing a) a chapter on research design focusing on the conceptual and theoretical framework, rationale for the selection of research methods and sampling strategies; b) a chapter on data collection methods, procedures and data analysis and c) a further chapter on the originality of the research, challenges and opportunities of conducting the research in China regarding validity and reliability of data and data collection methods coupled with issues related to research ethics. The findings of the research are reported in the order of three key themes as in the literature review chapters which also informed the basis of the following three chapters of discussion.

Given the obvious limitations in terms of researching a complex area in a country as vast and diverse as China, comparative perspectives from within China and internationally enabled me to construct new knowledge and understanding of this research area. The implications drawn from this study allowed me to make 
suggestions with regard to the current policy, research and practice concerning special and inclusive teacher education and professional development within a specific research context. I conclude the thesis with some recommendations based on the evidence from the research, bearing in mind that they may not be generalisable in the research context in China as a whole. However, the new knowledge thus constructed from the study does give indications for a future research agenda to be conducted nationally and Internationally. 


\section{Chapter Two: Research Contexts}

This chapter comprises two parts. The first part provides a general account of the international research context in relation to special and inclusive education. This provides a broad view for an understanding of the research context in China. The second part starts with an overview of the current educational developments in China and concentrates on the key aspects of the system, namely, basic education, higher education and adult education. This is followed with a focused discussion of special and inclusive education in China with regard to teacher education and professional development. In addition, a brief account of the cultural context for career choice in China is given. The chapter concludes with a brief description of the context in which the research was conducted coupled with the rationale for the choice of this context.

\subsection{The international research context}

\subsubsection{International policy initiatives in special and inclusive education}

The right to education for all has been enshrined in the Convention on the Rights of the Child (United Nations, 1993) and addressed in several significant and internationally approved declarations, including the World Declaration on Education for All (1990), the Standard Rules on the Equalisation of Opportunities for Persons with Disability (1993), the UNESCO Salamanca Statement and Framework for Action (1994), the Dakar Framework for Action (2000) and the global action plan to improve support to countries in achieving the goals of Education for $A / l$ (2007). These international policy initiatives have recognised an entitlement for every child to receive optimal schooling in accordance with their circumstances and needs, which should, in principle be met in mainstream school systems.

With these initiatives, there is an increasing recognition of the right to inclusive schooling for children with SEN (UNESCO, 1994; 1998; 2001), albeit with various forms of support to be provided in mainstream schools and beyond. Whilst for many countries the principles espoused within these documents may prove challenging, significant advancement in this area has been witnessed across the world in recent years (Ainscow, 2005). Effective endeavours have been made in 
the promotion of educational provision in many countries to actively promote improvements in the education of children and young people described as having SEN, as seen for example with the Warnock Report in England in 1978, or the Comprehensive School Act, 1993 in Finland. Meanwhile, internationally dilemmas have been witnessed in policy implementation as well as in theory, research and practice in the process of moving towards inclusive education (Pijl, Meijer and Hegarty, 1997; Mitchell, 2005; Slee, 2006; Ainscow, Booth and Dyson, 2006a; Norwich, 2008). This is especially true in several economically disadvantaged countries, although recorded evidence is not as extensive for these as for some western countries.

\subsubsection{The international research context in special and inclusive education}

A significant body of research has been conducted in this area, though this has varied depending on the economic strengths and more importantly, the awareness of social and educational factors presented in different countries (Potts, Armstrong and Masterton, 1995; Booth and Ainscow, 1998; Chen and Hua, 1998; Tilstone and Rose, 2003; Slee, 2005, 2006; Florian, 2006; Forlin and Lian, 2008). The notion of moving from special education to developing more inclusive approaches has been advocated, promoted and researched internationally for more than two decades and is seen as an on-going process (Booth, 1983; Chen, 1996; Tilstone, Florian and Rose, 1998; Farrell and Ainscow, 2002; Thomas and Loxley, 2007). This is best demonstrated by commentaries made on a global commitment to supporting and welcoming diversity among all learners (Booth and Ainscow, 1998; Ballard, 1999; Ainscow, Booth and Dyson, 2006b; UNESCO, 2001). However, it is necessary to urge some caution when considering such commitment, which clearly varies according to national priorities and is invariably influenced by other political and socio-economic demands upon nations. This is a particularly important consideration in respect of those countries which are economically disadvantaged or have been subjected to social or political turmoil.

Whilst investigation into the efficacy of various forms of provision for learners with diverse needs has been welcomed, research in special education has been identified as problematic (Clough and Barton, 1998). Little co-ordinated national or international attention has been paid to the type of systemic reform of teacher education and teacher qualification requirements to support classroom teachers 
under pressure to increase academic performance for all learners (Florian, 2009:533). In fact, most research in special education has focused on the nature and impact of specific interventions on the learning or behaviour of children (McLeskey and Ross, 2004: 347). Inconsistencies of terminology and interpretation of needs, coupled with cultural traditions and expectations inevitably present difficulties for the researcher who wishes to discuss special or inclusive education at anything beyond the local level.

Therefore, in writing this thesis I have been conscious of the challenges identified by other researchers and writers in this field who emphasise the need to avoid generalization or to indulge in naïve international comparisons. The experiences of children with SEN within mainstream or special schools still vary from country to country (Mitchell, 2005; Pijl, 2007) and making direct comparisons across these is fraught with difficulty. Similarly, interpretations of what constitutes inclusion have also proven problematic. The placement of children with SEN into mainstream schools is no guarantee of successful participation either in learning or in everyday life (Rose, 2003; Xu, 2008). Similarly, whilst teacher opinions and in some instances the views of parents have been sought, little is known about whether children with SEN prefer to receive their education in special or mainstream schools (Farrell, 2000:157). Few studies (Hunt and Goetz, 1997: 16) have been conducted to date that investigate the effect of membership of 'inclusive classrooms' on the educational achievement of students in the class. Where this has been conducted, evidence is often inconclusive (Farrell, Dyson, Polat; Hutcheson and Gallannaugh, 2007; Black-Hawkins, Florian and Rouse, 2007). This indicates the need for greater commitment towards researching the voices of all parties involved in order to give consideration to matters of equity for those described as having SEN or those who engage with them (Clough and Barton, 1998; Gorard and Sundaram, 2008). This situation also emphasises a need for further researching Into the lives of teachers (Jordan and Stanovich, 2003) who play a key role in the process of inclusive schooling. Research on teachers' attitudes towards inclusion shows reasonably consistent findings (Lindsay, 1997; Farrell, 2000) and these are discussed later in this thesis both within the review of literature and in relation to my own work in China. 


\subsubsection{The international context In special and inclusive teacher education}

\subsubsection{The quantity and quality of teachers in general}

The demand for teachers who have the flexibility to address the diverse needs of learners is apparent in most countries, though it provides a particular challenge to those with poor socio-economic situations. Teacher supply varies across subjects, regions and countries. The demand for quality teachers is mostly readily satisfied by the growth in the supply of fully qualified teachers who have received appropriate initial training and professional development. In some countries, teaching as a career has become an increasingly popular option. For example, evidence shows that the number of people considering teaching has made teacher supply less of an urgent issue in some countries as identified in England and Wales (Gorard, See, Smith, and White, 2007). Teacher shortages, when they do occur, are often regional and may vary according to subject areas. In the USA, the problem is one of increasing demand rather than diminishing supply (McLeskey and Ross, 2004). Other research reports a trend of people with prior occupational experiences entering teaching as a career in countries like Australia and New Zealand (Priyadharshini and Robinson-Pant, 2003; Watt and Richardson, 2007; Anthony and Ord, 2008). This may well result in a changing profile of teachers in some countries' with an increasing number of these colleagues bringing a wide range of life experiences to the classroom. Nevertheless, this is less the case in China where mid career change is less frequently recorded and most teachers enter the profession early and stay throughout their working lives.

\subsubsection{The quantity and quality of teachers in speclal and Inclusive education}

In some countries, the shortage of special and inclusive education teachers has been chronic and remains to be a challenge (Booth, Nes and Stromastad, 2003; Dart, 2006; Kuyuni and Desal, 2007). Even within the USA, the increasing shortage of fully certified special education teachers represents a major issue for policy and practice (McLeskey and Ross, 2004). The problem relevant to developing and sustaining a qualified teaching force is serious and is perceived to have gradually worsened during the recent years (Boe, 2006). A review of the literature (Brownell, Ross, Colon and McCallum, 2005: 242) indicates that, although a substantial number of investigations have focused on special education, issues on special teacher education remains an under researched area. In England and Wales changes to teacher education have brought a greater focus to the need for all trainee teachers to have a greater awareness of special needs 
and inclusion issues. This has, in part been a response to the introduction of changes in the National Curriculum which includes the introduction of an inclusion statement reminding teachers of their responsibilities to address the full range of pupil needs in their classrooms. Changes in teacher training and professional development are gradually impacting upon the knowledge base of the profession as has been reported from several countries (Meijer, Soriano and Watkins, 2003). For example, evidence from Northern Ireland (Moran, 2007) suggests that initial teacher education programmes are expected to be improved (Garner, 1996) to prepare student teachers for inclusive education following the increasing trends towards inclusion.

Darling-Hammond (1997:251) suggests that, when examining the issue of teacher shortages, it is important to consider not only the supply and demand, but also the quality of teachers filling positions. Teacher shortages in special education reflect both a quantity shortage of teachers (i.e., a shortage in the number of individuals who are available to fill positions) and/or a quality shortage of teachers (i.e., a shortage in the number of teachers who are fully certified for their positions and available to fill vacant teaching positions) (Katsiyannis, Zhang and Conroy, 2003:246). In this regard, Katsiyannis, Zhang and Conroy (2003) suggest that a national shortage of fully certified special education teachers in the USA has been a persistent concern over the years. They predict that the shortage may increase. One overall reason for teacher shortage is the decreasing number of qualified professionals entering the field of special education and the increasing number of special education teachers who are beginning to retire and/or leave the field. To address this severe shortage of special education teachers, some states in America, according to McLeskey and Ross (2004), have lowered standards to allow people with a bachelor's degree and who can pass a basic test to be certified where in the past the training was provided at higher degree level.

Teacher shortage in terms of quantity and quality in special and inclusive education is also keenly felt in many economically disadvantaged countries. In India, for example, despite the government's efforts in providing services for children with disabilities in line with recommendations from international aid agencies, a large number of individuals with disabilities remain out of school (Kalyanpur, 2008). A similar situation is reported in China (Deng and Holdsworth, 2007) which attributes this to multi-dimensional factors including the educational system which leaves teachers with limited resources at their disposal. 


\subsection{The research context in China}

\subsubsection{An overview of the current education system In China}

An appreciation of developments in education in China is important for any reader who wishes to understand the current situation with regard to inclusive schooling and teacher training within the country. China is one of the oldest countries with the largest population in the world. As the world's third largest country in territory, China presents with great geographic disparities (Bray, 1998). An unbalanced economic development in different regions of the country and significant variations in social structure adds to the unevenness of development in terms of education.

As a whole, China has a civilised history and distinguished Confucian tradition of valuing education. Throughout history, the education system in China has undergone successive transformations which accompany the ideological changes of those in power. The establishment of the People's Republic of China in 1949 proclaimed the end of the imperial era together with its education system which was mainly for the elite and privileged. With Mao Zedong's pursuit of communist ideals, education was seen as a key tool for social equality. However, through the turbulent ten years of the Cultural Revolution (1966-1976) during Mao's regime, China experienced tremendous turmoil in education. The government attached a limited priority to education for the majority of the population. This resulted in a halt in development which in turn led to little or no opportunity for education for a whole generation of Chinese.

The successive reforms since the late 1970s in all aspects including its education system initiated by Deng Xiaoping enabled China to resume its dynamism. In the recent three decades, the Chinese government has conducted macro management over education to ensure the correct direction of educational reform and the implementation of the national educational guidelines. The great successes in economic reforms have fed back to the country's educational field in terms of increased investment and adaptation of more favourable policies and initiatives in education (e.g., The 9 Years' Compulsory Education Law, 1986; the Law on the Protection on the Rights of the Disabled, 1990; The Teacher Act, 1993; The Education Act, 1995). These have guaranteed the impartiality of education and equality for children to access education and above all, maintained the lawful rights and interests of students, teachers and schools (Chinese National 
Commission for UNESCO, 2004). Joint efforts from all levels and sectors of education have also improved the country's intellectual outlook and boost the economic and social development in China.

Below is a brief description of the current education system in China divided into three categories: basic education, higher education and adult education. A more detailed description is attached in Appendix II.

\subsubsection{Basic education}

Basic education includes primary and regular secondary education. China has achieved tremendous progress in basic education and witnessed historical development owing to the concerted efforts of the central government and society as a whole. However, the country has been and is still experiencing unprecedented challenges in its development process.

On the one hand, the 9 Years' Compulsory Education Law by the Ministry of Education (MoE, 1986) entitles equal education opportunities for all eligible children from ages 6-15 for at least nine-year of compulsory schooling tailored to local conditions. Funds to support compulsory education in rural areas are cofinanced by the central and local governments. In particular, the amended law (National People's Congress of China, 2006) regards the refusal of children with diverse learning difficulties, problems, disorders or disabilities for inclusive education as a violation of the law (Article 57, 2006). By the end of 2003, the law had offered education opportunities for $91 \%$ of its eligible population. In 2004, nine million full-time teachers were teaching in basic education (MoE, 2005). The number of adult illiterates has also dropped sharply (UNESCO, 2008), which largely accounts for the rise in the average adult literacy rate for developing countries.

On the other hand, as the world is striving to achieve the Millennium Development Goal of Education for All by 2015 (UNESCO, 2007), achieving the right to education for diverse learners in basic education is still very challenging in China. Although enrolment in primary school has been nearly universal in most of the economically developed areas, access is still very restricted to secondary senior schools for students, especially those from rural underdeveloped areas or economically disadvantaged families or for students with SEN (Piao, 1992; 1995). These include the off-spring of migrant workers who join their parents in cities but are reserved no places in some city schools. In addition, problems like solely 
pursuing high continuation rate in mainstream schools and academic pressure on students have not been fully tackled. In addition, the de-centralisation of education increases the variations in local government expenditure on education from region to region. Significant barriers to full participation in education remain as is described later in this chapter.

Moreover, traditional cultural beliefs may best be reflected in basic education. Chinese education is teacher-centered and text-driven with both the teacher and the text regarded as authoritative sources of knowledge, a belief which stemmed from the authoritarian values of Confucianism (Forrester, Motteram and Liu, 2006). China is developing an essentially quality-oriented education which involves the reform of the curriculum. Given China's size, resources and diversity, the quantity and quality of teachers is still recognised as a critical challenge in basic education (Paine and Fang, 2007). This challenge continues to be significant for a sustainable solution for improving quality education today.

This and other challenges are likely to remain for some time. Although the central and local governments are increasingly making investment policies for teacher education, the proportion of teachers holding the required qualification is still low (Li, 1999). Wang, (2004) argues that the criteria for teaching set in the Teacher Act (1993) are not demanding enough since they only focus on teachers' qualifications. That is, graduates from junior secondary schools are trained in either a 3-4 year programme to be prepared for primary education. The minimum requirement for teaching in secondary schools is a bachelor degree without the necessity of a teacher training certificate. Even so, by 1999 , the percentage of primary education teachers holding a tertiary qualification reached only 13, although the World Education Indictor mean was $64 \%$ (Organisation for Economic Co-operation Development/UNESCO, 2001). In 2002, the percentage reached 31 (Wang, 2004:12), contrasting with the International Labour Organisation and UNESCO's report which suggested that a truer picture might be less than two out of ten (Siniscalco, 2002).

\subsubsection{Higher education}

Higher education operates on a centralised enrolment system under the national Ministry of Education. Enrolment is determined and granted only on the basis of a strict matriculation examination result (UNESCO, 2001), though occasionally, physical and moral qualifications are also adopted as criteria for consideration. 
Higher education suffered tremendous losses during the Cultural Revolution (1966-1976) due to the shutdown of the system. The reinstating of a National University Entrance Exam in 1977 created opportunities for more students to enter higher education. The recent economic. development of China under the challenges of internationalisation and globalisation has led to the urgent demand for highly trained personnel in the increasingly competitive domestic and international job market. Beginning from 1994, an institutional merger took place in Chinese higher education. The planning and implementation of the merger was largely a top-down process, a strategic policy for the transition period from a planned economy to a market economy. This has been subject to political intervention, which in many cases has caused the difficulty of building a unified identity for the new institutions (Wan and Peterson, 2007).

The further expansion in higher education in the last decade has provided senior high school graduates with more chances of accessing higher education, a sign of movement in higher education from the 'elite' stage into a 'mass' stage (Lin and Zhang, 2006; Wen, Xie and $\mathrm{Li}, 2007$ ). Research (Hung, Chung and Ho, 2000) indicates that in Shenzhen, the first and largest Special Economic Zone in China, a large majority of secondary students have a positive intention to pursue higher education. They act in accordance with predictions in the human capital theory. Nevertheless, issues like unemployment of university leavers have been increasingly serious due to the expansion (Wan and Peterson, 2007), which has not fundamentally enabled China to move forward in the face of various challenges like the recent global economic recession.

\subsubsection{Adult education}

Adult education is an important part of the Chinese educational landscape, which has parallels with the basic and higher education categories. This aspect of education refers to the specialised/vocational/technical education with the length of programmes ranging from two to four years depending on the nature of the training after 9 years' compulsory school education. Since 1978, the Chinese government's policies relating to adult education have laid a foundation for accelerating its development. The Outlines for Educational Reform and Development in China (MOE, 1993) regarded adult education as a new education system. It plays a role in developing conventional school education toward lifelong education, in the continuous enhancement of the national quality, and in the promotion of economic and social development. 


\subsubsection{Special education}

Politico-historical forces have shaped the development of current educational practices in special education in China (McLoughlin, Zhou and Clark, 2005) which can be roughly divided into three stages (Ellsworth and Zhang, 2007):

The early stage (1874-1949) began with the western influence in the form of provision developed by religious missionaries. Special education as an institution was then established (Deng, Poon-McBrayer and Farnsworth, 2001). Schools were mainly for students with hearing and/or visual impairments and were restricted to those who could afford education expenses. Education for individuals with learning difficulties or other disabilities was nonexistent (Pang and Richey, 2006).

The second stage (1949-1980) saw a development in which special education became a part of public education following the liberation of the country. Some special schools were established to accommodate children with visual and/or hearing impairments. Yet, no special support was provided to children with other SEN due to the lack of teaching resources worsened by collectivist ideology and economic inability. In particular, no achievement was made in special education during the setbacks of the Cultural Revolution which attached no priority to education as a whole.

The third stage has witnessed the expansion and speedy growth of special education when the reform and opening policies transformed the country and provided a breeding ground for special education. In 1989, the educational provision only reached 6 percent of children with disabilities. This remained a great concern for the government. Therefore, the most comprehensive disability laws (the Law on the Protection on the Rights of the Disabled, National People's Congress, 1990, The Outline of the $9^{\text {th }}$ Five Year National Development Plan for the Disabled (1996-2000), National Council, 1996) were issued which formulated a series of both general and specific policies for reforming and developing the sphere of special education. Disability was identified in six categories: hearing and visual impairments, mental retardation, emotional disturbance and physical and multiple disabilities. The definition was made in the Law on the Protection on the Rights of the Disabled (1990) under the impact of the global rise of a movement for the rights of disabled people.

The policy initiatives have made explicit stipulations on safeguarding the rights to 
education of the disabled. In recent developments more inclusive education has been promoted by the government through requiring and empowering provinces to begin the process of giving everyone access to education, regardless of their diverse educational needs. The most vulnerable and disadvantaged people are now also benefiting from the education system.

Despite the significant progress witnessed in special education, there is a big gap across the country between the overall standard of development in the western and eastern, rural and urban regions caused by social, economic and geographic disparities. The local governments operate in a context of globalization, especially in terms of economic interdependence (Wang, 2006). Education is seen as a major investment for economic and social goals (Bray, 1998). It is arguable that some governments do not invest as much in special and inclusive education as it merits.

The following list shows the development and the current situation in special education in China:

- In 1979, the first special school for children with learning disabilities (mental retardation) in Shanghai (Potts, 2003)

- In 1982, the first special education diploma programme in a teachers' college in Jiangshu Province

- In 1982, the first diagnoses of individuals with autism in Nanjing (McCabe, 2008:106)

- In 1984, the first special education teachers' college (diploma) in Nanjing

- In 1986, the first bachelor degree programme of special education started in Beijing Normal University (Qian and Liu, 2002: 44; Wang, Gu and Chen, 2004: 55).

- In 1993, the first Master's degree programme in Beljing Normal University (Qian and Liu, 2002: 44; Wang, Gu and Chen, 2004: 55)

- In 1993, the first autism institute for individuals with autism in Beijing (McCabe, 2008:107)

- From 1990-1999, in the Chinese Journal of Special Education, only about $5 \%$ of the articles published on Learning in Regular Classrooms, another $3 \%$ of the articles on special and inclusive teacher education, and about $7 \%$ of all the articles published in the same journal at the same period are research based (Lin, 2000: 2)

- In 2003, the first PhD programme in special education in Beijing Normal 
University (Qian and Liu, 2002: 44)

- In 2007, the national mean of teacher student ratio in special education was 1:15.3. In Yuannan Province in the southwest of China, the ratio was $1: 42.3$ (China Statistics Year Book, 2008)

- In 2003 , about $20 \%$ and in $2004,0 \%$ of the student teachers graduated from bachelor degree programmes of initial special teacher education in Beijing Normal University chose to work in special education. In fact, since 1990, a large number of the student teachers of the same university chronically chose other professions upon graduation. Since 1996, about 10 - $25 \%$ of the student teachers applying to Master's programmes chose to further their studies in special education. Since 2000, an increasing number of the student teachers have applied to Masters' programmes (about 30\% annually). However, most of them applied to study other majors so that they could have chances to be in other professions than special education (Wang, Gu and Chen, 2004: 55).

- Since 1990, within those graduated from Beijing Normal University and joined teaching in special schools/or special education organizations, the attrition rate is $28.4 \%$ (Wang, Gu and Chen, 2004: 55 ).

Special education has been in the spotlight as the nation played host to the world's paralympians in 2008. Since the current amount of service provision in special education is clearly insufficient (Deng and Manset, 2000), the government is planning to establish more new schools for the disabled. This is to some extent due to anomalies which have emerged as advances in assessment that have developed at a greater rate than the development of provision. The specific case of provision for children with autistic spectrum disorders may be taken as an example here. McCabe (2008) has stated that, although educational opportunities for children with autism are increasing, demands are yet to be met. No official figures are available for the enrolment of students with autism for schooling due in part to the fact that students with autism are not correctly diagnosed and partly to the fact that autism does not have its own category under the law (see National People's Congress, 1990). In addition, the diagnostic system is not well developed for other learning difficulties including those associated with cognitive or developmental disorders (Wang, 2007). Moreover, a lack of awareness of SEN by teachers, particularly in rural or remote areas is very common (McCabe, 2008). Many students with SEN in West China are still denied school education (Pang and Richey, 2006a; Deng and Holdsworth, 2007). In economically disadvantaged areas, inclusive education has been encountering great challenge. 


\subsubsection{Inclusive education}

China has been given an impetus since 1986 under the pressure from an international agenda of moving towards inclusive education. Relevant laws (MoE, 1986; National People's Congress, 1990) entitled all children to a fundamental right to education by the Chinese constitution. According to the National Report on Education for All in China (MoE, 2005), school entrance rates of students with disabilities have increased dramatically in this aspect.

The experiment of Learning in Regular Classrooms (LRC), the Chinese version of inclusive education (Deng and Manset, 2000) has unique Chinese characteristics. It was the initiative of local governments in response to the urge for a favourable and supportive atmosphere for children with SEN (primarily sensory impairments or mild mental retardation) to be accommodated in mainstream schools. This LRC approach has contributed to a major increase in the education opportunities for those who used to be denied access to education of any sort. The new system was based on its unique socio-cultural situation whereby special classes and LRC became the mainstream policy and special schools became the main support. In 2004 , about $65 \%$ of students with disabilities were educated in general education settings (Ministry of Education, 2005). Special education thus entered a new era of development (Xiao, 2005). Nevertheless, the LRC is driven by pragmatic needs and has been practiced in a different social and cultural context from inclusive education initiatives in the West (Deng and Guo, 2007). The policies and legislation have not secured implementation and practices. A range of factors are yet to be addressed in the process of promotion of inclusive education. In particular, LRC has highlighted some weaknesses In Chinese educational provision (Deng and Manset, 2000; Feng and Jament, 2008).

Inclusive education (integration, to be exact) first began in rural and remote areas in the late 1980 s as the means of improving school enrolment and eliminating illiteracy. It was not a formal process of inclusion as neither specialists nor educators with basic and necessary knowledge were available to address the special needs of children. Integration conveys a sense that pupils must adapt to school, with no assumption that the school should adapt to accommodate a greater diversity of pupils (Mittler, 2000). It is therefore not uncommon for children with SEN to be physically integrated, marginalised or simply rejected. The problems posed by greater diversity are still seen as belonging to the children 
rather than the system (Potts, 1995; 2000). Although extra provisions were made, many children with SEN living in isolated rural areas do not have any schooling at all (Deng and Holdsworth, 2007).

Furthermore, SEN should in principle be met in the regular school system and it must also be made clear that it is the responsibility of local schools and local school authorities to ensure that this is implemented (UNESCO, 1994). Yet, government expenditure on education remains to be lower compared with some comparable economically disadvantaged countries (Hannum and Wang, 2006). Besides, too often, education to some Chinese policy makers is perceived as an opportunity rather than a right (Wang, 2006). Despite the priority given to reform in China, inclusive education still does not have full acceptance either as a concept or in practice in schools and society.

The philosophy of inclusion has posed challenges to the whole education system. The challenges imply that the awareness of inclusive education within society is yet to be raised sufficiently to support those who are still experiencing exclusion, discrimination and segregation from mainstream education. Despite the success achieved in China, there is still much to be accomplished for inclusive education, especially in special teacher training and the further and continuing professional development of teachers.

\subsubsection{Teacher education}

Teacher education in China is composed of two parts, namely, pre-service education and in-service training with both lay an emphasis on courses in the curriculum subject areas (Song, 2008). China is the largest provider of teacher education and training in the world which also sustains the world's largest number of primary and secondary schools (Yang and Wu, 1999). The setbacks in education during the Cultural Revolution (1966-1976) resulted in an overall poor qualification profile of the teaching force for all educational levels. This is evidenced according to international indicators (e.g., UNESCO, 2001) that China has the lowest proportion of teachers with tertiary qualifications for teaching primary and secondary education.

Since 1978, China has witnessed a succession of developments brought forth by a process of dynamic reform in policies and practices in teacher education. The initiatives (MOE, 1986; the Teacher Act by the National People's Congress, 1993) 
target the building of a mechanism of quality assurance for teaching as a profession by paying substantial attention to Improving, developing and restructuring teacher education (Zhou and Reed, 2005). The Teacher Act officially recognised teaching as a profession in China for the first time ever. Teachers are considered the key stakeholders who determine the standard of education and even the quality of the people of the nation. However, the criteria for teaching in the Act are set at a very basic level as they only focus on academic qualifications (Wang, 2004; Gu, 2006). Before the Act, in China, a large number of teachers were recruited with the minimum required qualification for teaching and some even started teaching without any qualification ( $L I, 1999)$. For example, the requirement for teaching in secondary schools is a bachelor degree without the necessity of a teacher training certificate. This is in contrast with the practices in many Western countries where individuals pre-qualify for entry into the teaching market conditional on certifications from the state authority and/or holding a graduate degree in education.

\subsubsection{Teacher professional development}

Teacher professional development in China has existed since the introduction of teacher education a century ago (Yang and $W u, 1999$ ). Since the late 1970s, to improve the ideological and professional competence of teachers to meet the demands in the ever Increasingly competitive world, China has devoted itself to enhancing the quality of existing teachers (Hu, 2005). This has achieved in quantity as well as quality. The regulations on teacher qualification required teachers to get teaching certificates before taking their jobs. The unified nationwide professional standards designed and issued by the government in the early 1980s (Gao, 1999; Zhou and Reed, 2005) urged teachers to seek further education opportunities through in-service training. This is evidenced by the government's efforts in restoring and establishing advanced training institutions to undertake in-service training, especially for those who missed their education and training during the Cultural Revolution years.

In-service training of teachers can be divided into degree and non-degree education (China Education and Research Network, 2000). Degree education includes not only the 'top-up' education for in-service teachers without qualified certificates but also the 'upgrading' education for in-service teachers with qualified certificates. The non-degree education for in-service teachers is the main part of continuing education. This has been the key to teacher training 
embraced by teachers to meet the ever increasing society expectations. It can be divided into two parts of a probation period of training for new teachers and post training of existing teachers. Training occurs mainly in four modes: a) university/college training; b) school-based training; c) district or county teacher training and d) on-line training for rural teachers. Schools are encouraged to establish partnerships with teacher education and in-service training institutions to create chances for teachers both in and out of schools.

However, the increased demand for 'change in the nature, the purpose and the mode of delivery' of professional development in teacher education (Garner, 2006:17) is particularly challenging due to the growing disparities in wealth within the country and the unevenness of the teaching force profile (Paine and Fang, 2006). In particular, since the mid 1990s, most professional development models have been influenced by the Government's priorities and the market economic system. Teachers are increasingly urged to seek professional development to provide quality teaching with insufficient support in many aspects.

\subsubsection{Special and inclusive teacher education}

Special teacher education sees its development only in recent decades. Before the early 1980s, there had been virtually no specialized teacher training system for special education programmes in China ( $X u, 2008)$. The growth in special education training programmes to prepare special education teachers has been remarkable (Ellsworth and Zhang, 2007). However, with regard to the quantity and quality of teachers in special education, China is still under tremendous pressure (Wang, Gu and Chen, 2004). Many issues need to be addressed in training special education personnel.

On the one hand, special teacher education is offered only in a very limited number of normal universities and colleges as opposed to general teacher education. Optional courses of special education are offered in certain colleges or universities in the hope that graduates can meet the future challenges of having diverse learners in mainstream schools. The main task of secondary special teacher training schools is to educate special education teachers for primary schools. In 1998, there were 33 secondary special education teacher-training institutions in China, three of which were fully devoted to special education. Secondary special teacher training institutes offer three specialties of education 
for the deaf, blind and mentally retarded. Normally they enroll graduates from junior secondary schools. The schooling lasts 3-4 years. The courses are made up of 4 parts of compulsory courses, optional courses, teaching practice and extracurricular activities.

On the other hand, pre-service teacher education in China involves little to no preparation for teachers of children with SEN (McCabe, 2008). Given that China witnessed a noticeable improved access of children with SEN into special schools, mainstream schools and/or even including universities and colleges, professional development programmes offer insufficient training to provide teachers with the necessary knowledge or skills. Schools as well as local governments encounter challenges of supporting effective diagnosis and funding for teacher professional development. The challenges are also encountered in areas such as inappropriately-designed curricula in terms of flexibility and content. Mainstream schools are selective and competitive with normally large sized classes. As a consequence, children with SEN have not yet received enough attention, largely due to the flaws in inclusive teacher education.

Given the tremendous efforts made by its government, China has not yet helped itself as expected, in the international profile of teachers for inclusive education. This remains among the greatest challenges for a sustainable solution for improving quality in education today. The recent international and comparative efforts (the United Nations Educational, Scientific and Cultural Organisation and the World Education Indicators (UNESCO, 2001; 2006a) reveals that the quality of education in China is still well below international standards in some key aspects, in particular, the number and the qualification of teachers in basic education.

\subsubsection{The quantity and quality of teachers in special and inclusive education}

It is then clear that in China one of the most pressing problems facing special and inclusive education is the scarcity of well qualified teachers (Gan, 2004; Wang, 2006). Given that the central and local governments are increasingly making investment policy initiatives for teacher education, the shortage of teachers in special and inclusive education remains a serious issue. The statistics issued by the Ministry of Education of China (MoE, 2003) explain the current situation. Among 30,349 teachers and staff in special schools, there were only 48 teachers with graduate attainment, 3,757 with undergraduate attainment and the rest had 
lower educational backgrounds. About $50 \%$ of the teachers and staff had recelved some special training to be qualified in special education (MoE, 2003). This has little significance in comparison with the total number and qualification of teachers in other education sectors in the country.

Furthermore, teachers' limited knowledge and expertise leads to more children being excluded or disengaged in class (Feng and Jament 2008), although there are no reliable figures available as there is little awareness about a range of learning difficulties of children (Wang, 2007). For example, it is reported (McCabe, 2008) that at the Autism Institute, the most well known educational institute for children with autism in Beijing, none of the teachers had taken a formal class in special education when they began to teach in the school at its early establishment in 1993.

Another example is a comparison between the expected teacher student ratio by Chen (1990, cited in Potts, 1995:165) and the most recent statistics in this respect. According to her report on a survey on the number and quality of teachers in three coastal provinces (Liaoning, Jiangsu and Shandong) commissioned by the Chinese government in 1988, Chen (1990) calculates that if working on a teacher student ratio of $1: 6$, the provinces would need 68,500 more teachers. She further states: 'If China could really solve all of its many difficulties and reach the pre-set target laid out in the development plans, then by the year 2000 China's Special Education work will be able to join the ranks of middle-level developed countries' (Chen, 1990:2, cited in Potts, 1995:173). However, statistics (China statistical Yearbooks, 2008) indicate that the number and quality of teachers is incomparable with the mounting number of children with SEN. According to the Basic Statistics on Special Education by Region 2007 (China statistical Yearbooks, 2008), the national mean of teacher student ratio in special schools was 1:15 whilst the highest rate was 1:42. One recent study on the current situation and strategies on special education teachers in Jiangsu Province (Jiang, Wang and Fan, 2008) may well illustrate the Issue. Jiangsu Province is in the leading position in the development of special education in the country. The teacher student ratio was 1:11 in 2007(China statistical Yearbooks, 2008), which was well above the national mean, although it was almost double the size of Chen's expected ratio (1990). However, less than 25 percent of teachers researched have a BA degree. Only about 36 percent of the teachers have been trained in special education whilst about 6 percent of teachers do not even have teaching qualifications. Most of the schools in Jiangsu Province would demand 
that teachers have degrees for entry. According to Jiang, Wang and Fan (2008: 47), each year, among the students who graduate with a BA degree in special education in the country, quite a few choose to further their education or work in other professions. There are few people with a BA degree available to teach in the schools in Jiangsu Province. This finding supports Wang, Gu and Chen (2004:55).

A similar report has been produced in relation to an investigation into special education teachers' professionalization in Shanghai (Wan, Wang, Du and Chen, 2008). The ratio of teacher student in Shanghal was 1:9 in 2007(China statistical Yearbooks, 2008), which ranks in the top 10 according to the national mean. Nevertheless, the percentage of teachers who have received professional training was insignificant. About 30 percent of the teachers researched have never received any training in special education prior to and/or post service. This indicates that the diverse educational needs of children may not be addressed properly if at all, as a result of the insufficient number and poor quality of teachers available.

\subsubsection{Cultural context for career decisions}

From 1949 to the early 1990s, the Chinese government undertook the responsibility of job assignment leaving little choice for individuals. The national economic planning policy in China under the ideal Marxist system was used to secure jobs for all graduates, including college students and high school students. People depended heavily on the government's placement arrangements for jobs. Students educated in the collective culture with communist ideology were convinced of the necessity to obey and accept whatever positions were given to them by the government. Students believed that they were obliged to contribute to the socialist society by working on the occupations needed, not necessarily the occupations they were interested in. This job placement system granted all employees in the state or collective sectors lifelong employment with promotion by seniority known as the 'Iron Rice Bowl' system (Zhang and Pope, 1997, cited in Zhang, Hu and Pope, 2002) which guaranteed also benefits such as pension, free medical service and cheap housing. Research (Hu, Chen and Lew, 1994; Zhang, $\mathrm{Hu}$ and Pope, 2002) reveals that off-springs could take on their parents' jobs after their parents' retirement. Once the job was taken, they could never be lost.

In 1992, the National Congress of the Communist Party of China stated that the 
goal of China's economic reform was the construction of a soclalist market economic system. With the transition from a planned economy to a market economy, steps have been taken to promote the transition which is a revolution in the Chinese employment system ( $\mathrm{Hu}$, Chen and Lew, 1994). This brings a dramatic change which affects nearly the entire population in all urban areas of China (Zhang, $\mathrm{Hu}$ and Pope, 2002). State-guaranteed jobs were no longer secured as before. Student placement systems were revolutionised in education institutions. Competitive and contractual employment systems were adopted. Nowadays, students have freedom in their career choices, although more often than not, they are provided with little counseling or advice from professionals but are solely guided by their family, friends or school teachers. Meanwhile, they have to face tough competition in job hunting and insecurity in employment.

\subsubsection{Teacher career motivation}

Factors influencing teacher career motivation are multi-faceted. Historically China has a long tradition of respecting teachers and valuing education. However, China has difficulties in recruiting the most promising teaching talent because of competition from more prestigious and lucrative professions (Chen, Lim and Gopinathan, 2003: 905). Due to an insufficient financial input into education, the payment and welfare package of teachers still remains uncompetitive. For social and economic reasons, the status of the teaching profession has been lowered. Some teachers find it difficult to devote their lives to delivering education. Teaching as a profession (Paine, 1991) has in many respects become a low priority for the majority of Chinese school leavers.

In response, a concerted effort was made by the Chinese government and the society to raise the profile and standards of teaching, to enhance the status of the teaching profession and attract more attention to teacher education. This is evident from the central government's policy initiative in reference to teachers. Apparently, teacher career motivation is enhanced with the issue of the Teacher Act (1993) which identified teaching as a profession. The Act specified teachers' qualifications for different levels of education paid more attention to teachers' economic status by addressing teacher salaries and benefits. The Educational Act (National People's Congress, 1995) further required the government to improve teachers' working and living conditions as well as their social status by waiving their tuition and also subsidizing a living allowance to those registered in teacher education programmes. Another policy document on the Outline for Education 
Reform and Development in China (MOE, 1993) specified new standards for teachers. It suggests that building a qualified, balanced and stable teaching force is fundamental. It aims at forceful measures to raise teachers' social status by improving the conditions of teachers' work, study and living so that teaching becomes the "most respected profession".

In the 1980s, teacher education played a strategic role in the central government's policles and laws. The reform of the 1980 s closed the teacher education system allowing only teacher education institutions to prepare teachers. The graduates from teacher institutions were appointed to positions in education by the institutions. This policy, on the one hand, ensured an adequate supply of teachers. On the other hand, it had negative effects. High school leavers preferred to choose universities other than normal universities and teacher education colleges. Thus normal universities and colleges were unable to recruit the most excellent students. Very often, male students in particular prioritised teacher education the least in their career choice.

Moreover, from a comparative perspective, as education is influenced by the unbalanced development in economic prosperity, there have been flows of welleducated and competent people to the areas where the economy is better. A teacher shortage coexists with relatively large geographic and/or economic disparities. Many teachers prefer urban posts for several reasons; mostly related to conditions such as quality of life, working conditions, opportunities for professional development and access to health facilities. The central and local governments use different strategies to deploy teachers so as to ease the issues caused by geographic disparities. In recent years, the government has waived university fees and offers a free year of courses at master's level if new graduates accept a three-year rural posting. This has improved the recruitment of teachers.

With regard to special and inclusive education, factors influencing teaching choice are made even more complex. Status in society and the level to which teachers feel valued and taken account of in society and within the education system affects the career motivation of teachers. Teaching pupils with SEN is perceived as work only for low status teachers in China. There is a lack of respect for this profession which consequently affects teachers' social, contextual and personal identities (Day and Sachs, 2004). Low status of the teaching profession and the poor benefits for teachers are primary reasons for teacher attrition. In particular, educational reform with its increased commitment to a reordered system by 
urging better provision for marginalized or excluded learners has placed huge responsibilities on teachers. Teachers are expected to work with a wider diversity of students without revising their approaches to classroom teaching. Teachers are increasingly frustrated by the challenges presented by inclusive education due to the widening gap between the high expectations of inclusion policy and the lack of suitable tools to implement it. Whilst the need for teachers is ever increasing, schools are losing teachers as a result of low income and a poor financial situation. Many talented young people are reluctant to study to be teachers and others try to leave the teaching profession (Yang and $W u, 1999$ ). This has also had the result of encouraging students once in further education to remain there and complete higher degrees and ultimately pursue a career teaching at tertiary level (Wang, Gu and Chen, 2004: 55; Lamie, 2006: 69). Hence, it is important to examine teacher career motivation for special and inclusive education.

\subsubsection{The local research context}

The broader Chinese context described within this chapter has been presented in order to assist the reader in being able to contextualise the district where the research reported in this thesis was conducted. It is important to recognise that neither Zhejiang Province nor Shaoxing city is presented within this work as being representative of China as a whole. The motivations for conducting this research are in part related to opportunities to effect change within my own working environment. This has necessitated a focus upon my own city whilst taking account of what can be learned from the wider context in China.

\subsubsection{The country}

China is a country with much diversified territory and immense regional disparities between urban and rural areas (Liu and LI, 2006). In terms of the economy, China is divided into a patchwork of developed and under-developed regions. As far as education is concerned, the 9-Year's Compulsory Education Law (1986) divided China into three categories:

- Cities and economically developed areas in coastal provinces and a small number of developed areas in the hinterland

- Towns and villages with medium development and

- Economically backward areas.

Table 2-1 shows the basic statistics of the number of schools, students and 
teachers in China by levels of education in 1,000 units (2007) (Data source: China statistical Yearbooks, 2008).

\begin{tabular}{|l|l|l|l|}
\hline National total & Number of schools & Total enrollment & $\begin{array}{l}\text { Full-time } \\
\text { teachers }\end{array}$ \\
\hline Special schools & 1,6 & 419,3 & 35 \\
\hline Primary schools & 369 & 107,899 & 5,652 \\
\hline Secondary schools & 92 & 103,216 & 5,784 \\
\hline
\end{tabular}

Table 2-1: Basic statistics of the number of schools, students and teachers in China by levels of education in 1,000 Unit (2007) (Data source: China statistical Yearbooks, 2008).

From the table, it is evident that the numbers of special schools, students with SEN and teachers in special schools are significantly small as compared with those for general education. This information is necessary for an understanding of the local research context.

\subsubsection{The province}

The research reported in this thesis was conducted in Zhejiang Province located in the southern part of the Yangtze River Delta on the southeast of China with a population of 49 million reported in 2005 (www.zj.gov.cn). Zhejiang belongs to the first category listed above. At present, its economic standing ranks fourth in China.

Zhejiang has long been noted for its high level and complete nature of education. At the end of 2004, the province had a total of 73 institutions of higher learning. In 2007, 75,000 middle school teachers and 145,000 primary school teachers received in-service training at all-level teachers' training organizations. Table 2-2 shows the basic statistics of schools, students and teachers in special education in China and Zhejiang Province (2007) (Date source: China statistical Yearbooks, 2008).

\begin{tabular}{|l|l|l|l|}
\hline & Schools & Total enrollment & Full-time teachers \\
\hline National total & 1618 & 419316 & 34990 \\
\hline Zhejiang province & 63 & 12993 & 1326 \\
\hline
\end{tabular}

Table 2-2: Basic statistics of schools, students and teachers in special education in China and Zhejiang Province (2007) (Data source: China statistical Yearbooks, 2008).

The teacher student ratio in special schools in 2007 was 1:9.8, which was above the national mean of $1: 15.3$ (China statistical Yearbooks, 2008). The number of special schools in Zhejiang ( $N=63)$ in 2007 was the total of six provinces and one 
city in China (Detailed information is attached in Appendix III).

\subsubsection{The city}

Shaoxing is a city under the direct jurisdiction of Zhejiang provincial government. This medium-sized city in the eastern part of China south of Shanghai has a population of 4.3 million in six administrative divisions. There are currently 5,632 schools of different kinds, in which over 1,127 million students are studying (http://www.sx.gov.en). The fast growth in economic strength makes Shaoxing one of the developed cities according to per capita GDP levels, which indicates that it belongs to the second tier next to the economically well developed cities such as Shanghai, Beijing and Shenzhen. The educational aspirations in this city have always been high due to historical reasons and current tough competition at all levels and in all aspects. There are 2 special schools serving children with SEN from the urban district with a population of 620,000 people and beyond. Below is a description of the schools.

\subsubsection{The schools and the university}

Table 2-3 shows some basic information of the sample researched in 2007.

\begin{tabular}{|l|l|l|l|}
\hline Schools & $\begin{array}{l}\text { Students } \\
\text { on roll }\end{array}$ & $\begin{array}{l}\text { No. of full-time } \\
\text { teachers }\end{array}$ & Type of school \\
\hline 1 & 6500 & 364 & Mainstream senior school \\
\hline 2 & 2600 & 200 & Mainstream junior school \\
\hline 3 & 3400 & 196 & Mainstream junior school \\
\hline 4 & 3800 & 200 & Mainstream junior school \\
\hline 5 & 8000 & $4 b o u t ~ 1,000$ & Mainstream independent school \\
\hline 6 & 1500 & 85 & Mainstream primary school \\
\hline 7 & 2500 & 110 & Mainstream primary school \\
\hline 8 & 92 & 12 & $\begin{array}{l}\text { Special primary school for pupils } \\
\text { with learning difficulties }\end{array}$ \\
\hline 9 & 130 & 24 & $\begin{array}{l}\text { Special primary school for pupils } \\
\text { with speech and hearing } \\
\text { impairments }\end{array}$ \\
\hline 10 & 20,000 & 1,600 & \begin{tabular}{l} 
University \\
\hline
\end{tabular}
\end{tabular}

Table 2-3: The description of the university and the schools for the research.

Seven mainstream schools, two special schools and one university (http://zscas.edu.cn) were involved in the study. The seven mainstream schools 
researched cover a range of primary, secondary junior and secondary senior schools. They are all located in Shaoxing. There are only two special schools accommodating children with learning difficulties (mental retardation) and hearing and speech impairments in the urban and nearby areas. The university is a provincial multidisciplinary higher learning institution growing in both popularity and strength ( $A$ more detailed pen portrait of the schools and the university is attached in Appendix II).

\subsubsection{The rationale for the selection of the research context}

Research on teacher attitudes towards special and inclusive education has been conducted in some areas in China (Zhang and Chen, 2002; Peng, 2003; Guo and Shi, 2004; Deng and Guo, 2007) mostly with the joint commission and/or funding from the Chinese government and some international organizations including UNESCO (e.g., Deng and Holdsworth, 2007). Individual research has also been undertaken in some major cities or some disadvantaged areas on teaching quality which identifies issues in quantity and quality of teachers in special and inclusive education (Wan, Wang, Du and Chen, 2008; Jiang, Wang and Fan, 2008) However, until now no research has been conducted to investigate teacher career motivation in special and inclusive education, in Zhejiang province, or arguably in the country. Additionally, no research has thus far tried to relate the motivation for a career to motivation for professional development by examining factors influencing attitudes and perceptions on special and inclusive education. This important factor is further discussed in the methodology chapter where originality of the research is considered.

Shaoxing is a medium sized city in terms of the population and area. It is reasonably developed in economic terms compared with many other cities of its size. This leads to more tension in academic competition for students as well as job opportunities for school leavers. The choice of the schools and the university in the city for this research is mainly because of a personal and professional interest in seeking the perspectives of teachers in this particular area to test $\mathrm{my}$ assumptions and hypotheses of the research topic. This element is also elaborated in the methodology chapter where sampling strategies for the research are discussed.

This chapter has set the context for the research and provided information which will enable the reader to consider the methods deployed and the discussion of 
findings on the basis of some understanding of the situation within Zhejiang Province and a wider Chinese context. The conditions within the province and the city of Shaoxing and the current state of educational development in China as a whole were influential in terms of the decisions made throughout the research process. 


\section{Chapter Three: Literature Review (I)}

The analytical review of the literature is reported in this thesis in three subchapters with a focus on teacher career motivation for, knowledge and skills of, attitudes towards special and inclusive education and perspectives on professional development. It is noted that this study is not intended to be internationally comparative in nature. However, as limited research has been conducted or reported in this domain in the Chinese context to date, a corpus of international literature has been reviewed inductively. An overview of substantial studies from the wider world provides me with a comprehensive picture within which to locate my own research. It also enhances my understanding of the research topic, which seems to have been overlooked in the Chinese context. This review is not conducted solely for the purpose of guiding or directing the study. Rather, it is used as suggested by Creswell (1994), as a joint framework for the research. In particular, it is used for the formulation of a rationale of assumptions and hypotheses, the development of research questions, and the interpretation of previous research to facilitate a comparison of the results of my own investigation with other studies.

Teacher career motivation and professional development provides the major focus for the study. In conducting this review at the initial stage, my approach was founded upon a key word and key concept search from a range of data bases and indexes such as the Education Resources Information Centre (ERIC), British Education Index (BEI) and other search facilities. Once some key literature was identified, further relevant references were obtained through hand searching and by the use of regular alerts services. A body of relevant literature was thus established with reference to books, journal articles, conference papers, official websites and research reports with a focus on the research topic.

This chapter reports on a review of teacher career motivation to be followed by subsequent chapters on teachers' knowledge and skills of, attitudes towards special and inclusive education and teachers' perspectives on professional development. These three parts are considered to have correlations and could have an impact on one another. This arguably creates an alternative route (Rinke, 2008) to the understanding of teachers' careers by linking professional life to a professional development path. 


\subsection{Motivation theories for researching teacher career choice}

\subsubsection{Motivation theories}

Motivation theories are concerned with the processes that describe why and how human behaviour is activated and directed. A review of motivation theories formed an inevitable undertaking for the construction of the framework of my research. Being aware that there is a substantial body of theories of motivation influencing research on human behaviour with none of them being universally accepted, it was beyond my capacity to have a full comprehension of all. Therefore, I decided to narrow my search for those theories on organisational behaviour which have been accredited with a recognisable impact internationally. This enabled me to have a better understanding of some theories that have gained prominence and general acceptance on the basis of their strong empirical validation (e.g., Maslow 1943; Herzberg, 1966; Vroom, 1964; Deci and Ryan, 1985; 2008).

Within the body of the theories, the most influential one is arguably Maslow's Theory of Hierarchy of Needs (1943). Focusing on the psychological needs of human beings, Maslow structures human needs in the form of a hierarchy, ascending from the lowest to the highest. Maslow states that every individual strives to satisfy their basic needs at least minimally before he advances to the next level. He concludes that when one set of needs is satisfied, it ceases to be a motivator.

Largely based on Maslow's theory, but taking a different approach, Herzberg (1966) developed his Two-Factor Theory, also known as Hygiene-Motivator Theory. In the work of Herzberg, there are just two sets of factors that impact upon motivation in the workplace, typically referred to either as satisfiers and motivators or extrinsic and intrinsic motives, with the motivators (i.e., intrinsic motives) being considered to be of a higher order. He claims that hygiene factors such as status, working conditions, company policy and administration, money, supervision, interpersonal relations, and security do not motivate individuals, but rather increase performance and prevent job dissatisfaction. What strikes him most is that these are separate groups with separate evaluation, and not a part of the same continuum.

The Two-Factor Theory gives rise to the development of other motivation theories 
in that it touches a major issue in work organizations in terms of job context and content. It also makes factors of motivation more concrete. Other theories which expand and extend those of Maslow and Herzberg include Vroom's Expectancy Theory (1964). Whereas Maslow and Herzberg look at the relationship between internal needs and the resulting effort expended to fulfil them, Vroom separates effort (which arises from motivation), performance and outcomes.

\subsubsection{Self-Determination Theory}

The theories briefly summarised above enhanced my understanding in studying organizational behaviour related to career motivation. Whilst Maslow and Herzberg could be used to describe which outcomes people were motivated by, Vroom's theory could be used to describe whether people will act based upon their experience and expectations. There are some aspects of these theories that are consistent with Self-Determination Theory (SDT) developed by Deci and Ryan (1985), which also stems from their own previous theories like CognitiveEvaluation Theory (CET) (Deci, 1975; Deci and Ryan, 1985). CET is formulated to describe the effects of social contexts on people's intrinsic motivation. To summarise this notion, it explains the links of contextual elements to the different motivational factors. It has received some initial attention in the organizational literature. However, the simple dichotomy between intrinsic and extrinsic motivation makes the theory difficult to apply in work settings. Differentiating extrinsic motivation into types that differ in their degree of autonomy leads to the SDT model.

Self-determination theory (SDT) is an empirically based theory of human motivation, development, and wellness. The theory focuses on types, rather than just amount, of motivation, paying particular attention to autonomous motivation, controlled motivation, and amotivation as predictors of performance, relational, and well-being outcomes (Deci and Ryan, 2008:182). This model, as summarised in Gagne and Deci (2005), contains concepts of intrinsic motivation, extrinsic motivation and amotivation. Intrinsic motivation Involves people doing an activity with personal interest and spontaneous satisfaction. In other words, it occurs when people are internally motivated to do something because it either brings them pleasure or reward, or they think it is important, or they feel that what they are learning is significant. Extrinsic motivation, on the contrary, refers to some instrumentality between the activity and the consequence. Whereas extrinsic motivation comes into play when people are compelled to do something or act in 
a certain way because of factors external to them. Amotivation involves a lack of intention and motivation. Intrinsic motivation is far stronger a motivator than extrinsic motivation, yet external motivation can easily act to displace intrinsic motivation.

SDT as a theory of work motivation develops CET by differentiating extrinsic motivation into types that differ in their degree of autonomy. Like Maslow's Theory of Hierarchy and others that built on it, SDT posits a natural tendency toward growth and development of motivation. SDT is specifically framed in terms of social and environmental factors that facilitate rather than undermine intrinsic motivation (Ryan and Deci, 2000: 58). Unlike other theories, however, SDT requires active encouragement from the environment. The primary factors that encourage motivation and development are autonomy, competence feedback, and relatedness. As with previous theorists, Deci and Ryan use a concept of psychological needs and hypothesise that satisfaction of these needs are associated with more effective performance and well-being. They tend to endorse participative approaches that allow people to experience satisfaction of their psychological needs. Moreover, SDT focuses on the Importance of intrinsic motivation in driving human behaviour.

SDT recognises the continuum of extrinsic motivation from the controlled regulation to autonomous regulation. This develops Herzberg's Two-Factor Theory (1966), which only separates extrinsic motivation from intrinsic motivation without identifying the continuum. SDT (Ryan and Deci, 2000a, 2000b, 2002; Deci and Ryan, 2007; 2008) has led to much research for the last 25 years (Vallerand, 2000; Vallerand, Pelletier and Koestner, 2008). It has received widespread attention in working domains in studying employees' career motivation. For example, Spittle and colleagues (Spittle, Jackson and Casey, 2009) apply the model in their study of social and psychological mediators behind student choices for their career. It has also been applied in educational research (Reeve, 2002; Ryan and Brown, 2005; Guay, Ratelle and Chanal, 2008), such as, teachers' support on students' learning autonomy, the motivational impact of testing as educational reform, and the role of SDT in creating optimal learning in optimal contexts for students. 


\subsubsection{Motivation theories for researching teacher career choice}

The incentive value of theories on motivation has, in some instances inspired relevant research on teacher career motivation. Meanwhile, research in this domain has been influential in the development of a range of motivation theories.

For example, the Expectancy Theory (Vroom, 1964; Expectancy-Value Theory (EVT), Wigfield and Eccles, 2000) is not about self-interest in rewards but about the associations people make towards expected outcomes and the contribution they feel they can make towards those outcomes. This theory therefore contributes an insight into the study of employee motivation by explaining how individual goals influence individual performance. Founded on Expectancy Theory, Watts and Richardson (2007) developed the Factor Influencing Teaching-Choice (FIT-Choice) framework. This framework has provided a comprehensive and coherent model to guide systematic investigation into teacher career motivation in both Australia and the USA. Their research also investigates individuals' perceptions about the demand and reward aspects of the teaching profession, which contains a measure of career satisfaction and commitment (2007: 32). According to the framework, there are altruistic motivations as well as more personally utilitarian motivations and intrinsic motivations together with abilityrelated beliefs for teachers' career choice. People with altruistic motivations see teaching as a socially worthwhile and important job, a desire to help children succeed, and a desire to help society improve. Whereas intrinsic reasons cover aspects of the job content itself, such as the activity of teaching children, and an interest in using their subject matter knowledge and expertise. These are in contrast with extrinsic reasons which are not inherent in the work itself, such as long holidays, level of pay and status.

Another example is the application of Herzberg's Two-Factor Theory (1966) which emphasises work related factors to explain issues concerning motivation. For Herzberg, motivators are factors which directly motivate employees to work harder as they are more concerned with the actual job itself. These motivators can include how interesting the work is, and how much opportunity it gives for extra responsibility, recognition and promotion. However, Hygiene factors would de-motivate an employee if not present but would not in themselves actually motivate employees to work harder. Building mostly on this theory, Frase (1992) named the described factors as Work Context Factors and Work Content Factors. In education, according to Frase (1992), Work Content Factors are the crucial ones in motivating teachers to high levels of performance as they are intrinsic to 
the work itself. They include opportunities for professional development, recognition, challenging and varied work, increased responsibility, achievement, empowerment, and authority. Work Context Factors, in contrast, are those that meet baseline needs. They include working conditions such as class size, discipline conditions, availability of teaching materials; the quality of the principal's supervision; and basic psychological needs such as money, status, and security. These factors, if adequately supplied, prevent job dissatisfaction.

A recently reported application of SDT theory is a study of student teachers' motivation for becoming physical education teachers (Spittle, Jackson and Casey, 2009). This work indicates significant gender differences in relation to motivational influences. According to this study, there is a significantly lower level of intrinsic motivation among males when compared to their female counterparts. These authors indicate that researchers in this field need to be aware of the influences of significant variables such as gender when considering motivation in respect of professional positions. A similar example of the application of theories of motivation is to be found in the research undertaken by Reiss $(2000 ; 2004)$ who claims that there are 16 basic categories of desires and values that guide nearly all meaningful human thoughts and actions, including power, independence, curiosity, and acceptance. This challenges the Two-Factor Theory (Herzberg, 1966) and SDT (Deci and Ryan, 1985). According to Reiss (2000), it is impossible to reduce all of the 16 categories into just two categories of intrinsic or extrinsic motivation as individuals are different with diverse human needs and motivations. This tends to support the ideas expressed by Spittle, Jackson and Casey (2009) with regard to the necessity of the awareness of the key variable influences. Reiss's theory on motivation argues there is no real evidence that intrinsic motivation even exists or that one is more influential than another as there are flows in logic, or too many important uncontrolled variables. Moreover, Reiss suspects the possibility that the negative effect of rewards has nothing to do with intrinsic or extrinsic motivation. Instead, rewards may cause some people to pursue an activity less because of the negative feelings they cause, such as performance anxiety. Avoiding an activity because of performance anxiety related to a reward is not the same as avoiding it simply because the reward undermines intrinsic motivation.

In the process of reviewing the literature related to teacher career motivation, a key word for the research, that being pay, occupies a predominate place. Based on the factor theories (Herzberg, 1966; Frase, 1992), people tend to perceive pay 
as a hygiene factor, which means that even the most intrinsically motivated teacher will become discouraged for the lack of sufficient pay for their work. However, some research (e.g., Gorard, See, Smith and White, 2006) argues that, financial incentives have much less appeal than is often assumed. Chapman and Adams (1998) suggest that overall quality of work-life, rather than the power of any particular reward, is the important factor motivating teachers.

I further reviewed literature to see if these arguments could be used to explain that more people in economically well-off cultures with better social welfare articulated altruistic reasons as the driving force for them to enter teaching. I assumed that, when Maslow's lower level needs have been satisfied, people would naturally move forward to look after their self-actualisation. In this respect the recent trend of changing career to teaching (Priyadharshini and Robinson-Pant, 2003; Richardson and Watts, 2005) is also an interesting phenomenon deserving attention. This movement by individuals from other careers into the teaching profession is particularly interesting when considering that much of the literature (e.g., Wang, Gu and Chen, 2004) has stated that, compared with other professions, teaching is not a well-paid job. This being the case, it is seen as valid to pursue research evidence which may explain the motivations for teacher career choice.

\subsection{Teacher career motivation in special and inclusive education}

\subsubsection{Research on teacher career motivation}

Research in the motivation of teachers has been increasingly conducted (Addison and Brundrett, 2008) despite the fact that, since the early 1980s, research interest has been attached mainly to the shortage and quality of teachers. Nevertheless, work values and job motives of teachers have been much studied recently in many economically advantaged countries (Younger, Brindley, Pedder and Hagger, 2004; OECD/WEI, 2005; Richardson and Watts, 2005, 2006; Malmberg, 2006; Cameron, Berger, Lovett and Baker, 2007; Hargreaves, 2007). Factors that motivate and de-motivate both pre-service as well as in-service teachers have been analysed (Spear, Gould and Lee, 2000). Research has also investigated what would motivate individuals to become teachers when the demands on teachers are greater than ever and that there are plenty of alternative occupations from which to choose (Watts and Richardson, 2008). In addition, attention has been attracted to the international comparative research in 
this area (Kyriacou, Hultgren and Stephens, 1999; Sharma, Forlin, Loreman and Earle, 2006). Notably, Bennell and Akyeampong (2007) synthesize 70 main findings and recommendations of an international research project on teacher motivation and incentives in sub-Sahara Africa and South Asia.

In an era of teacher shortages, a number of studies have been reported which have explored the reasons for the shortage of teacher supply. Teacher shortage is also researched in the Asia-Pacific Region (Gopinathan and Sharpe, 2002; Chen, Lim and Gopinathan, 2003). The keenly felt shortage of teachers elsewhere is identified in most of the countries in this region as the challenge to ensure the sustained supply of well prepared and motivated teachers. This finding applies to the Chinese context in that China has to create a large number of teachers who are well-motivated individuals with skills and adaptability to match the development (Yang and Wu, 1999). Therefore, the United Nations Educational Scientific Cultural Organisation (UNESCO, 2006a, 2006b) has attached great importance to the study of teacher career motivation, in the hope of attracting, developing and retaining effective teachers in economically backward countries.

Studies ( $L I, 1999)$ reveal that not enough people are making teaching as their career choice, resulting in a shortage of high quality applicants to teacher training courses. Still others (e.g., Gorard, See, Smith and White, 2007:419) identify that the shortage is regional and subject specific. The difficulties in recruiting teachers are suggested to be largely related to policies regarding recruitment targets and entry requirements. Teacher surpluses and shortages may coexist in the same country, for example, urban surplus and rural shortage (Chapman and Adams, 1998; Wang, Gu and Chen, 2004). Meanwhile, motivation differs from prospective teachers to in-service teachers with regard to teaching a range of students with diverse educational needs at different educational settings in different countries.

\subsubsection{Research on teacher career motivation in speclal and Inclusive education}

In a comparison with research in general education, research on teacher career motivation in special and inclusive education is still limited internationally. Given this is recognised as an important area, researchers (e.g., Garner, 1999: 62) identify that in special education, not many books provide a truly comparative analysis of these factors and that even within single countries little has been done to understand motivational factors. It has been stated that few international 
studies have been carried out to understand pre-service teachers' concerns and preparedness for teaching diverse learners (Sharma, Forlin, Loreman and Earle, 2006). Among the existing studies, a limited body of literature describes the feelings and thoughts of teachers in special education (Chen 2005), although in general teacher career motivation research, the impact of emotions on the personal well-being has been investigated (e.g., Hayes, 2003). 'Few studies examine how teachers' motivation can either directly affect their teaching behaviours or mediate the effect between contextual factors and teaching behaviours' (Pelletier, Se'guin-Le'vesque and Legault, 2002:187). Even fewer focus on special education teachers' motivation for their career choices.

\subsubsection{Key findings from the literature on teacher career motivation}

A motivated teacher is one who not only feels satisfied with his or her job, but is also empowered to strive for excellence and growth in instructional practice. Much of the impetus for the research on this topic has come from a concern in many countries, for example, in England (Addison and Brundrett, 2008), where a series of rapid, multiple and systemic changes in education are likely to have affected teachers' motivation and morale. English and Australian teachers are found (Scott, Cox and Dinham, 1999) to be motivated most strongly by altruism, affiliation and personal growth. The study by Addison and Brundrett (2008) indicates that the principal motivators for teachers in primary schools include positive responses from children, and staff experiencing a sense of achievement. This reassuringly reflects the traditionally held view of why teachers teach, namely, because they want to work with children and to see them achieve. They consider children as a core element in their career decision. Understandably, teachers find themselves de-motivated if children misbehave or do not achieve as much as expected.

In many countries, including Japan, China and Germany, most school teachers enter the teaching profession as a lifelong career (Su, 1997). Although, teachers cite pragmatic reasons for their decisions, in general, the intrinsic rewards as well as typical altruistic reasons are seen as the most important (Su, 1997). Teacher career decision can be influenced by intrinsic, extrinsic, and altruistic motivations (Brookhart and Freeman, 1992). Kyriacou, Hultgren and Stephens (1999) raise caution in interpreting the differences between countries or differences in the working conditions of teachers in these countries. They report that both groups of student teachers in England and Norway are strongly influenced by enjoying the 
subject they would teach, liking to work with children, and the fact that teaching would enable them to use their subject knowledge. This is broadly in line with other studies such as that conducted by Watts and Richardson (2007). However, there is a tendency for more of the English sample to place value on teaching children whereas the Norwegian sample place more value on long holidays and/or social hours.

Motivation can be influenced by interpersonal, social and environmental factors of self-concept, life experiences, interests and/or abilities and have long-term consequences on their professional life, well-being and their social situation (Creed and Wong, 2006). Teacher motivation for career choice varies from country to country. Studies from economically advantaged countries suggest that altruism is the major reason for career choice (Cooman, Gieter, Pepermans, bois, Caers and Jegers, 2007). Research in Belgium (Cooman, et al. 2007) explores teacher motivation to pursue a teaching job based on job motives and work values. They find that teachers consider intrinsic, altruistic and interpersonal features as strong job-specific motivators. Research in New Zealand (Hall and Langton, 2006; Kane and Mallon, 2006; Cameron, Baker and Lovett, 2006) identifies the same reasons that attracted teachers in entering teaching careers as described in the international literature (UNESCO, 2006b). Teachers define their professional identities in altruistic and moral terms, which have a strong synchrony with their reasons for becoming teachers. Without exception, these are related to their commitment to children, and to their desire to impact positively on their lives by helping them to become 'better people' and 'the best person they can be' (Cameron, Baker and Lovett, 2006).

Research has also studied teacher career motivation from a teachers' personal well-being perspective (Hayes, 2003; Song and $\mathrm{Xu}, 2006$; Day and Kington, 2008) by studying the impact of school experience upon their motivation for teaching. Studies (Hargreaves, 1998: 835) suggest that in addition to equipping trainee teachers with curriculum knowledge and teaching skills, more attention needs to be paid to their emotional welfare as 'good teaching is charged with positive emotions'. Still other research investigates the attractions of teaching from those who change careers to teach (Priyadharshini and Robinson-Pant, 2003). Reasons are perceived (2003:110) as both idealistic (wanting to have a 'moral' career, serving the community) as well as pragmatic (security, stability) in their decisions to change already established careers. 
Particular attention has been paid to the reasons given by student teachers for choosing a career in teaching. Sinclair (2008) studies student teachers' motivation to be primary teachers and their commitment to teaching after their first practicum. The findings indicate that the most common reasons for choosing teaching reflect a positive self-evaluation of their attributes and capabilities to be teachers, to work with children and for the potential intellectual stimulation teaching would provide. Similar studies in countries such as Brunei Darussalam (Yong, 1995), England (Reid and Caudwell, 1997), and the USA (Young, 1995) indicate that the most frequently given reasons for choosing teaching fall into three main categories, namely, wanting to work with children; wanting to contribute to society; and the enjoyment of teaching. There are some marked differences in the rankings of various reasons given in different nations and cultures. This may well be a reflection on the differences between countries in their social, economic and cultural context, and in the general image held of teaching as a career. For example, in nations where economies are buoyant, and jobs other than teaching are more readily available, the number of high quality applicants to teacher training tends to decrease. Yong's (1995) study in Brunei Darussalam finds that almost $15 \%$ of his sample enters teaching as a last resort. These studies tend to stress the fact that social, economic and cultural differences can facilitate or undermine individuals' motivation at different times (Ryan and Deci, 2000).

\subsubsection{Key findings from the literature on teacher career motivation in special and inclusive education}

Special education teachers are valued mostly for their commitment to serve a vast dimensional group of children with SEN, which is often perceived as one of the hardest and most complicated jobs in the field of education (Payne, 2005). In studying why people decide to work in special education and to clarify the problems and challenges met by the teaching profession, Kearns and Shevlin (2006) identify patterns in the positioning of what is currently construed as special education needs knowledge within pre-service courses. They suggest better frameworks for initial teacher education by arguing that special initial training for teachers is no longer favoured in Ireland (2006: 25). As moves towards inclusive education have been prioritised, so has a lessening of specialist training in relation to SEN. This has been related to a notion that all teachers need a good understanding of special needs issues rather than relying on the expertise of a few well trained individuals. However, Kearns and Shevlin are 
concerned that in some instances the impact of this move upon teacher training has been to marginalise special needs because of a lack of expertise or interest amongst teacher educators.

Interestingly, seeking the point of view of new special education students from a Norwegian sample, Hausstatter (2007) notices that the main motivation for teaching in special education is that special education teachers are highly sought after in the Norwegian labour market. The desire to take on the challenges presented by children with SEN is not always foremost in the considerations of student teachers. Although some researchers do mention philanthropic reasons and an eagerness to engage with the theoretical side of education, as highlighted in Hausstatter's study, considerations of the labour market have the greater priority over other concerns. This is in contrast with Richardson and Watts $(2005$, 2006) who perceive a wave of altruism influencing general education teachers.

In an attempt to better understand differences in job satisfaction, Stempien and Loeb (2002) compare the teachers of emotionally or behaviourally impaired students in special education, teachers of students in general education, and teachers responsible for both groups of students. Teachers of students in special education programmes are found to be the most dissatisfied. Specific stresses and frustrations, both from within and from outside the classroom, are found to be the main causes of this dissatisfaction. The difficulties are particularly common in younger, less experienced special education teachers whilst those who are older and have more experience seem to be better motivated. Other research (Cunningham and Oliver, 2007) focuses on the perceptions and experiences expressed by teachers to understand the factors that might influence perceptions of status and teacher attitudes. In their study, special education teachers are found more commonly to complain about inadequate resources due to the low status attached to the nature of their work in some special schools.

Most of the international comparative studies related to teacher career motivation in special and inclusive education focus on the exploration of attitudes of pre- and in-service teachers towards including children with SEN and/or teacher confidence for inclusion (Martinez, 2003; Sharma, Forlin, Loreman and Earle, 2006; Chong, Forlin and Au, 2007). Sharma and colleagues (2006) find that participants from Hong Kong and Singapore are significantly more concerned about their status when compared to their counterparts in Australia and Canada. If attltudes relate to job motives, then it is tempting to assume that negative attitudes lead to low 
job motivation.

In China, the lack of qualified teachers is further exacerbated by a teacher shortage and special education teacher attrition, leading to alternative certification routes that involve very little specialized training (McCabe, 2008:105). Researchers (Wang, Gu and Chen, 2004) argue that a market economy contributes to the high attrition of student teachers trained for special education. Wang and colleagues (2004) reveal that the situation of special education teacher attrition is becoming worse ever since the reform of higher education. During the planned economy years (before early 1990s) in China, the government could recruit students for special education programmes without having to get approval from the students. However, the market economy has impacted on the consequent reforms in higher education which provide middle school leavers with more choices and has enabled university graduates more freedom in their career choice. As has been reported in the contextualisation chapter, a revisit to the statistics about the student teachers educated in Beijing Normal University speaks for itself.

According to their findings (Wang, Gu and Chen, 2004), Beijing Normal University started the first bachelor programme of initial special education teacher training in 1986 and the first masters' programme in 1993 in China. From 1990 to 1992, the highest percentage of graduates choosing to work in special education was $67 \%$. In the following years, the percentage was always below $40 \%$ (except the years 1998 and 2002). In 2003, the percentage further deceased to 20\% whereas in 2004, nobody chose to work in special education. They also point out that since 1996, among those who have applied to study Masters' programmes, only about $10-25 \%$ of them have chosen to further their studies in special education. Since 2000 , about $30 \%$ of the bachelor degree student teachers annually have applied to Master's programmes. They further report that, unlike those bachelor students who were recruited by the government (instead of making their own choice) into the special education programmes, most of the Masters' programme applicants voluntarily choose to be in these programmes. However, a majority of them voluntarily gave up chances to be in special education as opposed to the motivation of doctorial students in special education in America (Pion, Smith and Tyler, 2003). In other words, they simply used their Masters' degrees as an alternative route for other professions upon their graduation. 
Studies on teacher career motivation in special education have not been extensively conducted. Consequently, little is known about, for example, whether a market-driven tendency has strengthened the role of education in promoting intergenerational income mobility and social equity, or whether policies, culture or attitudes have more influence on the choice of professions in China (Liu and Wang, 2006). An international review of the state of teacher recruitment indicates a widespread problem (UNESCO, 2006a). Some economically developed countries have been using a range of financial incentives to attract new entrants to teacher training courses, as well as providing an increasing diversity of training routes for those who want a career change to teach (Priyadharshini and Robinson-Pant, 2003). It is still the case that many recruitment campaigns tend to highlight altruistic reasons for choosing teaching as a career.

The implication of such findings provide evidence that more can be made of the fact that teaching enables people to continue working in a subject area they enjoy, and to benefit from certain aspects of the working conditions of teachers (such as long holidays and social hours). Initial teacher education and/or professional development programmes can be improved to motivate teachers. The prospect of identifying a series of low-cost incentives to motivate teachers to perform in new or better ways has a powerful appeal to countries caught in the squeeze of simultaneous declines in educational quality and resources (Chapman, Snyder and Burchfield, 1993). This may also be seen by many potential applicants to be attractive features of the job, although some other aspects of the working conditions of teachers (such as the level of pay) may need to be improved before they will act to encourage applicants. This can be a useful basis for further exploration of why people choose teaching as a career, which in turn may lead to more effective action to improve teacher recruitment and retention especially in the area of special and inclusive education.

By studying some key research findings from the limited literature in China (Chen, 1996, Deng and Poon-Mcbrayer and Farnsworth, 2001), I have become aware that much needs to be investigated in special and inclusive teacher career motivation in China. The research in China by Wang, Gu and Chen (2004) plays an important role in the formulation of my research assumptions and hypotheses in that it has significant implications in terms of illuminating issues in respect of teacher career motivation, recruitment, attraction, retention and attrition. The 
issues identified in their research concerning an increasing number of student teachers in special education applying to study other majors so as to avoid being in special education has a specific Chinese character. It is understandable that those who did not choose special teacher education but were recruited by the government have no intrinsic motivation in this career. With this fact in mind, I was highly motivated to conduct this study in a different context in China to a different sample for the purpose of gathering evidence to test my assumptions and hypotheses.

\subsection{Motivation theory for the current research on teacher career motivation in special and inclusive education in China}

Work values and job motives have drawn increasing interest for researchers in recent years (Cooman, et al., 2007). For example, Porter and Lawler (1968, cited in Gagne and Deci, 2005:331) propose a model of intrinsic and extrinsic motivation. This model advocates structuring the work environment to produce total job satisfaction. The assumption implicated in this model is that intrinsic and extrinsic rewards are additive, yielding total job satisfaction. Nevertheless, the SDT theory is the only theory that has detailed the processes through which extrinsic motivation can become autonomous (Gagne and Deci, 2005:348). Central to the SDT (Gagne and Deci, 2005:333) is the distinction between autonomous motivation and controlled motivation. Autonomy involves acting with a sense of volition and having the experience of choice. Intrinsic motivation is an example of autonomous motivation. In contrast, being controlled involves acting with a sense of pressure, a sense of having to engage in the actions. Based on the SDT (Gagne and Deci, 2005), when certain behaviour is motivated depending on the perception of a contingency between the behaviour and a desired consequence, it is considered to be externally regulated, otherwise known as extrinsic motivation contrasting with intrinsic motivation. When externally regulated, people act with the Intension of obtaining a desired consequence or avoiding an undesired one. The action is thus Instrumental.

The SDT has nonetheless maintained that it is important to keep the concepts of intrinsic motivation and autonomous extrinsic motivation separate both theoretically and empirically as the types of autonomous motivation (namely, intrinsic motivation and identified/integrated extrinsic motivation) share many qualities (Gagne and Deci, 2005:348). The SDT further suggests that: 
'the two types of autonomous motivation will be differentially effective in predicting various outcomes, with intrinsic motivation being a better predictor of behaviours that are interesting and enjoyable in their own right, whereas identified/integrated regulation will be more effective in predicting performance on tasks that require some discipline and concerted effort' (Gagne and Deci, 2005:348).

The model applied in the research reported in this thesis allows me to analyse and interpret the findings with the awareness of the spectrum of extrinsic motivation. That is, extrinsic motivation can change from the controlled end to the autonomous regulation apparent at the other end of the spectrum. I am particularly interested in investigating factors that impact on change. Most importantly of all, I was curious to find out the possibilities of the change from different categories of motivation rather than the change within the continuum of extrinsic motivation. I assumed human beings might not always be able to reason the motivational factors which influence their behaviour in that some overlapping might exist between intrinsic motivation and autonomous extrinsic motivation. In terms of career choice, I assumed that people might reach a decision based on their assessment of joint motivational factors. It could be that some are more intrinsically regulated whilst others are less so. For example, some intrinsic factors (e.g., liking teaching, liking children) influencing teaching as identified in literature and reported in this part of the chapter (Cooman, et al., 2007) do not have a convincing difference from those extrinsic motivational factors (such as: liking the subject, wanting to see children achieve, wanting to share learning by teaching). If this is the case, I venture to propose a discussion about whether the change within extrinsic motivation could be understood as the change including the one from the autonomous extrinsic motivation to intrinsic motivation. In other words, is it possible to make a difference between autonomous extrinsic motivation and intrinsic motivation?

By using this research to seek answers for my queries with regard to SDT, I aimed to make sense of the argument by Reiss (2000) that there is no real evidence that intrinsic motivation even exists or that it is better than other forms, regardless of its name or spectrum. 


\section{Chapter Four: Literature review (II)}

This chapter reviews literature on teachers' knowledge and understanding of and attitudes towards special and inclusive education. It starts with a brief summary of the diverse interpretations of the terminology of special and inclusive education as the key concepts for researching this topic in China. The comparison of the different perspectives from across the world is served for the purpose of better examining the factors influencing Chinese teachers' perspectives in this respect. The knowledge from this review is critical as the factors influencing knowledge, understanding as well as attitudes are assumed to have an impact on teacher career motivation and professional development in special and inclusive education.

\subsection{Special and inclusive education}

\subsubsection{Interpretations of special education}

Special education as a term has a diversity of interpretations and definitions problematic in respect of gaining a universal understanding. There is no unified or fixed legal definition of special education as it changes with the time and in contexts (Luo, 2000). The changes are brought forth with the previous understanding of it as 'a medical treatment for children and young people with physical disabilities' (Fish, 1989:26) to the more recent understanding of the education and training for those with learning difficulties. Moreover, it is often culture-specific. At present, for example, in England and in many other western countries, special education has been generally understood and interpreted to cover the provisions ranging from insitutions to special schools, special classes and resource rooms/teachers (Warnock, 1978; Mitchell, 2004:2). This is a significant move forward from an original interpretation based largely upon deficit models and focused upon a pseudo-medical approach to the management of children with disabilities to learning difficulties (Fish, 1989). It has received increasing consideration as an appreciation of environmental factors and others associated with low expectation and inappropriate schooling (Slee, 2001; Rose 2002). This is achieved globally over the years as special education is becoming increasingly a priority from policy to practice level.

Nevertheless, in some less socially or economically advantaged countries such as 
China, the definition of special education changes with the relevant policy initiatives (The Law of Protection of the Disabled, 1990; the Outline of the $9^{\text {th }}$ Five Year National Development Plan for the Disabled, 1996). Despite of the change from the interpretation of the education for the disabled to a broader meaning of the education for those with SEN (Piao, 1995), special education continues to be seen by many in China as the education of those described as disabled (Luo, 2000; Chen, 2005). A global understanding of the ways in which terms such as special and inclusive is yet to emerge.

\subsubsection{Interpretations of inclusive education}

Meanwhile, inclusive education, as a crucial move forward of special education in terms of equity, diversity and social justice, also has different interpretations in different social and cultural contexts and at different levels. To some, inclusive education refers to 'a philosophy of education that promotes the education of all pupils in mainstream schools' (Florian, 1998:13). It is about the provision for children with learning difficulties and disabilities in ordinary schools and their engagement in the learning environment. It also refers to changing the school, improving support and expertise of mainstream teachers (Thomas, Walker and Webb, 1998). As such, it is often justified in terms of promoting an inclusive society and at least a society which aims to reduce social exclusion (Norwich, 2008a). It is about the entitlement of all children and young people to quality education, irrespective of their differences or dispositions. It is also about embracing educational values of equity, diversity and social justice. However, research (Booth and Ainscow, 1998: 3) identifies that inclusive education continues to be thought of as 'a new name for special education for children having low attainment, deviance in behaviour or disabled'.

International documents and legislation such as the Salamanca Statement (UNESCO, 1994) and the Dakar Framework for Action (UNESCO, 2000) have drawn attention to the issues, challenges and opportunities which may be provided by a focus upon inclusive education and the promotion of a more inclusive society. In many cases, inclusive education values diversity and emphasises the rights and benefits of and provision for all children in ordinary schools and their engagement in the learning environment. Nevertheless, inclusive education still has different definitions and interpretations according to social and cultural contexts. Widespread confusion and a lack of common understanding exist due to multi-dimensional differences from country to country. 
Inclusion is seen as an unending set of processes with no limit of addressing and responding to the diversity of needs of all learners through increasing participation in learning, cultures and communities and reducing exclusion within and from education (Sebba and Ainscow, 1996; Booth, 1996). Whilst inclusion is more about just including children with SEN, inclusive education in China was initially implemented as a political strategy to urge mainstream schools to accommodate children with SEN (Deng and Manset, 2000). It has created recognisable education opportunities but meanwhile reflected some weaknesses in the Chinese educational provision. Limited resources are available (Deng and Holdsworth, 2007). Therefore, inclusive education is seen to be more about the opportunity for children who are independent in their life, and who do not interrupt other children in their education than it is for those with more complex or challenging needs (UNESCO, 2003). In practice, 'Integration' and then 'Learning in Regular Classrooms', the Chinese versions of inclusive education, are better accepted as concepts by Chinese teachers (Chen, 1996; Xlao, 2005). It is less about celebrating diversity and difference, confronting disadvantage and addressing exclusionary practices (Moran: 2007:132) as advocated and promoted internationally.

\subsection{Teachers' knowledge and understanding of special and inclusive education}

\subsubsection{Teachers' knowledge and understanding of special and inclusive education internationally}

Teachers are increasingly recognised as the key to the development of more inclusive education (Garner, 2001; Barton, 2003; Ainscow, 2008b). According to Florian (1998: 17), 'teachers need to satisfy themselves with the knowledge that a philosophy of inclusive education can be applied in mainstream schools and classrooms'. Recent studies have reported that teachers' attitudes depend largely on their knowledge and understanding, their values and beliefs, and their self evaluation abilities in relation to this fast developing field (Doveston and Keenaghan 2006; Khatib, 2007; Ferguson, 2008). This may be pivotal in motivations which influence teachers' career choice as described in the previous chapter.

International perspectives from teachers have been constantly modified with the 
improved awareness, understanding and interpretation of special and inclusive education based on their experiences with children with SEN in diverse contexts (Ballard, 1999; Martinez, 2003; Deng and Holdsworth, 2007; Berry, 2008). This is achieved by a consensus of conditions for the successful implementation of inclusive education. Specifically, it relies on teachers to have 'a positive attitude about the learning abilities of all pupils, teacher knowledge about learning difficulties and skilled application of specific instructional methods' (Florian, 1998: 23). Substantial reform in initial teacher education has provided improved programmes to prepare student teachers with more knowledge and skills for inclusive schooling.

A host of factors that impact upon teachers' acceptance of inclusion as a concept, principle and process have gradually been identified and interpreted. Inclusion, it is argued (Clough and Garner, 2003: 87), is being stalled because educational institutions are not fit to include all children because of the barriers of 'lack of knowledge, lack of will, lack of vision, lack of resources and lack of morality'. Studies (Loreman, Sharma, Forlin and Earle, 2005) have suggested that teachers' attitudes towards inclusion are positively correlated with the amount of related courses taken at an undergraduate level to a truly inclusive education which ensures the full enjoyment to children from all disadvantaged, marginalised and school-distant groups. Still others (Brown, Welsh, Hill and Cipko, 2008: 2093) suggest that a critical issue is the degree to which the regular education faculty possesses the skills and knowledge necessary to incorporate the material into their courses.

With a strong agreement regarding the necessary conditions to promote inclusive schooling, Chong, Forlin and Au (2007) examine the adequacy of an inclusive education module within initial teacher training on the attitude change of preservice teachers. The results show that student teachers are less prepared psychologically and more overwhelmed by their perceived inadequacy of preparedness for dealing with students with serious disabilities. They suggest it be related to student teachers' little or no experience of learning with classmates who had disabilities and therefore being unfamiliar with the concept of inclusive classrooms. The lack of knowledge and expertise in managing students with diverse learning needs leads to less positive attitudes towards including those children in regular classrooms.

Whilst this research presents interesting findings, some cautions should be 
exercised about their efficacy. In particular, attention should be given to the fact that this research based on a sample within a single institution which may not be typical of others providing initial teacher education programmes. Researchers investigate perceived flaws in the training and professional development of teachers. Some findings (Garner 2001; Kearns and Shevlin, 2006; Lambe and Bones, 2008) reveal important efforts yet continuing limitations in the preparation of teachers. Other research suggests that teachers need a repertoire of skills, expertise, knowledge, pedagogical approaches, adequate teaching methods, materials and time if they are to address diversity effectively within their classrooms (Meijer, 2003). These results are consistent with the recent findings (Brown, Welsh, Hill and Cipko, 2008) Indicating that general educators are frequently unsure of their abilities when working with students with learning disabilities.

\subsubsection{Chinese teachers' knowledge and understanding of special and inclusive education}

It is not the focus of this chapter to rationalise the purpose or the strategies of the Chinese government in getting involved in the global movement of more inclusive Education for All. A much more detailed description of this has been provided in the Research Contexts chapter. However, it is Important to revisit this research area with a brief summary to make better sense of the literature with this regard.

Before the Law of Nine-Year's Compulsory Education (MOE, 1986), education for those with physical or intellectual disabilities was entirely the responsibility of their families. Despite the government's endeavours, access to school for disabled children is still limited in some disadvantaged areas. Although local governments were urged to run special educational schools or classes for children with disabilities (MoE, 1986, Article 9; National People's Congress, 1990), education for children with severe learning difficulties was not mentioned directly in the policies (Pang and Richey, 2006a). Moreover, some further documents to facilitate reform in special education (MOE, 2001) still did not include education for children who were physically able but with a range of SEN. The term special education is very often narrowly or exclusively related to the education for the physically or intellectually disabled in China (Deng and Holdsworth, 2007). This conveys a generally misleading message to teachers. Therefore, those children are deemed to be excluded from inclusive schools. This also causes the problem of conceptual equivalence in international fieldwork. 
Inclusive education in China has some distinctive characteristics from its commonly known international interpretations (e.g., Centre for Studies on Inclusive Education, 2000). It is more integration based in a Chinese context. In rural west China, many children without disabilities do not attend school due to some socio-economic reasons (Plao, 1992). A large number of children with SEN are still excluded from education (Deng and Manset, 2000). This situation is more severe than expected in some disadvantaged areas, for example, in West China, that 'the prefecture and the four counties had on one with any knowledge of special education or inclusion In education' (Deng and Holdsworth, 2007:511). An investigation into special education teachers' professionalisation in Shanghai (Wan, Wang, Du and Chen, 2008) indicates that the ratio of teachers with professional training is low. About 30 per cent have not received any special education training prior to or after their teaching. Besides, teachers in general lack Inclusive education literacy such as the concept, knowledge, skills, and abilities of inclusive education and they hold negative attitudes (e.g., Zuo and Wang, 2008). Teachers' limited knowledge and expertise lead to more children being excluded or disengaged in mainstream classrooms. One study by Guo and Shi (2004) reveals that half of the student teachers studying special education worry about going to special schools as they perceive their knowledge and expertise are not sufficient to meet the expectations.

On the one hand, the Chinese government's documents (e.g., the Guidelines on Curriculum Reform of Basic Education, 2001, Article 10) attach great importance to the training of teachers for special education. On the other hand, statistics (MOE, 2003) show that only about $50 \%$ of the teachers and staff had received some special training. The Educational Laws for the Disabled (1994, Article 4) make it clear that it is the local government's responsibility to oversee the education of the disabled. Yet, there are tremendous regional differences in the educational provision and the support for teacher education due to financial constraints. Moreover, inclusive education remains relatively a low government priority despite that there are about 83 million people with disabilities alone in this country. This is evidenced (Xiao, 2005; Liu and Xiao, 2005; Yu, 2008) that currently, special education is not yet a compulsory module in the curriculum of initial teacher education in teacher training colleges or universities. This results in a vast majority of teachers with little or no knowledge for inclusive schoolings. 


\subsection{Teachers' attitudes towards special and inclusive education}

\subsubsection{Teachers' attitudes towards speclal and inclusive education internationally}

Attitudes of teachers as main stakeholders in special and inclusive education have been a burning issue which has received unprecedented interest in different countries (e.g., Avramidis and Norwich, 2002; Lambe and Bones, 2006). Substantial research (Ainscow 1999; Avramidis and Norwich, 2002) has identified that teachers' attitudes are a critical variable in the development of successful inclusive schooling. Positive attitudes are seen as necessary or even decisive (Moran, 2007; Ainscow, 2008; Wedell, 2008; Symeonidou and Phtiaka, 2009) as their attitudes can have tremendous impacts on their motivation for work to achieve inclusive education. To be more precise, their attitudes are critical factors influencing the degree of their job satisfaction, senses of achievement and their professional identity.

Limits to and possibilities for the educational reform remain much debated topics (Slee, 2006) with a focus on teachers in many countries (e.g., Davies and Garner, 1997; Sharma, Forlin, Loreman and Earle, 2006; Kearns and Shevlin, 2006). Nevertheless, generalisations in this respect are yet to be drawn. This is due to the incomparable nature of education systems in different contexts (Crossley and Watson, 2003). This is further coupled with the impact of historical, philosophical, political, socio-economic and cultural variations of teachers' attitudes (Avramidis and Norwich, 2002; Norwich, 2008a) which are bullt upon teachers' knowledge and understanding, values and beliefs, and self-evaluation abilities in relation to special and inclusive education.

Research identifies that teachers' attitudes depend heavily 'on their experience (specifically with students with SEN), their training, the support available in the classroom and other conditions such as the class size and their. workload' (EADSNE, 2005:13). The findings from Cyprus (Symeonidou and Phtiaka, 2009) suggest that teachers' conceptualizations of inclusion are problematic. Teachers tend to think on the basis of a medical and charity model and that they favour special schooling for specific groups of children. Richards and Clough (2004) identify that inclusive teaching is not considered to be an issue that would affect many student teachers personally. Student teachers perceive that most of the students with SEN in England are in special schools with their needs addressed by 
those with specialist qualifications and training. Differing views give rise to tensions for those attempting to understand fundamental issues around the inclusion of disabled people. Often, non-disabled people's views predominate in professional practice with disabled people, and in consequence 'attitudes to inclusion may be derived from historical acceptance that special needs are better met in special places' (2004:78).

In terms of placement, one of the early versions of inclusive education (e.g., Wilczenski, 1992:307) suggests that all students with disabilities are mainstreamed and become the responsibility of the regular class teacher who is supported by specialists. A recent argument (Norwich, 2008b) is that, schools, regardless of the type, need to strive towards commonality in multi-dimension. This is termed as the 'flexible interacting continua', a model concerning identification, participation, placement, curriculum and teaching and governance.

Comparative research suggests that, in culturally and geographically diverse countries, for example, Canada and Singapore, differences exist in teachers' beliefs about inclusion (Klassen, Chong, Huan, Wong, Kates and Hannok, 2008). Findings from economically disadvantaged countries have shown some sharp contrasts from advantaged countries (Wei and Yuan, 2000; Yuen and Westwood, 2001; Zhang and Chen, 2002; Xiao, 2005). At the Initial phase of the development of inclusive education, Leyser, Kapperman and Keller's (1994) crosscultural study shows that there are differences in attitude to integration between the USA, Germany, Israel, Ghana, Taiwan and the Philippines. Other studies (e.g., Al-Zyoudi, 2006) also show that the majority of the teachers surveyed in the 'developing' countries had strong negative feelings about inclusion. Lambe and Bones (2006) argue that lack of appropriate preparation, concerns about class size, resources managing other adults and coping with increasing numbers of pupils with diverse SEN are the key issues to be addressed within initial teacher education in advance of the radical changes planned. In Northern Ireland, mainstream schools show whole-hearted commitment to the philosophy and practice of inclusion, and can critically examine what they have achieved so far. Nevertheless, student teachers' positive attitudes (Lambe, 2007) are tempered by concern about personal competence to teach in an inclusive classroom and by continued attachment to the current system of academic selection with which they are familiar. In Malaysia (Ali, Mustapha and Jelas, 2006), teachers hold positive attitudes believing that inclusive education enhances social interaction and minimises negative stereotypes on special needs students. However, in 
Cyprus (Koutrouba, Vamvakari and Steliou, 2006), mainstream teachers are impacted by infrastructural insufficiency, prejudice and, above all, the lack of specific knowledge about special education. In many cases, the aforementioned poses obstacles that undermine their efforts. Similarly, in Ghana (Ocloo and Subbey, 2008), factors impeding inclusive policy implementation comprise inadequate facilities available and a lack of adequate training for teachers.

A correlation between insufficient teacher training and less positive teacher attitudes has been identified. Lim and Tan (2004) have recognised inclusion as being dependent upon a radical rethinking of the fundamentals of schooling which must begin with the promotion of more positive attitudes towards learners who have previously been denied access to education. Research (e.g., Jordan and Stanovich, 2003) argues that this has little to do with the reluctance of teachers to rise to the undoubted challenges presented by children with SEN, though undoubtedly such reluctance does exist. Elementary classroom teachers who believe students with SEN are their responsibility tend to be more effective overall with all of their students (Jordan, Schwartz and McGhie-Richmond, 2009). This is supported by Rose (2007) who suggests that 'slow progress is far more inhibited by a lack of clarity about the nature of inclusion and the imposition of imprecise expectations upon teachers and learners' (Rose, 2007: 26). He argues that 'for most teachers a commitment to inclusion has become the norm and they are now in need of support of a more concrete nature to move forward' (2007:31). Studies (e.g., Garner, 2000) also identify that some attitudes of mainstream subject teachers in secondary schools as a major inhibitor of movement towards full inclusion. Some teachers are diffident or even hostile to having greater involvement with children with learning difficulties, whatever the statutory guidelines specify. It is of note that the majority of Rose's research has been conducted in primary schools (Rose, 2002). By contrast, Garner's work in this area has examined largely secondary school teachers and Initial teacher trainees (Garner, 2000; 2001). It may be that the more positive attitudes encountered by Rose relate to teachers working in a more pastoral environment whereas secondary schools have a more detached and academic focus which result in teachers being more at a distance from the individual child.

The literature provides few insights into the influences that head-teachers' attitudes may have upon the acceptance of students with SEN. What is known is that some head-teachers in the UK have been influenced by the competitive nature of the English education system which has resulted in a focus upon 
academic outcomes to the detriment of creating an indusive ethos (Booth, Ainscow and Dyson, 1998). In China, the education system is every bit as competitive as that seen in England. It is understandable therefore, to find (Zhang and Chen, 2002) that middle school teachers are more negative as they have more pressure for students' academic attainments. These can be the high academic competition in schools, high expectations of teachers from school administrators for league table ranking, or from parents with high education aspiration for their children.

Inclusive education is a complex and problematic concept which requires major shifts from old to new educational paradigms with cautions in exercising inclusive models on multi-dimensional contexts (Mitchell, 2005). As such, Clough and Garner (2003) argue that successful inclusion may be dependent first upon teachers' attitudes to its implementation and, second, upon their perceived competence to deliver this important educational initiative. Teachers are Influenced by the contexts they are in (Day and Sachs, 2004). Cross-national differences are identified (Judge and Oreshkina, 2004) among the teacher preparation programmes due to special education reform efforts and the cultural, sociopolitical, and historical beliefs of each country. Therefore, Mitchell (2005) cautions that:

'Considerations should be given to each country's own social, economic, political, cultural, and historical singularities. Each country's indigenous philosophies, ideologies and practices should be encouraged, respected, challenged, overthrown or blended with exporters' (Mitchell, 2005: 19)

\subsubsection{Chinese teachers' attitudes towards special and inclusive education}

Chinese teachers' acceptance of inclusive education is influenced by factors such as the dense population, huge geographic disparities, unbalanced economic strengths in diverse regions (Yang and Wang, 1994), ill-implemented policies and collective culture (Liu and Wang, 2006). Teachers' perspectives can be explained, to some extent by the fact that in China, given that enrolment in general education doubled since 1995 (OECD/WEI, 2005:41), the goal of universal compulsory education is not yet met. Some children covered by the compulsory education are, in fact, out of school (OECD/WEI, 2005:117). Traditional attitudes towards people with SEN, especially with learning difficulties and disabilities can be hostile (Su, 1993, Wu, 2005; Pang and Richey, 2006b). Marxist commitments to fixed social roles provide this nation with collective identities with a very different framework from that in the wider world. Western values (Potts, 2000) such as individualization, self-advocacy and diversity have not found equivalents 
In China. For example, research (Pang and Richey, 2006a; Ding, Gerken, Vandyke and Xiao, 2006) reveals potential barriers for implementing individualised instruction in China. American and Western prorammes and services may benefit the development of special education in China. But they need to be culturally sensitive and appropriate for the economic, social and cultural realities and individualised and localised to China and its education system.

Findings on Chinese teachers' attitudes reveal the correlation between their knowledge and understanding of special and inclusive education, the support for teaching and professional learning and development (Zhang and Chen, 2002; Pen, 2003; Guo and Shi, 2004). A study by Liu, Du and Yao (2000) indicates a significant difference in mainstream primary school teachers' acceptance of children with SEN in Shanghai. Those who receive some training on inclusive education hold more positive attitudes than those who have not. Other research (e.g., Feng, 2007) identifies some barriers for mainstream teachers in respect of their developing positive attitudes towards the inclusion of children with SEN in some economically developed areas in China.

Teachers' lack of competence in inclusive education (Chong, Forlin and Au, 2007) is attributed to resources rather than attitudes, values and beliefs, or their own abilities in relation to special and inclusive education bring challenges, as echoed by participants in Liu and colleagues' research (2000). Lack of support from paraprofessionals or teacher assistants to support the teacher seems to be an important factor that may make individualised instruction challenging as the system now operates (Ellsworth and Zhang, 2007: 62). Most often, nelther the appropriate resources nor specialised skills are available. In a comparison of the attitudes by teachers from different special schools, Peng (2003) indicates that teachers from the schools for the students with visual impairments are more positive than those working with the mentally retarded. Their attitudes also have to do with their training and age with an indication that that younger ones (below the age of 40 ) are more positive than their senior colleagues.

Despite the government's policy initiatives, due to the vast geographical disparities, the lack of identification and diagnostic procedures, and the establishment of family and professional collaboration, inclusive education still do not have full acceptance in schools and society. How government policy initiatives on school improvement and SEN/inclusion are translated into practice by schools and how this practice is lived and understood by the society at large remains to 
be a problematic area. Insufficient initial teacher training and professional development fails to prepare teachers with the necessary skills to work with children with SEN leaving them physically integrated, marginalized or simply rejected (Wu, 2005; Yu, 2008).

Inclusive practice relies on knowledge, skills and understanding, resources and attitudes. Positive attitudes are a necessary starting point but by themselves they are rarely sufficient without the other elements (Florian, 1998). Global understanding of inclusion remains far from complete. Teachers' knowledge and understanding of, beliefs and attitudes towards special and inclusive education are speculated to be correlated with teachers' career motivation and their motivation for professional development. Yet, research has not been able to provide substantial findings. The complexities of the issues need further researching. 


\section{Chapter Five: Literature Review (III)}

This chapter reviews the literature on teacher professional development in special and inclusive education in three aspects.

First of all, I briefly summarise some of the literature from international contexts on teacher professional development in general as well as in special and inclusive education. As literature of this nature is substantial, and the topic involves extensive aspects of teacher education, I focus on some key concepts in teacher professional development, per se. Given the complex nature of the terms, this is a synthesis of literature together with my own interpretation based on the premise that different understandings of the concepts have impacted upon the models for professional development in teacher education in China. The challenges to professional development are also examined.

Secondly, I synthesise the literature on teacher professional development in the Chinese context using a similar approach. Models of professional development which have been much researched and debated are discussed.

Finally, literature from the wider world on beliefs and attitudes of teachers towards professional development in special and inclusive education is reviewed. This serves the purpose of making sense of the assumed correlation between teacher career motivation and their motivation for professional development within the Chinese context.

\subsection{Teacher professional development in International contexts}

\subsubsection{The development of some key concepts In teacher professional development}

As stated earlier in the Research Context chapter, internationally, teaching as a profession has been widely recognised and researched. Understandings and interpretations of the concepts related to the professional development vary in different social and cultural contexts reflecting the priorities attached to it by all levels. Concepts like professionality and professionalism in teaching have been debated (Hoyle, 1975) and interpreted in several ways (e.g., Evans, 1999; 2008). According to Hoyle (1975), 'professionality' refers to the knowledge, skills and 
procedures which teachers use in their work. Building on this definition, Evans (1999) redefines the concept as an ideologically-, attitudinally-, intellectually-, and epistemologically-based stance, on the part of an individual, in relation to the practice of the profession to which s/he belongs, and which influences her/his professional practice. In other words, it 'reflects what the individual believes education and teaching should involve. It also influences and is influenced by realistic expectations and relative perspectives' (Evans, 1999: 177). Given the differing expressions from these two writers, it is important to note that both acknowledge that professionality is not the same as professionalism. To Hoyle (1975), professionalism refers to status-related elements of an occupation whereas Evans (1999) perceives it to be principally related to ways, or even codes, of behaviour.

These concepts indicate the focus within the overall context of teacher education in terms of professional development. They also have a significant impact on the direction of policy initiatives, research and practice on professional development in different contexts. Evidence based research in this area has enhanced understanding of teaching as a profession (Johnston, 1997; Nunan, 2001). Given that it is a much researched area (Darling-Hammond and Sykes, 1999: Day, 1999; 2004; Wang, 2004; Fraser, Kennedy, Reid and McKinney, 2007; Paine and Fang, 2007), professional development remains an ambiguous and contested concept in its definition and purpose (Evans, 2002; Friedman and Phillips, 2004). According to Friedman and Phillips (2004: 363), there is no single concept of continuing professional development that is widely accepted. Some place an emphasis on life-long learning and personal development (Friedman, Durkin, Phillips and Davies, 2000) whilst others see it as a means of training professionals to fulfil specific work roles. Still others regard it as a guarantee of individual professional competence (Faulkner, 1996). There is some concurrence of the view that professional development is 'the process whereby teachers' professionality and professionalism may be considered to be enhanced' (Evans, 2002:131). This process calls for teacher professional learning and continuing professional development.

There are strong arguments in favour of a much broader, intrinsic and ethical purpose for teachers' professional learning and development (Day, 1999). Researchers (e.g., Fraser, Kennedy, Reid and Mckinney, 2007) also try to clarify the distinction between professional learning and development. Fraser and colleagues (2007) suggest that teachers' professional learning represents the 
processes which result in specific changes in the professional knowledge, skills, attitudes, beliefs or actions of teachers, whether intuitive or deliberate, individual or social. Professional development, on the other hand, refers to the broader changes that may take place over a longer period of time resulting in qualitative shifts in aspects of teachers' professionalism (2007:157). The latter entails change for emotional and social as well as intellectual and practical engagement in the processes (Day, 2004). Both changes demand an exploration of various models to improve the quality of teachers, which create opportunities as well as challenges for teachers and teacher education.

\subsubsection{Demands for new models of professional development: an international perspective}

Diverse models of professional development have provided enormous learning opportunities for teachers. Yet, there is a paucity of literature addressing the spectrum of continuing professional development models in a comparative manner (Kennedy, 2005). Constant change in the form and content indicate the advancement of teacher education. This, in turn, becomes the driving force for the adaptation and implementation of new models, with a consequence of improved understanding of the concepts of professionality and professionalism.

There is a need for greater interrogation of both the purpose and the potential outcomes of professional development structures. The need calls for investigations into the efficacy of professional training programmes. According to Kennedy (2005:236-237), professional learning opportunities can be located along a continuum of models. The underpinning purposes of particular models can be categorised as 'transmissive', 'transitional' or 'transformative'. That is, the continuum of models increases capacity for teacher autonomy as teachers move from transmission, through transitional to transformative categories (2005:248). This seems to me to accord with Hargreaves and Fullan's (1992:2) three types of teacher development, namely, knowledge and skill development, selfunderstanding, and ecological change. This develops the understanding of the concept of professionality as defined by Hoyle (1975) in that it puts forward the idea of teacher self reflexivity and capacity building in making a change in teaching. Transformative models of professional development have the capacity to support considerable professional autonomy. These authors suggest strong links between theory and practice, internalisation of concepts, reflection, construction of new knowledge and its application in different situations, and an awareness of 
the professional and political context. They urge a rethinking of the traditional models of teacher professional development. This calls for a priority of teacher 'knowledge of self' other than 'knowledge for, of and in practice' (Day and Sachs, 2005:9) in all aspects of professionalism.

Other researchers also expect teachers to have not only a strong academic background, expertise in pedagogy and classroom management, but pedagogical control knowledge as well (Tatto and Plank, 2007). The latter is defined as knowledge about how to communicate unfamiliar content to students (2007: 272), which used to be overlooked by traditional teacher education programmes. They support the views expressed by Hargreaves and Fullan (1992) and suggest that knowledge can only be acquired through rigorous professional preparation, followed by ongoing professional development (Tatto and Plank, 2007). Therefore, the focus of teacher development is on raising the standards and integrating curriculum model (Hardman, 2009) which leads to an internal sense of confidence and competence as a teacher. This kind of development might involve acquiring the skills for effective teaching.

In addition, international research examines the limitations of in-service teacher training. Researchers (e.g., Garner, 2001) are particularly worried about the security and relevance of initial teacher education provisions. Garner sees the development of competence based models of training as challenging the opportunity to develop a more autonomous and professionally confident work force. There are reasons for the worries. In many contexts, teachers are no longer automatically respected for their knowledge. They are also expected to call upon their own resources to undertake additional higher education themselves (Potts, 2000: 310). Besides, teachers are increasingly visible in the education system and increasingly vulnerable to public scrutiny and public sanction if their performance does not match predefined expectations' (Tatto and Plank, 2007: 268). This argument is supported (e.g., Gao, 2008) that cultural tradition undermines teachers' feelings of professional authority and . becomes an unexpected source of their professional vulnerability.

Meanwhile, criticisms (Chapman and Adams, 1998) emphasise the lack of application of teacher education programmes to actual classroom situations, the absence of developmental and career planning, and the lack of participation of teachers in the design of tralning. Providing teachers with valued incentive and motivation is of vital Importance. The prospect of Identifying a series of low-cost 
incentives to motivate teachers to perform in new or better ways has a powerful appeal to countries caught in the squeeze of simultaneous declines in educational quality and resources (Chapman et al., 1993).

The changed status of teachers as professionals and also the call for ever more effective teachers has led to a demand for a 'change in the nature, the purpose and the mode of delivery' of professional development in teacher education (Garner, 2006:17). Specifically, Garner argues that professional development should be treated as an on-going, daily routine work instead of an incidental event. Teachers themselves have to develop mechanisms of control which are organic to their work and context that can result in the development of what can be seen as professional responsibility. This is a view further endorsed by others (Tatto, 2007; Rinke, 2008). Teachers are encouraged to seek professional development to provide quality teaching and to get professional promotion (Richards and Nunan, 1990). They are expected to make changes in their teaching through innovative professional development programmes. Above all, teachers are challenged to develop their knowledge and skills for teaching and consider their values and beliefs through professional development.

\subsubsection{Teacher professional development in special and Inclusive education in international contexts}

In the process of moving towards inclusive education, rapid development in teacher education has been witnessed internationally. Teacher professional development in special and inclusive education is emphasised as a key factor in developing an understanding of inclusion with regard to the conditions required to promote a more equitable education system (DFEE, 2000; Mittler 2000; Garner, 2006). Subsequently, some common issues have been identified and to some extent addressed. An increasing attention to the issues has been apparent within all educational levels and sectors. Research in this area is illuminated by the evidence of practices from teacher professional development in general to deal with some key issues in the development of inclusive education (Garner and Davies, 1997). Yet, very little has been reported about teacher education in terms of special teachers' professional development. In particular, there are specific areas where research on professional development in general has so far been overlooked or little reported. This creates opportunities as well as challenges for researching in special and inclusive teacher education. 
There are many contributory factors such as policy initiatives (Education for All, 2000), societal support, and acceptance of inclusion either as a concept or in practice which can be seen as influential in relation to this issue. For example, Barton (2003) indicates that the position of teacher education in the development of inclusive thinking and practice on the part of student teachers is of fundamental importance. Substantial research (see research evidence detailed in the Literature Review on teachers' attitudes) supports this argument in that insufficient training of special and inclusive education leads to less positive attitudes towards inclusion. Evidence has also shown the correlation between improved initial teacher education and professional development programmes and improved provision and services to children with SEN. However, as Gargiulo (2008) puts it, teachers need more than just academic knowledge about exceptionality. They need an awareness and understanding of the human side of exceptional students and their families. Most specifically, the improvement of teachers' attitudes towards special and inclusive education is equally important for inclusive schooling as the improvement of knowledge and skills. This can be achieved with the improvement of teacher professsionality and professional identity.

Nevertheless, commenting on teacher education, Cochran-Smith (2004) argues that little has really changed in the ways student teachers are prepared. Besides, there are dramatically different perceptions of teacher education for diversity, as well as major disparities about notions of equity, teacher learning and social change (2004:140). It appears that there remains a common feeling among educational professionals that training, to date, has been inadequate, despite continuing requests for the training of all teachers in the pedagogy of SEN. The literature related to knowledge of and attitudes towards special and inclusive education is considered in the previous chapter.

\subsection{Demands for new models of professional development: opportunities and challenges in the Chinese context}

China's reform on teacher development is affected by the process of globalization (Paine and Fang, 2006). Given the tremendous efforts made by its government, China, as the largest provider of teacher education and training in the world (Yang and Wu, 1999), has to make further efforts. On the one hand, teacher education is now one of the government priorities in China. The focus of in-service training has shifted over time to reflect social and economic changes, and changes in the 
needs of schools and the backgrounds of their teachers (Lamie, 2006; Paine and Fang, 2007). Yet, more often than not, professional development is seen as the development through training. There remains a tendency to prepare teachers with few opportunities to develop pedagogical content knowledge. The flaws in the system have caused much stress for some teachers who enter classrooms with insufficient knowledge and expertise to provide effective learning for their students. This is largely due to the fact that teacher education has been under strong state control. Besides, reform has depended on the aims of the state rather than reflecting international knowledge and understanding of the development of pedagogy (Tatto, 2007:11).

The reform in professional development rests on a cascade model (Paine and Fang, 2007) presented in at least two dimensions.

First of all, the national and provincial governments develop their plans, objectives and measures. Local education authorities develop further plans accordingly. Secondly, the training of key teachers is the central mechanism for the training of other teachers. This pragmatic strategy makes up for the financial constraints of each level of governments. During the years 1999-2002, qualification upgrading training has basically achieved its goals. At present, the national plan for 2003-2007 has shifted the focus to supporting the development of rural and minority teachers (Paine and Fang, 2007: 48). This is because in China, rural schooling poses particular challenges for improving the teaching force (Potts, 1995) since the highest proportion of unqualified teachers is found there (Robinson and $\mathrm{Yi}, 2008$ ). Access to professional development presents a particular challenge for teachers living and/or working in geographically or economically disadvantaged areas. Retaining qualified teachers in poor rural areas has been more difficult as decentralisation of school finance has created disparities in the economic resources available to schools in different locales (Paine and Fang, 2007:24).

In addition, research (Tatto and Plank, 2007) Identifies that the Chinese government has accomplished relatively little progress toward closer control over teachers' professional practice. Meanwhile maintaining control over teacher preparation has proven to be increasingly difficult. Professional development is too closely tied to the development of knowledge and skills of teachers in classroom teaching. There is a clear mismatch between the authoritarian state control imposed upon the professional development of teachers and the identified 
needs for knowledge and understanding that could positively impact upon the quality of teaching and learning.

The changing professional and political context has resulted in unprecedented investment in continuing professional development in some countries, as can be seen for example in, Scotland (Fraser, Kennedy, Reid, and McKinney, 2007) and the Netherlands (Villegas-Reimers 2003). In China, teachers used to be financially supported by the government or their schools to take part in a range of continuing studies. However, the policies of education decentralization mean that provinces essentially have to fund their own school systems. 'The educational standards of some economically disadvantaged provinces inevitably fall behind those of their richer neighbours' (Chapman and Adams, 1998: 648). Nowadays, instead of getting financial support and being allocated study time for professional development from their institutions or the government, teachers at different levels are encouraged to take an active part in engaging themselves in professional development programmes in terms of time and finance (Feng and $\mathrm{Yu}$, 2008). This is evidenced in other research conducted internationally (e.g., Hustler, McNamara, Jarvis, Londra, Campbell and Howson, 2003) that financial cost (perceived and/or real), distance from training opportunities, and workload, are important inhibitors of access to continuing professional development, the last especially true for older teachers.

Teachers are expected to manage a number of dilemmas (Paine and Fang, 2007) with little resources at their disposal. These dilemmas often include the lack of knowledge and understanding necessary for including children with SEN; little or no support from paraprofessionals or learning support staff; large class size and above all, the examination-oriented system. This is demonstrated by the growing disparities in wealth within countries like China where unevenness of teaching force is highly significant (Paine and Fang, 2006; 2007).

\subsubsection{Models of professional development in China}

For a long time, teacher professional development in China places an emphasis on teachers' academic qualifications (The Teacher Act, 1993; Yang and Wu, 1999). Substantial efforts have been made to improve the quality of existing teachers at all levels, especially those who started teaching with limited qualifications. Teachers have different opportunities to build their professional knowledge, which already appears to have impacted on their teaching practices, job satisfaction, 
motivation, and career decisions.

Meanwhile, diversified degree and non-degree education training models have been adopted to meet in-service teachers' different needs. The programmes have provided great opportunities for teachers (Gu, 2007; Xu and Connelly, 2009). However, legitimacy of professional development activities, as Friedman and Philips (2004: 369) indicate, is often perceived in terms of formal training courses linked to work or gaining a qualification. For example, degree training, as compensation for the inefficiency of initial teacher education programmes, provides 'catch-up' education for in-service teachers without qualified certificates and upgrading education is for in-service teachers with qualified certificates. Nondegree education, on the other hand, is the main form of continuing professional development targeting the orientation of new teachers during the probation period and enhancement of the basic skills of all those holding teaching posts.

In general, programmes devoted to further training for teachers have typically been offered in a variety of settings, ranging from local schools to in-service teaching training universities or colleges. Distance education constitutes another in-service model, as do school-based training activities organised by individual schools (Wang, 2004:22; Paine and Fang, 2007). In China, accountability for teacher development has traditionally been placed in the hands of 'master teachers' within a tightly knit school community in a centralised system and with a complex bureaucracy that works well in the culture and context where it evolved (Tatto, 2007:12). Traditionally both teacher and school quality are thought to be maintained by relying on organic accountability, with more experienced teachers working closely with younger teachers to assure quality. Most teachers have informal opportunities to develop their teaching, which, whilst easily overlooked, can impact upon their abilities and confidence in the classroom. In the best practice, this is built upon more structured opportunities to observe other teachers' teaching and by obtaining formative feedback on their own teaching and their students' learning.

Furthermore, professional development has been strongly focused on the teaching aspect of academic work, with research development a relatively neglected area of study. For example, drawing on the findings of contributors to one of the top educational journals in China and in America respectively, researchers (Zhao, Zhang, Yang, Kirkland, Han and Zhang, 2008) identify that school teachers and administrators in China author a surprisingly small 
percentage of the articles (slightly over 1\%). There is a need for additional investigations of teacher development as teacher researchers to balance and integrate with the research into teaching. To raise awareness of research capacity building by improving models of professional development, attention should be drawn on teacher motivation for professional development and challenges should be recognised.

\subsubsection{Challenges in professional development in China}

The models currently being deployed in China, whilst reflecting a willingness to change, are not without their limitations. Teacher training is increasingly acknowledged as needing more than conventional training in pedagogic skills and strengthening of academic content. Research demonstrates that, in order to change teachers' attitudes, values, and practices, something more than technical training is needed (Evans, 2008). In that sense, professionalism may be interpreted and utilised for the development of education professionals. Researchers (e.g., Wang, 2004) argue that professional development programmes should be part of the continuum of teacher education which starts with initial teacher training. However in China, professional development programmes are run by teachers' education colleges which use a different and less effective training system from those more recently advocated and seen as innovative. Wang (2004:5) identifies that within this system, trainers are not as qualified or experienced as those in teachers' colleges or universities. Approaches to teacher development fall broadly within a 'skills and knowledge-based' paradigm through which a predetermined level of skills and understanding are targeted. In other words, the understanding of professional development is rested on professional learning whilst anything beyond this basic level is ignored. This remains the core feature of most professional development at both initial teacher and post qualification levels in China.

\subsubsection{Teacher professional development in special and Inclusive education in China}

Like teaching and teacher education, professional development in special and inclusive education has always been influenced by national policy and legislation. The Chinese government's documents and regulations (The Outlines for Education Reform and Development, 1993; The Education Act, 1995) with regard to teacher education have contributed to an unprecedented development in teachers' professionalism since the 1980s (Wang, 2004; Zhou and Reed, 2005). In 
particular, since the mid 1990s, teacher professional development in special and inclusive education has been influenced by the government's priorities.

The inclusion of children with diverse educational needs Into mainstream schools has provided equal opportunities for children with disabilities and/or difficulties, but meanwhile posed new challenges to the whole teacher education system. These challenges imply that with China being caught in the shift to a new paradigm, especially with the increasing demand on teachers with special education training and their further professional development. Research (Liu, Du and Yao, 2000) shows that there is an urgent need to improve the quality of teachers who have missed their training in initial teacher education and need to catch up for inclusive education. Liu and colleagues find in their sample of primary school teachers in Shanghai that professional development is listed top in need. However, many teacher educators themselves, perhaps even most teacher educators, have not had the transformative learning experiences necessary to interrupt the conservative assumptions underlying teacher education programmes at many higher education institutions. Few programmes and departments have built into their ongoing operations, the intellectual and organisational contexts that support teacher educators' learning about issues of diversity and social justice in education (Cochran-Smith, 2004).

\subsubsection{Models of professional development in special and inclusive education in China}

Models of professional development in special and inclusive teacher education do not differ much from those for mainstream school teachers. Among them, schoolbased professional development is frequently applied. Research (Wang, Gu and Chen, 2004) identifies that the majority of teachers researched in special schools are transferred from mainstream schools. For these teachers, the training model provided by their schools used to be a master teacher, mentoring or short training sessions (Wang, Gu and Chen, 2004: 55). Some teachers (Liu, et al., 2000) find this kind of training models superficlal and not practical and welcome schoolbased training models. This is supported by McCabe (2008) who has provided evidence about important features of an effective school-based, on-going, on-thejob teacher training model. The findings reveal that teachers quickly gain the skills and knowledge needed and the model benefits from collaboration, cooperation, and discussion in training sessions leading to positive improvement in teaching. This kind of school-based professional development model has been frequent, particularly for teachers in special schools who have had few 
opportunities to develop pedagogical content knowledge through a formal traditional model of professional development conducted in or by higher education institutions.

\subsection{Teacher motivation for professional development in special and inclusive education}

With regard to teacher motivation for professional development, according to Johnson (1986:61), merit pay indicates a bonus plan that 'supplements the standard pay scale and rewards teachers for special services, a multi-track pay scale that provides rapid salary advancement for outstanding teachers...or conducting in-service training. In other words, in order to keep higher levels of pay and status, teachers carry on showing high performance. For high performance, economic rewards are important. Teachers' salary is a perennial issue in most Asian countries including China and in fact has been seen as important in providing a set of incentives that have been used across many countries in attempts to encourage better teacher performance. Stout (1996) supports the findings and illustrates his ideas with four motives teachers have for participating in professional development: salary enhancement, certificate maintenance, career mobility (building their résumé to move up the ladder into administration or pursue other careers), and gaining new skills or knowledge. He also argues that none of the first three motives, in itself, necessarily leads to better performance. The weight of the research suggests that overall quality of work-life, rather than the efficacy of any particular reward, is the most important factor motivating teachers (Chapman and Adams, 1998:656).

Moreover, studies (Hustler, McNamara, Jarvis, Londra, Campbell and Howson, 2003) on attitudes towards continuing professional development reveal that complex interrelationships between local structural and cultural factors, and teachers' career stage, age, and subject affiliations can affect teachers' attitudes towards and understandings of professional development. Research in Scotland (Hustler, et al., 2003) indicates that teachers generally feel that continuing professional development has impacted positively on their motivation to teach. Yet, the substantial proportion of students undertaking award-bearing courses do so for personal, rather than professional reasons, according to the study on motivational and inhibiting factors affecting postgraduate professional development for teachers (Arthur, Marland, Pill and Rea, 2006:214). Arthur and colleagues' (2006) study also finds that personal circumstances and commitment 
from individual teachers and time and support in the workplace are influential motivational or inhibiting factors.

An ever increasing demand for professional development has put teachers in the spotlight. As professionals, teachers find it very challenging to live up to the social expectations of their peers. Generally speaking, even though not better off financially, Chinese teachers are asked to take their profession very seriously and, therefore, they are often praised for their dedication to what they are doing. Fraser and colleagues (2007:159) argue that the purpose of professional learning is attitudinal development. That is, changes in intellectual and motivational aspects as well as functional development (Evans, 2002). It is not uncommon to see most of the Chinese teachers stay in the teaching profession for more than ten years and even for life (Song, 2008). Most of the teachers are aware of the necessity of professional development. However, their motivation for professional development varies.

In China, much research in special and inclusive education has focused on teaching methodology and initial teacher education. Research into teachers' motivation for professional development from teachers' own perspective has not yet drawn enough attention. Evidence is missing from research that investigates whether teacher development, as currently arranged, can produce the links of participating in professional development programmes and the improvement of teachers' performance. This provides space for further investigation into motivation for and attitudes towards professional development. But if nothing exists in the system to ensure, or perhaps even encourage the motivation for knowledge and skill through professional development, it may be that as Stout (1996) has suggested, high levels of enhancement in the various kinds of knowledge essential to effective teaching cannot be delivered. 


\section{Chapter Six: Methodology (I)}

The methodology for the study is reported in three chapters following a sequence of events of the research design, data collection methods, procedures and data analysis. This is coupled with a discussion of the originality of the study, the opportunities as well as challenges in conducting the study in terms of methodology. In so doing, it endeavours to present an honest appraisal of the strengths and weaknesses of the methods deployed. Interpretative research of this nature is invariably a dynamic process which requires modification and presents challenges at every stage. The realities of implementing the methods and the effectiveness of data collection are discussed throughout the chapter.

The first chapter reports the research design. It is explained with attention given to the focus of the research, the development of a conceptual framework and research questions as well as theoretical framework underpinning the current study. It is followed by a report of the development of the research methods and sampling strategles together with a brief description of the sample for the study.

\subsection{Research design}

\subsubsection{The focus of the study}

The study focuses on the relationship between teacher career motivation, their knowledge and understanding of, and attitudes towards special and inclusive education and their professional development in a Chinese context. The research therefore, was founded upon a flexible design.

\subsubsection{Conceptual framework}

The idea for the study originated from my own career experience. I had been a lecturer of English language at a university in China since 1986. In 2005, I asked for a study leave from my home university and applied to the University of Northampton to seek personal and continuing professional development by funding myself. Due to my long years in higher education, I had barely enough knowledge and understanding of special and inclusive education, which is mostly provided in primary and secondary levels. Although most of my students were student teachers and in-service teachers, as a lecturer, my responsibility was to 
teach the subject knowledge (More detailed accounts can be referred to in Appendix I). Moreover, my initial contradictory attitudes towards inclusive education reflected my perspectives on special and inclusive education described as follows:

Like many teachers in China, I perceived that people with SEN were different from others in many senses because of their diverse disabilities or learning difficulties. Therefore, from the educational point of view, I tended to support the argument that it was best to educate them in special schools. This was based on my knowledge and understanding of the Chinese context. Taking into full consideration the learning aptitudes, attitudes and abilities of those children with SEN, and the quality of the current teaching force as well as resources available, I contended that 'exclusion' of the children with SEN was for the benefit of all.

However, I soon noticed the change in my attitudes towards special and inclusive education owing to the extensive learning and experiences I gained from my school placement and elsewhere during $m y$ MA year in the University of Northampton. The more I was exposed to the theory and practice of special education and inclusion in the UK and internationally, the more I became aware, by comparison and contrast, of the differences in provision in different sociocultural contexts for people having SEN. I assumed that there might be reasons why there were obvious differences in the provisions from the international comparative perspectives. I began to closely examine the current educational provisions in China from teachers' perspectives. At this stage, by reviewing the literature and reflecting upon my own knowledge and experiences in this area, I started to develop some hypotheses and formulate a conceptual framework for the study. Whilst the research assumptions, hypotheses and research questions can be referred to in the Introduction chapter, here, I provide a brief account of it.

\subsubsection{The research questions}

I assumed that there might be a generally low career motivation from Chinese teachers in respect of working with children with SEN. I also assumed that insufficient pre-service training and in-service further education contributed to teachers' limited knowledge and expertise in special and inclusive education. This, I surmised, would lead to a lack of career motivation for and positive attitudes towards special and inclusive education. This would further impact upon their perspectives on their continuing professional development. I contributed the 
causal factors to the low priority attached to special and inclusive education in China, which I believed to be multi-dimensional and contextual-specific. I was very curious in investigating the following questions:

- What are the motivations of teachers with regard to teaching children with SEN?

- What is the impact of teachers' professional knowledge and understanding of, and attitudes towards special and inclusive education on their career motivation?

- What is the impact of teacher career motivation and their perspectives on special and inclusive education on their motivation for professional development?

I was highly mindful of the fact that some economically advanced countries such as the UK had attached more priority to researching in theory and practice in the area of special and inclusive education as opposed to a limited approach in China. In order to rationalise the multi-dimensional factors which influence special and inclusive education in the context of China, I focused the study mainly on the investigation of teacher motivation in their career choice and professional development by using the international literature as comparative indicators to reflect upon the situation in China.

\subsubsection{Theoretical framework}

\subsubsection{The model of SDT}

While I was reviewing the literature of motivation theories, especially the ones for studying career choices, I identified that many theories had been developed over time (This is reviewed in Part One of the Literature chapter). I realised that for my particular study, it might be best to concentrate on a specific theory to see if the model could be used to describe, explain and/or interpret the career motivation of teachers in my research context.

My major interest in the investigation of teacher career motivation led me to the initial assumption that teachers under investigation might vary in their motivation of working with children with SEN. This further allowed me to assume that their motivation could be extrinsic due to a range of factors which impacted upon their career choice. I began to examine closely the model of SDT and eventually decided to apply this model in the analysis of the data collected and the discussion of the findings. As I anticipated that diverse regulations of extrinsic 
motivation might exist, I tended to believe that SDT could best suit my research purpose in the analysis and interpretation of teacher career motivation in special and inclusive education in China (to be detailed in the following chapters).

The application of SDT does not imply the discard of other models because of their irrelevance. It is simply used to make better sense of the evidence yielded from the research. For example, altruistic motivation and extrinsic motivation in FIT Choice framework (Watts and Richardson, 2007) are not specific enough to be applied in my study as this model does not specify the continuum of extrinsic motivation. However, the framework is still much reviewed and referred as comparative factors for my research in the design and data analysis.

The most important aspect of the SDT model, which is considered as a critical factor for its selection, is the proposition that extrinsic motivation can vary in the degree to which it is autonomous rather than controlled. SDT has enlightened practices and policies focusing on motivating studies through sanctions, rewards and evaluations as well as career decisions for teachers (Spittle, Jackson and Casey, 2009). Nevertheless, whilst SDT proposes that extrinsic motivation can vary greatly from controlled to autonomous regulations (Deci and Ryan, 1985; Gagne and Deci, 2005), research has not yet been reported about the possible continuum from the very end of autonomous extrinsic motivation to intrinsic motivation in studying motivation for career choices. Moreover, the amotivation or unwillingness is seldom reported in literature on teacher motivation to distinguish from passive compliance to active personal commitment ( $A$ much detailed review of SDT for the illustration of my points can be referred to in the Literature chapter).

\subsubsection{A social constructivist paradigm}

The design of the study was influenced by the assumptions described above and was driven by the research questions. It was thus conducted within a social constructivist framework which provided its philosophical underpinning (Gergen, 2001). It was my hope that meaning and knowledge with regard to teacher career choice and their professional development could be soclally constructed by investigating the multiple interpretations surrounding this complex issue. This means that I did not try to verify a pre-existing theory or theories. Instead, I was interested in conducting an analysis that identified the connections between career motivation, professional knowledge and professional development, which I assumed was 'hidden behind surface appearances' (Gredler and Claytor-Shields, 2008:29). I tended to achieve a better understanding of the research topic in the 
research process and followed the established principle (Gergen 2001) that a theory and/or theories could be socially generated on the completion of the study.

Constructivism, according to McCarthy (2006:26), is based on the contention and belief that knowledge is constructed from within and that 'we are constantly involved in the construction of meaning for ourselves. We all have to make sense of the world for ourselves and we continue to develop and extend this understanding throughout our lives'. I contend with his argument that all understandings are private and individual constructions whilst knowledge is actively constructed by the learner instead of actively received from the environment. This argument claims that social interaction and social communication are critical components in supporting individuals to construct their own relational understanding which enables them to make connections between prior knowledge, the incoming new knowledge and new experiences (McCarthy, 2006). The basic principle is that knowledge is co-constructed through social interaction and is the result of social processes (Gergen, 1995). It, according to Simina and Hamel (2005:219), is shared (Prawatt and Floden, 1994) and seen as an 'ongoing, dynamic process within a social activity'. In particular, social constructivists focus on collaborative social learning rather than individual learning in the creation of learners' perceived social reality.

This study was based on the social constructivist paradigm in that learning is a social process whilst knowledge is a human product, which is socially and culturally constructed through interactions with each other and with the environment they live in (Gilbert and Swift, 1985; Gilbert 1995). With this understanding, meaningful learning was gained when I engaged myself in social activities through a range of data collection methods. This enabled me to form my own conceptions relying also on other research evidence from the existing literature from/about China and beyond. As social constructivism gives emphasis to the importance of culture and context in forming understanding (McMahon, 1997), the reality was thus reproduced and constructed through the research activities to be incorporated with my interpretations of the data.

Researchers (Booth and Ainscow, 1998:235) caution that 'perspectives may be highly complex, interweaving strands of experience, knowledge and belief. Furthermore, there may be inconsistencies within the perspectives...and these may change overtime'. I was aware of this negative aspect of knowledge construction that, as social constructivism (Anttonen, 1999) differs from the 
psychological views of constructivism in which individuals construct scientific knowledge in their individual minds, the objectivity and the reliability of socially constructed knowledge could be problematic. Therefore, mixed research methods were purposefully designed to lessen the potential problems.

\subsection{Research approach}

The research developed for this study was built upon a traditional flexible design. To explore the research questions, I sought to listen to informants and to build a picture based on their ideas (Creswell, 1994:21). The openness and flexibility were powerful and important for the research topic when little about the topic was known. Therefore, a mixed-method approach was deployed in conducting the research. The value of collecting data using a mixed-method approach is that different forms of data are combined to 'make a more coherent, rational and rigorous whole' (Gorard, and Taylor, 2004:4). The methods were applied through the use of self-completion, close and semi-structured questionnaire surveys, faceto-face, in-depth semi-structured interviews, and non-participant observations alongside document scrutiny (Punch, 2005; DiCicco-Bloom and Crabtree, 2006; Bryman, 2008). The approach aimed at the cross referencing and the triangulation of data set. It allowed me to identify cases for further interrogation of the research questions by using narrative enquiries to collect stories about teachers' professional life. The analysis and interpretation were based on my basic beliefs about the process to be studied, which influenced the selection of the methods for this study.

\subsubsection{Rationale for the research approach}

The selection of the approach is twofold. First, I was interested in accessing a wide variety of data and appreciating the meaning attached to them. Qualitative data using a naturalistic approach allowed me to investigate people's feelings and beliefs from a variety of sources (Vulliamy, 1990). Quantitative data from questionnaire surveys enabled me to establish the extent to which insights were generalisable to a wider population.

The other rationale is for data triangulation. The approach was to assist in obtaining valid and reliable data. To ensure objectivity, I remained as an 'outsider' researcher to avoid influencing or being influenced by the participants I studied. In addition to maintaining a degree of detachment, I adopted the position of a 
naturalist researcher in collecting narrative accounts. I was highly mindful that my assumptions on the research topic based on my previous knowledge and personal professional experiences might lead me to preconceived opinions. Besides, the literature I used was largely from countries other than China. There was a potential danger of me being critical towards the research context in China. Therefore, I was particularly cautious in making efforts to avoid biased opinions. The mixed methods had the strength to increase the reliability of the data collected from a purposive and selective sample as they compensated the potential weaknesses of the approaches if deployed solely.

\subsection{Sampling}

Sample selection is of critical importance in qualitative studies as it has close links to the external validity and generalisation of the findings (Robson, 2002). In this study, my initial assumptions helped me to refine the research questions and further guided me in sampling. However, research of this nature was to be developed and the target population in China for this small scale study was too large for me as a student researcher with constraints in many aspects. In fact, it was simply unfeasible and unrealistic to study the whole population, even of one particular context, to get their opinions and views. Therefore, I had to extract samples from the target population to conduct the research.

\subsubsection{Rationale for sampling}

The decision of sample type and size prior to the actual research being undertaken was a matter of judgment as 'it depends upon the purposes of the study and the nature of the population under scrutiny' (Cohen, Manion and Morrison, 2000:93). For data to be reliable and generalisable, a sample must be representative of its population and fit the research purpose. In other words, inferences about the population are only valid to the extent that the sample accurately represents the population of interest. I had to pre-define the groups of people in sampling. However, since the target population for each sample is often dictated by the hypotheses under test or by research questions, a truly representative sample is 'an abstract ideal unachievable in practice' (Coocican 1992:26).

\subsubsection{Sampling strategy and principles}


My sampling strategies were based on Miles and Huberman's (1994) principles of sampling. That is, sample strategies should be feasible, ethical and relevant to the conceptual framework and the research questions. Besides, the sample should be likely to generate rich and believable descriptions or explanations on the type of phenomena to be studied and to enhance the 'generalisability' of the findings (Miles and Huberman, 1994:34). All the above criteria were at the forefront of my mind in developing a sampling strategy.

For my research, I also followed the principle that when samples are small in qualitative research, if studied intensively, each one can generate a large amount of information. This is because qualitative research is designed to make possible analytic generalisations, but not statistical generalizations (Curtis, Gesler, Smith, et al. 2000:1002). In practice, I considered the criteria and made the decisions on the basis of practicality and feasibility in terms of time and resources available. I balanced all these in light of obtaining information that would be both rich and useable. I realised that it would be natural, appropriate and feasible to locate the sample in a city in China where I used to work for years at a tertiary level as a teacher trainer. This would enable me to utilise my contacts with the local schools and educational sectors to find the participants. Whilst this might be considered a weakness in terms of developing an opportunity sample, this was justified when examined in terms of the safeguards put in place described in this part of the chapter.

Based on the research purposes and key questions, I chose a purposive and selective sampling strategy. I purposively drew the sample for the study from the frame of eligible population in a city in China. Given the time consuming nature of phenomenographic analysis, it is common to aim for the minimum sample that can be expected to show the range of variation that would be present in the population as a whole.

\subsubsection{Purposive and selective sampling}

Purposive sampling, often used for case studies, was a particular useful sampling strategy (Mason, 2002) for my research. I hand picked the subjects on the basis of my estimate of the sample's typicality and of my interest as a researcher (Robson, 2002). That is, when sampling from the population upon which I was focused, my principle was to obtain typicality and commonality of participants in 
relation to my research interest. The selection was purposive in nature (Patton, 2002) with the participants initially self-selecting and then being chosen because they had particular characteristics which could enable me for a detailed exploration and understanding of the particular phenomena being researched. To make the sample fairly representative, by selecting individuals from important sub-categories, I used purposive sampling which involved targeting a particular group because it was that group I was interested in. In this case, participants were required to meet some predetermined criterion for inclusion.

In particular, I was interested in what the sample could tell me about the population. I used a stratified random sample taken from the wider purposive sample identified to ensure representativeness. This sampling was obtained based on known properties of the population of interest. The characteristics of the sample were considered in detail which included their age, gender balance, education background, professional experiences, all of which were relevant to the study question.

The problem of field research in case study is to gather evidence in such a way as to make it accessible to subsequent critical assessment, to internal and external criticism and to triangulation. There was, of course a danger of creating a biased sample when this was selected from a known location. However, safeguards for this study were established through the development of a formal sampling process which was based upon identifying the characteristics of a required stratified sample which would be purposive and would thereby inform the study.

\subsubsection{Quota sampling and opportunity sampling}

Quota sampling was used in this relatively small research investigation conducted over a short period of time. This was supported by research (e.g., Coocican 1992:26) that 'as long as the researcher has a good knowledge of the population that she seeks to study, she can select quotas of individuals who are roughly representative of the research'. A further source is the student teachers as an opportunity sample (Broomfield 2006). I selected a sample from the existing frame of those teachers from mainstream and special schools who were willing to be contacted and interviewed. Reviewing the geographical location, I discovered that there were fewer special schools compared with mainstream schools in the research focus city. I therefore used the student teachers who were about to graduate from the university by the time of the field work. 
It is important to note that the variation within the sample reflected discrepancies within the desired population. Thus, the variation in classification included in the sample represented the majority of the population in the research field in the area. Besides, reduced variation in the sample did not invalidate the ways of understanding what emerged from the data, as these ways of understanding should still be present in the larger population.

I was aware that there was the potential for bias within the sample because of my predisposition towards a particular outcome based upon my experiences and beliefs about teacher attitudes and expectations. Furthermore, as I was interested in investigating people's values, attitudes and perceptions, I appreciated that there would be a need to confront significant ethical issues. Nevertheless, my judgment for sampling was that a mix of qualitative and quantitative research methods appropriately fit two groups of purposive and selective samples for the study. I drew on the strengths of using the more broadly focused questionnaire survey to illuminate current attitude trends and experiences of a large group of teachers and student teachers in the research focus city in China. The interviews with teachers from mainstream and special schools were used to capture the depth and understanding of their teaching experiences and their perceptions and attitudes of working with children with SEN. I purposely selected from the voluntary participants as my case study sample. The two methods by using two samples thus complemented each other.

\subsubsection{The sample}

The research was conducted in a city in China (described in the Research Context chapter). Altogether 326 teachers from seven mainstream schools, 37 teachers from two special schools and 565 student teachers from a university participated in the questionnaire surveys. I observed 8 classes in two mainstream schools and two special schools. 44 teachers were interviewed in all. Among them, 22 were from mainstream schools and the rest from special schools. The teachers selected represented as much variation as possible. They were of both genders. They were teachers of varied subjects with different education backgrounds and personal and professional experiences. The range of years of teaching experiences varied from a few months to approximately 35 years. Their ages ranged from mid-20s to late-50s. The student teachers were mostly in their early $20 \mathrm{s.}$ 


\subsubsection{Mainstream school teachers}

The participants at the heart of this study from the seven mainstream schools were selected by their headteachers and/or self-selected on a voluntary basis. The size of the sample for the questionnaire survey was intended to reach 400 . As I had no knowledge of the return rate, in order to encourage participation, I distributed 500 copies in all to the schools researched. The return was $N=326$. There were 36 teachers expressed their interest of being interviewed. I only interviewed 22 teachers from 5 schools because, from the voluntary list, I identified some names of my former students from initial teacher education and in-service teacher training programmes I used to be involved. In fact, I received contacts from some of them expressing their excitement that I would be going to their schools to do the research. They regarded it as an opportunity for a reunion which was a typical way of showing their respect to teachers in China. I expressed my high appreciation to them. However, I was aware of my role in this research. More importantly, I was mindful of the ethical issues as well as validity and reliability of data to be yielded (more discussion is available in the following chapter). I ended up interviewing 22 of them, among which 6 were my former students.

\subsubsection{Special school teachers}

As I have indicated that I had almost no contact with special school teachers before the research, I intended to engage them all by distributing 40 survey sheets to the two special schools. I saw that a chance for me to enhance my knowledge and understanding about their career life. I actually anticipated to interview all the teachers. But in reality, I got 10 volunteers for interview from one school and 12 from the other. I interviewed all of them.

\subsubsection{Student teachers in the university}

The cohort of student teachers also provided a purposive and selective sample in that it fitted the purpose of the research. Instead of using all four grades of student teachers in the bachelor degree programmes, I only selected the senior ones and involved them all $(\mathrm{N}=1078)$. This sample was limited as the participants were drawn entirely from one institution. However, as they were about to finish their school placement and was on the process of hunting for jobs at the time of my research, I anticipated that this cohort would be able to provide me with rich data as they were. In other words, they were experiencing the critical time of making their career cholce. 


\subsubsection{The pilot study teachers}

Six teachers from mainstream $(N=5)$ and special schools $(N=1)$ in the same city were chosen for the pilot study. The mainstream sample was a convenience one as I knew them personally and was aware that they were experienced in education and were able to express their opinions. As for the special school teacher, I got to know him at the research designing phase. The teachers showed their great interest in cooperating with me for piloting in the form of a focus group interview. Another 5 teachers were part of the piloting sample. They were also experienced teachers who I knew for years. I sent them emails with the research instruments attached. Their feedback was provided via emails and telephone conversations.

\subsubsection{The case study sample}

Two teachers were identified for case study, Ms. Shao Yang from the special school for children with speech and hearing impairments and Ms. Zhu Zheng from a mainstream independent school (both under pseudonyms). The identification was based on the observations made during the school visits and initial interview data processing. Both teachers had the characteristics of commonality and typicality which best served my research purposes. Below are the pen portraits of them to help justify my selection.

The commonality of Ms. Shao Yang relied on her initial controlled extrinsic motivation for career. She became a teacher in the special school in 1978 at the age 20 when she replaced her retiring father. It was a job assigned to her by the local educational government as the implementation of the policy during the planned-economy years before China transferred to market-economy in the late 1980s. Ms. Shao Yang had received no teacher education training of any kind when she got the offer. Neither had she had a degree or diploma to start her career. All she had was a junior middle school certificate. All these years, she had worked in the school without a change for other schools or opportunities for professional development. Nevertheless, she was used to the school life and system, perceiving herself as an ordinary teacher who was ready to retire in a few years' time. Given her positive attitudes towards special and inclusive education, she has little motivation for her personal or professional development. She was in fact not bothered much whether she was able to provide effective teaching. She had accepted the perceived social status and identity as a special education teacher. Like her colleagues researched, she had low self-esteem and lost her passion for her career over the years. 
However, what made her typical was that her father, who suffered from speech and hearing impairments himself like his wife, was one of the founders of the special school. He devoted his life to teaching in the school. Ms. Shao Yang's four siblings were all working in special education or serving people with disabilities. She married her husband who had no teaching qualification or training of any kind but a senior middle school certificate when he became a teacher in the same school as the placement of his retiring mother 30 years ago. Both of them had been working in the special school ever since. The husband actually had some chances of working in mainstream schools but refused to be transferred.

I was fortunate to have met my second case, Ms. Zhu Zheng, at the beginning of my research. Ms. Zhu Zheng had intrinsic motivation in teaching which had sustained her all through the $\mathbf{2 5}$ years as a teacher. She had previously worked in different types of schools in various parts of the country before she settled in the school researched. She was well respected nationally for her teaching as well as her ability in mentoring other teachers. During the interview phase, she had just returned from overseas with an MA in Education degree in special and inclusive education. She had been striving to make a change to her school ethos by urging and supporting teachers for their professional learning and development.

I had many informal conversations with her about my research topic. Her insightful perspectives reassured me that there were teachers like her who were so committed to teaching and could actually make a difference in education. In terms of her motivation for professional development, she was exceptional in that she had several opportunities for training at home and abroad sponsored by the provincial or local governments or her school in the past years. Unlike those who took advantages of the opportunities but not actively seeking learning and development, she was a real learner to make the investment on her rewarding to the sponsors. 


\section{Chapter Seven: Methodology (II)}

The chapter discusses the data collection methods, procedures and data analysis. It begins with an examination of the generic strengths and weaknesses of the different methods deployed in the research process. A description of data collection procedures using a range of research instruments is followed by a report of the data analysis approaches, strategies and procedures for the study.

\subsection{Methods of data collection}

A mixed-method approach allowed me to acquire diverse perspectives on the key research questions from teachers using a range of methods of data collection.

Punch (2003: 41) indicates that better planning for and greater efforts in data collection, control of data collection and the acquisition of good data are four key points when conducting small scale research. I was aware from the outset that there were possibilities of introducing additional research instruments during the process if the need arose as a result of either inadequate data accumulation from the initial approach or the need for further verification of data. Such flexibility of approach (Bassey, 1999; Mason, 2002) is widely regarded as essential when conducting work within an interpretative paradigm.

Within the constraints of finance, time and resources and taking account of the complexity and nature of the questions at the heart of my study, I considered the feasibility and practicality of the range of methods at my disposal. I decided to conduct the research in three phases. I started the research with a questionnaire survey, then followed with interviews and observations, and finally complemented the data collection with a case study.

\subsubsection{Questionnaire survey}

For the first phase of data collection, a self-completion, closed and open-ended questionnaire survey was selected as the research instrument. Whilst the provision of an opportunity to express Ideas and opinions is limited within questionnaire formats (Oppenheim, 1992), it is justified that respondents can bring unique insights and interpretations by providing a broad overview to phenomena which can be built on through other methods. 


\subsubsection{The strengths and weaknesses of questionnaire survey}

The selection of questionnaire survey was based on the possibility of obtaining information from a large number of respondents with relatively limited cost using standardized, anonymity assured questions. Since the main emphasis of a questionnaire is on 'finding facts rather than seeking causal relationships' (Bell, 1999:14), the questionnaire was designed to ask 'a mixture of factual and opinion questions' (Grosvenor and Rose, 2001:129). This allowed the respondents some latitude in expressing opinions whilst also presenting some factual data useful for understanding their varied experiences. In addition, analysis tended to be more straightforward, although this could be seen as a limiting factor within questionnaires for studying causal relationship. Being aware of the limitations, I attempted to combine the strengths of questionnaire survey in gaining a broad overview from my sample respondents by ensuring the use of other instruments in data collection.

\subsubsection{The design of the questionnaires}

The formulation of the questionnaire survey was undertaken only after a long period of time engaging myself in a critical review of the literature both in and out of China. This allowed me to construct three key topics, namely, teacher career motivation, teacher knowledge and expertise of and attitudes towards special and inclusive education, and teacher professional development. Based on the research aims, I identified some preliminary issues which I wished to investigate. The focus of the questionnaire was built upon my interpretation of a broad range of literature and research which had either considered similar issues or some issues yet to be explored. The design was constructed in a manner which allowed for analysis of data using a variety of approaches. Czaja and Blair's (1996:53) research model was adopted for my investigation. This model emphasises the researcher's task of linking research questions to survey questions. It also stresses the respondent's tasks, which involve interpreting the question, recalling information relevant to it, deciding on an answer and reporting the answer to the researcher. This model provided me with a valid measure of the research questions and also elicited the co-operation of respondents and encouraged accurate information.

In designing the questionnaire, I continuously tried the survey instrument (Robson, 2002:245) with colleagues, including those with a Chinese education background. Meanwhile, issues concerning question content, wording, forms of 
response and place of questions in the sequence were observed (Cohen, Manion and Morrison, 2007: 320). Issues like the use of general, vague, blased or leading terms in language were avoided. I was conscious of the fact that much of the literature available was from locations which differed greatly from China. This required me to give detailed consideration to both the language used and the concepts addressed within my questionnaire. This again was a limiting factor, but one which I was able to address more readily at the second phase of the research when conducting interviews.

\subsubsection{The format and content of the questionnaires}

The language of the questionnaire was Chinese and it was constructed in three parts:

The first part was a letter to the particlpants seeking both their support and consent. In the letter, I identified myself and stated the purposes of the study. The ethical code for the research was attached. As I indicated that I would be conducting interviews to follow up this questionnaire survey, my contact details were provided to welcome queries as appropriate. To keep in touch with the participants for possible interviews, those who would like to be further contacted were invited to leave their contact details on the survey sheets (See Appendix IV for the Letters of Consent and Appendix $V$ for the Ethical Code of the research).

In the second part, there were 13 multiple choice statements for student teachers and 22 for in-service teachers. The decision to use statements was for the purpose of achieving objectivity (Brown and Dowling, 1998) from the respondents. This part was made up of 4 Likert Scale of positive and negative statements relating to the attitude being measured. The respondents were asked to indicate the extent to which they agreed or disagreed with each statement. According to Grosvenor and Rose (2001), a Likert scale is sultable for the measurement where the research project demands data on the opinions, attitudes and beliefs of a sample population. Teachers' attitudes towards Inclusive education were measured based on the idea Inferred from the sixteen item scale of measurement developed by Wilczenski $(1992,1995)$. The Academic Motivation Scale (AMS) developed by Vallerand et al. (1992) was also reviewed. Considering the culture validity issues, all the statements in this section were purposively designed for this particular research in the Chinese context.

The last part contained 5 open-ended questions in each questionnaire for both 
student teachers and teachers. Four out of the five questions were generic ones to check participants' motivation for career choice, and also their knowledge about special and inclusive education. The specific question for the student teachers asked about their personal contact or learning/teaching experience with children with SEN. This was to examine whether they, as individuals who had clearly been successful learners at school, had ever had any knowledge about or learning experiences with children with SEN. Whereas the specific question for teachers aimed at investigating whether they regarded their career choice as positive or negative and why this might be (see Appendix VI for the Questionnaires).

\subsubsection{Interviews}

The major part of the data collection in the second phase was through interviews with teachers as an effective method of obtaining rich data in support of survey research.

\subsubsection{Acknowledging strengths and Iimitations}

A face-to-face, semi-structured in-depth interview was employed as the main research instrument both to validate data obtained and to complement other data collection methods. This relatively informal and naturalistic approach using openended questions allowed the interviewees much flexibility of response. It has its bases in phenomenology which places the experience of the individual at the centre of the enquiry and seeks to understand and describe that experience from the point of view of the participant (Creswell, 1998). In recognising that each respondent would construct their own view of the world based upon personal experience, expectations and beliefs, I was keen to enable them to talk freely about their ideas and opinions which I had a commitment to respect and value. As an instrument, interviews have strengths and limitations as well.

First of all, it was an appropriate method to capture subjective personal 'lived' experiences of teachers and therefore fitted comfortably within my research purpose. In addition, interviews play a significant role in the construction of the reality being studied (Herzog, 2005:26). This approach helped me to achieve a holistic understanding of the issues under study from the interviewees' points of view and/or to explore interesting areas for further investigation (Berry, 1999; Beale, et al., 2004). Meanwhile, it supported the interviewees in reflecting, exploring and analysing without constraint or preconception. 
Secondly, a semi-structured interview allowed me to ask predetermined questions to an individual or groups whilst making modifications based on my construction of wording, order, omission or addition of the questions researched (DiCiccoBloom and Crabtree, 2006). Complex questions were clarified in the interviews. Thus, the quality of data was improved.

Overall, an in-depth interview well suited my research which sought to gain the perceptions of respondents as the prime source of data from real life experiences. In essence, it involved not only asking questions, but the systematic recording and documenting of responses coupled with intense probing for deeper meaning and understanding of the responses from the target audience under study (Guion, 2006).

However, researchers (Rose, 2000; Beale, Cole, et al., 2004) raise concerns about issues based on the very nature of subjectivity and therapeutics of the approach. Moreover, other issues like the eagerness of the respondent to please the interviewer, or the tendency of the interviewer to seek out the answers that support his preconceived notions contribute to biasing of data can occur from this method.

Furthermore, there is always the danger of a negative impact of the interviews on interviewers and interviewees as skills including administration, organisation and friendly persuasion are involved. When dealing with emotive topics, as I was in many instances, I had to be conscious of the reactions of the respondents and be prepared to ensure that the drive to collect data did not overly discomfort them or possibly impact on participants' emotional well-being. In addition, a lack of standardisation within interviews inevitably raised concerns about reliability in critics of the approach. To some extent, this was addressed because I myself conducted all the interviews. There was less likelihood of inconsistency of the approach, though I accept that the perfect interview eludes most researchers including myself. I had gained some invaluable experiences in addressing these issues, owing to the training provided to me during participation in research projects under the direction of experienced researchers (Rose, Smith and Feng, 2009).

Given that data collected through interviews can be complex and rich, as interviews are sufficiently 'open' to allow a respondent to develop a point of view 
(Murray and Lawrence, 2000:117), well-designed interview schedules are of vital importance.

\subsubsection{Developing the interview schedule}

Interview schedules were developed on the emerging themes from the questionnaire survey and observations and were constantly revised on the pretesting, piloting and consulting with experienced researchers and supervisors. Questions which were likely to produce unfavourable reactions in the respondents were avoided as much as possible. The sequence of the questions was carefully considered before final decisions about the sampling plan and the coding procedures were made.

\subsubsection{The format and content of the interview schedules}

The interview schedules consisted of a set of questions including introductory comments, a list of topic headings, associated key questions, a set of associated probes and prompts and closing comments. There were 4 parts to the interview schedules for both teachers in mainstream and special schools. They were:

Part I: Teacher career motivation ( 6 questions for both mainstream and special school teachers)

Part II: Initial teacher education ( 2 questions for both mainstream and special school teachers)

Part III: teachers' perceptions of special and inclusive education ( 7 questions for both mainstream and special school teachers; 1 specific question for mainstream school teachers: Will it have an impact on your motivation to be a teacher to have children with special educational needs in your class? Why or why not?)

Part IV: Professional development ( 6 questions for both mainstream and special school teachers) (see Appendix VII for Interview Schedules).

The questions focused on factual biographical detalls, behaviour, beliefs, attitudes and perception about their career choice and professional development in special and inclusive education. The specifically designed interview guide covered such dimensions as:

- How long they have been teaching

- Why they chose to be teachers

- Whether they celebrated or regretted their choice

- Who, if any, influenced their choice

- What special and inclusive education meant to them

- How they evaluated their pre-service training and in-service practice 
- Why, according to their understanding, people choose to be teachers, especially teachers in special schools

- Whether they had the motivation to seek professional development

- Whether they were supported by their school for professional training and

- What kind or form of training they would like to be provided with.

Open-ended questions were used as they provided no restrictions on the content or manner of response. They were flexible, allowing me to go into more depth or clear up any misunderstandings. They also enabled me to test the limits of interviewees' knowledge and encouraging co-operation and rapport. This allowed me to make a truer assessment of what the interviewees really believed and could produce unexpected or unanticipated answers. Unstructured follow-up questions were to encourage further elaboration of the topic or to check the meaning that interviewees associated with key words they used. These probes and prompts took the form of, 'Could you tell me a bit more about that?', 'Could you explain that further?', 'What do you mean by that?' and 'Could you give me an example?' The aim of the questions was to provide opportunities for the interviewees to reveal their career experience as fully as possible without me introducing any new dimensions of the phenomenon not previously mentioned by the interviewees. The use of probes was to get the interviewees to expand on a response. Prompts were to suggest the range of possible answers that I expected. For example, when asking teachers about their desired professional training, I gave them as appropriate a list of choices such as educational theories, research methodology, classroom management, subject knowledge so that they could talk about specific training they preferred.

\subsubsection{Observation}

Given that it was not the core method of data collection, all through the three phases, observations were conducted as a supportive and supplementary method to triangulate, contrast with and complement perspective data obtained by other means.

\subsubsection{The cholce of observation as a method within this study}

I selected non-participant, semi-structured and informal observations for the study (Wragg, 1994). It was based upon a belief that over-familiarity with the classroom could serve as a biasing factor that would interfere with objective data collection. I intended to remain an observer and slightly detached from the action 
being observed. This enabled me to observe what teachers did every day which became a common factor in classrooms to the extent that teachers were almost unaware of or indifferent to my presence. Besides, I was aware that being a teacher participant observer, I should be familiar with the culture I was to observe. It was not practical for me to be a participant in all the schools researched. In addition, being a participant observer, I might relate my own motivation and thoughts to what others were doing as they went about their tasks. In such an event, I might form an inaccurate interpretation of observed events or, perhaps worse, not recognise that an event or a response was taking place. Similarly, I was aware that had I been a participant observer, I might have influenced the behaviours of both the teachers who were the subject of my study, or their pupils.

The observations were conducted within an intensive period of time. Informal observation risks the danger of ethical violation as the observed has little knowledge of when he/she is being observed. This was effectively managed. I ensured that teachers were aware of $\mathrm{my}$ intentions and were afforded opportunities for a de-briefing after the observations were concluded. However, informal observations were complex and required me to perform difficult tasks of synthesis, abstraction and organisation of the data collected from the notes taken in the research field. High reliability and validity are difficult to achieve in research of this nature. Nevertheless, the observations were used as a means of verification and triangulation as is common in qualitative studies of this nature.

\subsubsection{Observation schedule}

Observations in descriptive form were used with analysis conducted on the basis of the key research themes. The attention to specific phenomena, encoding and memory was highly selective. Interpersonal factors were considered to avoid all biases. An informal, semi-structured approach was preferred as it allowed me considerable freedom in gathering and recording the information which was seen as supplementary to, rather than dominant within the mixed-method approach. Consistency in observation was managed with the best efforts by focusing upon the research questions and eliminating peripheral issues. In so doing, I was mainly concerned to conduct unrestricted observations which allowed for identification and commentary upon the real life classroom situations being observed (see Appendix VIII for the Observation Schedule). 


\subsubsection{Case study}

On the third and also the last phase of the research, case studies were developed as a data collation method to gain an in-depth understanding of the situation and meaning for those involved (Merriam, 1998). Case study generation is based upon the collection and presentation of detailed information about a particular participant or small group, frequently including the accounts of subjects themselves. It observes the characteristics of an individual unit to probe deeply and to analyse intensively the multifarious phenomena that constitute the life cycle of the unit (Bassey, 1999:24). Whilst recognising the lack of rigour or generalisability, this empirical inquiry enabled me to investigate into particularity and complexity from the cases (Yin, 1993) and its capacity for understanding complexity within its real life context.

Case study well served the research described in this thesis in examining the research questions in full depth. I also perceived that case study would serve a valuable purpose in assisting with the eventual dissemination of the research by providing an illustration of the issues in a real life context for colleagues in China. It also helped to modify the line of enquiry, following up interesting responses and investigating underlying motives in a way self-administrated questionnaires cannot.

\subsubsection{Narrative Inquiry in case study}

Narrative inquiry 'describes lives, collects and tells stories of them (the participants) and writes narratives of experiences' (Connelly and Glandinin, 1990: 2). Researchers (e.g., Elliot, 2005; Webster and Mertova, 2007) have appreciated the application of this approach as it provides a framework through which they can investigate the ways humans experience the world depicted through their stories. According to Rose and Grosvenor (2001: 149), 'life story research engages with issues of motivation, with the construction of social identity and the making of meaning'. Within a social constructivist framework which emphasises different perspectives and interpretations of the world, this approach has considerable value.

Narrative inquiry (Webster and Mertova, 2007) was certainly at the forefront in considering methods for the case study. I found that adopting this approach would best enable me to explore my research interest. The study of narrative was 
the 'collaboration between researcher and participants' (Clandinin and Connelly, 2000:20).

\subsubsection{The strengths and weaknesses of narrative inquiry}

The recent emphases on reflective practice (Schön, 1983) and factors that influence the development of narrative research on teachers have strengthened the focus on listening to the voice of teachers and hearing their stories. Clandinin and Connelly (1990; 1996) work closely with teachers to achieve, through observation, conversation and mutual construction, an understanding of how teachers know their practice. They explain that in the construction of narratives of experience, particularly important stories can help explain the phenomenon of research utilization.

However, the use of a life story approach in research has encountered much criticism for its subjective nature and its reliance on highly personalised texts. However, narrative contexts are important for the ongoing development and expression of teacher knowledge in schools (Clandinin and Connelly, 1996). Researchers (Clandinin and Connelly, 1990:2) argue that 'education and educational research is the construction and reconstruction of personal and social stories; learners, teachers and researchers are storytellers and characters in their own and other's stories'. This is supported that:

'Life history work produces detailed personal subjective accounts because that is what it precisely aims to do. Rather than focus on the reliability and validity of the data produced, the researcher should be concerned with exploring and analysing issues of authenticity, interpretation and the social production of meaning (Hitchcock and Hughes, 1995:208).

\subsection{Data collection procedure}

The procedure for data collection was a technical stage which was divided into four main phases. The first phase started with an initial design of the research questions and piloting of the questionnaire surveys and interview and observation schedules. This enabled me to constantly revise the design of the instruments for the second phase when questionnaire surveys were administered. This was followed at the third phase by conducting in-depth interviews with respondents who indicated they were willing to be contacted. The last phase was the generation of narrative case study developed from interviews and observations. 


\subsubsection{Phase I: Piloting}

The piloting was a move from designing stage of data collection methods into fieldwork with necessary attention to collecting feedback on specific issues. These could be issues such as the access, adequacy and appropriateness of the questions and schedules, and confidentiality and bias. Attention was given to the stage of piloting in order that some insurance could be achieved against bias and ineffectiveness. More importantly, piloting enabled me to assess the possibilities of collecting rich data to be verified through triangulation with other data collection methods.

\subsubsection{Piloting using a focus group interview}

A pilot study of the research instruments was conducted at the draft version which had been constantly refined through discussions with professionals in this research area. I was well aware that well planned and piloted questionnaire surveys and interview and observation schedules decreased the refusal rate from the participants. In particular, as interviewing can be a highly subjective technique, interview schedules play a critical part in the success of the interviews and the reliability of data. I had to try the appropriateness of the interview schedules.

The piloting was undertaken with a small sample $(N=6)$ of teachers from both mainstream and special schools. A focus group interview was conducted. Question items were refined based on the interview discussion. The choice of focus group using semi-structured in-depth interview for the piloting was based on its strengths that allow me to elicit information and to alter questionnaires (Vaughn, Schumn and Sinagub, 1996; DiCicco-Bloom and Crabtree, 2006).

The discussion focused on whether the respondents to be selected have a common frame of reference; the degree of interest in the topic represented by the range of questions; motivation to comply with the research procedural requirement; the balance between structured and open questions; the practicality of recording methods and planned analysis (Bell, 1993:121). However, because of the public nature of the process that multiple participants shared their knowledge or experience about a specific subject, group interviews prevented delving as deeply into individual opinions. 


\subsubsection{Piloting using emails and other resources}

I was conscious at this stage that the time devoted to piloting would be well spent and that the inevitable weaknesses of any instrument designed would need to be further considered when developing later research methods. To make sure that I had enough feedback from piloting, a pilot study via email was conducted to a further 5 teachers from mainstream schools to test out the questionnaire before distribution. I also sent the interview and observation schedules for comments, which were provided through emails and telephone conversations. Colleagues in this research area in China and the UK were consulted. My supervisors played a decisive role with their timely suggestions and constructive ideas. The piloting enabled me to make amendments on the instruments. A further reviewing of literature helped me to adjust and readjust the research questions according to the pilot feedback.

\subsubsection{Phase II: Administrating questionnaires}

The survey followed the six main stages advised by Robson (2002:239): initial design and planning, designing the questionnaire, pre-testing it, final design and planning, data collection, analysis and reporting. On the initial stage of the questionnaire design, I planned the sequencing of questions and anticipated the type and range of responses that the questions were to elicit. A self-completion questionnaire with closed and open-ended questions was formulated on the basis of research questions and the availability and appropriateness of my sample. I took into consideration the variables which might affect the responses: gender, professional role, educational background, professional career experiences and so on. The surveys were revised and refined before Data were collected from the sample composed of the informants from $4^{\text {th }}$ year student teachers from a university and teachers from seven mainstream and two special schools in Shaoxing, China. I distributed them. I anticipated some reluctance in cooperation from respondents in the implementation of this instrument for the reason that the topic of the research might be perceived negatively. The results are shown as follows:

The questionnaire survey in the university was administered to all the student teachers $(N=1078)$ who were to graduate in 3 months time when the survey was distributed. My easy access as an academic staff member allowed me to get support from the deans or their secretaries of the 11 colleges who helped with the distribution and collection of the survey. A return of $52 \%(N=565)$ was achieved. 
Table 7-1 shows a detailed description of the survey distribution and return:

\begin{tabular}{|c|c|c|c|c|}
\hline $\begin{array}{l}\text { Research } \\
\text { context }\end{array}$ & Informants & Schools attached & Distribution & Return \% \\
\hline $\begin{array}{l}\text { Shaoxing } \\
\text { University }\end{array}$ & $\begin{array}{l}4^{\text {th }} \text { year } \\
\text { student } \\
\text { teachers }\end{array}$ & $\begin{array}{l}\text { Humanities } \\
\text { Foreign Languages } \\
\text { Music } \\
\text { Physical Education } \\
\text { Fine Arts } \\
\text { Education } \\
\text { Politics and Law } \\
\text { Maths, } \\
\text { Physics } \\
\text { Chemistry and Biology } \\
\text { Information Technology }\end{array}$ & $N=1078$ & $\begin{array}{l}N=565 \\
(52 \%)\end{array}$ \\
\hline $\begin{array}{l}\text { Mainstream } \\
\text { schools }\end{array}$ & Teachers & $\begin{array}{l}2 \text { primary } \\
4 \text { secondary junior } \\
1 \text { secondary senior }\end{array}$ & $N=500$ & $\begin{array}{l}N=326 \\
(65 \%)\end{array}$ \\
\hline $\begin{array}{l}\text { Special } \\
\text { schools }\end{array}$ & Teachers & $\begin{array}{l}1 \text { school for learning } \\
\text { disabilities } \\
1 \text { school for speech and } \\
\text { hearing impairments }\end{array}$ & $\mathrm{N}=40$ & $\begin{array}{l}N=12+25 \\
(93 \%)\end{array}$ \\
\hline
\end{tabular}

Table 7-1: Survey distribution and return

The distribution of the surveys to the schools was supported by either the headteachers or staff members assigned by head-teachers. The distribution in the mainstream schools $(\mathrm{N}=500)$ was not even between primary and secondary schools as there were less number of teachers in primary schools. The actual number of the teachers in the mainstream schools was far bigger than 500 . However I anticipated that there would be challenges in data processing. I therefore purposely controlled the distribution number. Participants were expected to complete the questionnaire and return it in a week's time to the headteachers in the research schools who agreed to offer help in chasing the survey sheets. The return was $65 \%(\mathrm{~N}=326)$.

In addition, a survey was conducted to all the teachers in the two special schools $(N=40)$. According to the two head-teachers, they had collected every survey sheet from their distribution $(\mathrm{N}=12+25)$, the exception being the three teachers who were then on a business leave. 


\subsubsection{Phase III: Conducting interviews and observations}

Interviews and observations were conducted after the preliminary analysis of the questionnaire data.

\subsubsection{Interviews}

From the questionnaires returned, I had consent from mainstream teachers $(N=36)$ willing to be interviewed, from which I filtered out the candidates $(N=22)$. The selection was based on the availability of the teachers and the variables they represented described in the part about sampling in this chapter. The process of making contact with them in the schools varied. I had direct contact with some as they were my previous students and we had been in touch since their graduation. With the rest of them, I had approached the headteachers as well as the teachers themselves to discuss the organisation of the interviews. Informed consent was obtained before the interviews, some in oral form (more discussion can be found in the following chapter). With their secured permission, I made arrangement for the interviews. From the schools, I received confirmation of the venues for the interviews after I showed them the proposed time arranged between me and the interviewees.

In the special schools, I got the informed consent from the headteachers for interviewing all the teachers $(\mathrm{N}=37)$. But to my disappointment, when I tried to get consents from the teachers, some showed their reluctance stating that they would not be able to provide me with rich data. They reassured me that their experiences would be more or less the same as others. Thus, they perceived that it would be a waste of time to interview them. I interviewed 22 teachers in total who gave me informed consent $(\mathrm{N}=10+12)$.

The interviews were semi-structured, flexible and in-depth. Different strategies for implementation at various stages encouraged voluntary participation and the generation of rich data. I put questions in a straightforward, clear and nonthreatening way, listened to their narratives and tried to eliminate cues which led interviewees to respond in a particular way. The sequence was as follows:

- Introduction, including my self introduction (education background, training, etc.) and the brief introduction of my research (my interest in the research area, the aims, purposes and nature of the study)

- Warm up, I told them how they were selected. I assured they were 
informed with the ethical code of the research. There would be no judgment of the answers as the answers would be regarded as only personal opinions and experiences. They could interrupt or ask for clarification. I also asked their permission to tape-record the interviews and explain why I wished to do so

- Main body of the interviews, which were followed generally through the same schedules. There were times that some of the questions had already been answered in teachers' narratives before I had a chance to ask them. In that case, I rearranged the orders of the questions.

- Cool-off and closure was also a strategy which enabled me to bring the interviews to a natural ending by expressing my appreciation of their time and cooperation.

All the interviews were digitally recorded. In addition, field notes were written up. Most of the participants were interviewed individually for about 25 minutes to as much as 45 minutes. The interview time was about 30 minutes on average. Six were interviewed in groups of two as arranged by the teachers themselves for saving time as they had busy schedules during my fieldwork. A life history approach was adopted in conducting the interviews to obtain a holistic understanding of participants' life events related to their perceived motivations for teaching. In the interviewing process, I used the techniques of crystallization and confrontation (Maxwell, 1996) to enhance the clarity and trustworthiness of their narratives. In cases of ambiguity, I asked the respondents for detailed and concrete examples and, in case of inconsistencies, for further clarification and reinterpretation.

\subsubsection{Observation}

For this research, face-to-face interviews were complemented by observation of teachers working in their classes and/or after class. During field work I was a non-participant in observation, a role which from the very beginning of the research was made clear to the schools and teachers. In order to ask the teachers to explain various aspects of what was going on in their school and their professional life, I tried to establish a close working relationship with the teachers. The observations during the phases of the research process were mostly informal. Therefore, not all the visits to the schools were recorded, though I observed the schools and the teachers as much as I could with the focal questions in my mind. However, for the observations in class time, descriptive notes were made on the spot or afterwards. Due to the nature of the research 
questions, data from observations were used but only to validate those obtained in the questionnaire surveys and interviews. However, the observations played a critical role in the identification of the cases for the study.

\subsubsection{Phase IV: Case study}

The last, though in many ways, the most crucial phase of the research was the development of the case studies of two teachers. Narrative inquiry was deployed in the case study as the central means by which I engaged with teachers, by interpreting their accounts, their identities and gave their lives meaning (Bell, 2002). The option for in-depth narrative interview was obvious since I wanted to acknowledge the subjective perception and the narrative character of the professional identities of my respondents. It allowed me to understand participants' experiences and the impact of those experiences upon their personal and professional lives. This was important to me as I was in a position of wishing to gain insights about issues deeply personal to my respondents. It also provided me with tools to understand and to explore the assumptions of the participants. The interviews were conducted with the same interview schedules used for teachers. However, more probes and prompts were used to ask the respondents for clarification and explanation.

\subsection{Data analysis}

\subsubsection{Data analysis approach}

The data analysis approach was interpretative and descriptive in nature. The choice of the approach was part of the original research design and drew upon interpretative and descriptive methods (Miles and Huberman, 1994; Rose and Grosvenor 2001). It was based on the principle that theory, data collection and data analysis are closely related (Burgess, 1984). The justification of the approach is illustrated as follows:

\subsubsection{Interpretation and description}

Interpretive analysis is meaning-orientated for theory-bullding (Tesch, 1990). It is largely descriptive to a certain extent and all aspects being sclentific in nature, contribute to theory. This implies that issues like subjectivity and complexity in qualitative interview-based projects are inevitable (Broom 2005). There is no wholly objective way to assess the accuracy and the quality of subjective 
interpretations. Sometimes 'little transparency' (Gorard, 2005:158) exists in some small-scale qualitative educational research. Yet, interpretation as a subjective qualitative measurement is necessary in data analysis (Maxwell, 1992).

Research (Miles and Huberman, 1994:8) supports the notion that theoretical underpinning of a social construction of reality plays a crucial part in data analysis. There is an inevitable 'interpretation' of meaning and 'practical understanding' of actions as researchers are not detached from their informants. Besides, researchers have their own understandings, convictions and conceptual orientations as members of a particular culture at a specific historical moment. This view reflects Kirk and Miller's (1986) description of the phases of qualitative research methodology. Interpretation occurs partly through a reconsideration of the reliability and validity of all the data related to the same event from several sources brought together to induce its overall meaning for the last phase of explanation. Interpretation constitutes an ongoing, repeated examination and analysis of the data, combining this with the researchers' insights gained from their personal involvement on the scene in the field.

In my research, I aligned myself sympathetically with the view of ongoing analysis as an important feature of studies of this nature. This approach invited me to make connections between elements of the study and my own professional experiences. However, I started my research with some assumptions and a belief that special and inclusive education was not prioritised amongst the sample population, and that this might have an impact on teachers' motivation in working with children with SEN. Therefore, during the whole research process, I was not looking for the evidence to ground a theory or theories. Instead, I used my research questions to induce data. I described and interpreted the patterns to see if the data provided the evidence to support my hypotheses. I further developed conceptions for my research questions. In so doing, I jointly constructed new knowledge and understanding by seeking to establish a coherent and inclusive account of a culture from the point of view of those being researched. In other words, this interpretative and descriptive approach for my data analysis was based both on the meaning and social reality of the researcher and the researched. 


\subsubsection{Data analysis strategy}

Challenges of data analysis lie in the processing and making sense of massive amounts of data from different sources (Miller and Crabtree, 1999). An Inductive data analysis strategy was used. This requires that researchers gain skills related to the development of professional insights and capabilities in reducing the information contained within data, identifying significant patterns and constructing a framework for communicating the essence of what the data reveal (Patton, 2002). The usual approach involves strategies based upon analytic induction (Bryman and Burgess, 1994a:4). That is: the extraction of key themes and ideas from data and a testing of these with reference to a range of sources including the literature. This form of triangulation ensures the verification of data and affords an opportunity to make inductions on the basis of systematically reviewed evidence. There are two phases of this strategy, basically data organizing and preparation for interpretation.

An analytic 'editing approach' (DiCicco-Bloom and Crabtree, 2006: 317), as an initial strategy, was used for interpreting the in-depth interviews. This approach demands reviewing and identifying text segments while making interpretative statements during the process of identifying patterns for organising text. It relies on using codes for tagging segments of text and then sorting text segments with similar content into separate categories for a final distillation into major themes (Miles and Huberman, 1994; Silverman, 2001). Mason (1996) describes this as a 'template approach' as it involves applying a template category based on prior research and theoretical perspectives. The data were reduced and reconstructed to develop and integrate categories. Connections to existing literature were sought for interpretation.

After the initial classifications, pattern descriptions or in-depth interpretations were developed. I reviewed the data to locate all relevant instances to support the claims, to search for confirming and disconfirming evidence, and to try out alternative claims or interpretations. I returned to data collection when I felt additional evidence was needed. This process resulted in an initial set of claims or interpretations which represented the preliminary learning from the research. The available sources of evidence were reviewed, and alternative interpretations were tried out in the process. Intended or unintended circumstances were Identified that might have significant implications for interpretation of the outcomes. 
In addition, in the analytical process, linking or integration of qualitative with quantitative data is also crucial (Mason, 1994). This was achieved by comparing and contrasting to triangulate the reality and validity of the data. Attending to the data included a reflective activity that resulted in a set of analytical notes that guided the process. It called for constant interaction with and interpretation of the data. I interpreted the observations in the very basic sense of reflecting until a better understanding was achieved.

Analysis acquires experience, methodological knowledge and intellectual competence in organising various forms of data, including oral, textual or statistical data. My research methods enabled me to see the perspectives of the researched. Therefore I planned my data analysis to be more qualitative before I even started the research. Researchers (e.g., Tesch, 1990: 96) acknowledge that there is no one 'right' way to manipulate qualitative data during analysis. 'No ways exist of perfectly replicating the researcher's analytical thought processes' (Patton, 2002:433). I used a combination of interpretative and descriptive approaches in the data analysis procedures, which were fit for my particular research.

Being aware of the issues related to the validity and reliability of an interpretative and descriptive approach to data analysis, instead of looking for illustrative examples within the transcripts, I analysed the data with a more thorough process of reading, categorising, testing and refining, which was repeated until all categories were compared against all the participants' responses, and the analysis was validated across individuals. In so doing, I tried to make sense of the data with a deeper understanding of the claims made by my respondents. Interpretative commentary was made to explain why the patterns described might have occurred, in which social cultural or historical contexts they took place, how they related to one another, how they supported or challenged theory and findings from previous research, and what alternative practices were used to develop and enhance the warrant for the claims made. During interpretation, I also looked for discrepant cases to see how they fit the emerging themes or whether explanations were needed. A description of this including the search for disconfirming evidence and alternative interpretations of the same evidence is provided in the discussion of data analysis procedures. 


\subsubsection{Data analysis procedures}

Data analysis occurs concurrently with data collection to generate an emergent understanding about research questions (Tesch, 1990; DiCicco-Bloom and Crabtree, 2006). This in turn informs both the sampling and the questions being asked. Early analysis helps to inform subsequent data collection by identifying categories of events for further analysis within the ongoing study.

The data analysis procedures addressed the research questions and led to the outcomes with the following focuses: approaches to data collating, sorting and coding, segmenting and categorising, comparing and contrasting and concept formulating. In addition, memos and discrepant case analysis are discussed. A brief description of using computer software is also provided.

The existing literature on qualitative analysis does not make clear distinctions between the procedures used for descriptive/ interpretive and theory-building analysis process. In fact, during the analysis procedures, I realised that I was employing certain elements more commonly found within a grounded theory approach in the conceptual formulation process, though arguably the approach was an interpretative and descriptive one.

\subsubsection{Data collating and sorting}

The collation and sorting was based on the data types, informants, sources, variables and purposes. Questionnaire data from closed statements were in quantitative form whilst the rest of the data from all the other research instruments were qualitative. On the completion of the collation, I further separated the documents according to the same event from several sources. I started by sorting the data in several documents or files according to the data types, sources, variables or purposes. For example, I read the data to achieve the overall sense. I copied all the responses to a particular question as one document headed by the text of the question with each response preceded by a number coded in numerical or alphabetical order.

The quantitative data from the questionnaire surveys were entered in Excel and then transferred to SPSS for frequency processing. The qualitative data from the surveys and interviews were transcribed into English and saved as Excel and Word documents respectively. Field notes from observations conducted in schools were written in English and saved as Word documents in chronological order. For 
easy retrieval, I divided the interview data into several files according to the time and venues of the interviews, the main questions and sub-questions. The questions were arranged according to the cohorts. The process of note taking was highlighted as a means to understand the social structure under study and also an important location of formal and informal analysis through commentary (Bryman and Burgess, 1994a: 11). After each research activity, I wrote down some observations for reflection, which I called 'research journals'. The journals were written in English and saved as a Word document.

\subsubsection{Coding}

Coding represented a key step in the process of creating categories from interpretation of the data (Bryman and Burgess, 1994b) and was regarded as building blocks that provide the link between the data and the conceptualisation (Miles and Huberman, 1984) It is 'the process of breaking down, examining, comparing, conceptualising and categorising data' (Strauss and Corbin 1990:61) representing the gradual building up of categories out of data.

The initial coding was 'open coding' (Strauss 1987). The coding frame was developed out of initial readings of the data from different sources. In my approach, the general purpose of coding was to serve for sorting and categorising the different data. It allowed me to locate data for the following more complicated procedures. In this way, I was able to move on to the next step of sorting and categorising before formulating concepts for the research. In addition, numerical coding for the quantitative data enabled me to have a clear vision of the data for processing. Moreover, I found codes located in the margins very helpful in that the codes narrowed down the massive data into more manageable forms. Therefore, instead of regarding coding as the process of categorising and sorting data, I coded the data in initial letters or Latin numbers without recognising them as to serve to summarize, synthesize and sort any observations made out of the data.

In the process of entry of the quantitative data from the questionnaire survey, I numbered the informants in numerical order. For the qualitative data from the open-ended questions, I used a combination of letters and numbers. Thus, the code, for example, SQ1-20, stood for 'survey question 1, informant 20. If the informant is a student teacher, the code will be SQ1-US-20. Here, 'US' referred to the data from the university student teachers. Examples of codes are shown here as a means of illustrating the ways in which data were handled: 
ST: special school teacher

MT: mainstream teacher

IQ1: interview question Number 1

IQ1-MT-20: interview question Number 1 from mainstream school teacher Number 20

QS-US-10: Questionnaire survey by student teacher Informant No. 10

In brief, first, Latin numbers were used to refer to the number of informants whilst alphabetical letters were the first letter of the word to mean either the educational organisations the informants attached or the research instruments. Second, codes at margins represented my initial understanding and summary of the sentences or chunks in word or phrase forms. To illustrate this, I present an example of the computer analysis of the survey Question 4 from the university student teachers as below:

Survey question 4: How do you understand special education?

\section{SQ4-US ( $N=404)$}

Do not know $(\mathrm{N}=56)$

Necessary $(\mathrm{N}=53)$

Very important $(N=20)$

Very $\operatorname{good}(\mathrm{N}=14)$

Not $\operatorname{good}(\mathrm{N}=5)$

Important $(\mathrm{N}=27)$

Needs improvement $(N=9)$

Positive and negative $(\mathrm{N}=2)$

No comment $(\mathrm{N}=10)$

Should be developed $(N=1)$

\subsubsection{Categorising and segmenting}

Once coding was completed, I started to notice features and patterns and assembled the data materlal belonging into each category in one place for a preliminary analysis. This involved segmenting data into different themes or pattern categories. During the initial stages of data analysis, I segmented the data by classifying school types, actions or people. This was the process of decontextualisation (Tesch, 1990) to separate relevant portions of data from their context.

For the data from the interviews, I worked with a randomly selected document first, then made a list and tried out the topics on the list on additional documents. 
Selective coding was used to generate numerous categories encompassing each response. Categories generated by this process accounted for most of the individuals' responses. As the coding progressed, categories were compared to subsequent responses and revised to continue to encompass individual responses. Broader categories were then created from the codes to develop a more manageable list (Wasburn-Moses, 2008). This procedure involved a repeated, careful examination and consideration of the data combined with my professional insights gained from my personal involvement on the scenes in the field. Here is an example.

\begin{tabular}{|c|c|c|c|c|}
\hline $\begin{array}{l}\text { SQ } \\
1- \\
\text { ST }\end{array}$ & $\begin{array}{l}\text { Why did you choose to be a } \\
\text { teacher? }\end{array}$ & Codes & $\begin{array}{l}\text { Intrinsic } \\
\text { motivation }\end{array}$ & $\begin{array}{l}\text { Extrinsic } \\
\text { motivation }\end{array}$ \\
\hline 1 & I like children & like children & & \\
\hline 2 & $\begin{array}{l}\text { I had the dream since I } \\
\text { was young. I like children. I } \\
\text { enjoy being with innocent } \\
\text { children. }\end{array}$ & $\begin{array}{l}\text { Dream, like } \\
\text { children }\end{array}$ & $\begin{array}{l}\text { Dream, like } \\
\text { children }\end{array}$ & \\
\hline 3 & $\begin{array}{l}\text { I like teaching. I obey the } \\
\text { government's assignment. }\end{array}$ & $\begin{array}{l}\text { like teaching, } \\
\text { government's } \\
\text { assignment }\end{array}$ & like teaching & $\begin{array}{l}\text { government's } \\
\text { assignment }\end{array}$ \\
\hline 4 & $\begin{array}{l}\text { Teaching is a stable job. It } \\
\text { educates people. It gives } \\
\text { me a sense of } \\
\text { achievement. }\end{array}$ & $\begin{array}{l}\text { stable job, sense } \\
\text { of achievement }\end{array}$ & & $\begin{array}{l}\text { stable job, sense } \\
\text { of achievement }\end{array}$ \\
\hline 5 & $\begin{array}{l}\text { I did not think too much } \\
\text { when I chose to be a } \\
\text { teacher. I only wanted to } \\
\text { have a good job so that my } \\
\text { parents could be proud of } \\
\text { me. I could help improve } \\
\text { the living standards of my } \\
\text { family and became a citizen } \\
\text { in a city and left the farm. }\end{array}$ & $\begin{array}{l}\text { a good job, for } \\
\text { parents, support } \\
\text { family, become a } \\
\text { citizen in city }\end{array}$ & & $\begin{array}{l}\text { a good job, for } \\
\text { parents, support } \\
\text { family, become a } \\
\text { citizen in city }\end{array}$ \\
\hline
\end{tabular}

Table 7-2: Categorising and segmenting data from special school teachers on Survey question 1: Why did you choose to be a teacher?

I randomly chose 5 responses to Survey Question 1 from special schools. Reading the data, I had some initial codes. As it is obvious from Table 7-2 above that 
teachers varied in their motivation for their career, I divided the motivation into two major types, namely, intrinsic and extrinsic. In this way, I could rearrange the codes into two segments. By tagging the categories into the segments, I had developed sets of categories to be tried in other data of the same source.

Some categories existed before the analysis as they were related to particular research questions in major topical categories. Others were developed from the analysis with frequent modification according to the further emerging themes and were refined until a satisfactory system was established. The tentative system became refined as the analysis process continued. The assembling was recontextualisation through the process (Tesch, 1990). I was sensitive to repetitions of incidents, words or irregularities, unusual occurrences (Bryman and Burgess, 1994b). I ensured that the coding categories were such that a minimum of relevant information was lost. I organised sets of substantive categories or codes into which segments of data could be organised. Concepts or categories used by other authors (e.g., Richardson and Watts, 2005) in previous related studies were also categorised.

\subsubsection{Comparison and contrast}

Comparison and contrast was used for practically all intellectual tasks during analysis: forming segments to new categories, summarising the content of each category, finding negative evidence, discerning conceptual similarities and refining the discriminative power of categories and to discover patterns.

The process of comparing and contrasting data for similarities and differences was the key to extrapolate information to inform the research findings by looking for principle structural relationships that related as well as distinguished the transcripts to and from each other. Once the data was collated and segmented to further categories, broad boundaries were set. I analysed the assigned data in an iterative manner, involving repeated readings of the transcripts, comparing and contrasting each of the forms of data and assessing them for credibility, authenticity, reliability, and validity. The data were interrogated with regard to the emerging themes and were formed into new categories. This process was inductive to discern conceptual similarities.

\subsubsection{Concept formulation}

All qualitative data analysis processes operate on a conceptual and concrete level simultaneously. Verbatim was chosen by determining which word, set of words, or phrases would constitute a concept. In this process, selective reduction was the 
central idea of content analysis. Text was reduced from a huge amount of data to categories consisting of a word, set of words or phrases on which I attached importance in achieving genuine understanding of the questions under study. Specific words or patterns were indicative of the research questions and determined levels of analysis and generalisation.

It was important to distinguish key data elements on which interpretations were based. They were crucial to the logic and interpretation of the outcomes. The result of this process arrived at a higher level of synthesis. During this time, I assembled all the data conceptually and topically in one place according to their commonalities from multiple and diverse perspectives. To generalize concepts during coding, I developed a set of rules by which less general concepts were translated into more general ones. This required me to determine from a given set of emerging concepts which of these were explicit or implicit, and then code for the frequency of their occurrence. Description of the social context was supported with evidence of its relative frequency.

\subsubsection{Discrepant case analysis}

Discrepant case analysis was done to help change and sharpen theoretical presuppositions. It helped suggest alternative claims that need examination. Since not all answers fitted neatly into the categories, I had to make some judgments about how to deal with the items by losing the least useful information. Data were pieced together to help determine patterns. The search was made for key links that pulled together data related to the same event, person, or scene. The whole process of interpretation and description was one of pattern analysis, and an attempt was made to bring together in a meaningful fashion as many items of data as possible into a meaningful whole. As key themes and dimensions started to emerge, the analysis shifted to an iterative process of alternating between the emerging analytic outcomes and the original transcript data, looking to confirm, contradict or refine emerging hypotheses about meanings and relationships with respect to the data. This continued until a consistent set of categories emerged, with repeated iterations leading to no further refinements. This helped in the interpretation of individual data.

\subsubsection{Computer software in data analysis}

The lack of transparency in the process of qualitative data analysis has led to the suspicion that findings may not be robust enough to be used as evidence (Chih, 2007). Therefore, accurate and reliable coding using computers may be central to 
the content analysis process.

Whilst the computer technology that facilitates mixed-method data analysis is becoming increasingly available, literature provides limited practical guidance on how such integration can be practically achieved. For the data analysis, software of Excel and SPSS were used to process the quantitative as well as qualitative data yielded from questionnaire survey. The most obvious advantage of using computer software was demonstrated in sorting, coding, segmenting and categorizing data. Computer helped ease the time spent managing data and finding extracts, and, ultimately, was a guarantee that no important quotations were overlooked. For the interview transcripts, computer helped when the number of subcategories and the relations between them varied at each additional reading of the transcripts. Moreover, other powerful advantages included the possibility of tracing back, saving interim categorisations, replicating an analysis at a later stage, enhancing the credibility and acceptability of qualitative research and colouring texts as well. However, I was still in charge of building up the analysis, having the ideas, engaging with the data and making all the decisions about the study.

\subsubsection{Definitions in data analysis}

The following terms are used following the definition of Ryan and Deci (2000a): Intrinsic motivation, extrinsic motivation and amotivation.

- Intrinsic motivation: refers to the doing of an activity for its inherent satisfactions rather than for some separable consequence. It is the innate need for competence, autonomy and relatedness, recognising that basic need satisfaction accrues in part from engaging in interesting activities.

- Extrinsic motivation: refers to the doing of an activity because it leads to a separable outcome or instrumental value. It can vary greatly in the degree to which it represents self-determination. Internalisation and integration are the processes through which extrinsically motivated behaviours become more self-determined.

- Amotivation: refers to unwillingness, passive compliance or the state of lacking an intention to act. It results from not valuing an activity, not feeling competent to do it, or not belleving it will yield a desired outcome.

However, it has to be made clear that there are no strict boundaries across the three types of motivation made in the description of the data as, very often, the motivational factors were described as a mixture of various types by the 
respondents. I categorised them into a certain type of motivation according to my interpretation of the data. I was aware that on some occasions I could be subjective in analysis. Thus, some interpretation might be inappropriate for the lack of opportunities in seeking clarification, especially in questionnaire surveys. For example, to a survey question: why did you choose to be a teacher, a special school teacher answered:

It is the fate which decided my life. I took the place of my parent.

And from some student teachers:

I was forced to.

--QS-US-14, 143,168, 288, 373

I considered the statements as extrinsic motivation, given that I also believe there was a feeling of unwillingness from the teachers when entering teaching. Another example is the answer to the survey question: Have you ever regretted your choice? A mainstream teacher only gave:

What do you think?

Since he/she left the job to me as the researcher, I referred to his/her answer to the question: why did you choose to be a teacher. I got the answer that:

I was too naive when I was young.

I thus interpreted the answer as positive. That is: Yes, I have regretted my choice. 


\section{Chapter Eight: Methodology (III)}

The chapter starts with a discussion of the originality of the study. Research of this kind which is largely based on the narrative accounts of the researched is still in an early stage of development in the Chinese context. Therefore, an examination of some specific methodological challenges and opportunities emerged in conducting the comparative education research with reference to the literature of this nature as comparators from a wider world is provided. This includes a justification of the approach with regard to the validity and reliability of the methods for data collection and data analysis in the research process. This . chapter ends with an examination of the basic ethical guidelines for dealing with ethical issues as well as their implications. I report and discuss the identification of a series of culture and context-specific ethical issues and dilemmas that arose in the research process.

\subsection{Originality of the study}

There are some differences in researching special and inclusive education internationally. Much research in economically advantaged countries is conducted through naturalistic approaches and focuses largely on the implementation and assessment of policy initiatives in special and inclusive education (e.g., Slee, 2005; 2006). Within much of the literature in this area, children, parents and teachers are increasingly empowered to articulate their perspectives on effective learning environments for inclusive schooling (Ainscow 1999; Shevlin and Rose 2003; Armstrong and Moore 2004; Florian, 2007). Attitudes towards inclusive education have been researched (see Literature Review II). Issues relating to initial teacher education and professional development have been identified (see Literature Review III). This differs considerably from the research conducted in economically disadvantaged countries like China where research in the area of the empowerment to key stakeholders in education, especially those children with SEN and teachers who work for them, has been given a low priority.

China has attained remarkable education achievements during the past halfcentury (Guo and Lanham, 2005) with the rapid increase In economic strength and the awareness of social inclusion in this nation. However, there is a significant lack of literature that reports teacher voices in their career motivation and professional development in special and inclusive education in China. Most of the 
research into the education of students with SEN focuses on the development of special and inclusive education (Fang, 2000; Deng and Manset, 2000; McLoughlin, Zhou and Clark 2005; Pang and Richey, 2006a). Although some research has been conducted to investigate teachers' attitudes towards inclusion (Zhang and Chen, 2002; Wei and Yuan, 2000; Guo and Shi, 2004; Xlao, 2005), limited literature is available concerning the experiences of children with learning difficulties in mainstream and special schools. Research rarely encourages voices from children with disabilities, learning difficulties or emotional and behavioural problems. Voices from teachers on their motivation for working with children with SEN are seldom heard or responded to. This study is intended to fill this void of teachers' aspirations (Payne, 2005) of their career motivation in special and inclusive education and their professional development. Research of this nature is arguably original in the context of China.

\subsubsection{Opportunities and challenges in doing research in special and inclusive education in China}

Educational research is being increasingly challenged for not contributing effectively enough to the improvement of policy and practice worldwide with 'more relevant, cumulative, accessible and cost effective studies' (Crossley and Holmes 2001: 395). With regard to education research in special and inclusive education in economically disadvantaged countries like China, there are significant issues and challenges that remain to be resolved as these countries attempt to address ever increasing international education agendas (UNESCO, 1994; 1998).

For this arguably pioneering study, it was difficult to gain support from educational administrators or the population researched as research of this kind in special and inclusive education was not yet regarded as a priority. I experienced polite refusals from some headteachers in seeking informed consent for conducting the research in their schools. Discouragement also came from some administrators in the local education authority who either showed their indifference to the research topic or their ignorance with regard to special and inclusive education. This was evidenced in that, when I tended to ask for the consent for interviews, I was declined. I received similar declines from some headteachers, who gave me consent to conduct the research in their schools but were too busy to be bothered with interviews themselves. In addition, when I tried to approach some nationally and indeed internationally renowned 
researchers in the research field in China, hoping that some guidance and advice for conducting the research could be provided, I was told that research was very much a personal undertaking. I was basically dismissed as a novice researcher. All these added to my initial disappointment. I thus had to frequently remind myself that there would be situations beyond my control in the research process. Certain adjustments in conducting my research in China might be inevitable. Anyhow, I embraced the challenges with a more firm commitment.

\subsubsection{International comparative studies in special and inclusive education}

International comparative education studies are used for the purposes of understanding, improving, developing, and reforming of different countries' educational systems, policies, and practices, and predicting the success and consequences of educational change (Fairbrother, 2005:7). The demands for reliable and policy-oriented comparative analysis are Imperative to discuss the issues and challenges in relation to national reforms of education systems (Watson, 2001). The recent advancement in comparative educational research from economically advantaged countries (King and Buchert, 1999; Watson 2001; Crossley and Watson, 2003; Phillips and Ochs, 2003; Trahar, 2006) has brought forth the opportunities as well as challenges for economically disadvantaged countries (Crossley and Jarvis, 2001). This, in particular, is demonstrated in comparative studies in special and inclusive education (Potts, Armstrong and Masterton, 1995; Booth and Ainscow, 1998; Mitchell, 2005; Feng and Jament, 2007; Norwich, 2008).

Comparative study into special and inclusive education and qualitative approaches in China continues to face major challenges (Bray and Gul, 2001). China needs to consider its distinctive educational needs and priorities in respect of its traditions, cultural values and socio-economic strengths when compared to the wider world. This necessitates not only interpreting systems and approaches from outside of the country, but also ensuring that these are introduced in a way which is sympathetic to the research traditions prevalent in the country. This provided me with opportunities to add some knowledge to the literature in this research area. Overall, the study enables me to investigate the issues in this respect in a context in China through the construction of a detailed and focused study allowing for some comparison to the findings from other countries. 
Whilst this study was not purely international comparative in nature, it made extensive use of the literature from elsewhere in the formulation of research questions and a theoretical framework. The research reported here is not directly comparative in respect of comparing the systems of one country to another. Yet, the methodology deployed has its basis upon an interpretative paradigm which is not common within a Chinese context where positivistic theories continue to dominate.

\subsection{Methodological challenges}

Increasingly, methodological issues in educational research are becoming a major concern as education becomes more standardised to meet policy makers' goals. 'Educational research was deemed non-reliable and inconclusive...especially, qualitative research which often lacked triangulation, was characterized by sampling bias, purposeful distortion and ideological bias' (Oancea, 2005:167). With this challenge in mind, the research discussed in this thesis has been conducted with full consideration of the essential socio-cultural influences. These have inevitably impacted upon either comparative study or the use of methodologies which transcend national boundaries.

As previously reported in this thesis, this study was conducted through a mixedmethod approach. It was the nature of the research questions which directed the methodological approach adopted (Gorard and Taylor, 2004:2). Reasons for the approach to be mainly qualitative in nature are that the study is a) exploratory because not much has been written about the population under investigation, b) interpretative because the key themes for the study are complex phenomena in the social reality and c) descriptive and explanatory because narrative inquiry is deployed in case study researching teachers' reflexivity of their career life and perspectives on special and inclusive education.

With regard to the prevalent methodology in educational research of the past few decades, most of the investigations in this area are conducted through positivist approaches (Zhao, et al., 2008). Much research in the field of special and inclusive education in China has been characterised by the application of traditional quantitative methodology (Liu, Du and Yao, 2000; Peng, 2003; Xu, 2008). Critiques (Vulliamy and Webb, 1992) observe that there have been relatively few published qualitative research studies on the themes of special education, despite the prominent impact of qualitative approaches on educational 
research more generally. More research of this kind is needed to gain a greater understanding of the phenomenon of inclusive education, from the perspectives of the people involved in their natural settings. Though the findings from quantitative research have contributed significantly to the debate of special and inclusive education (Chen, 1996; 1998), calls for qualitative research in this field have been increasing.

The relatively informal and flexible approach to applying the research instruments using open-ended questions for in-depth interviews and part of the survey complemented and triangulated data obtained from other research instruments. Nevertheless, due to the nature of the research approach, the data were collected and analysed with much effort in terms of the validity and reliability.

\subsubsection{The validity and reliability of the data from a mixed-method approach}

Research using a mixed-method approach is inevitably a complex process. Researchers (e.g., Mason, 2002) suggest that because of the interpretative nature of studies such as this, validity and reliability are difficult to attain. In particular, research which uses teacher perceptions and opinions and is then dependent upon the interpretation of these by the researcher does not lend itself readily to systems of accurate measurement or statistical procedure. Indeed, it has been argued (Bassey, 1999) that within qualitative studies of this nature, it is beholding upon the researcher to verify statements made through triangulation which is best achieved through a mixed- method approach such as that which I adopted.

The concepts of validity and reliability are central in qualitative research which, unfortunately can often be overlooked. Critics of methodology for educational research focus on 'flaws of empirical research, especially that of a qualitative nature for the lack of triangulation, sampling blas, purposeful distortion and ideological bias' (Oancea, 2005: 167). This, in a sense, contributes to the phenomenon in China that researchers are still indulging themselves in superficial opinions rather than in-depth understanding of some educational issues in special and inclusive education. Qualitative research approaches are yet to be considered as scientific, valid or reliable compared with the dominant quantitative approach which can obviously cover a much larger population, thus, are perceived more generalisable in terms of the findings. 
Evaluating the research, I would argue that the methods of data collection allowed for verification and therefore issues of validity were addressed. Reliability in conventional terms means that the data collection process is not selfcontradictory - that the data collection is based upon appropriate and sound measures. I therefore feel secure in respect of the data collected and reported in this thesis.

The methods were arguably valid as the flexible designed study had the potential of providing rich and highly illuminating material. Triangulation-by-method and triangulation-by-analysis enable a cross examination of various aspects of the same topic. In this research, I was aware of the reliability weaknesses of the data collected from the in-depth interviews as well as the data interpretation and processing under the social constructivist paradigm. To compensate for this, I used questionnaire surveys and non-participant observations together with the narrative inquiries from the case study in which reliability was strengthened. The reliability and validity of survey data depend to a considerable extent on the technical proficiency of the running of the survey. A low response rate was avoided and this provided data at an acceptable level which was also suitable for me to handle in this small scale research. The use of case study strategy for the collection of data on complex social situations was selected to validate other methods of data collection. It was used as an illustrative approach which I found manageable. All respondents were presented with the same standardised questions, carefully worded after piloting, and it was therefore possible to obtain high reliability of response (Robson, 2002:231).

The validity of data collection methods and the reliability of data obtained were always important issues to consider when I tried to evaluate the research. Special consideration would never be enough in research design, data collection, analysis and interpretation. To extract rich data by a qualitative approach to construct social reality in this particular context in China, I had to take precautions on major issues including the ethical gathering, elicitation, selection, transcription and co-construction of life stories, and personal and group narratives with interviews. Because as Rose (Rose 2000:5) points out: '...often teachers will present a view of their situation which may be more of a reflection of what they believe happens than an accurate description of actual classroom processes'.

I would also suggest that the data collected was reliable. Rellability was achieved 
as the data collection process was both consistent and stable. Different strategies to secure the methods of data collection were used. For example, one of the challenges I anticipated was the risk of low response rates for the questionnaire survey if I were to administer it by post. So I arranged meetings with the school headteachers so that they could help me to distribute questionnaires to individual teachers. Besides, I was informed that most of the student teachers were doing their school placement during my data collection period. To avoid low response, I discussed my research purpose with the deans of the schools in the university. With their informed consent and support, student teachers' questionnaires were sent to each school. Secretaries of the deans were asked to administrate the questionnaire survey on class basis in their respective schools. Each school then handed me the returned sheets. On some occasions, secretaries had to chase certain classes for cooperation.

Meanwhile, the reliability of the data I acquired through using instruments such as questionnaire and interview could be challenged on the grounds that the respondents might have given answers that were not actually true. This was especially true for the case study. The case study sample was selected on the basis of typicality and ordinariness. So the research was not repeatable. Such data might lack reliability if the respondents deliberately lied, or gave answers that did not actually represent how they behaved in reality. For this reason, I conducted non-participant observation to secure the reliability of data from the case study. Objectivity was achieved through a heightened sensitivity to the problem of subjectivity and the need for justification of the claims by the teachers. In this way the necessary bases of reliability and validity were achieved.

\subsubsection{Language barriers}

The under development of comparative educational research in China is largely due to language barriers (Bray and Gui, 2001). Most of the educational research reported in international journals and conferences is in English which is not accessible to many educational researchers or practitioners in China. This can be the result of their lack of English language competence or that of the financial constraints which make funding for international journal subscriptions, conference attendance, or internet use unavailable for conducting research. With little access to up-to-date research findings in the wider world, Chinese researchers have to base their studies mainly on the literature in Chinese with limited secondary sources of literature available for reviewing. This can further impact on the 
framing of theories and designing of research questions.

Given that I am able to use English as a working language, the translation of qualitative data from Chinese language to English presented a challenge to me. Transcribing tape-recorded interviews into text was a complicated process as a range of issues interfered with the accuracy of transcribed data (Poland, 2002). There were expressions which I was not able to find the equivalence in English language. For example, phrases like 'Hukou', 'Dinti' and 'Zinong', mean 'residency certification', 'replacement of retiring parent' and 'settling in the countryside areas' respectively. These phrases all have unique political and cultural connotations in the socialist country of China. The correct translation became challenging as the wrong interpretation implied the possible violation of participants' rights and distortion of the facts. Problems with translation and interpretation might exist.

Finally, seeking approval of the transcripts in English from the participants who were non-English speakers became problematic. It means that I had to translate the accounts back to Chinese for their confirmation.

\subsection{Ethical issues in conducting the study}

\subsubsection{Ethical guidelines and code of practice}

Ethical principles can guide ethical choices (Miles and Huberman, 1994: 289) and raise ethical consciousness. A professional code of ethics, according to Punch (1986), cannot cover all the eventualities in field work but can operate as a guide to legitimate and discipline the profession involved. Researchers, regardless of their cultural backgrounds, have to comply with certain ethical principles and guidelines as code of practice built upon the commonly accepted conventions, norms and values of the society. Nevertheless, ethics in educational research in some countries have been neglected in debate (Burgess, 1989). There is still no well-formulated set of ethical guidelines usable by qualitative researchers across a range of disciplines (Miles and Huberman, 1994: 289).

Whilst I was following Educational Research Guidelines endorsed by the British Educational Research Association (BERA, 2004), I was looking for similar guidelines in China. Generally speaking, there was a growing awareness of ethically sensitive issues in research and an increasing demand for scholarly and 
professional research activities in China. Given that informal conventions (Heath, et al., 2007) have been established regarding ethics in fieldwork, ethical guidelines and a specific written code of ethics had not been formulated and applied within the context for researching special and inclusive education. It was understood that, most often, research practices were executed under general laws or common sense principles and were validated by certain conventions followed through by researchers.

\subsubsection{Strategies}

To ensure the research was conducted in a professional way, it was felt most appropriate to adopt the securely established code of ethics. Therefore, I signed an ethical code at the beginning of the research (Tinker and Coomber, 2004). This code was informed by the principles established in the Revised Ethical Guidelines for Educational Research (2004) issued by the British Educational Research Association (BERA). The research ethics for this project were scrutinised by both the School of Education Research and Consultancy Committee (SERCC) and the Research Degrees Committee of the University of Northampton, as is standard procedure. As a consequence, I had to apply the ethical guidelines mainly for researching in the UK in my context with distinctive differences in multidimensional areas. I complied with sets of ethical guidelines which formed a basis for my ethical judgement in the real world research.

Ethical issues cannot be avoided in research (Griffiths, 1998:134). A series of issues need attention before, during and after qualitative studies. At the initial stages of reviewing the literature and selecting the research methods, I noticed that much of the literature on special and inclusive education published in China tended to attach priority to methods of data collection with little discussion of ethical issues. This is evidenced in the Chinese Journal of Special Education, one of the few journals in China dedicated to this field of study. Some literature published in English discusses 'an assurance of confidentlality' (Deng and Guo, 2007:699). I anticipated that it might become complex when I had to follow ethical principles practiced in the UK research contexts to be implemented in the culturally different populations in China. Although I was theoretically ready to conduct the study, the complexities of ethical issues within my research context posed certain challenges or dilemmas as I progressed. Therefore, I approached the key personnel in the local departments of educational policy and research for ethical guidelines to conduct the research. The replies were surprisingly negative. 
Obviously, dilemmas arose out of the conflicts between accepted ethical guidelines which I, as international student studying in a university in the UK, was obliged to abide by and the research conventions in my home context.

\subsubsection{Ethical issues and dilemmas}

Complying with the research conventions in my own context, I observed the complexities of the 'grey areas' where ethical guidelines were not administered systematically or used as legalised practices. I encountered a range of ethical dilemmas, additional or culture-specific, to those envisaged for the UK. These were specifically related to informed consent, confidentiality and anonymity, reciprocity and power, and subjectivity and bias. My interest in this area led me to discuss these issues with a colleague from India (Feng and Jament, 2008).

\subsubsection{Informed consent}

First of all, informed consent occupies a central place in research ethics. Nevertheless, for this study, seeking informed consent was seen as a new concept for the participants in my research as discussed elsewhere (Evans and Jakupec, 1996; Heath, Charles, Crow and Wiles, 2007; Hutton, Eccles and Grimshaw, 2008). To get access to the research schools, letters of consent were sent to the heads expressing the nature and the purposes of the research. The sensitivity the research implied with regard to the questions concerning teachers' career motivation was thus informed. To get the support and cooperation from the student teachers of the university, consent was also sought from the deans. Individual teachers and students were given access to the ethical code for the research.

As usual, the participants were asked to sign consent forms which were regarded as evidence for their voluntary participation. However, it was not easy for some to see that they could exert some control and refuse to participate, despite their rights being made clear. In real world research, many of the interview participants were reluctant to give their written consent for various reasons. Although this study had achieved voluntary consent, either written or oral, there were possibilities of reluctance from the participants.

\subsubsection{Confidentiality and anonymity}

Secondly, as the narrative accounts from the interviews formed the main body of research source, I was very much aware of the confidentiality and anonymity 
issues (Trahar, 2006). Researchers (Miles and Huberman, 1994: 288; Grinyer, 2002) question the value of anonymity if people and their colleagues can easily recognize themselves in a case study. Therefore, protecting the autonomy of persons, with courtesy and respect for individuals as persons was one of my ethical choices. Confidentiality was assured to the interviewees. I was responsible to make sure that no research of any form was conducted without the informed consent from the participants, in written and/or in oral. Questions for the interviews were handed to the interviewees prior to each interview. I would double check the interviewees had a clear idea of the research purpose and that they were confident of their secured confidentiality. In particular, the participants were informed that participation was voluntary and that their answers would remain completely anonymous and confidential. In case their data would be used, they would be reported in group format and would only be used for academic purposes.

However, I was challenged by sensitive socio-cultural issues in the protection of the participants' rights to confidentiality and anonymity and the generation of valid data. I was asked on some occasions to erase certain parts of the recoding in the interviews by some participants. 'Face' culture seemed to be the main factor for the dilemmas. Participants might feel the risk of 'losing face' if they chose to speak out the truth that, for example, the low priority attached to special and inclusive education was a significant factor which impacted their career motivation. Besides, participants had concerns of articulating openly their opinions on the opportunities or support they could get from local educational authorities or their schools for their professional development, which also closely related to their career motivation. They might feel insecure as their opinions entailed some aspects of criticism which could influence the reputation of their schools or themselves.

As the analysis of the data was inductive, the stories being narrated were constructed in the moments of the interviews to the extent that neither I nor the interviewees could predict the details of what was going to be discussed in advance of the event. There existed a source of the major problems (Nunkoosing, 2005:702). To be ethical, I had to make Interview transcripts available to the participants for them to remove any part of the interviews that they did not want to be included. 


\subsubsection{Reciprocity and power}

Thirdly, in terms of reciprocity and power, the purposive and selective sample and the research context contributed to the complex relationship I had established with the participants. Due to my professional identity, I was familiar with many participants in the schools who turned out to be former students in the university. This provided me with little difficulty in establishing rapport. The 'trustworthiness' was also easily built up with those who did not previously know me but were introduced to me by the ones I knew. It was positive in the sense that interviews became natural. However, the reciprocal relationship and negotiation of power presented challenges in that the familiarity was also a danger of obtaining data which did not reflect the participants' reality of their beliefs and behaviour in the research area. This could be because the participants specially chose positive answers to please me in terms of, for instance, their perspective on professional development (an explanation of this will be given in the Discussion chapter).

Moreover, the democratic principles and values associated with research participation were quite alien to some teachers. Being used to a management system which expected conformity, those requested to become involved either felt obliged, reluctant or de-motivated to provide data for my study under the pressure from top-down decisions. In cases when access to research settings was gained from 'gate keepers' (e.g., local educational authorities and /or headteachers), there existed the risk of power in-balance. As customary within the culture in China, researchers with higher qualifications than participants are considered superior. Very often, such researchers are regarded as sources of knowledge and wisdom. Surrendering to such authority is valued and kept high profile. Due to my familiarity with some head-teachers (I am their former teacher), the respect for authority from head-teachers to me as the researcher and/or teachers to their head-teachers, might have caused the passive involvement from certain number of the participants.

\subsubsection{Subjectivity and bias}

Finally, I experienced the dilemmas of subjectivity and blas arising out of being respectful and attaching value to the information provided while remaining critical and neutral. With knowledge about literature from a wider world and the exposure to special and inclusive education in the UK, I found adopting neutral attitudes towards the research context difficult. My previous life and profession was quite distant from teachers in special education. However, as an insider researcher, I was aware of the status of special and inclusive education based on 
my national and professional identity. In a sense, I had the temptation to be too critical about the provisions in special and inclusive education in my own context.

To analyse the data, the potential ethical problems and dilemmas that were likely to emerge were identified as misinterpretation. Language is not in a passive relation to reality...language signifies reality in the sense of constructing meaning from it' (Fairclough, 1992; 42). I had to translate narrative accounts from Chinese language into English. Accurate capturing of the spoken word in text form sometimes presented challenges because of sentence structure, use of quotations, omissions and mistaking words and phrases for others. When working with audio data, I listened to the recording while reading the transcriptions to ensure accuracy during transcription.

In addition, interpretation is personalised and non-systematic which can be affected by values and political orientation and further guide the stances to researchers' chosen methodology. One type of bias concerned the time span or settings sampled. This problem was anticipated when I was planning the timeline for the observations. I realised that if I had conducted observations for just one period of time, I might not be able to get a better understanding of the research settings. Additionally, a major bias concerns the subjectivity of the data collection methods. As the study was mainly a qualitative one which involved interpretation in constructing knowledge with the data from the participants, I had the tendency to be biased about what I saw. The problem was treated eventually by collecting observation data over a time span of the three research phases. Further problems could have occurred if I misinterpreted what was really happening. To solve this issue, I remained a non-participant observer trying to avoid influencing and being influenced by the participants.

Biases of various types are a major threat to the validity of qualitative research. Bias is related to the values and politics of the researcher which comes not from the researcher having ethical and political positions but from not acknowledging them (Griffiths, 1998:133). Biased opinions were inevitable for me as being an 'outsider' (as PhD student in the UK) and an 'insider' (a native of the research context). A major blas concerns the subjectivity of observers. In my school observations, wrong interpretations could be formed by me reading my own motivation and thoughts into what teachers were doing. I was at risk of reporting my own reality rather than the reality I should have observed. As invalid data led to biased interpretations, during the data collection process, I had lots of informal 
conversations with teachers to check my interpretations of their behaviour. In the data analysis process, I was aware of the potential blased opinions. Following guidelines of qualitative research helped make these observations a better "objective analysis of subjective meaning" and led to more insightful interpretations of what had been observed. 


\section{Chapter Nine: Findings}

The findings of the study are presented in this chapter in three parts. Part one reports teachers' career motivation. Part two demonstrates the appropriateness and sufficiency of teacher training programmes as indicators of teachers' knowledge and understanding of special and inclusive education. Also in this part, I report the attitudes of the teachers towards teaching children with SEN. In the final part, different perspectives on continuing professional development are revealed.

The data are presented by comparison and contrast of the perspectives of the participants as a whole as well by individual cohorts. The quantitative results are illustrated in percentages. Full transcripts of the interviews with the cases can be referred to in Appendix IX. Additionally, some class observation notes are shown in Appendix X. The codes used in the report such as 'QS' and ' $I$ ' stand for questionnaire survey and interviews whilst the numerals are the codes of the participants (details are provided in the Methodology chapter on Data Analysis).

\subsection{Teacher career motivation in speclal and inclusive education}

In this part, findings are reported focusing on the factors influencing teacher career motivation. The key question of this part, which was also one of the three key questions of the whole study, was: 'Why did you choose to be a teacher in special and inclusive education?' This was placed in the most prominent place in the research instruments, especially in the interview schedules and was further explored with probes and prompts for better understanding and clarification. The same question was asked in the questionnaire surveys to the three cohorts. In the surveys, I used some statements to investigate teacher motivation in working in special and mainstream schools (see Appendix VI). Also reported in this part are teachers' perceptions about why other teachers made their career choices. Meanwhile, the questions: 'Have you ever regretted your choice? Why or why not?' helped me to make better sense of the motivation regarding its typicality and/or commonality. During the interviews, especially the ones with the case study teacher, I had the opportunities to look deeper into the factors influencing teachers' career cholce. Meanwhile, I also collected supportive data from observations conducted in the schools. With this, I was able to reason and interpret the data in this respect and present the findings. 


\subsubsection{Key findings on teacher career motivation in special and inclusive education}

The key findings from the overall data set of this part of the study are:

- Mainstream and special school teachers were mostly extrinsically motivated in their career choice. Comparatively, student teachers were slightly better intrinsically motivated.

- Teachers from each cohort perceived controlled motivation in their career decisions due to recruitment policies, family backgrounds or personal conditions, academic attainments, and/or other relevant social and economic situations which were beyond their control. Yet, few mainstream or student teachers were amotivated in teaching as opposed to the unwillingness of special school teachers when they had to be in compliance with a career which was not of their own choice.

- A large number of mainstream teachers and student teachers had no willingness to work in special schools or with children with SEN in mainstream schools despite the respect they commonly showed to special school teachers. Most of the special school teachers would like to teach in mainstream schools if possible.

- The majority of the three cohorts would like to choose other professions than teaching if possible. About half of the in-service teachers were regretful for their initial career choice.

Specifically, each cohort showed varied motivation for special and inclusive education. The following tables provide an overview of the findings. I also use direct quotes from the surveys and interviews to provide evidence for the raw statistical data. In fact, the narrative accounts are the core of the study in that they are articulated in more a detailed manner. Those quotes well-illustrate and reflect teachers' self-assessed motivation in their career choice as they share some commonalities. Although some quotes are exceptional which do not represent the voices of most of the teachers researched, the reason for the inclusion of them in the report is that motivation as behaviour entails individual differences. The detailed commonalities and differences from the different cohorts are reported in the next section.

It is noted that the participants were encouraged to give multiple reasons for their career choice to the open-ended questions both in questionnaire surveys 
and interviews. The tables sum up the factors. The total percentage is therefore not $100 \%$ in some data sets.

\begin{tabular}{|l|l|l|l|}
\hline Questionnaire Surveys & $\begin{array}{l}\text { MT } \\
(N=326)\end{array}$ & $\begin{array}{l}\mathrm{ST} \\
(\mathrm{N}=36)\end{array}$ & $\begin{array}{l}\text { US } \\
(\mathrm{N}=565)\end{array}$ \\
\hline $\begin{array}{l}\text { I would like to be a teacher in a mainstream } \\
\text { school }\end{array}$ & $\begin{array}{l}(\mathrm{N}=275) \\
84 \%\end{array}$ & $\begin{array}{l}(\mathrm{N}=25) \\
69 \%\end{array}$ & $\begin{array}{l}(\mathrm{N}=439) \\
80 \%\end{array}$ \\
\hline $\begin{array}{l}\text { I would like to teach children with special } \\
\text { needs in a special school }\end{array}$ & $\begin{array}{l}(\mathrm{N}=96) \\
29 \%\end{array}$ & $\begin{array}{l}(\mathrm{N}=29) \\
81 \%\end{array}$ & $\begin{array}{l}(\mathrm{N}=316) \\
56 \%\end{array}$ \\
\hline $\begin{array}{l}\text { I would like to teach children with special } \\
\text { needs in a mainstream school }\end{array}$ & $(\mathrm{N}=133)$ & $(\mathrm{N}=17)$ & $(\mathrm{N}=258)$ \\
$40 \%$ & $48 \%$ & $46 \%$ \\
\hline $\begin{array}{l}\text { I would like to choose other professions than } \\
\text { teaching if possible }\end{array}$ & $(\mathrm{N}=250)$ & $(\mathrm{N}=22)$ & $(\mathrm{N}=360)$ \\
$76 \%$ & $65 \%$ & $65 \%$ \\
\hline $\begin{array}{l}\text { I think teaching in a mainstream school is less } \\
\text { demanding than teaching in a special school }\end{array}$ & $(\mathrm{N}=147)$ & $\begin{array}{l}(\mathrm{N}=16) \\
45 \%\end{array}$ & $\begin{array}{l}\mathrm{N}=391) \\
69 \%\end{array}$ \\
\hline $\begin{array}{l}\text { I think teaching in a mainstream school is } \\
\text { more enjoyable than teaching in a special } \\
\text { school }\end{array}$ & $(\mathrm{N}=194)$ & $(\mathrm{N}=18)$ & - \\
\hline
\end{tabular}

Table 9-1: Percentage of questionnaire survey data (agree or strongly agree to the close statements) regarding teacher career motivation in special and inclusive education from the three cohorts Note: The last statement in the table was asked only to the in-service teachers.

A large number of mainstream ( $84 \%)$, special school (69\%) and student teachers $(80 \%)$ liked to be teachers in mainstream schools. Only about $29 \%$ of the mainstream school teachers had an interest in pursuing opportunities to teach in special schools. However, most of the special school teachers ( $81 \%)$ expressed their willingness to teach in special schools. About half of the in-service teachers perceived teaching in mainstream schools less demanding whilst a bigger number of them perceived it to be more enjoyable. In comparison, less than half of the three cohorts would like to teach children with SEN in mainstream schools. They believed it would be more demanding. More student teachers than the other two cohorts perceived teaching in mainstream schools less demanding.

\subsubsection{Intrinsic motivation}

The data from the questionnaire survey on the mainstream school teachers $(N=129)$ show that only $23 \%$ of the teachers chose the profession out of intrinsic motivation as they liked teaching/children; it was their childhood dream; they are interested in teaching and/or they simply wanted to be a teacher. 


\begin{tabular}{|l|l|l|l|}
\hline Intrinsic motivation & $M T(N=129)$ & $\mathrm{ST}(\mathrm{N}=36)$ & $\mathrm{US}(\mathrm{N}=433)$ \\
\hline I like teaching/children & $(\mathrm{N}=12) 9 \%$ & $(\mathrm{~N}=6) 16 \%$ & $(\mathrm{~N}=114) 26 \%$ \\
\hline It was/is my dream & $(\mathrm{N}=15) 12 \%$ & $(\mathrm{~N}=4) 11 \%$ & $(\mathrm{~N}=38) 9 \%$ \\
\hline $\begin{array}{l}\text { I am interested/I want to be } \\
\text { a teacher }\end{array}$ & $(\mathrm{N}=3) 2 \%$ & $(\mathrm{~N}=2) 5 \%$ & $(\mathrm{~N}=26) 6 \%$ \\
\hline Total & $(\mathrm{N}=30) 23 \%$ & $(\mathrm{~N}=12) 32 \%$ & $(\mathrm{~N}=178) 41 \%$ \\
\hline
\end{tabular}

Table 9-2: Percentage of intrinsic motivation influencing teacher career choice from the open-ended questionnaire surveys from the three cohorts: Why did you choose to be a teacher?

The data from the close-ended questionnaire survey show that a large number of the special school teachers would like to teach children in special schools $(81 \%)$ (see Table 9-1). Interestingly, for the open-ended part of the survey, less number of special school teachers expressed their intrinsic motivation for being a teacher, although the intrinsic motivation is mostly similar to those articulated by mainstream school teachers. Some expressed their intrinsic motivation in the survey as follows:

I used to be able to do very simple calculations and later I learnt a lot. I thought teachers were great. So I chose to be a teacher.

QS-MT-63

I had the dream since I was young. I like children. I enjoy being with innocent children.

QS-ST-2

Over half of the student teachers from the survey data expressed their willingness in teaching either in special schools (56\%) or mainstream schools $(80 \%)$. Again, the intrinsic motivation is of no obvious difference from the other cohorts. $41 \%$ of the student teachers out of 433 expressed their intrinsic motivation as being like teaching and children $(\mathrm{N}=114)$, interested in teaching $(\mathrm{N}=26)$, and it was their dream $(\mathrm{N}=38)$. The percentage is the highest among the three cohorts.

Being a good teacher has been my dream. I adored teachers when I was young. I hope with my teaching, more children will gain knowledge. I deeply believe that education can change a person's life. So I hope with my efforts, more children will make the right steps in their life.

QS-US-407

It is a passion, a dream. I always adore teachers. Now I feel it is my responsibility and my mission. 
Similar reasons were given by a mainstream interviewee:

When I was young, I always wanted to be a teacher. It is my dream. My parents wanted me to do other things. I went to ... University to study English language. I was not in the teacher training programme. When I graduated, my parents found me many chances to work in different companies. I went there for interviews. But I really did not like that. I just wanted to be a teacher. I like the life in a school.

Interestingly, when interviewed, no teachers expressed any intrinsic motivation to start their career working in special schools, although some had intrinsic motivation to start their teaching career in mainstream schools as evidenced in the survey data.

\subsubsection{Extrinsic motivation}

The open-ended questionnaire surveys from the three cohorts show that only a very small number of mainstream school teachers $(\mathrm{N}=5)$ regarded teaching as a glorious job, a job for transmitting knowledge or to influence people. They thought children were lovely, teaching was easy and education was important (Table 9-3). There are elements in teaching which might have been their intrinsic motivation in their career choice. This can be seen as altruistic motivation (e.g., Richardson and Watts, 2005) or as the extrinsic motivation with autonomous regulation (Deci and Ryan, 1985). If taking the percentage (4\%) away from the total $(72 \%)$, still a significant number of teachers $(68 \%)$ chose this profession out of extrinsic motivation, categorised from autonomous to controlled regulation in Deci and Ryan (2007). Teachers articulated that they made their choice by comparing and contrasting teaching with other jobs or professions.

At that time, it was considered a better thing to do to be a teacher than to be a farmer.

QS-MT-16

Factors include, but were not limited to, as some did not specify, their limited university entrance scores which did not allow them to choose other programmes than teaching when they applied for higher education. The volce of 'no choice' is repeated by a larger proportion of teachers expressing their reluctance.

In fact, I was not meant to make the choice. I got poor scores which did not allow me to be a university student. So I had to choose to go to a teachers' college... 


\begin{tabular}{|c|c|c|c|}
\hline Extrinsic motivation & MT $(N=129)$ & ST $(N=36)$ & US $(N=433)$ \\
\hline $\begin{array}{l}\text { No choice/I was } \\
\text { forced/wrong choice/low } \\
\text { scores/family problem }\end{array}$ & $(N=43) 33 \%$ & $(N=12) 32 \%$ & $(N=35) 8 \%$ \\
\hline $\begin{array}{l}\text { Make a living /Job } \\
\text { opportunity }\end{array}$ & $(N=25) 19 \%$ & $(N=5) 14 \%$ & $(N=20) 5 \%$ \\
\hline $\begin{array}{l}\text { Parental influence/I was } \\
\text { naive }\end{array}$ & $(N=4) 3 \%$ & $(N=8) 22 \%$ & $(N=35) 8 \%$ \\
\hline Stable job & $(N=8) 6 \%$ & - & $(N=41) 9 \%$ \\
\hline $\begin{array}{l}\text { Glorious job/transmit } \\
\text { knowledge/ Good social } \\
\text { status/teaching is } \\
\text { easy/education is } \\
\text { important }\end{array}$ & $(N=5) 4 \%$ & $(N=3) 8 \%$ & $(N=82) 19 \%$ \\
\hline By chance/recrulted & $(N=9) \quad 7 \%$ & - & $(N=4) 1 \%$ \\
\hline Total & $(N=77) 72 \%$ & $(N=28) 76 \%$ & $(N=217) 50 \%$ \\
\hline
\end{tabular}

Table 9-3: Percentage of extrinsic motivation influencing teacher career choice from the open-ended questionnalre surveys from the three cohorts: Why did you choose to be a teacher?

The extrinsic motivation of special school teachers fits well with the continuum of the spectrum described in Deci and Ryan (1985; 2008). That is, those with extrinsic motivation when entering teaching became less controlled and more autonomous in motivation over time. Some aspects of the extrinsic motivation are similar to those of altruistic motivation which overlap with some elements of autonomous extrinsic motivation (Ryan and Decl, 2000b). For example, to the question: why did you choose to be a teacher? One special school teacher answered that:

...To educate people and transmit knowledge to younger generations. Meanwhile, I can learn from teaching so that I can be more confident. My knowledge can be renewed.

Similarly, their initial amotivation or unwillingness had somewhat altered to the controlled extrinsic motivation. In other words, they felt less resentful at working in special schools as a result of years of accumulation of knowledge and skills in teaching students with SEN. They contributed the change to their improved professional identity and social status due to the increasing priority attached to special education by the government or the society at large. 
However, as the question was general, that is, why did you choose to be a teacher, I was unable to interpret if teachers were talking about teaching in special school as well. Besides, as I could only probe and prompt in the interviews for more specific details, I did not feel evidenced enough to locate the reasons in the category of the intrinsic motivation. This failure was also caused by the anonymity of the survey participants which did not enable me to spot him/her in the interviews.

Table $9-4$ is a comparison of the factors influencing teaching choice from the special school survey data $(N=36)$. The question asked was: Why did you choose to be a teacher? In the interviews $(N=22)$, I specially asked about their motivation in working in special schools: Why did you choose to be a teacher in special school?

\begin{tabular}{|l|l|l|l|}
\hline $\begin{array}{l}\text { Survey data: Why teaching in } \\
\text { general }\end{array}$ & $\mathrm{N}=36$ & $\begin{array}{l}\text { Interview data: Why } \\
\text { teaching in special school }\end{array}$ & $\mathrm{N}=22$ \\
\hline $\begin{array}{l}\text { No choice/ Family economic } \\
\text { pressure/ Government's city } \\
\text { dwelling policy }\end{array}$ & $32 \%$ & $\begin{array}{l}\text { Being recruited /No } \\
\text { choice/ Family economic } \\
\text { pressure/ Government's } \\
\text { city dwelling policy/ } \\
\text { Health/Family concerns }\end{array}$ & $63 \%$ \\
\hline Parental influence & $22 \%$ & Parental influence & $5 \%$ \\
\hline Job opportunity & $14 \%$ & $\begin{array}{l}\text { Job opportunity/ Supply } \\
\text { for the retiring parent }\end{array}$ & $18 \%$ \\
\hline Transmit knowledge & $8 \%$ & - & - \\
\hline Total & $76 \%$ & Total & $86 \%$ \\
\hline
\end{tabular}

Table 9-4: Data in percentage from questionnaire surveys and interviews on the factors influencing teaching in general and teaching in special schools from special school teachers

Whilst teachers articulated Intrinsic motivation such as like children and/or teaching in general, once it came to the teaching in special school, these reasons no longer seemed as important. The change is obvlous from the survey data of like children/teaching (32\%) (see Table 9-2) to the interview data with the latter having no indication of 'childhood dreams' or 'I wanted to be a teacher'. In fact, from the interview data, most of the special school teachers were extrinsically motivated.

I did not think too much when I chose to be a teacher. I only wanted to have a good job so that my parents could be proud of me. I could help improve the living standards of my family and became a citizen in a city and left the farm. 
Data show the perceived influential factors in the participants' career choice. 'Being recruited' ranks the highest from the interview data. Reasons for being recruited, a very controlled motivation as I interpret it, include, according to the data, academic scores, school merge, government/school needs, and/or job promotion.

Before I left [graduated from] my middle school, a head-teacher [from a local school] looked for me because he was told that I was very good at sports. He wanted me to be a PE teacher in his school and I agreed.

I graduated from... Normal School. Student teachers graduated from that school all went to mainstream primary schools. The local education bureau went to our school to look for the ones they wanted. They needed someone who was a female, who had a heart of love and patience for the special school. They talked with my class-master. He recommended me. They [the special school she had been working] wanted also someone who lived in the city. I did not even know there was such a school. I did not like the school at all when I came. But people said that there was no pressure to teach students in this school and the treatment was good. As I had no other schools to go through relations, I started to respect the teachers here who had been teaching in this school for more than ten years.

The government's city dwelling policy for those living in the countryside areas and/or supplying for the retiring parent had strong influences in teachers' career choice. Notably, parental influence ranks highest in the survey data. That is, about teaching in general. This influence includes having parent/parents being teachers themselves, parents' choice, and/or parents' retirement from their teaching posts which created job opportunities. But parental influence in terms of positive support for career choice in special schools no longer ranks as high from the results of the interviews (5\%) whilst other factors predominated.

I came, I came I came here because I was not in good health at that time. When I was teaching in the mainstream school, I had to get up very early and stayed in the school at lunch time as I was the class teacher. I had late lunch and I had stomach problem. So I thought I should not go on working like that. I suffered from stomach bleeding. Here [special school] is a quite place. There is less pressure of academic attainment or high school rates... I was then in poor health.

Extrinsic motivation was also expressed by many interviewees from mainstream schools who were originally from countryside areas but wished to live and work in 
cities. When they claimed that they had no choice, they explained explicitly that it was the government's city dwelling policies which did not allow residency of farmers in cities. The following is from a mainstream science teacher who expressed his choice as 'no choice'.

I was born in the countryside. I have several siblings. I was the one who could study. At that time, I did not want to be a teacher. But I wanted to leave the countryside. According to my examination scores, my scores were not good enough for me to choose other profession. I actually could choose other professions. But in order to secure a place, I chose to study in a normal college in a city. So according to my own wish, in fact, I did not want to choose to be a teacher. I think I fit to be a business person. I was more interested in business. But, the result is... It is not my wish to be a teacher. I had no choice.

Due to family economic pressure, teachers were tempted by the living allowance subsidised by the government to student teachers. It could also mean that they were recruited without their previous knowledge. They had to obey the 'selection' to secure a job opportunity. In addition, parental influence and expectations were also factors influencing their choice. Whereas some chose to teach to make a living as they saw it a stable job or a job with good social status, others regretted that they were naive or they made the choice without careful consideration. They believed it was a wrong choice ( $2 \%)$.

Extrinsic motivation of the student teachers is as follows: stable job $(N=41)$, Job opportunity $(N=19)$, Parental influence $(N=23)$ no choice $(N=7)$ I was forced $(\mathrm{N}=9)$ and by chance $(\mathrm{N}=4)$.

I can get prepared to be a good mother in the future. I will learn how to teach my own child.

Student teachers also expressed similar motivation of family or parental influence.

It was the decision of my parents and teachers. I did not object. The situation at that time forced me to the line.

Parental expectations, the restriction of examination scores, I came and I think it is the right profession for me. 
The findings from the interviews on teachers' perceptions of career choice for other teachers show that most of the perceived factors are extrinsic ones. These being the ones stated in the order of frequency and motivation type: extrinsic motivations: stable job, income, holiday, exam scores, family influence, social respect, recognition and status, and for females teaching their own children; intrinsic motivation: interests. Comparatively far more teachers related extrinsic motivations as main factors influencing their choice.

... to think about the society... I think it is a comparatively stable job. Female one chose to be teachers. It is good for them to bring up their own children. They may like teaching and like children. They have stable life. Some may not have any choice. Low marks, countryside to cities...

They [females] think it is stable and the social status is not too bad, in the recent few years, especially. If we include male teachers, in fact, some people when they chose the profession, they were still students. They did not have much experience. They did not even know how to compare this job with other professions. They were not able to do that. They were influenced by their teachers around them. When they were tired of work, they later compared themselves with other former classmates. They find that they could actually do other things. They just listened to other people's opinions. Or they might not have good academic marks for other professions. When some people studied teacher education, the country gave them living allowance. Some might think that they could not do other things, so they chose to be teachers. The family influence is important. Some people were born in teachers' families or tailors' families. They eventually became teachers or tailors.

For students today, it is their marks. So I would say that it is very difficult to improve teacher qualifications, because now the student teachers are not as good as the ones before. We can tell from them when they came to our school for placement. It is getting worse year after year.

I-MT-19

\subsubsection{Amotivation}

I categorise 'wrong choice' as amotivation for the reason that it implies zero appreciation from the teachers of their own choices, but a sense of unwillingness or regret. Statistically, it is not significant as I sorted them out by their exact words from the questionnaire data $(N=3)$. However, in the interviews, more teachers stated that they started their teaching with a sense of unwillingness. In addition, lack of training in SEN is seen as an indicator of de-motivation. A very limited number of teachers had received special training before they started to work in the special schools (Table 9-5). 


\begin{tabular}{|l|l|l|l|}
\hline Amotivation & MT $(\mathrm{N}=129)$ & $\mathrm{ST}(\mathrm{N}=36)$ & US $(\mathrm{N}=433)$ \\
\hline wrong choice & $(\mathrm{N}=3) 2 \%$ & - & - \\
\hline
\end{tabular}

Table 9-5: Percentage of amotivation influencing teacher career choice from the open-ended questionnaire surveys: Why did you choose to be a teacher?

The case study teacher in the school for children with sensory impairments began her teaching career 30 years' ago with a junior school certificate like some of her colleagues.

To be quite honest, this has to do with my parents. My parents are deaf and dumb. They worked here [special school]. We grew up in this school. We ate and lived with the students here. Then I went to the countryside to work. When my father retired, I was given a job opportunity. The then educational bureau asked me where I would like to be placed: mainstream schools or kindergartens... which one I would choose. At that time, though I was 20 years old, I was very immature. If I went to work in other places, I thought I would feel unfamiliar with the situation and I was afraid as I went to the countryside right after I finished my junior middle school. I did not even go to senior middle school before I was asked to go and work in the countryside [the government policy during the Great Culture Revolution 1966-1976]. Since I was given a teaching position, comparatively, I knew myself well how much knowledge I had. I did not dare to go to other schools. I thought I'd better stay in this school since I knew the school well and it would be a piece of cake for me to teach here.

Case I

Second, some special school teachers expressed their strong unwillingness working in special schools, although their motivation became less controlled and more autonomous with the years of teaching experiences. This is evidenced in the following narrative accounts.

I did not apply for that. I did not think about that. But that college recruited me without my consent. I applied to study teacher education...No. I was not [happy]. I did not know anything about it [special education] at all. I did not want to teach mentally retarded children. I would like to teach children in mainstream schools. I had never thought that I would be teaching mentally retarded children. I did not want to go there [teachers' college].

At the beginning I was not used to that. But when we were in third years, we had teaching practice in schools. I got used to that. I got to understand that it was not too bad to be a teacher like that.

At the beginning I was a teacher In a primary school. About 15 years ago, I moved to Shaoxing with my family. I have teaching qualification. But when we arrived in the city, the Education Bureau did not arrange me to teach in primary schools. Instead they asked me to teach in a kindergarten. I was very unhappy. I cried many times and I did not like the arrangement. In the kindergarten, they called me aunt. But I should be called teacher. I tried to find some people who could help me using their relations with the local educational government. I talked to them and eventually, they told me that this special school needed teachers. If I agreed, they could help me to get into the school. At the beginning, I did not like the school at all. It was so small and the children were all retarded. I felt that it was a shame to work in such a small school. People looked down upon me. But later, I found the children were actually lovely. They are simple, much simpler than other 
children. They listen to me. I take care of them after lunch, the nap time. Sometimes other teachers could not handle the children. They would ask me for help. When I went to their rooms, children would stop making noises. So later, the school asked me to do the job every nap time. You know it is really smelly in their dorms. What can I do? I have to learn to get used to this. Now I am used to it.

I-ST-18

\subsubsection{Other findings related to motivation for special and inclusive education}

\section{Regret at career choice}

First of all, about $65 \%$ of the special school and student teachers would like to choose other professions than teaching as compared to a bigger number of mainstream school teachers $(76 \%)$. Meanwhile, from the survey data, more teachers from mainstream schools showed no regret at their career choice $(49 \%$ verses $41 \%)$. This is largely consistent with the responses from the interviews. Whilst some remained in teaching as they had no choice, others had not regretted as they thought:

...If I compare with others working in factories, it is a good job. I can take care of my child.

I can earn more than laid off workers and the job is safer than mining.

QS-MT-30 Or:

The job is far better than the jobs for the floating population

QS-MT-29

I get along well with my colleagues. I enjoy my work. I am happy when my students get good marks.

I am doing my job with great passion after 32 years. I have no regret now. I like teaching profession. I attach importance to special education. I would like to contribute my all to the silent world.

Secondly, a significant number of mainstream school teachers were not committed to their career. This is evidenced in the survey $(\mathrm{N}=326)$ analysed in SPSS that $77 \%$ of the teachers agreed or strongly agreed that if possible, they would like to choose other professions than teaching. The reasons were explained as work-related stress and/or pressure, seeking better pay and/or better chances in life. 
Boring, too high expectations from the society, little respect. Pay a lot but gain a little.

It is hard to be a teacher now... Though I earn more now, the pressure is too great.

QS-MT-64

The following quote shows a teacher's desire for other careers:

For me, I think I am very successful in becoming a school administrator. I have a sense of satisfaction. But from the bottom of my heart, I am still looking for ways to leave teaching. I have always been looking for chances to jump from this circle. Especially in these years, this feeling is becoming stronger and stronger. To teach junior middle school students, though it is interesting to be with the students, I do not really like to communicate with students at this age group. So I have always been thinking of jumping out of the circle. I do not want to be a teacher. I have been trying to find ways. For the past few years, I have been taking exams to work in the government. I applied to work in the government offices. Recently I have been visiting some places to seek job opportunities. To tell you the truth, I do not want to be a teacher.

From the survey data, 8 special school teachers among the 35 regretted their choice, though not always.

Yes, sometimes. I felt very much stressful. After a few years' teaching experience, I feel I need to be charged with knowledge. Besides, I feel highly pressed about students' safety. I am a class teacher. I have to be responsible for my students' safety. The school signed all kinds of agreement of responsibility with teachers. I become their body guard. I have to be sure that they are always safe.

QS-ST-33

A bit. There is no feeling of achievement working in special education. There is no chance of professional development. Special school teachers are like frogs at the bottom of the well. They have no chance to experience the wonderful world. Special schools and teachers in special schools are not prioritised and sometimes they are even discriminated.

\section{Mainstream school teachers' motivation for working in special schools}

When asked about their preference of teaching in mainstream or special schools, many of the mainstream school teachers expressed their reluctance in respect of special needs work. From the survey, only $29 \%$ would like to teach in special schools. One teacher told me in the interview that she put special school as her second choice just to secure a job opportunity. Besides, more than half $(58 \%)$ in the survey disagreed or strongly disagreed to have an interest in teaching children with SEN in mainstream schools. This could be that: 
If you have a child like this [with special needs] yourself, you may want to go

I-MT-9

I do not have the patience

I-MT-10

This was agreed by another teacher.

I will go for a try. I will not want to stay there for long. My personality will not allow me to be very patient. I have to do things my way. I will lose my temper. It does not mean that I do not want to take care of them.

I-MT-13

The reluctance was attributed to the insufficient training they received with regard to special education. However, still a few expressed their interest to try as:

This experience will help me to work better in a mainstream school to meet the needs of students

But, according to those willing to try, the same or better terms and conditions they were enjoying in mainstream schools should apply. One of the interviewees expressed her real interest in teaching as she tried very hard to be a teacher since she did not have any formal training. She explained that she had a loving heart to work for children with special needs. However, the material world and the harsh reality convinced her that she was not realistic:

I often have the idea of being a teacher in a Project Hope school. If I were younger, or I were not married, maybe... Well, now, people will think that I pretend to be somebody... My brother used to laugh at me: 'Oh, you are so great. Why don't you first give all the things at home to those who need them? You should not live in the ideal world without any material needs. Once you have given away all your belongings, you can then give yourself to those people'. He used this argument to make me more realistic. He is right. I can not be a person that great. So the idea never becomes a reality.

Moreover, when asked about whether having chlldren with SEN would affect their motivation in teaching, most of the teachers gave negative answers.

I may complain to the school. But no influence on my choice 
Other teachers also agreed that there would be no effect because:

In my class, I have a student. He can not speak properly. He can not speak English. So in class, we just ask him not to talk. Sit there. When it is play time, play with others.

No. There are limited numbers of them. It will not affect me if I fall to teach one child.

Another mainstream teacher did not believe that teachers in special schools would have the intrinsic motivation. In his words:

They were assigned to teach there, they had to accept the reality. Like us, we were assigned to teach in certain schools. Later, they might have been moved unconsciously. No, I will not choose to go. The ones I know, they were assigned there. Then they were moved and they stayed. So they have been working there all the years.

\section{Teaching chlldren with SEN}

Over half of the student teachers did not want to teach children with SEN in mainstream schools. Even more perceived teaching in a mainstream school is easier than teaching in a special and inclusive school. They (65\%) thought that children with SEN should be educated in mainstream schools. Some thought that 'children educated in a special way will have gaps in their relationship with ordinary children. They can not get along well' (QS-US-287).

Some feel that 'it is good and bad. Children are simple. They are vulnerable. Special education can help some children develop, but will hurt some others. The most important is the balance' (QS-US-243). When asked if children with SEN should be educated in special schools, $56 \%$ of them agreed or strongly agreed.

\subsection{Professional knowledge and understanding of and attitudes towards special and inclusive education}

This part of the chapter reports the findings on the following aspects: teacher' knowledge and understanding of, attitudes towards special and inclusive education, and their self competence evaluation in working with children with SEN in China. The data reflect the quality of teachers as professionals. Meanwhile, findings on teachers' perceptions of and attitudes towards special and inclusive 
education indicate the correlation with teachers' motivation for professional career and development.

\subsubsection{Key findings on professional knowledge and understanding of and} attitudes towards special and inclusive education

- Teachers from the three cohorts had limited knowledge and understanding of special and inclusive education. They attributed this to the flaws in initial teacher education which did not prepare them with sufficient knowledge of SEN. Most student teachers were especially not happy with the initial teacher education programmes or resources for learning. Comparatively, special school teachers outperformed the other two cohorts, despite the fact that very few teachers from special schools started teaching with formal training in special education. Most of them were either transferred from mainstream schools or started teaching without qualifications at all even for general education. Nevertheless, they accumulated knowledge and understand of and skills for special education largely from on-the-job learning. They perceived more confidence in teaching children with SEN in mainstream schools.

- Most of the teachers from mainstream schools and student teachers showed their respect to teachers in special schools whilst they expressed their reluctance in working in special schools or working for children with SEN in mainstream schools. A majority of them accepted inclusive education as a concept but showed their skepticism towards more inclusive schooling. They agreed or strongly agreed that children with SEN should be educated in special schools. Meanwhile, most of the special school teachers acknowledged the positive change of social attitudes towards their work and the improvement of their social status over the years. Still others felt more positive attitudes needed to be nurtured to meet their expectations.

Key findings on professional qualifications for and attitudes towards special and inclusive education are presented in Table 9-6. 


\begin{tabular}{|c|c|c|c|}
\hline Questionnaire Surveys & $\begin{array}{l}\text { MT } \\
(N=326)\end{array}$ & $\begin{array}{l}\text { ST } \\
(N=37)\end{array}$ & $\begin{array}{l}\text { US } \\
(N=565)\end{array}$ \\
\hline $\begin{array}{l}\text { The years' experience in the mainstream } \\
\text { school has prepared me to teach in a special } \\
\text { school }\end{array}$ & $\begin{array}{l}(N=326) \\
40 \%\end{array}$ & $\begin{array}{l}(N=33) \\
36 \%\end{array}$ & - \\
\hline $\begin{array}{l}\text { The years' experience has prepared me well to } \\
\text { teach children with special needs in a } \\
\text { mainstream school }\end{array}$ & $\begin{array}{l}(\mathrm{N}=326) \\
50 \%\end{array}$ & $\begin{array}{l}(N=36) \\
72 \%\end{array}$ & - \\
\hline $\begin{array}{l}\text { I think children with special educational needs } \\
\text { should be educated in special schools }\end{array}$ & $\begin{array}{l}(N=326) \\
77 \%\end{array}$ & $\begin{array}{l}(N=37) \\
48 \%\end{array}$ & $\begin{array}{l}(N=546) \\
56 \%\end{array}$ \\
\hline $\begin{array}{l}\text { I think children with special educational needs } \\
\text { should be educated in mainstream schools }\end{array}$ & $\begin{array}{l}(N=326) \\
37 \%\end{array}$ & $\begin{array}{l}(N=36) \\
33 \%\end{array}$ & $\begin{array}{l}(N=564) \\
65 \%\end{array}$ \\
\hline $\begin{array}{l}\text { I am satisfied with the course offered by the } \\
\text { university on special and inclusive education }\end{array}$ & - & - & $\begin{array}{l}(N=563) \\
37 \%\end{array}$ \\
\hline $\begin{array}{l}\text { I am satisfied with the library resources in the } \\
\text { university on special and inclusive education }\end{array}$ & - & - & $\begin{array}{l}(N=564) \\
44 \%\end{array}$ \\
\hline $\begin{array}{l}\text { The four-year's learning in the university has } \\
\text { prepared me well to teach in a special school } \\
\text { or inclusive school }\end{array}$ & - & - & $\begin{array}{l}(N=560) \\
48 \%\end{array}$ \\
\hline $\begin{array}{l}\text { The four-year's learning in the university has } \\
\text { prepared me well to teach in a mainstream } \\
\text { school }\end{array}$ & - & - & $\begin{array}{l}(N=562) \\
77 \%\end{array}$ \\
\hline
\end{tabular}

Table 9-6: Percentage of questionnaire survey data (agree or strongly agree to the close statements) regarding teachers' qualification of and attitudes towards special and inclusive education from the three cohorts

Specifically, first, the data indicate that, first, within the mainstream school cohort $(\mathrm{N}=326), 50 \%$ perceived that they were not well qualified or equipped to teach children with SEN in mainstream schools. $60 \%$ felt that they had no qualification or experience for teaching in special schools as far as their selfevaluated competence was concerned. $77 \%$ agreed or strongly agreed that those children should be taught in special schools. Over half of them stated that they had low motivation teaching those children in mainstream schools.

Second, less than half of the special school teachers perceived that the years' experience in the mainstream school had not prepared them well to teach in a special school. On the contrary, the majority of the teachers from special schools perceived more confidence in teaching children with SEN in mainstream schools. About $69 \%$ of them would like to teach in mainstream schools. 
Third, although most of the student teachers $(77 \%)$ perceived that they were well prepared to teach in mainstream schools, less than half perceived that they were able to teach in special or inclusive schools. They were not satisfied with the library resources. Attitudes were less positive in that less than half of the three cohorts would like to teach children with SEN in mainstream schools. Most of them believed that children with SEN should be educated in special schools. This contrasted with a similar number of teachers from special schools who believed that children with SEN should be educated in mainstream schools. A slightly over half of the student teachers agreed to the concept of inclusive education.

\subsubsection{Professional qualifications for special and inclusive education}

\subsubsection{Special school teachers' professional qualifications in special education}

The research context for my study is similar to Jiangsu Province and Shanghai in terms of the overall economic and educational development (more description can be referred to in the Research Contexts chapter). Therefore, the findings of the teacher supply in special and inclusive education do not differ much from the above mentioned research (Wang, 2006; Wan, Wang, Du and Chen, 2008). There are 12 full time teachers working for 92 students aged 6-17 with a range of learning difficulties and 24 full time teachers for 130 students aged 7-18 with sensory impairments. Table 9-7 shows the professional qualification of teachers interviewed in special schools.

\begin{tabular}{|c|c|c|c|}
\hline $\begin{array}{l}\text { Years in special } \\
\text { schools }\end{array}$ & $\begin{array}{l}\text { With initial training } \\
\text { on special education }\end{array}$ & $\begin{array}{l}\text { With teaching } \\
\text { qualification or } \\
\text { degree to start with }\end{array}$ & $\begin{array}{l}\text { Without any } \\
\text { certificate / degree }\end{array}$ \\
\hline $\begin{array}{ll}20+: & 36 \% \\
10+: & 27 \% \\
10-: & 36 \%\end{array}$ & $14 \%$ & $55 \%$ & $31 \%$ \\
\hline
\end{tabular}

Table 9-7: Interview data in percentage on professional qualifications in special education from special school teachers $(\mathrm{N}=22)$

Most of the special school teachers received little or no training in special education with some having no teaching qualification or degree to start their career. Of those interviewed $(\mathrm{N}=22)$, about $55 \%$ had teaching qualifications to start teaching either within mainstream or special schools. Among them, only $14 \%$ were initially trained on special education. 3 cover teachers $(14 \%)$ in one special school did not have any teaching certifications by the time of my field 
work. This is in contrast with industrialized countries where individuals pre-qualify for entry into the teaching market conditional on certifications from the state authority and/or holding a graduate degree in education (Smith, Pion, Tyler and Gilmore, 2003; Yu, 2008).

Below is quoted from the interview with a teacher having no teaching qualification, no training or willingness to start teaching in the special school for children with speech and hearing impairments after she graduated from her middle school. She got the job as a replacement of her mother who was then retiring from her teaching post. According to the government policy, she was assigned to the school, given that she had showed her unwillingness towards the assignment.

Interviewer: So did you choose this school?

Interviewee: Well, what shall I say? You can erase this part after listening if you want. Actually, at that time we did not want to be teachers. I did not like to be a teacher. At that time, we had to take entrance exams for universities. I did that and I got marks 6 points lower than the mark for universities.

At that time, banks held exams for those people who missed universities. I took that exam and I got good marks. They liked those who could not go to universities. They wanted me and I wanted to go. But the local education authority said that I could not go to the bank just because my mother was a teacher. I could only go to a school. I was surprised to hear the news. I asked why? But... I did not like to be a teacher. Teachers had low social status. I had no way. I did not like to be a teacher. But my mother encouraged me. So I said that I could go to a school but I did not want to teach. The education authority said that I could be an accountant. I said fine.

At that time this school wanted a teacher, a young teacher. The education authority said that they could choose from the candidates. The leader of the school chose me. I really did not want to come to this school. I was afraid of people who were deaf and dumb. They promised me that I could leave after one year. There was another school, ... Middle School. My father was a teacher in that school. They said that after one year, their accountant would leave the school so that I could have that vacancy. I said fine. So I came to this school. After one year, I did not bother to change... That is alright. When I came here, I was a teacher and an accountant. But I worked as an accountant. Now I am no longer working as an accountant. I am a teacher. I have been a class teacher for 8 years. I have been teaching Math all these years.

I-ST-12

\subsubsection{Student teachers and malnstream school teachers' professional qualifications in special and Inclusive education}

The survey data show that, some student teachers expressed confidence in teaching in special schools, although they were qualified to teach in mainstream schools. According to the School of Education of the University researched, very little on special and inclusive education had been integrated in the curriculum of the training programmes all these years. No student teachers were placed in any 
special schools during their 6 weeks of teaching practice. No school observation was organised for them in special schools.

Moreover, none of the mainstream school teachers interviewed $(\mathrm{N}=22)$ have had any form of training on special education, despite that some are now having children with diverse SEN in their classes. The interviewees identified issues within educational provisions in that they felt helpless in managing the challenging needs with their limited understanding and expertise coupled with inadequate resources at their disposal.

\subsubsection{Knowledge and understanding of special and inclusive education}

\subsubsection{Knowledge and understanding of special education}

The mainstream school teachers and student teachers researched had limited knowledge and understanding about special and inclusive education. Table 9-8 presents the survey data from mainstream school teachers and student teachers.

\begin{tabular}{|l|l|l|}
\hline $\begin{array}{l}\text { SQ-3: How do you understand special } \\
\text { education? }\end{array}$ & $M T(N=110)$ & US (N=404) \\
\hline Do not know & $N=21(19 \%)$ & $N=59(15 \%)$ \\
\hline No comments & $N=3(3 \%)$ & $N=11(3 \%)$ \\
\hline Negative responses & $N=7(6 \%)$ & $N=14(3 \%)$ \\
\hline $\begin{array}{l}\text { Never had a chance to learn / Never cared } \\
\text { about it }\end{array}$ & $N=8(7 \%)$ & $N=7(2 \%)$ \\
\hline Total & $N=39(35 \%)$ & $N=91(23 \%)$ \\
\hline
\end{tabular}

Table 9-8: Survey data in percentage from the mainstream school teachers and student teachers: How do you understand special education?

Among the mainstream cohort ( $N=326), 100$ of them did not answer any of the open-ended questions (34\%). The remaining 226 had full or partial answers. 110 teachers answered this question. About 35\% had either no knowledge or negative attitudes towards special education. It is important to note that many answered the question with positive attitudes without providing any understanding or interpretation of it. For example:

It demands more care and patience from teachers. It needs the attention from the whole society. In China all these are lacking.

Or: 
The rest gave their varied understandings such as:

It is to special students. They are the ones who have mental problems and have difficulties in study.

QS-MT-96

Special education is only for special schools

QS-MT-63

Whilst among the student teachers $(N=565), 91$ out of 404 answered this question with either no knowledge of or negative attitudes towards special education $(23 \%)$. The remaining held positive attitudes even without any interpretation of what special education is. For example:

It is necessary to have more special schools. At present, the curriculum is limited and students do not learn a lot that will be needed in their future.

QS-US-238

The rest gave their varied understandings such as:

...The education for the rich people.

QS-US-326

It is the education for children with physical disabilities.

QS-US-158

In contrast, 35 out of a total of 37 teachers from special schools answered the question with more details compared with the other two cohorts. Although some did not explain how they understood it but just giving their attitudes towards it, others showed better understanding comparatively.

The children in special education are disabled. It urges teachers to be more caring and hard working. Though the teaching content is not demanding, the compensate education for the abilities needs teachers to be highly specialised and skilled. It is a job which needs caring, passion and it is the job for great achievement. 


\subsubsection{Knowledge and understanding about inclusive education}

Table 9-9 presents the survey data from mainstream school teachers and student teachers on inclusive education.

\begin{tabular}{|l|l|l|}
\hline $\begin{array}{l}\text { How do you understand inclusive } \\
\text { education? }\end{array}$ & MT (N=97) & US (N=387) \\
\hline Do not know & $\mathrm{N}=41(42 \%)$ & $\mathrm{N}=8(2 \%)$ \\
\hline No comments & $\mathrm{N}=3(3 \%)$ & $\mathrm{N}=88(23 \%)$ \\
\hline Negative responses & $\mathrm{N}=12(12 \%)$ & $\mathrm{N}=39(10 \%)$ \\
\hline $\begin{array}{l}\text { Never had a chance to learn / Never } \\
\text { cared about it }\end{array}$ & $\mathrm{N}=1(1 \%)$ & $\mathrm{N}=14(4 \%)$ \\
\hline Total & $\mathrm{N}=57(58 \%)$ & $\mathrm{N}=149(39 \%)$ \\
\hline
\end{tabular}

Table 9-9: Survey data in percentage from the mainstream school teachers and student teachers: How do you understand inclusive education?

Among the mainstream school respondents $(N=326) 57$ teachers $(58 \%)$ expressed their lack of knowledge about or negative attitudes towards inclusive education. Another 12 teachers (3\%) thought it was positive and negative to promote inclusive education in China, which indeed should be the answer to the last question asking about their comments. Similar to the answers about special education, to this one, teachers' understandings varied. Below are some examples:

It depends on the economic conditions of families or areas they are in.

Positive and negative. Students grow up in the common situations. But maybe teachers do not have time to care for them.

Good. But do not ask me to teach them.

Whilst among the university respondents $(N=565), 149$ out of 387 answered this question with either no knowledge of or negative attitudes (39\%). The remaining held both positive and negative attitudes $(N=12)$. Still others showed their positive answers without any understanding or interpretation of it. However, some student teachers seemed to be more concerned. For example: 
It is not reasonable. It is not fair to children with SEN. Because in the eyes of normal children, children with SEN are different, it will not ensure that children with SEN will be treated fairly in mainstream schools.

Inclusive education means to include children with special needs with all the other children so that children with SEN will feel they are like others. They can be in schools with normal children. But at present, they are bullied and laughed at and looked down upon.

Despite the fact that 6 teachers from the special schools did not know about inclusive education (18\%), the rest answered the question in more detail. They showed better understanding of it as opposed to the other two cohorts, although some did not explain how they understood it but just expressed their attitudes. Inclusive education is necessary in remote areas as education there is
undeveloped and there is a scarcity of teachers.

There are at present two concepts for inclusive education. Broadly, it means more involvement of students and less exclusion. Narrowly, it means to include children with special needs to mainstream schools. The reform for inclusive education can be in the education equity and multiplicity.

QS-ST-25

\subsubsection{Attitudes towards special and inclusive education}

\subsubsection{Mainstream teachers' perceptions on teachers in special schools}

Asking about mainstream teachers' attitudes towards teachers working in special schools, as I anticipated, almost all the interviewees showed their respect to teachers in special schools, believing that they had a loving heart; they were patient, caring and having strong senses of responsibility to the society. Some put it:

I really respect them. It needs patience. It is not just for a day, a month, it would be years...

Still others believed motivation was related to gender differences.

Females may have better motivation as they are mothers 
Well, this, I do not think we [male] should. First, the nature of it, second, a male teacher teaches in that kind of school?! I really think... You need patience. As a man, I will feel really bad. If I have to go for a year or two, I will. If this is the contribution, I will make the contribution. But if I have to teach there for all my life, I will not contribute my whole life. No!

\title{
9.2.4.2 Special school teachers' self-perceptions of their professional identities and social status
}

Special school teachers were interviewed about their perceived identity and social status to make comparisons with the perception of them from their mainstream peers. The following is from a teacher with long years of work experience about her feelings towards the local educational authority's attitudes towards special education.

Teachers from mainstream schools would say: you are just like that. I have also heard educational authorities said things which made me feel not happy.

This quote is reported here as it is a typical reply by the special school teachers interviewed about how they were judged by the society:

Not directly. But people think that we do not have pressure working in the special school. We only take care of the children. They think we do not have the abilities. They think it is much easier to teach children in special schools.

The next quote is also echoed by many interviewees regarding their social status as teachers in special schools.

\begin{abstract}
At that time, I did not even want to tell people I worked in this school. Because you know, we felt bad. We are different. When I was transferred to this school, people asked me where I was teaching and I told them. They did not know anything about the school. They just felt, well, such a school, well. Now I am used to it. But at the beginning, I felt ashamed of myself working in such a school. The society did not value this...After all these years...
\end{abstract}

\subsubsection{Comments on special and Inclusive education in China}

Again, the data here indicate that the majority of the mainstream school teachers $(87 \%)$ showed their limited understanding and negative attitudes. 
Do not know about special education in China. Inclusive education will lose its popularity under the pressure of all kinds of exams.

Table 9-10 presents the survey data from mainstream school teachers and student teachers' comments on special and inclusive education in China.

\begin{tabular}{|l|l|l|}
\hline $\begin{array}{l}\text { Perspectives on special and inclusive } \\
\text { education in China }\end{array}$ & $\mathrm{MT}(\mathrm{N}=87)$ & $\mathrm{US}(\mathrm{N}=390)$ \\
\hline Do not know & $\mathrm{N}=28(32 \%)$ & $\mathrm{N}=87(22 \%)$ \\
\hline No comments & $\mathrm{N}=23(26 \%)$ & $\mathrm{N}=177(45 \%)$ \\
\hline Negative responses & $\mathrm{N}=21(24 \%)$ & $\mathrm{N}=32(8 \%)$ \\
\hline $\begin{array}{l}\text { Never had a chance to learn / Never } \\
\text { cared about it }\end{array}$ & $\mathrm{N}=5(5 \%)$ & $\mathrm{N}=2(1 \%)$ \\
\hline Total & $\mathrm{N}=77(87 \%)$ & $\mathrm{N}=298(76 \%)$ \\
\hline
\end{tabular}

Table 9-10: Survey data in percentage from the mainstream school teachers and student teachers: Do you have any comments on special and inclusive education?

The student teachers (76\%) showed similar negative feelings.

To be exact, I do not know much. I had seen in ordinary schools children with mental retardation. Other children laugh at them and bully them instead of helping them. This is hurting to those children. They become more silent. Teachers showed their indifference. They have no way to help. I guess this kind of situation can be seen in many parts of China. There is not enough management and improvement.

QS-US-62

At least in the cities I live and study, I have not heard of inclusive education whilst special education is not being seen as important.

Among 32 teachers from special schools who answered this question, only 4 made no comment (12\%). The rest varied in their opinions.

We have to be practical in doing anything. We should not focus on form. We have to be practical. Form is not important.

Considerable reservations were expressed about the feasibility of inclusion, based on the types and severity of children's difficulties and the capacity of mainstream schools to meet them. The most frequently expressed criticism related to levels of resources. This is similar to the findings of Croll and Moses (2000). There were concerns expressed by teachers for the perceived number of children failing in 
their academic studies or disturbing others in schools.

\subsection{Teacher professional development in special and inclusive education}

This section of the chapter discusses findings on teachers' perspectives on professional development in special and inclusive education. This consists of the key themes such as their awareness assessment on professional development in terms of more learning and training in special and inclusive education; chances, opportunities and support available; and their perspectives on self involvement in their professional development.

It has to be noted that the research did not aim to assess teachers' understanding of the concept 'professional development'. I assumed that their interpretation of the concept would vary. Most probably the interpretation would be related to different training models rather than considering it in a more holistic way. My purpose for collecting data with this regard was to encourage their reflection on their career life as professionals. Thus, the data to be reported do not have a set definition to gulde or regulate teachers' thinking. Instead, the teachers enjoyed the freedom in articulating their perspectives whilst $I$, as the researcher, had the opportunity in constructing the knowledge with their varied perspectives of professional development in special and inclusive education.

\subsubsection{Key findings of teacher professional development in special and inclusive education}

- The three cohorts had high awareness of the need for professional development and strong motivation for learning about SEN. Among the three, the special school cohort showed the highest positive percentage $(95 \%)$. However, only half of the special school teachers would like to fund themselves for further education. The percentage from the mainstream cohort is a bit higher (60\%) in this respect.

- A higher percentage of teachers from special schools (95\%) suffered from work related stress as opposed to a slightly lower percentage of mainstream teachers ( $89 \%$ ). Most of the teachers acknowledged that their schools valued professional development. Whilst they were largely satisfied with the support from their schools, about half of them were not satisfied with the in-service training programmes offered by their schools. 
Over half of the two cohorts identified that the schools did not provide them with support in time and finance for professional development. Besides, over half of them are not satisfied with the provisions the schools offered to children with SEN.

\subsubsection{Teachers' awareness assessment of and motivation for professional development}

As has been reported in the previous part of this chapter, most of the mainstream school teachers and student teachers researched lacked the confidence and competence in teaching in special and inclusive schools. The findings from the surveys on their self evaluation of the need for more training about teaching children with SEN are consistent In that a high awareness of the need and motivation for professional development was keenly felt from the three cohorts. In particular, the highest awareness was demonstrated in the special school teacher cohort whilst the other two cohorts had the similar degree of awareness. Table 9-11 presents the findings from the surveys on teachers' awareness of and motivation for professlonal development.

\begin{tabular}{|l|l|l|l|}
\hline Agree and strongly agree & MT & ST & US \\
\hline $\begin{array}{l}\text { In the future I believe I will have a need for } \\
\text { more training about teaching children with } \\
\text { SEN }\end{array}$ & $\begin{array}{l}(\mathrm{N}=326) \\
72 \%\end{array}$ & $\begin{array}{l}(\mathrm{N}=37) \\
95 \%\end{array}$ & $\begin{array}{l}(\mathrm{N}=564) \\
73 \%\end{array}$ \\
\hline $\begin{array}{l}\text { I would like to learn more about special and } \\
\text { inclusive education }\end{array}$ & $\begin{array}{l}(\mathrm{N}=326) \\
72 \%\end{array}$ & $\begin{array}{l}(\mathrm{N}=37) \\
95 \%\end{array}$ & $\begin{array}{l}(\mathrm{N}=560) \\
76 \%\end{array}$ \\
\hline
\end{tabular}

Table 9-11: Survey data in percentage from the three cohorts on the awareness of and motivation for professional development.

The findings from interviews with this regard are more or less the same. On the one hand, the inadequate learning in initial teacher education programmes had an impact on teachers' motivation for their career. But having children with SEN in mainstream classrooms did not directly influence some mainstream teachers' career motivation. On the other hand, they felt they needed training. By this they meant professional development.

\subsubsection{Perceptions on the models of professional development}

The mainstream school teachers researched commented on the models of 
professional development with varied perspectives. It is understandable that their previous education, commitment in their career, the schools they were in and the students they taught were all variables that should be taken into consideration in understand their perspectives. Particularly, newly qualified teachers would like to have the training in teaching methodology. The following is quoted from a teacher in a mainstream school.

\begin{abstract}
...Teaching methodology. I did teaching practice in a senior school and I am now teaching in a junior school. I had no idea at the beginning. I am new. I do not know what to prepare. I do not know what to teach to a junior middle school student, what they have learned in their primary school, no ldea. I use the method for senior student in junior class. So till now, I can not see the improvement. So for new teachers, the method is the most challenging and most needed.
\end{abstract}

The other teacher interviewed at the same time, but with more teaching experience, disagreed with her in this respect.

You represent new teachers. For us, the research method is needed. I would like to reflect on the experiences from the years' teaching and would like to have them published. In fact, we had some training in this respect. But still I feel I need that.

Yes. They [the school] invited teaching experts to teach in this school. The experts are our mentors. We learn a lot from them. The school spends lots of money inviting experts. We can also go out of campus to learn new things...two ways. We had Professor ... to give lectures here. Those teachers who had a chance to observe other teachers' classes in other schools, had to teach a lesson to show that they had learned something and benefited from the observation when they came back. The school paid the money for the training.

Still others talked about professional development in terms of learning different teaching methodology.

I used to work in public [government run] schools for 4 years. This is my 8th years. In that school, we taught with a book and a piece of chalk. Here we use multi-media.

Some expressed their attitudes towards the models in a negative way in that they identified that the models lacked overall planning for individual teachers.

It [Professional development] is very important. At the moment, there can be the development all round. In many aspects, if we develop, then we can transfer to the students...Generally speaking, yes, though there lacks an over-all planning for 
teachers, a long-term planning for teachers, like in how many years you should reach which target....

One teacher also expressed his dissatisfaction towards the contents and delivery of the programmes.

Now we have further education. But it is very superficial. We went for the training and we just wanted to leave the first minute. The school arranged us to go. But I do not think it had great effect on us...The content was not interesting. It was not practical, not vivid. It was not what we wanted to learn. For example, if it was about internet, how to use PPT, we would like to listen. We could use it in teaching. Or if it was about research writing, we would be interested. But it was much theory based, very ideal. Professors gave us lectures. No teachers from junior schools were invited to teach.

I-MT-13

\subsubsection{Teachers' perspectives on chances and opportunities for professional development}

Most of the teachers agreed that more importance had been attached to teacher professional development in terms of chances and opportunities. They perceived positive changes in respect of the provision of training opportunities within the locality, which were both personally and professionally focused (Table 9-12). However, my observations during the school visits provided evidence of differences between teachers who had been and are still actively involved in professional development programmes and those who are not.

Since I became a teacher, I have had different kinds of training. I spent a lot of time and energy... They gave us financial support. They sent me for training... Most of the time, we observe good teaching, methodology training, all kinds of activities, lectures, discussions... the longest one lasted one month.

The findings from the interviews show that schools differed in the provision for professional development for teachers. Whilst in some schools teachers had opportunities for full-time learning, though normally in days or weeks, in schools or universities in other cities, for others, chances were very slim.

Yes, basically... and also the way for learning, observations, evaluations. But it is mostly school based. There is nobody being sent for training except for those so called 'backbones'... you know that ... [laugh] 


\begin{tabular}{|l|l|l|}
\hline Agree and strongly agree & MT & $\mathrm{ST}$ \\
\hline $\begin{array}{l}\text { My school values teachers' professional } \\
\text { development }\end{array}$ & $(\mathrm{N}=326) 82 \%$ & $(\mathrm{~N}=37) 86 \%$ \\
\hline $\begin{array}{l}\text { My school does not provide teachers with } \\
\text { enough time for professional } \\
\text { development }\end{array}$ & $(\mathrm{N}=326) 62 \%$ & $(\mathrm{~N}=37) 55 \%$ \\
\hline $\begin{array}{l}\text { I am satisfied with the support from my } \\
\text { school in my professional development }\end{array}$ & $(\mathrm{N}=326) 60 \%$ & $(\mathrm{~N}=37) 76 \%$ \\
\hline $\begin{array}{l}\text { I am satisfied with the in-service training } \\
\text { programmes offered by my school on } \\
\text { special education }\end{array}$ & $(\mathrm{N}=326) 49 \%$ & $(\mathrm{~N}=37) 49 \%$ \\
\hline $\begin{array}{l}\text { I am satisfied with the support from } \mathrm{my} \\
\text { school in teaching children with SEN }\end{array}$ & $(\mathrm{N}=326) 66 \%$ & $(\mathrm{~N}=37) 78 \%$ \\
\hline $\begin{array}{l}\text { I am suffering from the stress related to } \\
\text { my work at school }\end{array}$ & $(\mathrm{N}=326) 89 \%$ & $(\mathrm{~N}=37) 95 \%$ \\
\hline $\begin{array}{l}\text { I would like to fund myself for further } \\
\text { education }\end{array}$ & $(\mathrm{N}=326) 60 \%$ & $(\mathrm{~N}=37) 51 \%$ \\
\hline
\end{tabular}

Table 9-12: Data in percentage of the close-ended questions from the survey to the three cohorts on teachers' perceptions on the chances and opportunities for professional development.

\subsubsection{Motivation for professional development}

The interview data show that schools and/or the local educational authority had orgainsed some compulsory training for teacher professional development. Comments on the models reveal that they influenced teachers' motivation in taking part in professional development training opportunities.

If we do not have enough marks from study, it will have an impact on our promotion or bonus. They [the local educational authority] want us to get marks. They do not do other things afterwards. Reform is needed. Sometimes, they wanted us to write a report. We wondered if they ever read our reports.

Asked whether the availability of training had any impact on their motivation in teaching, one teacher from a mainstream school provided the following answers:

Well, I will have some complaint. But the feeling will not last... I do not think it will have an impact. If there are other reasons, maybe I will. Today, the training can also be done by web surfing.

For some, professional development was a chance for them to get promoted 
or leave teaching.

When I came here in 1996, I did not know that after two years, I would be studying some bachelor degree courses. From 2005, in the city, the Education Authority said, I was told that if we could get enrolled in MA programmes, they were going to pay 10,000 Yuan [less than 1,000 pounds] as encouragement. I have got into a programme. Anyhow, this can be a way for me to leave the teaching line once I get a degree.

For others, motivation for professional development changes over time, dependent on the availability of support and life priority. The interview with Case I reveals that, initially, she had strong intrinsic motivation in learning and development as she started teaching in the special school for children with speech and hearing impairments without even a degree or certificate. In her career life, she was very keen on learning. However, she had only a few chances of training away from her school, basically on a short time basis with the longest being a week or so for the last 30 years. At the time of the research, the teacher had lost all her interest. In her words,

\begin{abstract}
The younger teachers should have the training. I am going to retire. The school sees no point spending any money on me. They [the school] should have done that when I was young. But you know, when I was young, the school gave chances to those who had no training at all before they joined our school. Compare with them, I was experienced. So I was opted out. Well, I don't really mind. I see myself just as a teacher in such a small school. People see me this way, anyhow. I have lived my life like this. My son is in a university. My husband [who has also worked in the school for 30 years] has some interest in learning and development. I am waiting to get retired.
\end{abstract}

The other case from the mainstream school cohort (Case II) reveals the opposite perspectives. This teacher was identified as a case for the narrative enquiry which allowed me to investigate in depth her perspectives related to the research topic. In the research process, I had ample time observing her professional behavlour as a teacher and discussing with her about my research. She had a couple of times in her 30 years' career life being sponsored fully (In terms of time and finance) by the governments of different levels for short and long term professional training. This was very unusual for most of the teachers in schools. In this sense, she belonged to the lucky ones or the 'llmited few' as described by other interviewees. Her intrinsic motivation for her career and professional development together with her very positive attitudes towards inclusive education convinced me that the assumed correlation of the three key themes did exist. 


\section{Chapter Ten: Discussion (I)}

The core findings of the study are discussed in three subchapters according to the three key themes, namely, teacher career motivation for, knowledge, understanding of and attitudes towards special and inclusive education, and teacher professional development. This chapter provides a detailed analysis of the key motivational factors on teacher career choice with regard to historical, political, socio-economic and cultural contextual influences. This is preceded with an examination of the findings on the quantity and quality of special and inclusive education teachers. In the process of constructing meaning and knowledge, my personal reflections and interpretations of the findings in terms of the application of SDT model are also presented in this chapter.

\subsection{Quantity and quality of teachers in special and inclusive education in the current study}

Motivation for teaching in special and inclusive schools is a serious concern which could arguably have a direct impact on the quantity and quality of special education teachers. For a better understanding of teacher career motivation, it is necessary to discuss briefly this issue in China before multiple factors influencing teacher career decisions are discussed.

Different from many other countries, where teachers cannot have a teaching job unless they reach the qualification level or hold an appraisal certificate, In China, a large number of teachers used to be recruited with the minimum required qualification for teaching (LI, 1999). Although the central government of China is the most powerful authority in the governance structure of teacher education, its policy initiatives on reforming teacher education are difficult to implement to the same degree due to the huge discrepancies nation-wide between cities and rural areas (Zhou and Reed, 2005).

\subsubsection{The use of cover teachers (Dalke teachers)}

At present, Chinese government documents have made it mandatory that prospective teachers cannot get a permanent teaching position unless they reach the qualification level or hold an appraisal certificate before their application. However, the use of 'under qualified' teachers still persists. Local governments in 
economically or geographically disadvantaged areas are still employing cover teachers (Daike teachers in Chinese) to solve problems of teacher shortage or financial constraints (Robinson and $\mathrm{Yi}, 2008$ ). This can be that qualifled teachers are reluctant to work there or employing authorities cannot afford to hire them. These teachers holding temporary posts, known as 'Daike' teachers, are not part of the government's establishment of school staffing (Robinson and YI, 2008:36). They can be unqualified teachers employed on a 'temporary' basis or qualified teachers employed on the same terms and conditions as unqualified teachers. The rationale for using them is due to the lack of funding to support sufficient government-funded posts, and a shortage of available teachers in rural and remote areas. It is less so in other geographical regions, as identified in England and Wales (Gorard, See, Smith and White, 2007) where a general crisis in teacher recruitment and retention over the past decade is not keenly felt.

In China, local educational authorities have the strict control over the number of staff in schools, otherwise known as 'registered staff' (Blan $\mathrm{Zl}$ in Chinese). They are paid by local authorities. Schools are obliged to abide by the Bian $\mathrm{Zl}$. There is nothing schools can do to recruit more teachers without the consent from the authorities unless the schools can afford the payment for the extra teachers/staff they employ. The central government has been urging local governments to employ only qualified teachers for quality assurance. Given that the government statistics do not necessarily reveal the real scale of the problem of nongovernmental teacher employment (Robinson and $\mathrm{LI}, 2008$ ), till now, some local authorities or schools still have to take in cover teachers.

\subsubsection{The use of cover teachers (Daike teachers) In the speclal school for children with learning difficulties}

The documents of the seven mainstream schools researched show no employment of cover teachers owing to the government policy initlatives over the past two decades to maintain the quantity of teaching force In basic education, if not the quality. The use of the Daike teachers in the special school for children with learning difficulties was due to the shortage of qualified teachers with initial special education training in special education. This is evidenced by the fact that the number of teachers with the training was insignificant (only 3 out of 22 teachers in my interviewees). This well explains that, despite the great progress in professionalising the teaching force in the research context locally and provincially, the relatively unfavourable conditions in special schools have caused 
the persistence of the dual-track practice. According to the headteacher, the school was severely short of staff. They had to employ 3 Daike teachers to cover the registered staff vacancies. Besides, the local government had a tight budget which inhabited the ability to allocate as much as expected to the special school.

\subsubsection{Quality of teachers in special and Inclusive education}

The quality of teachers in relation to the sources of students for teacher education is a further and bigger concern under the new economic system (Yang and Wu, 1999:168; Smith, et al., 2003; Tyler, Smith and Pion, 2003). Although Chinese government has repeated its policy of encouraging talented young people to join teaching, the quality of students remains low as opposed to other professions. This is because students with good academic attainments are more interested in professions with a better income.

Although my research was not designed to investigate the quantity of teachers for inclusive education in the seven mainstream schools, the interview data show that no teacher had any formal training in special and inclusive education. Most of them were experiencing challenges in having children with SEN in their classes. It is evidenced through observations and document scrutiny that there were no teaching assistants (TAs) or SEN coordinators (SENCOs) available as TA or SENCo are yet to be introduced to school systems in China either as a concept or in practice.

Whilst the student teachers were leaving for their teaching post at the time of the field work, according to the School of Education of the University, none of them were given compulsory or optional modules on special and inclusive education in their four-year's study. It was explained that no teacher trainers in the school had any formal learning which could qualify them in teaching about special and inclusive education. In the special schools, on the other hand, the findings reveal that very few teachers had initial training on special education (14\% of the 22 interviewees).

In 2005, we had 5 teachers joining us, with bachelor degrees...but none of them learned anything about speclal education... We have only a few teachers graduated from special education colleges, only a few. They actually were not all specialised in speech and hearing impairments. Some studied mental retardation. They could not meet the needs in the classrooms. 
Nevertheless, this was not seen as a serious issue. Based on her own experience, the former deputy head of the school for children with learning difficulties believed that as long as teachers were patient, caring, loving and enthusiastic, they could teach with some support from teaching mentors and some senlor staff members.

One does not have to have rich knowledge to teach here. If you have had primary school education, you can teach here. Now teachers will special education knowledge are needed. But at that time... now they [the school] want teachers to have degrees and I am behind them.

Given that quality is not regarded as important due to some commonly held beliefs that children with SEN need love and care more than education (more discussion in the next chapter), motivation is prioritised. This finding agrees with (Cameron, Baker and Lovett, 2006) that if a teacher is motivated, loving the teaching profession, the students not only learn the content taught by the teacher but are also motivated toward learning. Investigating into teachers' initial career motivation illuminates how teachers made sense of their decision and identifies the motivational factors that are most salient for teachers. It is important to understand the components involved in the construction of motivation to become better motivated and remain so. However, literature on the motivation for teaching in special and inclusive education in the context in China is not widely explored, thus providing little knowledge.

\subsection{Teacher career motivation in special and inclusive education}

\subsubsection{Teacher career motivation In general}

The ranking of motivation for selecting a job varies from individuals and contexts in many countries. Research finds that in Japan, China and Germany, most school teachers enter the teaching profession as a lifelong career (Su, 1997). The study by Addison and Brundrett (2008) indicates that the principal motivators for teachers include positive responses from children and staff experiencing a sense of achievement. This reassuringly reflects the traditionally held view that teachers teach to see children achieve.

Other research (Hughes and Manuel, 2006) finds that a majority of student teachers in Australia make the decision to teach based on reasons that reflect 
personal aspirations to work with young people to make a difference in their lives; to maintain a meaningful engagement with the subject area they are drawn to; and to attain personal fulfilment and meaning. Anthony and Ord (2008) explore what or who motivates people to change their occupational paths and enter the teaching profession in New Zealand. They look at how these teachers' motivation and prior experiences impact on early and long-term career expectations and intentions. The matrix of reasons involves a range of factors related to previous work and family experiences, values and task expectancies. Other studies identify that the two main factors are money, which males prioritise, and enjoying the work itself, which females prioritise. These two primary reasons are followed by doing something they are good at, then intrinsic motivation to be followed by feeling satisfied and to achieve something (Kniveton, 2004).

\subsubsection{Teacher career motivation in my study: a comparison with international literature}

There is some evidence from my study of intrinsic motivation in teachers' career choice. However, my findings differ from the majority of the research (Edmonds, Sharp and Benefield, 2002, Younger, et al., 2004:247) that teachers are attracted to the profession largely for intrinsic reasons related to the profession itself and to personal fulfilment. Furthermore, the motivational factors from my findings are not robust altruistic ones as identified in previous studies (Kyriacou, Hultgren and Stephens, 1999; Manuel and Hughes, 2006; Richardson and Watt, 2006) that participants are strongly influenced by enjoying the subject they would teach, liking to work with children, and the fact that teaching could enable them to use their subject. In short, instead of perceiving intrinsic, altruistic and Interpersonal features as strong career-specific motivators (Cooman, et al., 2007), the findings of my study are more broadly in line with other studies in that the labour market is the prime impetus for working whilst the desire to help people with special needs is not foremost (Hausstatter, 2007). Extrinsic factors play a concerted role in terms of material reward or financial benefit (Kniveton, 2004; Wang, 2004), professional identity (Day and Kington, 2008), parental and family expectations (Oyserman, et al., 2002) and gender (Siniscalco, 2002).

The findings from the current study reveal some key issues reflecting a specific Chinese context with distinctive Chinese characteristics. Teachers' motivation for joining special education was multi-faceted, which included political, historical, socio-economic and cultural factors. The findings are consistent with the research 
(e.g., Lent, Brown and Hackett, 1996) that cross cultural factors are important contextual determinants. In the US, the persistent challenge of avallability of qualified personnel could be the result of a higher demand in special education (as opposed to general education) and a significantly low annual supply of new graduates trained in special education (Katsiyannis, Zhang and Conroy, 2003). In China, research (Guo and Shi, 2004) identifies that most of the student teachers originally from countryside areas choose to be special school teachers for salary purposes. Guo and Shi's research indicates that student teachers from cities avoid choosing special schools as they are more reluctant to work in special schools, especially those located in the countryside areas. Moreover, teachers are motivated principally by 'well-behaved, interested and motivated children' but in general become less well motivated as they get older, when they are more likely to become demotivated by 'long hours and high workload' (Addison and Brundrett, 2008;89). This appears to be confirmed by the findings from this study that fewer senior teachers are better motivated than those in middle management positions.

\subsubsection{The application of SDT model in my study}

Most of the special school teachers in my study started teaching with extrinsic motivation with controlled regulation while still some showed their amotivation (see Table 9-3 of the Finding chapter). Obviously motivation changed over time. Whereas some of them had developed a sense of altruism; quite a significant number of them were still at the controlled end of the spectrum of extrinsic motivation continuum (Ryan and Deci, 2002). Comparatively, data from the mainstream teachers and student teachers did not show any hard evidence of amotivation. But there lacked an intrinsic motivation from the two cohorts in working in special and inclusive education given that student teachers were better motivated to teaching than mainstream and special school teachers.

According to Gagne and Deci (2005:335), SDT posits a self-determination continuum ranging from amotivation, which is wholly lacking in selfdetermination, to intrinsic motivation at the other end of the spectrum, which is invariantly self-determined. In between is extrinsic motivation in four types, with the external being the most controlled or least self-determined, and intro-jected, identified and integrated being progressively autonomous and more selfdetermined. Intrinsic motivation (Gagne and Decl, 2005: 334) is an example of autonomous motivation. When people engage in an activity because they find it 
interesting, they are doing the activity wholly volitionally. In contrast, the use of extrinsic rewards in the early experiments is found to Induce controlled motivation (e.g., Deci, 1971). Being controlled involves acting with a sense of pressure, a sense of having to engage in the actions (see Chapter Three for more detailed rationale).

Below is a detailed discussion about the three cohorts' career motivation in special and inclusive education (Figure 10-1). Within this, Ryan and Deci's SelfDetermination Theory (SDT) $(1985,2002)$ is applied.

\begin{tabular}{|l|l|l|l|}
\hline Type of Motivation & Amotivation & Extrinsic Motivation & $\begin{array}{l}\text { Intrinsic } \\
\text { Motivation }\end{array}$ \\
\hline Type of Regulation & $\begin{array}{l}\text { Non- } \\
\text { regulation }\end{array}$ & $\begin{array}{l}\text { External regulation- } \\
\text { Introjected regulation- } \\
\text { Identified regulation- } \\
\text { Integrated regulation }\end{array}$ & $\begin{array}{l}\text { Intrinsic } \\
\text { regulation }\end{array}$ \\
\hline Quality of behaviour & $\begin{array}{l}\text { Non-self- } \\
\text { determined }\end{array}$ & & Self-determined \\
\hline
\end{tabular}

Figure 10-1: Self-Determination Continuum (Ryan and Deci, 2002:16)

In the process of data analysis and interpretation, I realised that the career motivation of teachers was so complicated that three major categories, even with the continuum (Ryan and Deci, 2000b, 2002) were not sufficient for explanation. Besides, I was highly mindful that teachers, in their reflective accounts might have contained or missed some critical elements which did not have a clear cut border-line between the categories of motivation. Therefore, in the discussion, I purposefully put the extrinsic and amotivation together so that a better understanding can be achieved of whether teachers were still in the line of special education despite their unwillingness. This is done for the same reason that in the discussion of intrinsic motivation, integrated forms of extrinsic motivation are mentioned as they share many qualities (Ryan and Decl, 2002:62).

For example, over half of the student teachers were extrinsically motivated $(\mathrm{N}=217)$ with a contrast to $72 \%$ of mainstream and $76 \%$ of special school teachers. The extrinsic motivation varies from more controlled regulation to less controlled and more autonomous regulation (Decl and Ryan, 2008). That is: when some teachers started working in special schools, they were 'forced' by extrinsic motivation as they had 'no choice' but needed to take the job for 'making a living' 
(A more detailed explanation of the motivational factors is to be given in the next part of the chapter). Nevertheless, their teaching experiences enhanced their motivation. Although still extrinsically motivated, there was a transition of motivation from the spectrum of very controlled to less controlled and more autonomous.

In some cases, some altruistic motivation identified in Richardson and Watts $(2005,2006)$ is considered as intrinsic motivation in this study. In addition, some extrinsic motivation like social status, salary, work-related stress and city dwelling policy are perceived as motivators or de-motivators by diverse participants.

\subsection{Key motivational factors contribute to teacher career choice in this study}

The research identified some critical issues in the motivation of teachers in their choice of working in special and inclusive education in the Chinese context. Unlike individually oriented Western cultures, in China, collective culture emphasises group conformity and mutual obligations, where community goals and ethics are placed above personal goals and competencies (Oyserman, Coon and Kemmelmeier, 2002). Career choice is thus less related to personal rights, wellbeing of the self and immediate family, personal autonomy and accomplishments but more to the work context factors (Frase, 1992; Herzberg, Mausner and Snyderman, 1993). Besides, with Its Confuclan past, Chinese society recognises the importance of teachers. However, teaching in China has often been a less distinguished profession (Paine and Fang, 2007:21). Factors influencing teaching choice from the current study are as follows:

First of all, for some of the researched, intrinsic motivation is percelved as: 'childhood dream', 'interested in teaching' and 'like teaching/children'. Secondly, for the majority, motivational factors are extrinsic, such as: 'no-option' because of the academic scores but to abide by the government's recruitment policy, 'rural urban migration', 'substitute for retiring parent in work organisations', 'financial constraints', 'social status', 'professional Identity', 'job satisfaction/stress' and 'family influences'. Finally, amotivational factors are not clarified but are accounted generally by some, especially those working in special schools as 'I did not want to teach there' or 'I did not want to be a teacher'. In a word, the key motivational factors contributing to teacher career choice reflect the specific historical period of its development in special and inclusive education in China in 
the past few decades.

\subsubsection{Intrinsic motivational factors}

\subsubsection{Interest In teaching and children}

Overall, intrinsic motivation for teaching in general was articulated by the three cohorts, though the majority of the researched stated a combination of intrinsic and/or extrinsic motivations. The frequently stated intrinsic motivation from the survey data is no difference from other research findings (Hargreaves, 2000; Addison and Brundrett, 2008) which emphasise 'like teaching, like children, interested in teaching, or simply, I wanted to be a teacher'.

It is interesting, though, that student teachers had the strongest intrinsic motivation ( $N=178$, about $41 \%$ ) whilst special school teachers have stronger motivation ( $N=12$, about $32 \%$ ) than mainstream school teachers ( $N=30$, about $23 \%$ ). This goes well with other data from the survey that mainstream school teachers had the lowest motivation in teaching children with SEN either in special schools (29\%) or in mainstream schools (40\%). This is in contrast to the majority of special school teachers and over half of the student teachers who expressed their motivation in teaching in special and inclusive education. This is further evidenced in that mainstream school teachers had the strongest intention to choose other professions than teaching if possible (76\%), which was about $10 \%$ higher than the intention of the other two cohorts. Although the student teachers had the highest percentage in the perception that 'teaching in a mainstream school is less demanding than in a special school', again mainstream school teachers scored highest in the perception that 'teaching in a mainstream school is more enjoyable than teaching in a special school'. The Interview data quoted below from a mainstream teacher reveal the strong intrinsic motivation for teaching.

When I was in primary school, my teacher wanted us to talk about our career ambitions: What will I be doing in 2000? I said that I would be standing in the classroom teaching. When I graduated from junior middle school, we had choices of going to normal schools or going to senior schools. For normal schools, you had to have high academic scores. I told my teacher that I wanted to be a teacher. She said that I did not have to do that as I am a city dweller. Normal schools could be a choice for those from countryside areas. I insisted, so I took the exams.

When asked about her motivation in teaching in special school, she answered with some hesitation: 
Yes, I would. I often have the idea of being a teacher in a Project Hope school [a kind of school for children from disadvantaged backgrounds, researcher's note]. If I were younger or I were not married, maybe... Well, now, people will think that I pretend to be somebody... My brother used to laugh at me: 'Oh, you are so great. Why don't you first give all the things at home to those who need them? You should not live in the ideal world without any material needs. Once you have given away all your belongings, you can then give yourself to those people'. He used this argument to make me more realistic. He is right. I can not be a person that great. So the idea never becomes a reality.

This goes well with the stages described in Ginzberg et al. (1951). According to Ginzberg et al., the initial fantasy stage of early to mid-childhood is followed through the early teenage years by the tentative stage, when individuals begin to think about their interests, capacities and values. However, in the realistic stage, the late adolescence, the individual shifts from a focus on subjective needs and interests to an appraisal of what the world has to offer.

\subsubsection{Teaching as a childhood dream}

The interview data from the special school teachers show that motivation for teaching is a complicated combination. This combination is evidenced that none of the teachers stated their intrinsic motivation as the motivation to be in special education, although that could possibly be the motivation for teaching in general. Some teachers stated that they liked teaching. However, teaching in special schools was not their first choice.

The next narrative account was by a cover teacher in a speclal school. She had no teaching qualification or degree but was doing no different job from full time teachers. She explained her motivation for teaching as a childhood dream.

I have liked to be a teacher since I was young. So this [qualification] will not influence me too much. My grandma and other family members are mostly teachers. I am influenced by them... I grew up at my grandparents'. They gave me some chalk and I was the teacher to $\mathrm{my}$ dolls.

A few teachers in the study showed their intrinsic motivation in special education claiming that they liked teaching and they like children. To this, I have to be mindful in interpreting the data as intrinsic motivation. Because over the years, as their teaching experience enhanced, teachers' Initial external regulation might become less controlled and become more autonomously integrated regulation. They might have been used to the school culture and have become more 
acceptable to their identity and social status. If this was the case, they might have highlighted the altruistic reasons for choosing teaching as a career (e.g. to help children succeed) and generalised it as their current thinking. It is evidenced that, given her strong desire for teaching, special schools were not the first choice for the teacher quoted. However, knowing that mainstream schools would not consider her application because they normally set the entrance criteria much higher than those in special schools in terms of teacher academic qualification, she managed to get a job in the special school for children with learning difficulties.

When I came for the interview [in the special school], the head-teacher asked me why I wanted to be a teacher. She said that it was hard work to be a teacher. I told her that I knew this and I would still enjoy it.

\subsubsection{Extrinsic motivational factors}

\subsubsection{Migration to urban areas}

Entry to teacher education programmes was merely a means for quite a significant number of the participants from soclo-economically distressed rural or remote areas to escape the life there. This implies very strong Chinese characteristics.

The migration decision of an individual was made by weighing the expected income or utility of migration against that of no migration. From 1953, people in China were classed as rural or urban residents. Rural residents were denied rights of city dwelling, mainly to stop them migrating to urban areas. To control ruralurban migration through administrative means, China relled on the household registration certificate system (Hukou in Chinese) (Liu, 2008), a system for people having official residency in urban areas. Rural life used to be socially despised due to many factors such as heavy physical labour and limited access to social welfare (see Wingfield-Hayes, 2006; Llu, 2008: 521).

Although the policy successfully warded off unplanned migrations, it has been criticised as an unfair development policy that promotes industrial growth at the expense of the agricultural sector and urban development at the expense of the rural sector. It is also contrary to the principle of economic efficacy that requires free movement of human resources across different reglons and sectors. According to Liu (2008), the system has been abolished in 11 out of 23 provinces. 
However, it used to motivate people from rural areas to seek residence opportunities in cities or coastal areas through joining higher education programmes.

Regional divisions in China can be made using different criteria. A broad geographical regional grouping is the division between coastal and non-coastal provinces. Economically advantaged provinces continue to enjoy substantial advantages in educational provision. Disparities between coastal and inner provinces in China in post-reform (Liu and $L i, 2006$ ), especially the geography and educational inequality (Hannum and Wang, 2006) are seen as the causes for the rural urban migration which is considered as a critical factor in career choice for many people including those in my study. The huge discrepancies between cities and counties make the policies from the central government difficult to be implemented to the same degree nation-wide. Migration of educated people to the coastal regions after reform (Liu and LI, 2006:450) exacerbates teacher shortages in geographical disadvantaged areas.

The unbalanced development in economic prosperity causes flows of welleducated and competent people to the economically dynamic areas where economy is better and to organisations for better income. Income disparities in China decreased both across provinces and areas from 1978 through 1984. After 1984 there has been an increase in disparity across areas (Zhang, 2001). Shortage of teachers is keenly felt in remote and rural areas as opposed to urban and more developed areas ( $L I, 1999: 187)$. One teacher entered the special school for children with learning difficulties at the beginning of its establishment in the later 1980s with a low self identity and little sense of achievement or job satisfaction. She represents her generation who sought chances for migration from rural to urban areas under the government's city dwelling policy. To her, teaching was just a job.

I used to be in the county. Then I was transferred to this city. I taught a few years in a primary school. That school was then merged to another school. At that time, I was not in good health and my younger child had just had a medical operation. So I asked to work here. It is not because I was lazy. It is because there was no fierce competition in this school. It is the truth. It is obvious that in mainstream schools, there were so many classes and lot of competition. At that time, there were quite a few teachers like me who came to this school... Young teachers did not want to come here. We were then in our 40 s. We really did not want to do too much. Next year I will be 56 and I can retire, too. That will be the end of my career life.

Chinese society has undergone a transformation in recent years. The income 
disparity has brought about other social inequalities between the rural and urban populations. The transformation from a planned economy policy to a market economy system means a far-reaching social change. More and more people are moving to cities, giving up their traditional lifestyles. The life of a rural citizen is treated as cheaper than that of a city dweller. The latest statistics from China's Agriculture Ministry suggest that on average, city dwellers earned 3.36 times more than those in the country. China's rural-urban wage gap, rising unemployment and the economic slowdown means there are fewer jobs available (Chen, 2009).

\subsubsection{Financial benefits}

Research (Gagne and Decl, 2005:333) identifies that most people who work have to earn money, so using monetary rewards as a central motivational strategy seems practical and appealing. Frase (1992) also argues that measures relying on external rewards have been insufficient. Teacher compensation, including salary, benefits, and supplemental income can have relation to long-term satisfaction with teaching as a career. My findings are aligned with their findings.

On the one hand, in China, according to one of the recruitment initiatives for initial teacher education from late 1970s to early 1990s, student teachers could enjoy financial benefits like free food and accommodation plus a waiving of tuition. This attracted a substantial number of students from financially disadvantaged family backgrounds. Many higher and adult education institutions charged students from other areas but student teachers were financially supported by the government (Yang and $\mathrm{Wu}, 1999$ ). These students could help release family burden with the free tuition and living allowance. In the interviews, many teachers expressed the seeking of financial benefits as decisive motivation for their career choice. The economic treatment of teachers in some areas is unsatisfactory. Although the government has repeated its policy of encouraging talented young people to study to be teachers, many talented young people feel reluctant in doing so. Moreover, many young teachers try to leave their teaching positions for better paid work (LI, 1999; Yang and Wu, 1999). However, the unattractive social and economical status of the teaching profession in China (LI, 1999) still attracts those who want to increase their human capital. They would unwillingly get themselves in teacher training programmes to secure a job opportunity in a city upon graduation.

It has to do with my job assignment, just a job. I was not interested in the school. No. No. No. 
On the other hand, driven by the Idea that there are many other professions that are materially more rewarding than teaching, good teacher candidates with choices (their entrance examination scores are high enough for a range of selections of higher education programmes, families are not economically pressed, city dwellers, just to name a few) are not encouraged to choose teaching as their career. They tend to enter other universities as they are more interested in professions in which a better income is available. The classical Chinese notion that education is a consumption good has been replaced by a strong belief that education is an investment, a source of future income ( $L I$, Morgan and Ding, 2008: 688). Job compensation such as extra payment for teachers working in special schools is also seen as attractive.

In addition, the educational choice has an Important bearing in China. Schooling is a form of human capital investment. Human capital is constructed from schooling years per capita (Liu and $\mathrm{LI}, 2006: 449$ ). According to Hung, Chung and Ho's (2000) study, ninety percent of students opt to continue into higher education on completion of senior secondary education. It is evident that students act in accordance with predictions in the human capital theory (Becker, 1964) in making their choice of higher education or work in the market-oriented sector of China. Education is understood as an investment in Increasing economic returns and in increasing the place of individuals in the competitive labour market.

\subsubsection{A job for a living}

The competition for jobs is increasing in China recently which has directly impacted students on their career cholce. It is important to note that, after the opening up policy, there is no guarantee for entry into teaching upon graduation for student teachers as they have to compete with many other equally qualified peers (Wang, 2004). This competition has become tense resulting in an increasing number of unemployed. This adds to the increased extrinsic motivation for entering teaching just as a job.

In addition, job opportunity in cities was seen as a very critical motivation for some student teachers and newly qualified ones researched. The rapld expansion of higher education in China has been accompanied by tensions and problems in employment in the job market for graduates (Yang, 2000; Gao, 2008; LI, Morgan and Ding, 2008). The decline in teacher vacancles these years results from the 
imbalance between supply and demand in subject and geographical areas. According to $\mathrm{LI}$, Morgan and Ding (2008: 690), rate of confirmed future for undergraduate is $77.9 \%$ whereas the rate of employment probability for graduate from Education is $28.2 \%$, the lowest in the rating list.

Moreover, China's graduates find it tougher than ever to get jobs. There are many graduates from previous years who are still jobless as China's economy slows down and unemployment rises. Teachers were traditionally employed in permanent positions by local educational authorities across the country (Wong, 2004). The traditional system from a planned economy of assigning jobs to teachers has been changed (Yang and Wu, 1999: 167).

\subsubsection{Teacher status}

Li (1999: 179) argues that the unattractive social and economical status of the teaching profession as well as cultural beliefs remain to be major problems in social value orientation in career choice. Generally speaking, in the Chinese tradition, teachers have been highly respected (Wang, 2004). However, as the country moves further along the line of a market economy and accordingly more people are becoming more money-driven in their value orientation, teachers are inevitably not enjoying as high a social status as they expect (LI, 1999: 186). The poor image of teaching, especially in special education, signifies the commonly held beliefs that teachers are those who cannot get into other higher education programmes with their entrance examination scores. This phenomenon has had a tremendous negative effect on special teacher education.

Given the increasing demand for teachers in speclal education, those who have received special education training are looking for other options to avold working with children with SEN as a result of the low social status and unattractive financial situation (Wang, $\mathrm{Gu}$ and Chen, 2004). Consistent with several international studies which identify the relatively low social status of teachers as one of the negative factors in teacher recruitment (Hall and Langton, 2006; Cunningham and Oliver, 2007), the findings show teachers' depressed feelings of their status within the profession because of school classifications and labels.

... When people knew that I was from this school [special school], I was always regarded as... even now when I went to headteacher training courses, when people knew that I was from the special school, they always had a kind of attitude... you know...not good attitude. 
This embarrassment is not caused by teachers' self perception, but by the social attitudes which lead to the low social status of special teachers (Hargreaves, 2007). Furthermore, the findings, as also reported in Cunningham and Oliver (2007), reveal the impact that various school classifications might have on the status of teachers. Positive achievements and evaluations of high performing schools appeared to engender a sense of high status for teachers working within such schools. These teachers considered school classifications and positive labelling to be advantageous because they provided the means to access more resources and working within well-resourced schools clearly have a positive effect for teachers' status. Understandably, teachers in poorly performing schools linked to the reputation, poor status, and parental evaluations to the poorly resourced working conditions and the low regard with which teachers felt they were held. These teachers felt embarrassment at their schools' names and that they personally were seen as lesser teachers because of the poor school performance and resultant labelling by official sources.

\subsubsection{Teachers and parental influences and gender factors}

This current study was not designed to compare who had more influence on the participants' initial career decision, teachers or parents? However, the finding differs from Watts and Richardson's (2007) in that few student teachers regard teachers' influence as an important factor in their career choice. Or, the influence of schoolteachers is far less than that of parents (Kniveton, 2004). The findings from this study show that both teachers and parents had a great influence in their selection of career. This can be interpreted that in China, social conformity and collective decision-making predominate. Thus parental and family expectations are more salient factors in the career decision-making process in China (Mau, 2000; Oyserman et al., 2002; Feng, 2007). Career guidance in China is yet to be developed (Watts and Sultana, 2004). Although evidence is needed, it is common practice that parents, lacking of education themselves, would encourage their children to consult with their teachers for advice.

Another interesting finding worth discussing is that the majority of teachers working in special schools are females. This matches with the literature (Siniscalco, 2002) that in some countries, higher access of women to the teaching profession, especially at the basic levels, has been encouraged as a measure to increase enrolment of girls in regions with persisting gender disparities. The highest increases in the proportion of women teachers are observed in China and Malaysia at the primary level and in Jordan and China at the upper secondary 
level.

\subsubsection{Extrinsic and/or Amotivational factors}

Quite a significant number of teachers interviewed from special schools $(27 \%)$ were amotivated to start their career. Some mainstream school teachers interviewed also expressed their unwillingness to work in special schools. This unwillingness implies that the nature of the students in teacher supply seriously undermines the foundation of special teacher education in China. Cautions have to be taken in interpreting the extent to which those mainstream school teachers know about the differences in the working conditions of the two types of schools.

The findings are concurrent with $\mathrm{LI}(1999: 188)$ that only a small fraction of the students attend teacher preparation colleges out of love for teaching while a great majority are generally not interested in teaching and some are not even interested in becoming teachers at all. Becoming a teacher may not be the first career choice for many middle school leavers. These students may not dislike being teachers, but they are generally not interested in becoming teachers either. Moreover, the findings also identify similar issues (Paine, 1991) that graduates of normal institutions try all possible means to avoid their assigned teaching posts. Demotivators (Addison and Brundrett, 2008) can be attributed to children's behaviour and work long hours with a heavy workload interpreted from the data that most teacher felt the work-related stress.

\subsubsection{Enrolment policy for Initial teacher education}

First of all, entrance examination scores are the rigorous standard for higher education which may have hampered the recruitment and development of quality teachers in a rapid expanding market economy. Many teachers mentioned that they were recruited passively because of their entrance examination scores, which used to be and still are the most important determining criteria for accepting candidates for higher education. The government is resolving the policy dilemma of maintaining strict control over teacher education (Chen, Lim and Gopinathan, 2003:509). Those who can not apply to non-normal programmes in higher education because of their examination scores enter teacher training programmes (Yang and Wu, 1999). One important reason contributing to this phenomenon is the normal institutions' priority in selecting candidates over other non-normal institutions (Li, 1999). The priority was provided by the central government in an attempt to secure sufficient numbers of students for initial 
teacher training. Subsequently, applicants for non-normal institutions were selected against their wish. Once those students were enrolled in normal institutions, mixed feelings of resentment, helplessness and dissatisfaction towards this selection system developed into a cynical attitude towards teaching and learning, which for some cases, led to the amotivation for their future profession.

Kyriacou, Hultgren and Stephens (1999) identify that in some countries like South Africa, as reported in Chuene, et al. (1999), an important factor of career choice for many student teachers is that they regard a degree-based teacher training course as an alternative access to higher education. Most of the student teachers in their study are motivated mainly by a desire to gain a diploma rather than a desire to become a teacher. This was echoed loud in my study as either being recruited or no choice. If a student's university entrance examination scores were not high enough to be enrolled in any other programmes, they would normally join teacher education programmes since the rejection rate for application was very low. This is in contrast with the teacher education recruitment system in some Western countries (e.g., Gorard, See, Smith and White, 2007), where a fairly amount of applicants considering teaching as a career are rejected.

We [classmates] asked each other why we were here [Teachers' college]. Many of them did not know before they were recruited to that college, either. Some of them failed to get offers to be in teacher education programmes for mainstream schools. So they had to get themselves into the college. At least it was also a college...

I-ST-5

\subsubsection{Substituting for a retiring parent}

For some teachers in the special school cohort, substituting for a retiring parent was the main reason for being in the schools. Little has been reported in and out of China concerning this kind of career motivation which is unique in the Chinese context. During the ten years' Cultural Revolution (1966-1976), school leavers from cities were demanded by the government to work in the countryside areas to be 're-educated'. The period of their stay varied from years to permanence. Lucky ones had to wait for their turns to be able to move back to the cities for further education or work opportunities. Chances could be that their parent was retiring from his or her work place. So the offspring could be the substitute for the parent.

Many accounts depict that part of history. It also well reflected broader social and political changes in China. About $14 \%$ of teachers in the special school interviews 
related their motivation to their parents' retirement. From the survey data from the special school cohort, 6 out of 37 teachers were the replacement of their parents. This is a surprising figure to me. In city mainstream schools, I assume that, after 20 years' reform in teacher workforce, there should be less numbers of teachers with this background, if any, still in service. In countryside schools, however, it may not be seen as unusual as they are less demanding in terms of teacher qualification and degrees. This finding is important in that literature has never reported the phenomenon which is arguably the cultural aspect in a special historical transition from planned economy to market economy policy only found in China from the late 1970 s to 1980 s.

Below is quoted from a teacher having no teaching qualification, no training or willingness to start teaching in the special school for children with speech and hearing impairments:

Interviewer: So you came to this school just because your mother was retiring as a teacher?

Interviewee: Yes, I did. We [pointed at two other teachers in the office] came to this school for the same reason. We learned from teaching after that.

I-ST-12

\subsubsection{Job mobility}

Job mobility is another factor which had caused the unwillingness of teachers working in special schools. Various policies have been implemented to keep teachers from leaving the teaching profession (Gao, 2008). Recent studies show that there is a growing regional imbalance in China (Liu and $\mathrm{LI}, 2006: 450$ ). The transfer from special school to general education has been discussed in Boe (2006). In the pre-reform years in China, school leavers and university graduates were assigned to a job in a particular region and affiliated to a particular institution. Job mobility has increased since economic reform. However,

The education bureau does not allow you to have the transfer frequently. If you want to go to other school, the school has to pay money to our school as the teacher was trained in our school and the teacher has to pay money to our school for the training. In fact, those who came to our school, they do not have relations which they could use for them to be placed in a better school. If they did not have that relationship when they were assigned to our school, they normally do not have relations later. So it will be comparatively difficult for them to be transferred to mainstream schools.

Though only 3 teachers from mainstream schools in the survey data show their clear amotivation in teaching, data also show that the majority of them $(71 \%)$ 
would prefer not to teach in special schools and about half of student teachers agreed with this. Some teachers in my research seemed to Ignore the practical day to day feelings towards teaching in the special schools. The Ignorance was interpreted as their lack of power in school system, the nature of special education, or simply their lack of passion for their profession.

Actually, if you look at the numbers of the students we teach... for me, I have been teaching them from the first year of primary school. They are now in their 9 years, all these years, I just teach these children. For the nine years, I am with them daily, what do you expect? This is a small school as you can see, I spend my days and years here with these children... they do not even greet back to us when we greet them. Am I motivated?!

\subsubsection{Other factors Influencing teacher career motivation}

\subsubsection{Professional identity}

According to Day and Kington (2008:9), identity is the way we make sense of ourselves to ourselves and the image of ourselves that we present to others. It is culturally embedded. There is an unavoidable interrelationship between the professional and the personal. They suggest that identity itself is a composite of interactions between personal, professional and situational factors. They also find that teacher identities are neither intrinsically stable nor intrinsically fragmented, but that they can be more, or less, stable and more or less fragmented at different times and in different ways according to the Influence of the interaction of a number of personal, professional and situated factors. The extent to which teachers are able to and are supported in managing the scenarios they experience will determine their sense of effectiveness. Change affects teachers' work and also how teachers feel about their work (2008: 8).

Ginzberg et al (1951) argue the choice of career is also influenced by people's conceptualisation of his or her abilities and preferences, and the pursuit of a match between these and job requirements. The motivation of the case study teacher from the special school for her career lllustrates this point (See Chapter Nine). Her self perceptions of their professional status differentiated it considerably from 'high' in terms of the reward and respect she could receive and the control and regulation to which she was subject. She identified the accompanying lowering of status. She also complained about inadequate resources due to the low status attached to SEN work, feeling depressed within the profession. 
Broader social conditions in which teachers live and work, the emotional contexts, and the personal and professional elements of teachers' lives, experiences, beliefs and practices are integral to one another, and there are often tensions between these which impact upon teachers' sense of self or identity.

\subsubsection{Teacher stress}

Stress is identified in this study as work-related such as the complicated work characteristics, conditions, workload, pressure caused by social status of special education and their own perceived professional identity. The stress level of special education teachers was higher than those from mainstream schools as identified in Feng, Pei and Cao (2008). Compared with mainstream teachers, they were less open. They were non-qualified or not fully qualified for their work as they lacked the knowledge and skills in teaching. More importantly, they lacked the sense of achievement. A recent survey (Guo, 2008) on the current situation of job burnout and its relationship with job characteristics in special education teachers reveals a close and complex relationship between job burnout of special education teachers and their job characteristics. There is an unbalanced development in each dimension. Younger teachers with less than 5 years' experience have higher burnout levels than their senior colleagues. Those with low qualifications have high burnout level. Those who worked in special schools the longest are the least burned out teachers.

Work challenges are particularly evident among the special education teachers with the least experience (Guo, 2008). The challenges special teachers face early in their teaching careers uniquely foster high frustration and dissatisfaction. Attrition rates among special education teachers have also been problematic (Katsiyannis, Zhang and Conroy, 2003). Reports from various states indicate that special education teachers leave special education teaching positions at disproportionally higher rates than their peers in general education (Katsiyannis, Zhang and Conroy, 2003: 247). These attrition rates confirm that some special education teachers leave special education positions in favour of general education assignments to escape work-related stresses. 


\subsubsection{Job security}

In addition to the favourable compensation, job security was also perceived as a significant attractor by many, especially by student teachers indicating that teaching provided 'stable job and stable pay' or 'a long-term job security'. This advantage did attract them to pursue teaching as a career. A chronic over-supply of graduates and a shortage of high end jobs had already been causing difficulties. But the mass lay-offs and business closures in recent years has made the situation even worse. Furthermore, widespread redundancies indicate there are more experienced people than there might have been in previous years, trying to secure the same jobs. The account from a junior teacher in the school for children with learning difficulties was representative of the current situation. She took the job that previous years' intakes would not have been willing to accept as a bachelor degree holder with initial teacher training for mainstream schools.

I noticed an advertisement... I did not know what kind of school it is. I have no idea. From the name of it, I thought it was just a primary school. I have never heard of it. I called [the school] and tried to apply. I did not specially want to come. The headteacher told me before I asked that this was a special school for mentally retarded children and I was like, $O h$, and I did not really understand what the retardation meant. I thought it meant that the students would be a bit slow in learning or a bit low in their IQ. I did not think much. Later they called me and asked me to confirm my application. So I thought it is better to come and have some experience in this school than to stay at home without a job.

\subsubsection{Qualification, family, health or other concerns}

The findings of my study indicate that female teachers, more than males, in their criterion for choice of career put more emphasis on factors of family life, often involving caring responsibilities and child rearing. Those who were older and had family commitments seemed to be less motivated but showed their acceptance of the reality. This is evidenced in the data from teachers graduated from general teachers' training schools who obeyed the government's assignments to teach in special schools upon their graduation or after a few years' of teaching in mainstream schools. They expressed their initial unwillingness in working in special schools. They were transferred to special schools for the reasons such as their low qualification, poor health conditions, ability in teaching or social communication competence (Wan, Wang, Du and Chen, 2008). For still others, as they got older and their health declined, they lose their zest for their job (Guo, 2008). 


\section{Chapter Eleven: Discussion (II)}

In this chapter, relevant findings on teachers' knowledge and understanding of, and attitudes towards special and inclusive education are discussed with a specific reference to the different aspects in teacher education and professional development. As one of the three key themes, the discussion aims to coordinate with the other two research focuses of this study.

In so doing, it is necessary to first briefly discuss the concepts of special and inclusive education as being generally accepted nationally and internationally. The interpretations of the terms are still being constantly modified owing to the different and more importantly, improved perspectives in diverse educational contexts across the world (Mitchell, 2005). Secondly, a discussion of multidimensional factors influencing teachers' knowledge and understanding of and attitudes towards special and inclusive education is set in a more holistic context in China. Finally, I discuss the correlation of the findings with teacher career motivation to link the discussion of teacher professional development. It is noted that the correlation is not measured statistically. Instead, it is largely based on my interpretations of the narrative accounts and the observations. The relative weakness in this respect is discussed in the Methodology chapter.

\subsection{Knowledge and understanding of special and inclusive education}

\subsubsection{Knowledge and understanding of special education}

At present, special education is broadly understood and interpreted across the world as the education for those with diverse educational needs. This is achieved globally over the years, especially in economically advantaged countries, as special education is becoming increasingly a priority from policy to practice levels. Special education has been influenced by Western values and ideology at various stages of its history in many countries in Asia where it has been, and still is, synonymous with the provision of special schools or speclal classes (Mitchell and Desai, 2005). In China, special education used to be defined and is still narrowly understood as the education for the disabled or those with learning difficulties (Chen, 1996; Piao, 1995; Peng, 2003; Deng and Holdsworth, 2007), given that government policy Initiatives have tried to match the international terminology. 
Ainscow (1998) discerns three perspectives to understand special educational issues. They are deficit perspective which locates the problem within the child; alternative perspective where problems are seen to stem from curriculum-based difficulties and interactive perspective which attributes to factors within the child and to other levels as well. Still others (Nilholm, 2006; Norwich, 2008a) argue from a dilemma perspective that special education can be seen as a context where ideological dilemmas are central and account for human interaction of different kinds (Billing, et al., 1988, cited in Niholm, 2006: 434). The perspectives have influenced the provisions in special education and the process of inclusive education.

As shown in the survey data (Table 9-8), which is concurrent with Zuo and Wang (2008:10), 35\% out of 110 mainstream school teachers had no knowledge about or negative attitudes towards special education.

My school is a key school. There are no students with special needs.

A headteacher in a secondary school

Special education demands nothing but caring and true love.

QS3-ST-30

Special education is to raise students' academic achievement.

QS3-US-60

Researchers (Sin, 2004; Chong, Forlin and Au, 2007) point out that Chinese teachers need three aspects of knowledge: content knowledge, pedagogical knowledge and pedagogical content knowledge. Garglulo (2008) also suggests that teachers need more than just academic knowledge about exceptionality. They need an awareness and understanding of the human side of exceptional students and their families.

\subsubsection{Knowledge and understanding of Inclusive education}

Inclusive education has its origins largely in Western education systems (Mitchell and Desal, 2005). Recently, inclusion is a main area of concern in the studies in most countries in Europe (Meijer, 2003). Inclusive education is not a fixed state but more a dynamic and unending process (Booth, 1996; Ballard, 1999; Slee, 
2001; Ainscow, 2005). It is seen as the entitlement of all children and young people to quality education, irrespective of their differences or dispositions (Sebba and Ainscow, 1996; Thomas, Walker and Webb, 1998; Moran, 2007). Nevertheless, the notion of inclusive education in Asia (Mitchell and Desai, 2005:195) has been limited to the education for students with mild disabilities, those with severe or profound disabilities either being catered for in special schools, or not at all.

'As a concept, inclusion will become recontextualized and this will imply that a multitude of new meanings are generated' (Nilholm, 2006:36). Findings from economically disadvantaged countries (Wei and Yuan, 2000; Yuen and Westwood, 2001; Zhang and Chen, 2002; Xiao, 2005) have shown some sharp contrast from economically advantaged countries in terms of teachers' understanding of inclusive education. About $43 \%$ of teachers researched had no knowledge of inclusive education. These teachers were unfamiliar with inclusive education as a concept.

Whilst inclusion is at times interpreted as the ability to enable children to participate in the life and work of mainstream institutions to the best of their abilities, whatever their needs, Sul Ban Jiu Du (Chinese translation) (Chen, 1996), was originally translated in English as integration of those children in mainstream schools. More recently, it is accepted as 'Learning in Regular Classrooms' (Deng and Manset, 2000). It has been adopted as the main mode of educating children with disabilities in economically disadvantaged areas with a limited number of special schools to accommodate these children. On the one hand, this Chinese version of inclusive education has a function of providing compulsory education to an increasing number of eligible children. On the other hand, it is not a formal process of inclusion as neither specialists nor educators with basic and necessary knowledge were available for inclusive schooling ( $\mathrm{X}$, 2008).

Teachers lacked the knowledge for working in Inclusive classrooms as also identified in Deng and Manset (2000). This attributes largely to the fact that teachers were inadequately trained and inexperienced in acknowledging children's issues caused by their learning difficulties and/or physical disabilities. Those children's difficulties were very often dealt with through existing discipline practices including the use of corporal punishment as found in certain areas of other countries in Asia (Feng and Jament, 2008). It is therefore very difficult to 
fully engage children with SEN in learning in the same environment with their peers in mainstream schools. Inclusion was thus understood as having children physically present but academically and/or emotionally disengaged.

\title{
11.2 Attitudes towards special and inclusive education
}

\subsubsection{Attitudes towards special education}

In China, despite the government's endeavour towards reform of special education, access to school for disabled children is still limited in some disadvantaged areas (Wang, 2006). Education for children with severe learning difficulties was hardly available (Pang and Richey, 2006a). The problem of confining special education narrowly to the education for the physically disabled and/or intellectually disabled in China (Deng and Holdsworth, 2007) causes issues in people's understanding of conceptual equivalence in international fieldwork. Consequently, these children are not entitled to receive special education as appropriate. The data from a special school teacher in the study reflect some negative attitudes. This teacher had been teaching for about 30 years in the special school for children with speech and hearing impairments. She joined the school with no choice and she regretted being in the school. She stated that:

\begin{abstract}
Teachers from mainstream schools would say: you are just like that. I have heard educational authorities also said things which made me feel not happy. They said: we have given you that much money. You can not present any evidence of improvement? But our school is different. We offer complementary education. But they do not think that way. They should. We should be treated the same as those in other schools. They think that it was not worth spending money on special education. At that time, there were some top leaders for some terms who shared the same view Hahaha [laugh]. We felt really uncomfortable. They would say: every year, we give you this much money and you have nothing to present us for your achievement. That money could have a lot in return if we had invested on somewhere else. You had nothing...[laugh].
\end{abstract}

\subsubsection{Attitudes towards Inclusive education}

Attitudes are the critical variables in the success of inclusive practice. The insufficient initial training for teaching in inclusive schools, somehow, leads to some mainstream teachers' lack of positive attitudes in the development of inclusive education.

Inclusive education is a good thing. But I am not interested in it. It is not realistic 
in China.

Research and practice has shown that when full inclusion appears to occur, it frequently takes the form of placement with little or minimal support due to the gap between theory and practice (Please see detailed description of the development of special and inclusive education in China in the Research Contexts chapter and Literature chapter). In fact, this integration first began in rural and remote areas in the late 1980 s as the means of improving school enrollment and eliminating illiteracy. It has been adopted as the main mode of educating children with disabilities in economically disadvantaged areas with a limited number of special schools to accommodate these children. It is not surprising, therefore, that teachers within the schools researched perceived inclusive education as follows:

It is necessary for countryside schools to have inclusion as there are not enough special schools and children need to receive this compulsory education.

Teachers' attitudes towards inclusive education are generally seen as decisive for achieving inclusive education. Factors influencing attitudes are clearly multidimensional. Specific problem areas are perceived as being insufficient teacher training which greatly leads to less positive teacher attitudes. According to Wilczenski (1992: 306) attitudes towards inclusive education might be expected to vary based on functional issues such as, the physical, academic, social or behavioural accommodations. All these inevitably influence career choices of people and the retention of teachers in special and inclusive education. However, very little literature exists that describes the feelings and thoughts of teachers in special and inclusive education (Chen 2005). According to the data obtained, I interpret that inclusive education is yet to be accepted by teachers researched. Some teachers researched attributed this to the resource issues rather than their attitudes, although attitudes have changed greatly in the last twenty years. The data from a mainstream school teacher shows his indifference.

I don't think we can provide inclusive education in China at present. Children with difficulties are only physically integrated. No support is available in their academic studies. If they catch up, they catch up, or they are excluded. Teachers don't care. Who can afford to care for them when you have another 60 students waiting to be supported? We are not to blame, are we? They [chlldren with 
difficulties] are different, anyhow. How can I possibly address the needs of all?

In most economically developed areas in China, there are still some implicit barriers for mainstream teachers to hold positive attitudes towards inclusion of children with SEN (Feng, 2007). These can be the high academic competition in schools, high expectations of teachers from school administrators for league table ranking, and from parents with high education aspiration for their children. Teachers are often aware of contradictory elements within their own thinking. In this respect it is interesting to note research studies which suggest that whilst a majority of teachers support inclusive education, they do so with reservations (Croll and Moses, 2000).

The expression of apparently contradictory views on inclusion is clearly more complicated than can be explained. Given that some teachers did have the motivation (Hausstatter, 2007) in helping children with SEN, the motives varied. Teachers expressed their lack of competence in inclusive education as has been indentified by Chong, Forlin and $\mathrm{Au}$ (2007). In the Chinese context where the research is being conducted, more than half of the teachers had no qualification or experience for teaching in special schools as far as their self-evaluated competence was concerned. The majority of the teachers $(76 \%)$ agreed or strongly agreed that children with SEN should be taught in special schools for the lack of their own competence in engaging children those children in their classrooms.

A girl is now in my class and I don't know what is wrong with her. She is so slow in learning. Anyhow, I am not responsible for this. She should not be placed in my class which is so highly competitive.

I-MT-11

\subsection{Factors influencing attitudes towards special and inclusive education}

A review of the literature by Avramidis and Norwich (2002) shows evidence of positive attitudes. However, teachers' attitudes are consistently found to be strongly influenced by the nature and severity of the disabling condition presented to them and educational environment-related variables. These can be associated with the availability of physical and human support, initial teacher 
training and professional development opportunities. This is also true in China, as inclusive education is yet to be accepted by teachers according to the data obtained. The factors that influence teachers' understanding which further cause their certain negative attitudes towards inclusive education and leads to further challenges of developing inclusion are discussed below:

\subsubsection{Flaws in initial teacher education}

Important efforts have been made in teacher preparation for SEN. Issues and limitations have been identified (e.g., Kearns and Shevlin, 2006; Chong, Forlin and $\mathrm{Au}, 2007)$. Garner (2001) is particularly worried and angry over the ways in which initial teacher training provision does little to promote inclusive thinking on the part of newly qualified teachers. With a strong agreement to the concern, researchers start to investigate the flaws in special teacher education. The old mode of curriculum leaves the future teachers unprepared for the ever-faster changes in different aspects (Song, 2008). Research (Brown, et al., 2008, 2092) suggests this inability of teachers has been attributed to the fallure of teacher preparation programmes in providing learning opportunities on special and inclusive education.

An overview of the data from this component of the study suggests that mainstream teachers were struggling in dealing with the realities of inclusion within the applied educational setting because of a lack of skills and support. The insufficient initial training for teaching in inclusive schools led to their lack of positive attitudes. This issue has inhibited the successful implementation of SEN strategies in the past in the area researched. This can be interpreted that inservice teachers researched emerged from initial teacher education programmes without any appropriate learning experiences of special and inclusive education. The setbacks in education caused by Cultural Revolution made it impossible for primary and secondary teachers to have received a proper teacher education (Yang and Wu, 1999: 160). Most of them joined teaching in the 1980s or 1990s, whilst positive attitudes to inclusion have not been well nurtured. In their teaching practices, they had encountered tensions and dilemmas in engaging more students with limited support from all levels. Once they formed certain negative attitudes, these would be difficult to change, particularly when exposed to tremendous pressure and stress as articulated by the teachers researched. It is understandable that most student teachers researched were in favour of inclusive education accepting it as a gulding principle. The following quote is given by a 
mainstream teacher on the placement of children with SEN in special schools.

If they have disabilities, there are specialists there [special schools]. If they come to the mainstream schools, they will be bullied.

Teacher education programmes have been undergoing a process of dynamic reform to meet the increasing and changing demands for large numbers of qualified teachers (Yang and Wu, 1999; Zhou and Reed, 2005; Paine and Fang, 2006). However, it still fails to meet the demand of the vast change of the society and the nature of teacher's work ( $\mathrm{Gu}, 2006$ ). There is an over-emphasis on subject matter knowledge with little stress on professional education (LI, 1999). In an average normal institution, the professional education courses for prospective teachers are often psychology, educational philosophy, and subjectspecific methodology ( $L I, 1999: 189$ ). Approximately $60 \%$ of the total class hours are dedicated to courses in subject area, approximately $30 \%$ to the required core courses, and $10 \%$ to professional educational courses and a 6 to 8 week practicum. The purpose of general secondary teacher education is to train primary school teachers. General teacher training schools enrol graduates from junior secondary schools, offering either 3-4 year programme.

Research (Ellsworth and Zhang, 2007) on initial special teacher education in China identifies that training programmes are developing rapidly. However, an understanding of theory is more highly valued than student teaching competence. Special education student teaching experience lasts only about 4 weeks. Special education teachers are the most challenged for their knowledge and skills in teaching (Yu, 2008). This is also mentioned in Liu and Xiao (2005). Training programmes are mostly not related to special education (Wan, Wang, Du and Chen, 2008). Therefore, teachers may acquire a negative experience from working with SEN students, developing a correspondingly negative stance towards the inclusion process. These teachers researched attributed their doubts regarding inclusion to various factors which are similar to the ones identified in Koutrouba, Vamvakari and Steliou (2006:391). That is, the lower academic performance of the class as a result of necessary adjustments in teaching to cater for the abilities of SEN students, given the lack of appropriate infrastructural equipment in the school that might have improved their performance. 


\title{
11.3.2 Professional development opportunitles and attitudes towards special and inc/usive education
}

As identified in Deng (2005), the researched in his study have little or no training in teaching children with SEN in mainstream schools. No distinct disparities exist between rural and urban mainstreaming teachers In applying teaching adjustment strategies but rural teachers pay more attention to the adjustment of teaching strategies than urban teachers. The adjustment of teaching strategies is not affected by the factors of teachers' training, such as training type and time. Different from Deng's findings, my study indicates the level of acceptance of children with SEN is dependent on the amount of training they had, which enhanced their self-competence in teaching. The data from Case II from a mainstream school well illustrate this point.

\begin{abstract}
There was a student in Senior Two. Something happened in his family. So he jumped from a building and got disabled. He was in my class. So I asked my students to help him to move up and down the floors. Because of him, my class became united. They organized themselves in groups. But later the student could not keep studying as he had low self-esteems. Even parents complained that their children spent too much time on the student and it influenced their academic study. The students had to take part in the entrance exams. They [parents] wrote letters to the headteacher. They wanted me to leave the class. They thought that for this student, we had spent too much time. So the student did not even dare to ask for help to go to the toilet. It was ten years ago. Maybe things have been better today.
\end{abstract}

Case II

\subsubsection{The priority of special and Inclusive education In China}

Moreover, given that the Chinese government has expressed a clear view on inclusion, special and inclusive education remains a low priority in its education system in China. Some local governments still fail to provide adequate conditions which would allow for a flexible use of resources as also identified in Ocloo and Subbey (2008). In China, the growing emphasis on inclusion not only reflects arguments in favour of its social benefits, but also recognises the financial impossibility of funding special schools throughout the country (Mitchell and Desai, 2005: 175). The LRC initiative is not without its problems. This is evidenced in Deng and Guo (2007) that as Chinese inclusion is driven by pragmatic needs, LRC has been practiced in a different social and cultural context. The core value of inclusion such as equity, individualism, and pluralism has been missing in the LRC model. This is supported from a Western perspective (Mitchell and Desai, 2005: 172) that it is questionable as to whether inclusive education 
constitutes 'true' inclusion (Xu, 2008),

There are still challenges for teachers to accept inclusion either as a concept or in practice. The findings suggest that Chinese teachers holding more positive attitudes raise similar concerns as those from other economically developing countries (Ocloo and Subbey, 2008) in that they are encountering obstacles and challenges with limited resources and support from the society as a whole. The causes are examined in light of culture-specific factors. These include the fact that education system in this country is highly test-oriented and the attitudes towards disabilities as economic liabilities are historically-embedded. This results in the understanding of inclusive education as the promotion of pragmatic strategies for economic consideration rather than regarding it as an opportunity to engender equal rights for education.

\begin{abstract}
Above all, China has been striving to catch up with the world in the aspect of educational provision. But there exists a major gap from developed countries in special and inclusive education. At present, China is still encountering challenges related to the poverty in vast rural areas with a total population of $80 \%$ living in these areas. The identification and diagnostic procedures for children with special needs is undeveloped. Family and professional collaboration has not been established. The education facilities for children with special needs are not sufficiently equipped. Curriculum is not timely revised, just to name a few.
\end{abstract}

A head-teacher of a junior school 


\section{Chapter Twelve: Discussion (III)}

In this chapter, I discuss the findings in relation to teacher professional development in special and inclusive education. A central focus of this chapter is provided with the indicators from the findings that a): teachers' limited knowledge and expertise in special and inclusive education leads to a general awareness from the teachers researched of the necessity for professional development. However, the awareness does not generate a clear recognition that teachers themselves should also accept some responsibility for this process; $b$ ): the lack of motivation in taking the initiative of engaging in professional development programmes is seen to be related to teachers' motivation in respect to their career and their attitudes towards special and inclusive education, and $\mathrm{c}$ ): the low priority attached to special and inclusive education in China is creating more challenges than opportunities in teacher professional development, which further impacts on teachers' career motivation, values and attitudes towards special and inclusive education.

To discuss the aforementioned indicators, multi-dimensional factors are analysed relating Confucian and socialist ideologies, historic and culture influences, economic disparity and pragmatism. In particular, some specific concerns are interpreted in terms of the availability of time and finance, support and incentive, as well as teachers' life and work priorities and the appropriateness and relevance of available professional development programmes. Throughout this discussion, models of professional development programmes are examined which indicate both the needs and opportunities for improvement. The models under consideration are those which were seen to be in operation in the area where I conducted my research and are also typical of those in evidence in China.

\subsection{Models of teacher professional development}

A number of models of teacher professional development can be extracted from the literature in this area (Darling-Hammond, Chung and Frelow, 2002; Paine and Fang, 2006; Maandag, et al, 2007). Within this study I was concerned to generate a discussion around the models of traditional professional development and jobembedded professional development (Smith and Gillespie, 2007; Zuo and Wang, 2008). These two are commonly practised models in both general and special teacher education internationally and in the research context in China. I deemed 
it important to ensure that my considerations were focused upon approaches, which were clearly in use in my research area and shared some similarities and differences with more general discussions of professional development within the international literature.

I was not surprised to find that the understanding of professional development by most of the teachers was training. This attributes to the commonly accepted perception that teacher training, teacher education and teacher development were different ways of expressing different aspects of teacher professional life, from their initial training stage to their in-service stage. These differences, from my understanding and interpretation, are viewed as resting in their motivation for, knowledge of and attitudes towards special and inclusive education.

Darling-Hammond and colleagues (2002) suggest that the extent to which teachers feel well prepared when they enter teaching is significantly correlated with their sense of teaching efficacy, their sense of responsibility for student learning, and their plans to remain in teaching. This was an important consideration for me during the data collecting process through which I was eager to find whether the principles and factors influencing professional development and its efficacy amongst colleagues in China were similar to those discussed in the wider international literature.

Meanwhile, the models investigated indicate issues of concern with regard to the lack of strategic overview or evidence of accountability within the area in which my research was located.

\subsubsection{The traditional and job-embedded professional development Models}

\subsubsection{The traditional Models}

The traditional professional development model refers to short-term training (days, weeks or a few months), or one-session workshops, seminars, lectures and conference sessions. This model has been commonly adopted in support of teachers and other education professionals in many administrations (Smith and Varma, 1996; Brighouse and Woods, 1999). This is considered as standard practice in many parts of the world, including Western countries such as America or the UK as discussed in Smith and Gillesple (2007). 
In the UK, the importance of teacher professional development in inclusive education has been emphasised at all levels as a key factor in developing an understanding of inclusion (DFEE, 2000). Teacher training and efficacy research have also provided a focus for areas of investigation (Younger, et al. 2004). Adequate teacher training and professional development are clearly perceived to be crucial in promoting a more equitable education system (Davies and Garner, 1997; Garner, 2000; Mittler 2000; Rinke, 2008).

The traditional model has had an equally dominant position in the development of teachers in Asia (Villegas-Reimers, 2003; Huang and Bao, 2006). Within China this model typically offers a menu of topics for training in subject areas such as Math, Science, or Language. Teachers are expected to attend optional or compulsory activities throughout the year, depending on their availability, interest, need for certification or degree upgrading, or overall staff development schemes for school improvement. Different levels of educational administrators, professional agencies, and teacher-training colleges and/or normal universities within China provide training of this nature.

However, in this 'top-down' or 'outside-in' method (Hargreaves and Fullan, 1992), teacher trainees only play a passive role. This may silence teachers' voice arising from their practice and prevent teachers from gaining true understanding for their own professional development as evidenced in the interview data in my study. Some research (e.g., Brownell, et al., 2005) recommends carefully designed field experiences that allow prospective teachers to integrate information gained in schools with what they are acquiring in coursework. Such an approach, it is argued, may enable better knowledge and skill development in beginning teachers. This kind of approach has also been advocated within an Asian context by Forlin, Au and Chong (2008) who believe that training, which is provided at a distance from the classroom, may not be readily put into practice unless it is directly contextualised to the learning situation.

\subsubsection{The job-embedded model}

The job-embedded professional development model locates training within the school, programme, or local context. This model is hybridised with Western practice of teacher professional development which is seen as a response to the research identifying the ineffective features of traditional professional development (Smith and Gillespie, 2007: 214). Activities such as open class sessions, group lesson preparation, model teaching competitions and/or teacher 
mentoring are commonly deployed. These activities allow teachers greater participation in shaping the content of instruction and also provide them with the opportunity to investigate problems of student learning more closely tied to their own contexts.

In some European countries, teacher education courses in the past had been perceived by critics as 'too theoretical and too politically engaged' (Maandag, et al., 2007: 168). This criticism leads to the decision to implement strict measures to involve schools in training teachers. This kind of learning in the workplace, also seen as school linked models or collaboration models for training in schools in some European countries, is an important development in teacher education, particularly in secondary Education (Maandag, et al., 2007). Tilstone (2003) has emphasised the strengths of school based professional development of teachers. She suggests that this approach enables teachers to focus upon real life situations within their own schools and to reflect upon how new ideas or initiatives might be practically implemented for the benefit of students. This view also finds favour with Blake and Monahan (2007) who express similar ideas that school based professional development may assist in changing school cultures by uniting staff in addressing common issues. Within the Asia Pacific region, school based training models for increasing awareness and changing attitudes towards children with SEN have begun to find some favour (Dowson 2007; Wang 2008; McCabe, 2008). However, within my study it was evident that the impact of such an approach varied dependent on individual teachers at the heart of my research.

In China, with constant reform in the recent years, the Government has been actively emphasising on the cultivation and training of teachers in various forms of continuing professional development. As a result, the qualities and the structural levels of teachers have witnessed vast and obvious improvement. More importantly, the awareness of teachers for professional development has been raised. Initial findings from the surveys indicate that teachers shared some common understanding of the importance of learning in their career life. However, perspective on and motivation for professional development varied.

\subsubsection{Comments on the effectiveness and flaws In the professional development models}

China has made great progress in providing improved multi-level and multi-media conventional and distance teacher training (Chen, Lim and Gopinathan, 
2003:900). A positive climate is In evidence within the Chinese context where it is possible to see a growth in special education training facilities. This relates to both physical facilities (I.e., buildings) and teaching staff (l.e., faculty members and instructors) which have been put into place in a relatively short time. However, teacher education is an unprecedented concern at government level and for society in general (Wang, 2004). For a long time, teacher professionalism in China emphasises teachers' academic qualifications, the obtaining of which was not demanding. In the Teacher Act (National People's Congress of China, 1993), teachers' qualifications for different levels of education are specified. For example, a teacher education school certificate is required for primary teachers whilst a college diploma or university bachelor degree is required for secondary school teachers.

Substantial efforts have been made to improve the quality of the existing teacher workforce, especially those who have missed their education and training during the Cultural Revolution. Since 1982, many higher and adult education institutions have offered courses for teachers who have been financially supported by the government. Teachers are encouraged to take part in any form of continuing studies that enhance their knowledge and skills as teachers.

Although teacher education has targeted issues of quality assurance, at present teachers' life long learning system has not been well established (Wang, 2004:6) due to the resource limitations and established cultural practices (Paine and Fang, 2006: 284). The findings from my study show that some teachers in the special schools did not have any teaching certificates when they entered teaching. They became teachers incidentally as their parents were retiring from schools and they had opportunities to inherit their positions. The government assigned these school leavers to take the place of their parents. Whether they had the motivation for teaching was not the concern of the government whilst to obey the government's assignment was the only option for the teachers to get a job paid by the government. Nevertheless, the teachers who followed their parents into positions in my study had all managed to obtain teaching certificates through traditional professional development model. They were qualified to teach in the schools at the time of the research.

Besides, strategic professional development planning for individual teachers researched was not made from the prospective teachers. As little existed in the school system to ensure, or perhaps even encourage teachers for professional 
development, there lacked an incentive for seeking opportunities.

International research (Chong, Forlin and $\mathrm{Au}, 2007$ ) argues that training of staff at all levels is not being adequately met. There is a suggestion that little or no training and capacity building opportunities exist in socially and economically disadvantaged areas or countries. Where such training does exist, it tends to be fragmented, uncoordinated, inadequate or unequal and often inappropriate to the needs of the relative context (Wang, 2004). Researchers, for example, Deng and Manset (2000) have been pessimistic about the prospects for educating enough teachers for special and inclusive education in China. This concern is further endorsed by evidence that during the early stage of development in special education in China, teachers began teaching their own small group of students immediately after being hired, and with no further support, in part due to the shortage of teachers, and training opportunities available to those who were teaching full-time (McCabe, 2008:108). Moreover, initial teacher education, according to Paine and Fang (2006) was not inconsistent with continuing professional development which mainly aimed to raise teachers' academic qualifications in 1980 s and early 1990 s rather than examining issues of pedagogy or classroom practice.

Programmes to prepare special education teachers have developed rapidly. In Nanjing province, a start was made in 1993 on in-service teacher training to provide support for children with mild learning difficulties (McCabe, 2008). However, issues of ongoing development for teachers once full academic status has been achieved are only more recently being addressed. The available literature remains limited in respect of the unbalanced attention given to professional development. This is compared prior professional development for upgrading teaching qualifications with life long learning.

\section{2 'Teachers' awareness of and perspectives on the Importance of professional development}

Professionalism is seen of vital importance (Gopinathan and Sharpe, 2002) as key stakeholders in education whilst professionality reflects what the individual believes and perceives (Evans, 2000:177). In China, the current educational climate is driven by an overriding concern with student achievement and what promotes it. The position of teacher education in relation to its contribution to the development of inclusive thinking and practice is of fundamental importance in 
this process (Barton, 2003:21). Teachers are no longer automatically respected for their knowledge and are also expected to undertake more higher education and professional development themselves (Potts, 2000: 310). Initial findings from the surveys indicate that a need was keenly felt from the teachers researched, for professional development, regardless of their school type. Teachers shared some common understanding of the importance of professional development in their career life.

However, through the research, other voices were also heard which highlighted different perspectives. One way of thinking about professional development supports Stout's view (1996) that, for some teachers, development is seen as occurring primarily during the early stages of an academic career. Development continues until a threshold point of competence and confidence or success and recognition as a teacher has been achieved. People with comparatively lower educational levels in professional fields often recognise the need to upgrade their educational skills and abilities. They may also be beginning their professional career, a time when they recognise the need for additional information and skill building (Livneh and Livneh, 1999:100). Then, once that stage is reached, the idea of further development is not perceived as relevant.

\subsection{Teacher motivation for professional development}

Given the general high awareness of the importance of professional development, teachers' motivation varied in the study. This can be influenced by a number of interpersonal, social and environmental factors of self-concept, life experiences, interests and/or abilities and have long-term consequences on people's professional life, well-being and their social situation (Creed and Wong, 2006). Dornyei (2001:165) defines teaching as a profession in which energy is supplied from intrinsic motives. He states that there are some damaging elements which weaken and destroy the intrinsic character of teacher motivation. This definition applies to the teacher motivation for professional development in my research context. The findings suggest that no matter how strongly teachers felt about professional development, as long as external conditions or environments were not supportive, even the intrinsic motivation for professional development could not be sustained.

Teachers' motivation to attend professional development appears to be a key factor in change. Stout (1996) proposes four motivations teachers have for 
participating in professional development: salary enhancement, certificate maintenance, career mobility (building their résumé to move up the ladder into administration or pursue other careers), and gaining new skills or knowledge. According to Stout, teachers talk about the fourth motive, but in vague terms. Almost always the language is of gaining new skills or knowledge to enhance classroom performance. The motive is both noble, and appropriate, from a public policy perspective. The problem, I would contend, is that the chances of policyappropriate motive connecting to available, timely, and intellectually honest sources are little more than accidental (Stout, 1996).

Consistent also with the findings of $L I(1999)$, in the special schools researched, a large number of teachers were recruited with the minimum required qualification for teaching. That is: some of them started teaching without any qualification whilst others had basic teaching certificates. Only a very small number of teachers held bachelor degrees. This is because in a current highly competitive job market within China, many graduates with a certificate level qualification or above chose to go for professions with better financial rewards or opted for teaching in mainstream schools. Therefore, those who joined special school teaching with limited qualification and experiences have been and are still encountering dilemmas which they found very difficult to cope with.

\subsection{Factors influencing teacher motivation for professional development}

With regard to the purpose of professional development, Garner (2006) raises issues such as, what counts as professional development for teachers, who benefits and the nature of support for professional development. My research demonstrates a contrast between the rhetoric of the positive perspective on professional development and the motivation for engagement with the process. The tensions and conflicts expressed by teachers indicate their struggle within an increasingly demanding educational context. The four key factors influencing teachers' motivation for professional development identified by Stout (1996) are gaining new knowledge and skill, salary enhancement, certificate maintenance and career mobility. These factors are considered in the interpretation of the data from this study.

12.4.1 Financial support for professlonal development versus salary enhancement 
Financial support for professional development is considered a crucial factor influencing motivation for professional development (Arthur, et al., 2006). This is understood in two ways: money invested in the professional development process and rewards, in terms of salary enhancement opportunities through promotion, after the process. At present, China has engaged in a significant transformation of its economy and social institutions, including its education system. Along with the country's shift from a planned economy to a socialist market one, Chinese teacher education has experienced a time of rapid transition from central control to devolved and distributed management and decision making at provincial and local levels (Shi and Englert, 2008). Given that teachers are required to have in-service training, this is not always realised due to the lack of financial support or the availability of training especially in remote or economically disadvantaged areas of China. Opportunities for training are tempting, important but not easily available. Teachers cannot afford to participate in in-service training. It is often impossible for teachers in those areas to continue any kind of in-service training without financial support from the governments.

In the research contexts where schools were administered by provincial governments, the chances for professional development sponsored or partially supported in finance by the local educational authorities and/or schools were reserved for a limited few, often considered as backbone teachers. The tight budget from official levels made it difficult for schools to support most of the teachers. For the majority of teachers, they had to either manage by themselves or they simply regarded professional development as a dream to which they aspired.

Our generation is the most neglected. When we were young, they [the school] thought that we were still young and lucked experience. When we got experiences, they think that young teachers deserve more care and training. What should I say? It is just a blank for us, the neglected one. We had very little chance to get training, very rarely, very rarely, indeed. For me, I have had almost no training at all for the past 20 years. I did have a few chances of observing a class or two in other cities. I have had no further training at all.

The perspectives offered by teachers in this study have identified some specific Chinese cultural aspects that greatly influence teachers' motivation. The majority of teachers were facing the dilemma of the zest for professional development and the practical barriers which prevented them from obtaining access. Research on the perspectives of Chinese tertiary teachers of English on motivation for 
professional development had similar findings in this respect (Feng and $Y u$, 2008). There exist barriers which explain teachers' reluctance in funding themselves for their professional development, given that they generally have the motivation for it. Below is a quote by the case study teacher In Feng and Yu's research (2008).

\begin{abstract}
They have no money. They have to buy houses, raise the baby. They have younger kids to take care of. Their kids' education and care is more important than anything else. They are waiting for their kids to grow up. By then they may think they are ready to go. Or they think their kids' education is more important than their own. They would rather save money to send their kids abroad, not they themselves. It is a fact. Life is expensive. The first thing in life is to eat and have a shelter. The next thing is to think about promoting one's education.
\end{abstract}

Merit pay indicates a bonus plan that 'supplements the standard pay scale and rewards teachers for special services, a multi-track pay scale that provides rapid salary advancement for outstanding teachers...or conducting in-service training' (Johnson, 1986:61). With regard to professional development, in order to keep higher levels of pay and status, teachers carry on showing a high performance alongside a commitment to their own professional learning. For high performance, economic rewards are often perceived as important (Hawley, 1985:58). This is demonstrated in teachers' attitudes towards professional development, which correlate with their motivation for active involvement in development programmes and activities.

\title{
12.4.2 Gaining knowledge and skills versus time
}

Teachers' opportunities for professional development are likely to be constrained by time. Although training programmes enable teachers to gain knowledge and skills, it demands enormous efforts and time from heavy work and family related commitment and responsibilities (Forrester, et al., 2006). Teachers cannot find the time for change in their already busy schedules as the demands posed by daily teaching and other aspects of the reform absorb a bulk of teachers' energy, thoughts and attention. In-service teachers invariably have to manage their teaching and classroom commitments with their own personal study time. Garner (2006) argues that there is a linkage between attitude and provision, both of which have contributed to the perception of a professional development experience. There has been growing unease and frustration noticeable amongst teachers at various stages about the way in which award-bearing professional development courses have been structured and delivered. When teachers receive no support in respect of tuition fees, they 'become defensive about and resistant 
to any further demands on their time' (Garner, 2006:18). The question raised by Garner (2006:19) of 'Who benefits from teacher's professional development activity, bearing in mind that there are intrinsic as well as more pragmatic benefits, and that these will relate to quite distinct audiences?' deserves attention.

Who benefits? Why bother? We do not want the pressure to further our study. What we have is enough. We want the time to enjoy life. We do realise the real needs for improving ourselves as professionals. But it is not so important. We can make do with what we have learned from books or the Internet.

Informal conversation with a teacher during school observations

\subsubsection{Certificate maintenance versus life priority}

On the one hand, unlike teachers from economically developed countries where individuals pre-qualify for entry into teaching conditional with at least a degree, many teachers in special schools researched started teaching with bachelor degrees or below. Besides, teaching was not the first choice for those who did not have intrinsic motivation. Many teachers would choose to go for professions with better financial rewards as indicated in the findings. Given a high awareness of the need for professional development, to some, once they had the basic qualification, their career priority gave way to their life priority.

On the other hand, some teachers researched articulated that government or school policies related to professional development were not consistent, which sometimes discouraged teachers taking initiatives in professional development. A call for learning to enhance classroom performance had been chronically ignored due to the tight budgets reserved for staff development. Besides, once teachers reached a certain degree or title, teaching effectiveness was not evaluated to make the pay difference.

The motivation for development after degree upgrading relied on teachers' priority. The barriers in their professional life could be the conflicts between their heavy teaching workload and their family responsibility and commitment, which left them little time or energy for studying (Forrester, Motteram and Liu, 2006). As little support in terms of time or finance was available, there was a lack of motivation from some teachers in my study for actively seeking further personal and professional development. Although some teachers still held their selfconceptions of good teachers, namely, teachers with sound pedagogical content 
knowledge (Zhang and Watkins, 2007), teaching was no longer conceptualised as a 'performance' entailing the effective utilisation and delivery of state prescribed texts (Cortazzi and Jin, 2001). It seemed that, once they had learned how to teach, they had passed a threshold. After that, they got on with their teaching. The concept of future development did not seem relevant. Therefore, they were not motivated for personal and professional development at their own cost.

\subsubsection{Teachers take the initiative?}

Professional development is seen by the current English government as an essential component of school improvement. As such, it rests on empowering individual teachers as learners in their own right (Garner, 2006:22). There is a view, now promoted widely by the English government that teachers themselves are at the heart of this change process (Garner, 2006: 20). In the Chinese context where it is often the case that established teachers are considered as a priority when official funding for the traditional model of professional development is available. Moreover, there is no clear difference in the pay scale or promotion opportunities between those who seek professional development and those who do not. This helps to explain why most of the teachers within my research did not have the intrinsic motivation to pay for their professional development.

I would argue that the social, cultural and educational contexts of China are decisive components on the motivation of teachers in this area, coupled with the availability of time and finance. But why would teachers bother to participate? At least four motives underlie teacher decisions to do so (Stout, 1996). One is salary enhancement. Participation pays off. Automatic salary raises often accrue quickly, and almost always eventually. Eligibility to compete for merit pay or to climb a career ladder is often tied to demonstrated commitment to personal and professional development. Another motive is certificate maintenance. A third motive is career mobility. Teachers take courses and degrees and participate in workshops to build resumes. Having done so, they attempt to leave education for other occupations or to pursue other careers within education, administration being the notable example (Stout, 1996).

It is important to note that these different ways of understanding professional development are not directly tied to different career stages, so cannot be seen as a simple developmental continuum from novice to expert teachers' views. No particular way of thinking about development was limited to either early-career or 
more senior academics alone; each view of development was described by teachers at a range of career stages, although there appeared to be a difference in the frequency with which different views were described at different career stages.

For most teachers researched, professional development provided chances for their teaching qualification upgrading or job promotion. As long as they managed to reach the goals, they saw less need for further development. In other words, once they were qualified as teachers, there were few efforts made to evaluate their teaching effectiveness and therefore little incentive to improve. In the mainstream schools, teachers were evaluated according to the academic attainments of their students, which very often created peer pressure for teachers. Whilst in the special schools, since the students had either learning disabilities or other difficulties, evaluation against academic attainment was not applied and there existed certain complacency that so long as students were occupied, the school was doing its job.

I can only teach with my current knowledge. We really do not know much. I really want to learn more. But the school will not let us go [professional development] because we do not have enough teachers. The school will not want to find other people to cover our classes.

For those established teachers researched, a recurring theme was 'I am qualified and I will soon be retiring, therefore professional development has no relevance to me'. Similarly there was a view that 'if professional development programmes would not make demands upon my own money and time, and if I can still learn, then I would be happy to participate.' A mainstream teacher with 20 years' teaching experience expressed her motivation as follows:

If my child can pass the exams for senior school, I would like to go [for training]. These years are very important for her. I am not going to leave her now even with the support in time and finance from the school.

I-MT-11

12.5 The correlation between career motivation for, attitudes towards special and inclusive education and the motivation for professional development

Hustler et al. (2003) argue that attitudes towards continuing professional 
development are shaped by complex interrelationships between local structural and cultural factors (within and between schools) and teachers' career stage, age and subject affiliations. Their research indicates that most teachers perceive school development needs and national priorities the principle driving forces which have taken precedence over individual needs. However, the status, knowledge, and approaches can radically affect, positively or negatively, on teachers' attitudes towards and understandings of continuing professional development.

Concerted efforts are made in teacher continuing professional development for changes in teaching as well as teachers' motivation for and attitudes towards working with children with SEN (Moran, 2007). Today's teachers choose teaching for a number of reasons, from the traditional motivators of working with children, service to the community, continuation, and material benefits to the more recently identified notions of subject matter and self concept (RInke, 2008:8). This has included changes in teacher professional development to reflect an increased knowledge and understanding of the issues confronting teachers. However, there is a need to improve existing educational attitudes from teachers and the reform in the models of professional development to meet high demands with few resources (Wu, 2005). 


\section{Chapter Thirteen: Conclusions}

\subsection{A summary of the research and the findings}

The study aimed to investigate three key issues on the promotion of inclusive education from teachers' perspectives which related to a) teacher careermotivation for teaching children with SEN either in mainstream or special schools; b) teachers' knowledge and understanding of and attitudes towards special and inclusive education and c) teachers' perspectives on continuing professional development. Opportunities for teachers to share their perspectives and life experiences with regard to these issues have not been widely provided in China. The research described in this thesis was designed to address some critical issues by examining teachers' experiences with a specific focus on teacher career motivation and perspectives on professional development.

This was achieved by deploying a mixed-method approach to seek evidence to interrogate my assumptions and hypotheses following the three key research themes. The approach enabled me to hear teachers' voices. Methodologically, this type of approach has not been widely used in a Chinese context (Hayhoe, 2004; Wu, 2004). Data were collected from a purposive and selective sample in a single city in China. The participants consisted of teachers from mainstream and special schools, and student teachers who were about to embark on teaching at the time of the research. Self-completion questionnaire surveys in light of a pilot study were coupled with face-to-face, semi-structured in-depth interviews with a range of participants, with the latter being the main method of data collection for this study. Meanwhile, other research methods including a case study using narrative inquiries for teacher stories, field observations and document scrutiny were used. Once the surveys were conducted, data were used to modify the interview schedules so that suitable subjects for Illustrative case studies were identified and developed. Descriptive and interpretative data analysis allowed me to make sense of my own professional experiences by critically analysing teachers' perspectives and reflexivity of the questions in focus ( $W u, 2004)$.

The data collected with the mixed-method approach enabled me to clarify and validate the findings of the study, which broadly supported the underlying assumptions and hypotheses. The key findings are summarised in three aspects: 
First of all, teacher career motivation for special and inclusive education varied, dependent on factors such as their age, types of school they taught in, life experiences, family or economic backgrounds, areas they were from and their entrance examination scores for higher education. Factors influencing teaching choices as expressed by the three cohorts were mostly extrinsic. A large number of them did not have a life long commitment for teaching and would like to change to other professions if possible. Most of the teachers in the three cohorts accepted the value of adopting a philosophy of inclusive education. However, many perceived that it was better to place children with SEN in special schools claiming that such children could not be fully included in current mainstream school settings. A majority of the teachers from the mainstream schools had high respect for teachers in special schools. Nevertheless, many of them, including those teaching in the special schools, given the cholce would have preferred to teach in mainstream schools. Some teachers from the special schools suggested that they had witnessed positive changes in themselves from their initial controlled extrinsic motivation or amotivation towards a currently more autonomous motivation. They acknowledged that this enhanced motivation was to some extent the result of the accumulation of knowledge and expertise for working in special schools.

Secondly, given that teachers acknowledged that their perspectives on inclusive education had been constantly modified with their improved awareness and understanding, widespread confusion and a lack of common understanding about special education and inclusion were evident. Teachers' knowledge and understanding of, and attitudes towards special and inclusive education were largely negative. There was a general acknowledgement from the three cohorts of their limited knowledge and understanding of special and inclusive education as a concept. This was attributed by many to the flaws in programmes of initial teacher education and professional development. Teachers perceived that inclusive education had grown from the bellef that education was a basic human right which provided the foundation for a more just soclety. They identified that special and inclusive education provision was currently challenged by insufficient resources, limited support from all levels coupled with the impact of an Intensified market economy on inclusive practices. The less positive attitudes towards special and inclusive education were also evident from their self evaluation and assessment in respect to their lack of competence and confidence in teaching children with SEN either in special or mainstream schools. 
Thirdly, teachers perceived that adequate teacher training and professional development were keys to inclusive education. Hence, there was a high level of awareness from the three cohorts of the need for professional development in special and inclusive education. Nevertheless, their motivation for professional development again varied in accordance with their age, the schools they worked at, teaching experiences and life priorities. Teachers were generally satisfied with the models of professional development offered by their schools, which were largely short-termed and school-based. However, chances and opportunities for professional development varied from school to school. In addition, most of the schools did not provide clear incentives such as pay rises or career promotion for professional development. Therefore, when it came to teachers' active engagement in terms of investing time and/or money as well as efforts for professional development, motivation generally gave way to other priorities in their life.

\subsection{The significance of the findings}

The findings reveal some issues and challenges in special and inclusive teacher education and professional development in the research context, which are similar to those identified in other areas in China as well as in the wider world. Nevertheless, there are some significant aspects implying very strong Chinese characteristics which are not congruent with the existing literature and have rarely been reported.

On the one hand, the findings are concurrent with the literature that teachers are key stakeholders in inclusive education (Forlin, 2008). Successful inclusion is dependent firstly upon teachers' attitudes to its implementation and, secondly, upon their perceived competence to deliver this important educational initiative (Clough and Garner, 2003). In particular, their professional knowledge of, and attitudes towards the inclusion of children with SEN have a significant impact on the success of classroom communication, which influences the inclusive approaches adopted in their classrooms. Attitudes towards special and inclusive education and confidence in working with children with SEN need to be greatly improved.

The findings also concur with those of Hodkinson (2005) that if inclusion was to be established as a core principle of educational policy, its future success may rest with the next generation of teachers and the professional development of 
current in-service teachers. The study reveals that student teachers apparently had a seemingly shallow knowledge and understanding of inclusion. Teachers of the three cohorts were similarly positioned, believing that it was currently not practical or feasible to include all children in education without improving the current workforce or providing further support. The inconsistency from government policy initiatives to the implementation of inclusive education at the local level had inevitably led to teachers' uncertainty and resistant feelings towards inclusive education. Tensions were explained by teachers by identifying the deficits in China's teacher education programmes which still attached a low priority to special and inclusive education regardless of the acute needs for more and better qualified teachers. The tensions were anticlpated as being likely to intensify as schools were increasingly exposed to the marketplace (Rouse and Florian, 1997).

On the other hand, this study identifies that motivation was impacted by factors which were multi-dimensional, contextual and individual-specific. The findings from this study support the argument that cross cultural factors are important contextual determinants in career decisions (Lent, Brown and Hackett, 1996). Unique Chinese characteristics had a significant impact on career motivational factors and perspectives on professional development for Chinese teachers. This is shown from the findings on career motivation which differed from most of the existing literature in the following aspects:

First of all, a considerable number of the research findings from economically developed countries tend to highlight intrinsic and altruistic reasons for choosing teaching as a career, especially for young teachers (Richardson and Watts, 2005; Cooman, et al., 2007). In contrast, this study suggests motivation was more influenced by a number of interpersonal, social and environmental factors of selfconcept, life experiences, Interests and/or abllities and had long-term consequences on their professional life, well-being and their social situation (Creed and Wong, 2006). Student teachers as well as in-service teachers in my study were more extrinsically motivated. Particularly, controlled extrinsic motivation tended to prioritise in teacher career choice, especially for those working in the special schools.

Secondly, factors such as a sense of achievement, job satisfaction, or emotional well-being are ranked high in the Western literature on career motivation (Kniveton, 2004; Richardson and Watts, 2005). The findings from my study show 
that at different development phases in teacher education in China, teachers were left with little or simply no choice for their career. This is evidenced by the data from some special school teachers reflecting their situations, for example, under city dwelling regulations, recruitment policies based on entrance examination scores and parental replacement initiatives in pre-reform years in China. This is also demonstrated in the data from newly qualified teachers and student teachers who were impacted by university expansion and the ever increasing competition in the job market.

Thirdly, issues including, but not limited to, teachers' knowledge and understanding of, beliefs and attitudes towards special and inclusive education were speculated to be correlated with teacher career motivation and their motivation for professional development. In specific, insufficient pre-service training and in-service further education were identified as the main causes for teachers' limited knowledge and understanding of special and inclusive education. Inevitably, this had also resulted in teachers' negative attitudes towards inclusion. Given that this had, to some extent, led to a high motivation for professional development as was surmised, teachers lacked active involvement initiative.

\subsection{The limitations of the study}

As the sample was small, purposeful and selective, I am well aware that the current research only covered a small portion of the population in the context in comparison with the teacher population in China. The findings are of relevance to those colleagues working within a single province. Without seeking a wider representation, the associated weaknesses and limitations often described in respect of research of this kind are clear. Therefore, any potential generalisation of the findings to a wider context may be seen as inappropriate without further searching for a full understanding of the research topic in other areas of the country. This understanding enables me to avoid any misinterpretation of the correlations of this research focus.

However, this does not detract from the overall value of the research which provides rich data related to the specific context in which the work was undertaken. The study has provided a model which could be replicated elsewhere in China. Subjective qualitative measurement is arguably equally as valid within research into teacher opinions and experiences as a quantitative assessment of 
the same situation. Moreover, within any qualitative study of this nature, combining methods using quantitative data compensate the potential weaknesses of a single method approach (Gorard and Taylor, 2004). Besides, the data collection was followed by a period of reflection recorded in a research journal which allowed me to examine the data from several angles. Furthermore, narrative accounts were cited to illustrate the responses of the researched about their career engagement and professional development aspirations. Therefore, I would argue that all these were important in enabling me to maintain an objective overview of the area of study.

\subsection{The implications of the study}

Given that the evidence presented in this thesis was extracted from a small scale study in the context of a single city in China, Implications can still be drawn as follows:

\subsubsection{The implications for policy}

The existing policies on special and inclusive teacher education need to be reinforced at different levels in China. More specific and relevant policies need to be formulated and implemented to help attract, retain and educate the next generation of teachers to meet the increasing challenges of forecasted teacher shortages in special and inclusive education. Despite the tremendous efforts made by its government, China, as the largest provider of teacher education and training in the world (Yang and Wu, 1999), has not yet helped itself as expected, in the international profile of education. According to (UNESCO, 2006a), China will need two million less teachers by 2015 , as the school-age population continues to decline. But between now and then, a sizeable portion of the teaching force will retire. So even though the projected stock will fall for 2015 , the government must still recruit 1.7 million new teachers over the next decade.

According to the Chinese tradition, education is an important means to acquire socio-cultural capital and achleve advancement on the socloeconomic ladder (Gao, 2008:156). The findings Imply that teaching experiences motivated teachers who started with amotivation in working with children with SEN to the controlled extrinsic motivation or even have changed them into more autonomous extrinsic motivation. This indicates very strong Chinese characteristics which explain the unique phenomenon that some teachers researched could endure 
certain unwillingness to be in education for their life. Whilst opportunities for teacher development in certain areas have become extensive since 1988, it remains more or less non-existent in some disadvantaged areas. This study indicates that the high aspirations for professional learning and development did not necessarily lead to teachers' intrinsic motivation in their active participation in continuing professional development. Issues like the costs for professional development should perhaps always be considered in relation to the effects on students in inclusive classrooms. A cost analysis model must be refined, validated and implemented within and across areas to produce an analysis that meets the standards of rigour that allow the outcomes to be used to guide policies at different levels (Hunt and Goetz, 1997: 16).

\subsubsection{Implications for practice}

\subsubsection{Teacher recruitment and retention}

The improvement of education quality depends first on improving the quality of teachers and is therefore closely related to teacher education. The structure and content of teacher education programmes leads to the development of teachers' practical wisdom in ensuring equity when responding to diversity (Florian, 2009:534). To solve the problems inherent in general teacher education, a consideration of social and economic status of teachers in special and inclusive education is the key issue in securing improvement. The government should pay urgent attention to strategically deal with problems of the quality of teachers, recruitment, retraining and training in rural areas, and further mobilising financial resources from all sectors of the society to special and inclusive education (Qian, 1994).

The evidence from the study implies that China has to create a large number of teachers who are well-motivated individuals with skills and adaptability to match the development (Yang and $W u, 1999: 160$ ). Despite that it has drawn attention from the Chinese government, teachers' lack of commitment to teaching as a lifelong career plus the current shortage will remain a serlous problem in the coming years. In the development of inclusive education, the most pressing challenge is the scarcity of qualified special teachers. Teachers' lack of motivation is due to the issues of low social status and recognition, poor salary, inadequate working conditions, and limited opportunities for professional development. 
The government has to realise that teachers' salaries have a direct impact on recruitment. Graduates are not being attracted into a profession that pays less than most other graduate jobs. Whilst research (Cooman, et al., 2007) has identified that rewards simply make people less interested in the intrinsic joys of an activity, this study indicates that some teachers in the special schools actually found rewards such as extra pay and /or less pressures had enabled them to enjoy increased job satisfaction. This satisfaction had motivated them to appreciate children with SEN and eventually led them to be intrinsically motivated in respect of their profession.

\subsubsection{Teacher education programmes}

The implication for adequately preparing pre-service teachers is to make changes in the curriculum of normal institutions to incorporate more professional educational courses into teacher education programmes (LI, 1999). Teacher knowledge and understanding of pedagogical issues which support and encourage inclusion must be reinforced through the development of initial teacher education and professional development. Teacher education programmes may consider offering workshops facilitated by experts in the area of special education tailored to different courses. Courses taught by experts in the area of special education are invaluable in helping teachers develop a broad scope of understanding of the various types of learning disabilities and how these may be addressed (Brown, et al., 2008). However, there is evidence in the literature (e.g., Ocloo and Subbey, 2008) to suggest that, stand-alone courses in this area may not be sufficient to increase the skill, competence, and confidence of the general educator. Specific issues identified in terms of teacher motivation for professional development must be addressed to improve the effectiveness and relevance of the teacher education system (Richards and Farrell, 2005). Narrative teacher accounts (XU and Connelly, 2009; Yang, 2008) could highlight the need for teacher preparation programmes to include and emphasise teacher professional development opportunities. The witness of one of the case teacher's constant search for career development and experiences of professional growth will open possibilities for a change of perspective from other teachers in their teaching profession.

Speclal education knowledge needs to be updated and expanded (Wan, Wang, Du and Chen, 2008). A significant number of teachers from the current study showed their ignorance of inclusive education as a concept and their lack of knowledge and expertise in addressing the special needs of children in their classroom practices. Therefore, the position of teacher education in relation to its 
contribution to the development of inclusive thinking and practice is of fundamental importance in the process (Barton, 2003:21). The process must also involve all the participants including university and college-based teacher educators, student teachers and teachers in schools working together with children with SEN (Cochrane-Smith, 2004). In the light of this, in-service or preservice teacher preparation programmes must pay attention to the importance of teachers as respected professionals, with specialised skills and knowledge that are valued both by students, administrators, and more experienced teachers (McCabe, 2008: 115). It would appear that much remains to be addressed during initial teacher education, if inclusive practices are to be fostered and embedded in teacher education. Knowledge and competency of pre-service teachers in describing the nature of learning disabilities and appropriate adaptations for teaching and assessment can be increased by exposing student teachers to instructions focused on SEN.

\subsubsection{Teacher attitudes}

Education systems are influenced by social forces, political and ethical issues of diverse kinds at different levels in its school system (Nilholm, 2006:434). China is facing a common set of dilemmas and associated tensions in the inclusive process (Mitchell and Desai, 2005: 195). The value placed on collectivism reflects the influence of Confucian thought and socialist ideology in the educational context which has placed special and inclusive education in the centre of these dilemmas. Meanwhile, various tensions are witnessed in its endeavours in balancing between the global and the local, between the Western and Asian philosophical assumptions of catering for students with SEN and between pursuing the ideology of inclusive education and adopting pragmatic solutions in practice.

In particular, within China, traditional attitudes towards people with SEN and Marxist commitments to fixed social roles provide the country with a notion of constructed collective identities. This is a framework which may be in conflict with current moves towards a more inclusive education system as advocated in recent Chinese education policy influenced by international agreements such as the Salamanca Statement (UNESCO, 1994). Western values such as individualisation, self-advocacy and diversity have not as yet found equivalents in China (Potts, 2000). The current development in inclusive education has extended and challenged the traditional roles and responsibilities of teachers. The issues identified from the study reflect the dilemmas teachers are facing with regard to their career motivation and professional development. The availability of 
professional development opportunities plays a critical part in their career motivation for, their knowledge and understand of, and attitudes towards special and inclusive education. Consequently, the joint factors affect their teaching effectiveness and services for children with SEN.

\subsubsection{Teacher professional development}

More efforts are urgently needed to address issues such as teachers' professional development under the auspices of market and knowledge economy and their effects on Chinese teacher education both in the short and the long term (Shi and Englert, 2008). Therefore, whilst the governments are urged to embed the concept of lifelong professional and personal development within inclusion policy (Daniels and Garner, 2000), teachers should be better encouraged. The government should mobilise more financial input for special and inclusive education. At present, to address shortages and limit costs, some local governments are still hiring teachers or unqualified personnel on temporary contracts as evidenced also in my study. The educational de-centralisation has not prevented some schools from keeping this practice to make up for the teacher shortage or budget constraint. Therefore, the need is felt to increase high-quality teacher preparation programmes in all parts of the country, not just in major cities such as Beijing and Shanghal (Ellsworth and Zhang, 2007). Otherwise, this consequently would have a negative impact on the improvement of teaching and education quality.

\subsubsection{The implications for the SDT theory}

Theories are always of necessity under test and development. With this study, I venture to propose a discussion about the SDT theory which could possibly attract attention to researching further into career motivation by applying the continuum of the SDT spectrum.

The SDT theory (Ryan and Deci, 2000) argues that the strength of a tendency to act in a specific way depends on the strength of an expectation that the act will be followed by a given outcome and on the attractiveness of that outcome to the individual. Intrinsic motivation is identical to some extent with integrated extrinsic motivation as they are both autonomous forms of motivation. However, they are generally considered as two different types of motivation. The data from my study prompted me to ask whether the continuum of extrinsic motivation in the SDT theory could possibly be a continuum to the far end of the whole motivational 
spectrum. That is: extrinsic motivation could possibly turn into Intrinsic motivation, dependent on time, content or context factors. The same could also be true to the change of amotivation to extrinsic or even intrinsic motivation. If the possibility existed, it would be easier to make better sense of the findings built on data in this respect. Specifically, it could explain the fact that amotivated teachers in my study could eventually stay in special schools for their entire career. It could also be understood that others, given their initial intrinsic motivation for the profession, could react so dramatically upon the news that they were allocated to special schools by the government (An example of motivational change is shown in Appendix XI). The change from controlled motivation or amotivation to autonomously extrinsic motivation or even to intrinsic motivation with their years' experience in special schools could happen as evidenced from the study.

The extrinsic motivation varies from more controlled regulation to less controlled and more autonomous regulation (Ryan and Deci, 2000). That is: for example, when some teachers started working in special schools, they were 'forced' by extrinsic motivation as they had 'no choice' but needed to take the job to 'make a living'. Nevertheless, their teaching experiences helped to enhance their motivation. Although still extrinsically motivated, there was a change of motivation from the motivation spectrum.

With this regard, I am curious about the possibility for certain extrinsic motivation to reach a higher level (e.g., job satisfaction) which could ignite potential or hidden intrinsic motivators similar to the effect of intrinsic motivators. The suggestion of this possibility is based on my assumption that the change of human behaviour in terms of motivation might not have a clear cut border line due to the complexity of human nature. In other words, there might be certain overlapping factors that belong to the categories of either integrated extrinsic or intrinsic motivators. In that sense, one might not be able to accurately identify what motivated them for changing or maintaining certain behaviours. In my study, the participants might have given certain obvious factors without being able to clearly locate the factors into the right category. As a consequence, I, as a researcher, might have misinterpreted their motivation aspirations.

\subsubsection{The implications for future research}

Teacher career motivation in special and inclusive education is still a virgin land 
waiting for future exploration. This arguably original study in the Chinese context enables me to propose future international comparative studies of this nature. In China, future research can also attach importance to middle school leavers about their career motivation in special and inclusive education as well as their parents' perspectives on their children's career choice. The assumptions are that China is undergoing a transition period in special and inclusive education. The recent reform and development in China has dramatically changed Chinese people's ideology from embedded collectivism to individualism. This, in a sense, brings hope for more attention to be paid to children with SEN. However, the change may also entail that the Chinese are becoming more ego-centered, moneyoriented or market-driven. If this was the case, intrinsic motivation or altruistic motivation of working for children might give way to motivation for other professions that would promise better social or economic value. In fact, the findings from the current study have implied this issue. More research is needed for the assumptions to be evidence based.

Meanwhile, little has been reported about ethical issues in researching disadvantaged and vulnerable children and young people with SEN, which I assume to be problematic currently (see Appendix XII for the implications of the ethical issues drawn from the current study). Last but not least, more voices should be encouraged from their teachers, who are equally vulnerable in terms of their self-esteem, social status and emotional well-being, just to name a few. Studies could address issues in this respect to advocate dialogues and empower children and their teachers to articulate their perspectives on special and inclusive education.

\subsection{Conclusions}

Western values such as individualisation, self-advocacy and diversity have not found full equivalents in China. This is due to the incomparable nature of education systems coupled with the impact of historical, philosophical, political, socio-economic and cultural variations on teachers' perceptions and beliefs (Booth and Ainscow, 1998; Mitchell, 2005; Norwich, 2008). Traditionally and socially, individualism is not prioritised and encouraged. The problems posed by greater diversity tend to be seen by the participants of the research as belonging to the children, rather than the system. Underpinning the Chinese culture are the traditional values of Confucianism which emphasise the development of the individual as a social being who should adapt to the collective society. Education 
in Chinese socialist ideology is to Illuminate individualism rather than to cater for individual needs (Cheng, 1990).

On the one hand, despite the concerns and problems associated with the implementation of inclusive education (Farrell, 2001; Evans and Lunt, 2002; Carlberg and Kavale, 1980; Hunt and Goetz, 1997), China has shown its persistence in promoting a policy of inclusion in the past two decades. Special and inclusive teacher education has witnessed vast development with policy initiatives and concerted efforts at all levels. The increased awareness and recognition of teachers' role by policy makers and society at large has resulted in further efforts in improving the quantity, quality and the structural levels of teachers. It has also influenced the direction of teacher education in recovering the system to meet the increasing and changing demands. Teachers have been prominent in the promotion of moving towards more inclusive education for all. Effective endeavours have been made in modifying its educational provisions.

On the other hand, the unbalanced development in all aspects in this densely populated country with extreme economic and cultural disparities has impacted on special and inclusive teacher education and presented great challenges. The balance between what is required of teachers and what is offered to them has a significant impact on the composition of the teaching force and the quality of teaching. This is one of the decisive components which impacts on their career motivation.

Given that there is a dramatic decrease in teacher shortages and significant improvement in teacher quality in China, teachers' lack of motivation in special and inclusive education can affect the services provided for students with SEN. A lack of intrinsic motivation coupled with limited knowledge and understanding may constitute barriers in teachers' attitudes and professional identity transformation. Inclusive education has provided equal opportunities for schooling for children with SEN but meanwhile posed new challenges to the whole education system. In a comparison with the educational provision for general education in this country, or with the provisions for children with SEN in a wider world, especially in some economically developed countries, China still has to make further efforts. In pursuing equity and excellence, China gives priority to providing education for the majority of their population.

Nevertheless, the low priority attached to special and inclusive education has an 
impact on teacher career motivation and professional development in special and inclusive education. This is evidenced from the study that teachers' initial lack of motivation in teaching in special schools as a career which could have been influenced by their limited knowledge and understanding of, and attitudes towards special and inclusive education. Whilst a majority of teachers supported inclusive education, they did so with reservations (Croll and Moses, 2000). Or, they simply believed that to keep a desk in their classroom for a child with SEN would be the best they could do (Slee, 1993). The flaws in initial teacher education programmes prepared them with little or no knowledge in this area which led to their negative attitudes towards educating children in special or inclusive schools. Their negative attitudes further influenced their intrinsic motivation either for their career or for continuing professional development. The intricate relationships of the three correlate with each other which reflect teachers' social and professional identity and status.

Moreover, educational competition has intensified in recent years as China is caught up in a global trend of educational commercialisation and devolution (Gao, 2008: 157). This is evidenced especially in the tertiary sector, which has dramatically increased individuals' stakes in education. The commercialisation process has a profound impact on all aspects of teaching and teachers, including teacher employment policies. This is reflected in the job market for tertiary graduates due to the university expansion. Although the government has repeated its policy of encouraging talented young people to study to be teachers, the quality of students in teacher education institutions is declining. The best students in terms of academic studies tend to enter other universities as they are more interested in professions in which a better income is available. Given that the increased prominence of special and inclusive education has made a shift from a negative to a more sympathetic and positive social and professional status of teachers working for children with SEN, more need to be done to provide teachers with valued incentive and motivation.

Above all, as the world is striving to achieve the Millennium Development Goal of Education for All by 2015, achieving the right to education for diverse learners is still a very challenging work in China. Although China has a firm commitment of educating students with SEN in regular classrooms, there are many obstacles to overcome if these students are to be provided with appropriate education. Some of these are logistical and economic. Others reflect deep-rooted cultural values (Mitchell and Desai, 2005: 176). The comparative low status of special and 
inclusive education in China means that it is impossible for the country to make as high an investment in special teacher education as it would like. In addition, the number and quality of teachers is incomparable with the mounting number of children with SEN, given there are no reliable figures available as special education used to and still is considered as the education for the disabled (Chen, 2005). I believe that the attitudes of teachers as main stakeholders in the inclusive education process will remain to be a burning issue. A significant number of children with SEN will continue to be integrated but not included (Feng and Jament, 2008). Less positive attitudes of teachers will continue to prevail and will critically affect the education services as well as teachers' motivation for career or professional development.

\subsection{The contribution of this study}

Work of this nature in respect of teacher voices is worthy of further exploration. This study invites re-examination of recruitment efforts, aspects of teacher education programmes and current models of professional development (Watt and Richardson, 2007). The study is hoped to contribute to special and inclusive teacher education and professional development in China in three aspects.

First of all, this study has striven to provide evidence of motivational factors which impacted on teachers in career choice and professional development. In so doing, it has identified some specific Chinese cultural aspects critically effect issues relating to teacher career motivation, their values, attitudes and perspectives on special and inclusive education. This is seen to have further influence on their career choices as well as their perspectives on professional development. The tension and conflicts expressed by teachers has provided evidence which indicate teachers' struggles within an increasingly demanding educational context. It has provided a useful basis for further exploration which may enable some guidance to the understanding of teacher career motivation and enhance the accountability of teacher professional development. Moreover, the identification of the barriers experienced by teachers and the articulation of the issues in teachers' voices has provided evidence to enhance inclusive education services through teacher education and professional development. Meanwhile, the analysis of teachers' voices has identified some important barriers and cultural frustrations to be overcome in teacher education. This allows for the study to provide academic and practical significance to the limited body of knowledge in research of this nature in China. 
Secondly, global understandings of Inclusion remain far from complete as the complexities of some of the issues impeding the development of special and inclusive education need further researching. Research based evidence can have an impact on policy decisions related to teacher education that will shape the nature and training of teachers in special and inclusive education settings. The findings may lead to more effective policy implementation and action from various levels. This in turn can improve teacher career motivation and illuminate the attraction, recruitment and retention of teachers in special education.

Lastly, as Mitchell (2005: 19) cautions, considerations should be given to each country's own social, economic, political, cultural and historical singularities. Each country's indigenous philosophies, ideologies and practices should be encouraged, respected, challenged, overthrown or blended with those of the 'exporters'. The scarce availability of special education training programmes in its vast geographical regions, especially in the rural areas, presents challenges for China (Deng and Holdsworth, 2007). The challenges imply that with China being caught in the shift of a new paradigm, especially in the increasing demand on teachers with special education training and their further professional development, there is a need to improve existing educational attitudes from teachers ( $W u, 2005)$. Understanding teacher motivation for choosing teaching as a profession has implications for teacher education planning and curriculum design, teacher recruitment authorities and government and intergovernmental planning and policy decisions (Watt and Richardson, 2007).

Overall, limits to and possibilities for the reform in special and inclusive education need to be further debated (Slee, 2006). It was anticipated that the current study could add knowledge based upon evidence to the limited body of literature in this area for a paradigm shift when China moves towards more inclusive education. I have chosen to encourage the hidden voices from teachers on their exercise of special and inclusive education in China. I hope that meaning and knowledge with regard to teacher career motivation and professional development could be socially constructed by investigating the multiple interpretations surrounding this complex issue. I also hope that this study could illuminate and encourage further research of this nature to be conducted nationally and Internationally so that better understanding could be achieved. Above all, teachers can eventually speak the same language as their international peers in the debate of 'making special education more inclusive'. 


\section{Appendix I}

\section{The motivation for the PhD study}

This appendix is the reflexivity of my motivation for the PhD study. In particular, I illustrate my career motivation in special and inclusive education and my perspectives on professional development. In other words, this is the data, the voice from me as a researcher.

I contend that teacher career motivation is multi-faceted whilst teacher professional development entails change for emotional and social as well as intellectual and practical engagement in the learning processes (Day, 2004). I agree that professionalism involves learning about oneself and gaining reflexive knowledge of social and cultural practices' (Alred, Byram and Fleming, 2003: 10). It also involves cognitive reflections on the provision of relevant experiences in order to enhance his/her professional growth, whereas intercultural experience has the potential to broaden and deepen the mind through reflection, analysis and action. With regard to special and inclusive teacher education, I believe that preparing new teachers to face the kind of diverse classrooms that many of them have never experienced themselves in their own schooling requires significant changes in educational thinking (Richards and Clough, 2004). As a consequence, the change is not only professional but also personal.

Reflecting upon my own learning experiences and teaching career, I would argue that it provides evidence of the constantly changing situation in teacher education in China since 1980s. My career motivation and professional development may not be representative in China nor can it be generalisible. Yet, it is an example of how a teacher is educated and developed in the recent decades.

My initial motivation of becoming a teacher was mostly intrinsic and the impetus for seeking professional development in the UK in September 2005 was a combination of intrinsic and extrinsic reasons. Given that I had years of teaching experiences as a language teacher trainer in the School of Foreign Languages of Shaoxing University, China and a couple of years' in-service continuing professional development at home and abroad during that period, I had very limited knowledge about special and inclusive education when I started my study in The University of Northampton in 2005. The shift from my professional career as a language teacher to a student of special and inclusive education was largely altruistic.

After working on the international affairs in my home university for long years with great responsibility and duty which left me with limited time for my professional development as a language teacher, I felt a strong motive to further my education overseas. I asked my university for a one-year self-funded study leave. By coming to Northampton, I thought I could coordinate the collaborative programmes I initiated for my home university and the University of Northampton. Meanwhile, I could take some time off work to further my study in linguistics and literature. I was my hope that a one-year's full-time learning would make an impact on my teaching upon my return to China. This motivation arose from my assumption that cross-cultural experiences could enhance cultural awareness, language competence and teaching effectiveness of teachers of English at tertiary levels, which could further motivate them for personal and professional development. The assumption led to a small scale pilot study in two universities in China in 2008. A paper based on the research was presented at the Asian-Pacific Educational Research Association Conference (Feng and Yu, 2008) and is being considered for publication in the journal Teaching English in China. 
To my surprise, being the only person applied for the programme of linguistics and literature, I was placed in the School of Education upon arrival. Considering my teaching experiences, the University suggested I join the Masters' programme in Education. Nevertheless, I did not expect the programme to be so much focused on special and inclusive education. None of my previous educational background, teaching or research was related to special and inclusive education. Obviously, I was not prepared for it academically or psychologically. Even when I was offered a position of post-graduate teaching and research assistant in the School of Education for my PhD study years, the motivation of changing my teaching and research direction was greatly challenged by the temptation of returning to my work as Acting Director of the International Office of my home university as well as a language teacher. Moreover, I was greatly discouraged by many Chinese colleagues and friends to study any further in special and inclusive education due to the restricted nature and status of special and inclusive education in China. According to them, professional development should not be the priority of a mature woman like me with considerable academic and personal achievements, especially under the circumstance that no financial support was available from my home university. In fact, I had to pay a substantial amount of money to the university for the study leave. To be honest, I was very much challenged by my commitment to the family envisaging the long journey to a PhD in a foreign and expensive country.

Nevertheless, I witnessed change in my motivation for and attitudes towards special and inclusive education in the MA study year. I was grateful to the opportunity of working with the colleagues in the Centre for Special Needs Education and Research of the University on a local government commissioned research project on Extended School in England (2005-2006). I acquired empathy for the values expressed in the field of special and inclusive education. My interest in this area was gradually raised with the intensive learning. Meanwhile, I was highly inspired by my supervisors and those who had been devoting their lives in research and practice for children with SEN. All this set me thinking about the current education provisions for Chinese learners with diverse needs, the opportunities of making changes in this research area in my home context in initial teacher education and professional development, and the possible contribution I could make to the limited body of knowledge with the completion of my study. I began to appreciate the learning opportunity rather than anticipating the challenges in the learning process.

My previous general knowledge and expertise in teacher education and the Masters' study raised my self-esteem in studying the PhD. At this point, my one year Sabbatical leave from long years' of enjoyable, rewarding but extremely stressful and challenging administration work in international affairs was extended to a full-time PhD study.

My initial limited understanding of this field was due to a range of reasons:

First of all, special education in China has been traditionally understood as education exclusively for the disabled (Chen, 1996). Before 1980s, children in China with disabilities were segregated in a limited number of special schools or were the sole responsibilities of their families. Therefore, I had never studied with disabled students in my life. In addition, the promotion of inclusive education started in China only in late 1980s. It was the Chinese government's strategic policy to provide equal opportunities for a 9-year compulsory education for all children, including those with diverse educational needs who would otherwise not be accommodated for the scarcity of special schools, especially in economically and geographically disadvantaged areas. Given that some higher learning institutions also accepted students with disabilities and/or learning difficulties, the 
access was limited to the few who had to prove their academic capacity as equal to that of their able peers. They also had to demonstrate their independence in their everyday school life. Therefore, it was not surprising or uncommon that in my long years' of teaching at the tertiary level, I have never had a chance to teach any students with physical disabilities. I remember there were some students in my teaching experiences who were different from others in terms of their learning abilities and/or their behaviour. However, I was not able to identify their problems or difficulties. Like many of my colleagues, I tried my best to help them without knowing whether I had appropriately addressed and met their needs.

Secondly, my initial teacher education in the early 1980s prepared me with mainly subject-based knowledge of English language. As far as I can remember, I had only had a few hours' formal learning from lectures in the university on the theories of education before being placed in a middle school for teaching practice. Special education was never integrated into any of the modules in the four years' degree study. At that time, teaching internship lasted six weeks in the last academic term for student teachers in normal universities. After a week's observation in a class in the placement school, which was a mainstream one, I was asked to teach a junior class of more than 50 students. I survived the teaching with the support from my teaching mentor who was an experienced and committed teacher. I was then granted a bachelor degree of English Language with distinction from the university which qualified me as a teaching assistant/lecturer in a teachers' college (now it has expanded to a comprehensive university).

Moreover, my motivation for professional learning overseas was challenged. I was told by my home university that I had to fund myself for the study as the university had very tight budget for teacher professional development. I was accustomed to this response. I understood that this was the common practice in most of the Chinese provincial universities, where institutional policies for professional development changed constantly in accordance with the national priorities in this respect. Moreover, budgets were never big enough to be spent on teacher professional development. It has become even so ever since the university expansion from late 1990s. Anyhow, I only wished that I could, upon my return in a year's time, better devote myself to the professional life as a language teacher, to which I had eternal passion from the time I started my teaching career.

My curiosity for this research topic became increasingly strong that it turned into the driving motive, passion and commitment for me to explore that of other teachers in their career choice. I was also keen on investigating their perspectives in professional development, which I assumed would have a close link with their career motivation, their knowledge and skills of and attitudes towards special and inclusive education. When I decided to study for the PhD, I knew I had chosen a new but hard journey for my professional life, a career full of opportunities but meanwhile presenting challenges. It was my hope that, with this study, more awareness of the importance of special and inclusive teacher education in China would be raised in China. 


\section{Appendix II}

\section{The research context in China: additional information}

\section{Basic education}

Basic education includes primary and regular secondary education. The latter is further divided into secondary junior and secondary senior education. Pre-school education is optional which lasts up to three years for children from age three to six. Primary and secondary junior schooling is compulsory which lasts 9 years. Secondary senior education lasts another three years for those wishing to continue their education but having to pass locally administrated selective entrance examinations. Besides, basic education also provides educational opportunities for adults with low standards of literacy.

Until 1993 the curriculum was totally controlled by the central government. A result of this strong uniformity created huge difficulties in practice. The centrally designed curriculum is extensive and demanding, leaving little flexibility for local adaptations. In the fall of 1993, a small portion (10\%) became the responsibility of local areas. The content which is inaccessible and un-motivating can be distant to the reality of diverse learners. The Curriculum Reform of Basic Education (Ministry of Education, 2001) has been implemented to integrate all dimensions of education. This reform aiming at promoting the whole development of students not only in intellectual and physical skills but also in knowledge-seeking skills is currently being practiced.

Although China will be demanding less number of teachers for basic education in the years to come before reaching the global target of 'Education for All 2015' (UNESCO, 2006), this is just a comparison with its past based on the decline of school-age population in the country in the recent few years. In fact, the Chinese government still needs to recruit 1.7 million new teachers over the next decade due to the retirement of a sizeable portion of the teaching force. The government planned for the partial implementation of the law in the early 1990s and full implementation in the whole country by the end of twentieth century. Whereas progress has been significant, there remain many challenges ahead for basic education in the country.

Concerning the contextual differences of education in different regions of the country, the law has stipulated free-tuition for compulsory education. It exempted school charges for students first in the rural areas of the backward western parts of the country in 2006 and nationwide in 2007, which further guaranteed schoolage children the right to free education. The gross enrollment rate of senior secondary schools was $\mathbf{4 2 . 1 \%}$ (Chinese National Commission for UNESCO, 2004).

\section{Higher education}

Higher education encompasses a broad range of different degree programmes to train specialists for all sectors of the country's development. For example, in the early 1990s, Chinese universities admitted very limited number of the school student cohort. Recently, the participation to higher education is much widened, though still limited to those who can pass the entrance examinations held annually nationwide.

\section{Adult education}

It has progressed as a socialist adult education system with typical Chinese characteristics and is changing in response to the ever increasing needs of the country. The purposes and objectives of adult education have been to raise the quality of life for workers; to train individuals for jobs and prepare specialists, administrators and managers; and develop people who are dedicated, moral, 
disciplined and well-informed.

\section{Teacher education}

General higher teacher pre-service programmes, which last for 4 years, are offered in normal universities and education departments of regular higher education institutions for the training of secondary level teachers. These institutions of higher learning play an active part in in-service training of secondary school teachers as well. Regular secondary teacher pre-service education aims mainly at the training of teachers for pre-school, primary and special education levels. The 2-3 years' programmes are conducted in teachers' colleges or schools where in-service teacher training is also offered in forms of distance learning, self-study, evening classes and other similar arrangements. At present, the proportion of non-teacher education colleges in the total number of teacher-training academies has risen to $54 \%$ (Chinese National Commission for UNESCO, 2004). The active participation of the colleges in teacher education has injected new vitalities into the construction of an open and flexible system of teacher education.

Overall, the curriculum structure for the teacher training schools, especially those pre-service training schools, consists of three main components: general education courses which offer a series of comprehensive training in political/ideological issues, foreign languages, physical education and computer science; subject matter courses within the academic areas in which the student teachers are enrolled (e.g. English, Physics, Chemistry, or History, etc.); and educational/pedagogical courses which offer training in the areas such as pedagogy, psychology, and subject matter content teaching methodology and the like.

Pre-service training institutes normally provide full-time education for student teachers in preparation to enter into the teaching profession whilst in-service training institutes provide more part-time based training (Song, 2008).

\section{Teacher professional development}

The Ministry of Education sets regulations on continuing education by defining the contents, categories, organisation administration, infrastructure standards, examination and verification, awards and penalties of continuing teacher education. The targets of such trainings are to meet primary school teachers' requirements of continuing education, to orient new teachers during the probation period and to enhance the basic skills of all that hold teaching posts.

One kind of professional development model is called Action Education (Xingdong Jiaoyu in Chinese). It is a form of school-based training model which aims at updating ideas of teaching and learning, and designing new situations to improve classroom practice through exemplary lesson development. As it directly tackles issues in teaching and learning, although there are some challenges in implementing the model, it has shown the potential to enhance in-service teacher learning and professional development with comparatively low cost. It is promoted in many schools in China.

\section{Special and inclusive teacher education}

The compulsory courses are classified into public and specialized categories. The public ones are mainly courses of subjects plus Ideological and Political Education and Introduction to Special Education. The specialised ones are offered for different specialties based on the local needs for special primary education. They include Psychology, Pedagogy, Methodology and other courses for broadening student teachers' knowledge, developing their interests and special skills in prevention and examination of deformity. Teaching practice includes visiting, 
probating and assisting special education teachers. Extra-curricular activities provide education in science and technology, arts and sports.

\section{Pen portrait of the local research context, sample schools and the university}

Zhejiang belongs to the first category listed above owing to its long history, dynamic economy, splendid culture and favorable natural environment. Following the introduction of the reform and opening-up policies, Zhejiang has made rapid strides in its economic, scientific and technological and social undertakings. In Zhejiang, the registered number of students in special schools for the disabled was 14,200 . The number of teachers in the province has been raised and teaching quality has been improved in coordination with the development of all types of educational goals.

Shaoxing is rich in cultural heritage with about 2,500 years of history and civilization. A public awareness of education and long tradition in running schools makes Shaoxing the home of a range of many well-known people in all walks of life generation after generation.

Among the seven mainstream schools, one is an independent primary and secondary school with 8000 students. Two schools are regarded as the top academically achieving schools out of 11 provincial key mainstream secondary schools. The schools enjoy a good reputation for the quality of teaching resources, a high percentage of students being admitted to higher education institutes and universities. The students are mainly from the local community though others come from other communities or cities attracted by the reputation of the schools. Students have to prove their high academic attainments to be admitted together with some considerable extra charge for their tuition. Teachers are very heavily loaded by an imperative for helping students to pass tests for access to good senior middle schools or higher education.

Another two, one primary and the other secondary junior, are key schools of the city. They are very much selective under the administration of the municipal people's government. The primary school is located in the centre of the city where children were mostly from economically well-off families and/or families with high social status. In contrast to the school located on the outskirt of the city which has in particular a large number of students whose parents are mostly physical labours from countryside areas working in the city, known as migrant workers in China. Being a community serving school, in a sense, the school is more inclusive in the enrollment of students. The final two schools were junior ones rating average in the local unofficial league tables.

The two special schools are the only ones in the city. The school for children with learning difficulties was established in early 1980 while the school for sensory impaired children was set up in 1947. This aligns with the country's overall development in special education. There are about 92 students with mental retardation aging from 6 to 17 . There are 13 teachers teaching in 9 grades in the school. In the school for the sensory impaired, About 130 students aging from 618 in 10 classes. They are taught by 24 full time teachers and served by 11 other support staff. There are children learning in different grades ranging from primary to secondary vocational. The two schools are rated as primary schools. Unlike the other schools researched, there are 3 cover teachers in the school for children with learning difficulties. The cover teachers work full time at the school. But they do not enjoy equal terms and conditions as other qualified teachers. They are college or university graduates but with no Initial teacher training before they were recruited (A discussion of this will be provided in Chapter VI). 
Approved by the Ministry of Education, the university was founded in 1996 on the basis of the amalgamation of several institutions of higher learning, chiefly a teachers college and an advanced professional college. The university can be traced back as a primary teachers' school founded in 1909 and has been forging ahead vigorously in the past decades from the teachers' school to a teachers' college till it was renamed as a university in 1996. It has undergone tremendous expansion in all disciplines it covers. In 2007 the university's full-time undergraduates reached about 20,000 in 52 undergraduate programs (grouped into 24 departments) which cover eight academic disciplines, namely, arts, science, engineering, medical science, law, pedagogy, management and economics. There are roughly 15,000 part-time students taking courses in various programs of adult education. There is an emphasis on initial teacher training, but there are also programmes such as humanities, languages, business and management, engineering, computer science, mathematics and information technology.

There is no module on special and inclusive education as no lecturer has had any formal training or qualification in teaching the modules, although they have research and teaching capacity in education in general. 
㝕宫

䓂ㅇำ

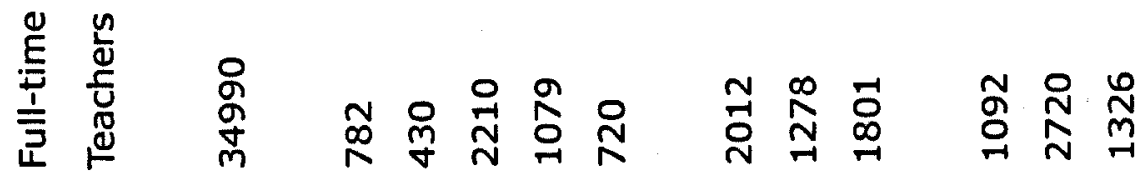

宅高

감

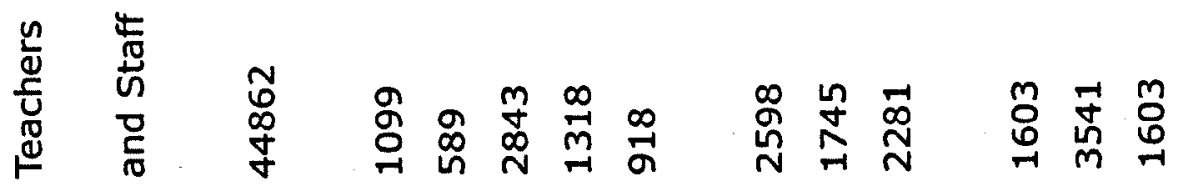

을 氙

焉

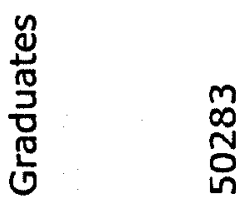

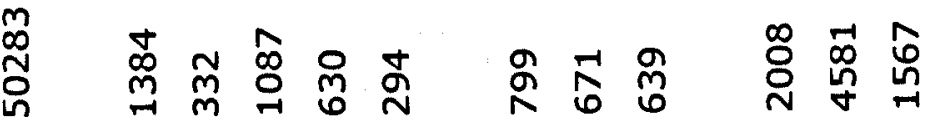

ᄃㅇㅇ응

总

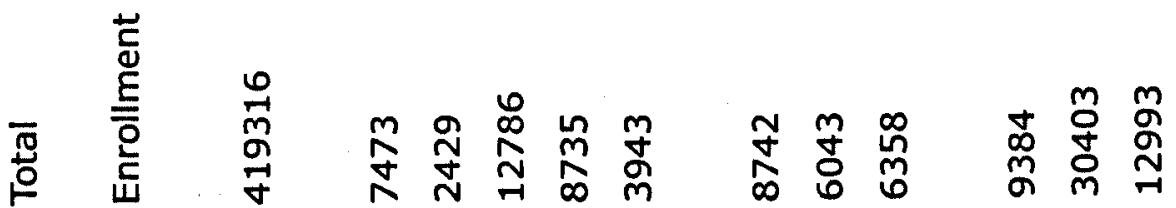

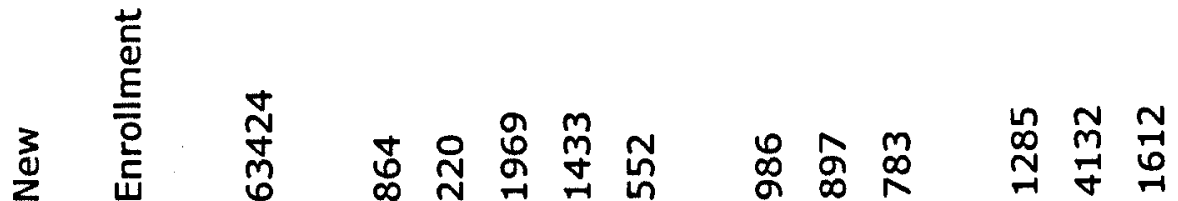

음

离

동

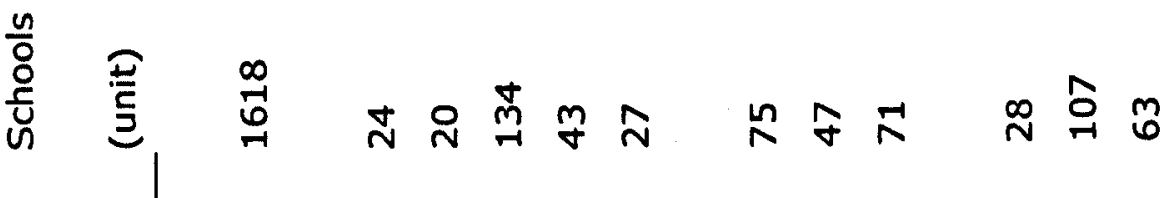

范

苞告

之管

㞾

$\frac{\sqrt{0}}{\frac{10}{\circ}}$

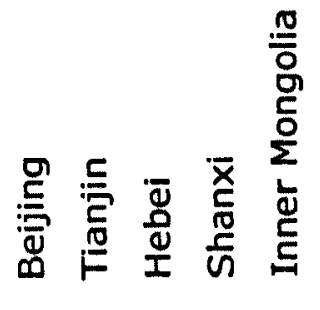

号 $\stackrel{\frac{0}{0}}{\frac{0}{0}}$

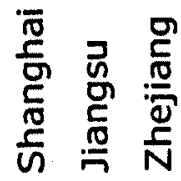




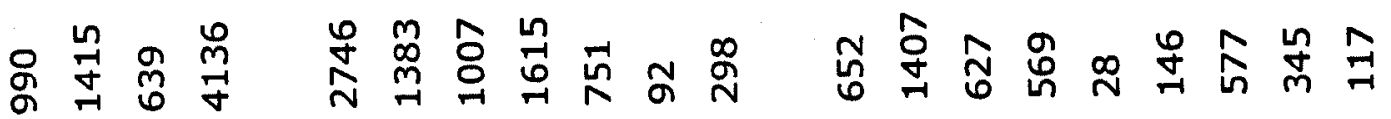

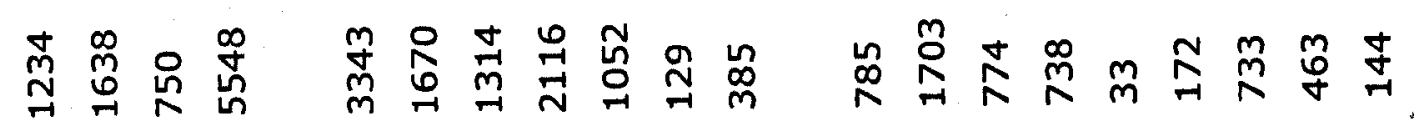

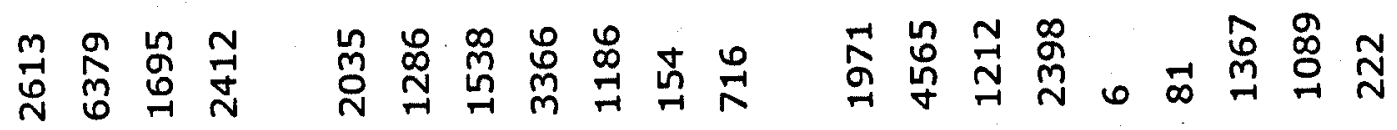

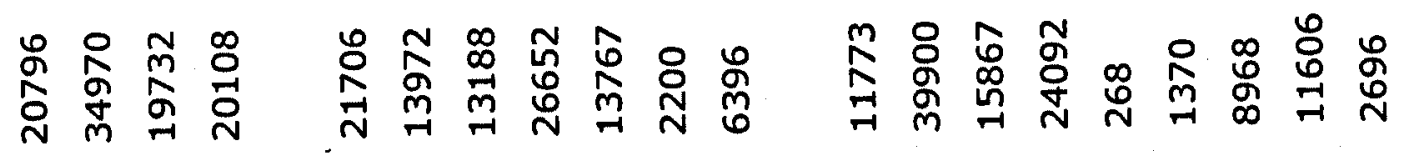

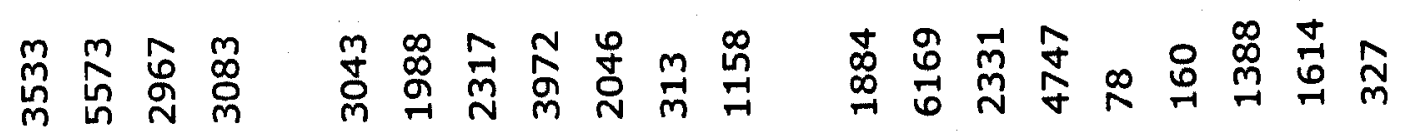

ธ

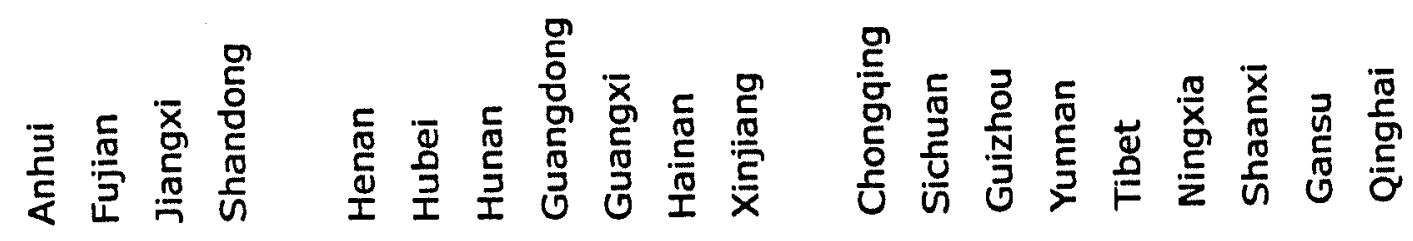




\title{
Appendix IV
}

\section{Letters of Consent}

The letter to the headteachers of the schools:

\section{Research on 'Teacher career motivation and professional development in special and inclusive education in China'}

\author{
Dear Sir/Madam,
}

I am FENG Yan. This research of "Teacher career motivation and professional development in special and inclusive education in China" is for my PhD study in Education in the University of Northampton, the UK. As I am also a lecturer in the School of Foreign Languages of Shaoxing University, I wish to conduct the research in some schools in Shaoxing including yours if I could get your kind consent.

The research will take place in the course of May 2007 to December 2007. During the period, I would be collecting data from your staff to investigate teachers' career motivation and their professional development in special and inclusive education. The purpose of the research is to identify the incentive value teachers attach to their choice of the profession and their perspectives on their career development in special and inclusive education. The research also tends to study the relationship between teachers' initial career motivation and their motivation for continuing professional development by examining their knowledge and understanding of, and their attitudes towards special and inclusive education.

A questionnaire survey will be administrated to your staff on their voluntary participation. The questionnaire represents an early stage of data collection which will guide me in further investigation by interviewing with teachers. I would also like to observe some classes and scrutinize your school documents on staff professional qualifications and professional development.

The research findings can be used in your school decision-making, in practice and for academic purposes only. The Ethical Code will be strictly followed (Please refer to the signed Ethical Code attached to this letter).

To support me in my academic study and also to inform your school with teachers' perceptions and perspectives concerning their career motivation and their professional development in special and inclusive education, I would be most grateful if you could approve this research in your school. Should you require further information related to any aspect of this research, please do feel free to contact me at:

\section{FENG Yan}

Centre for Special Needs Education and Research

School of Education

University of Northampton

Boughton Green Road

Northampton NN2 7AL, the UK

Tel: 0044-1604-89-2395 (office)

Email: maryfy@hotmail.com

Or:

FENG Yan 
School of Foreign Languages

Shaoxing University

508 Huancheng West Road, Shaoxing, Zhejiang, 312000, China

Tel: 0575-88347378 (office)

Email: maryfy@hotmail.com

Thank you very much in advance for your support. I am looking very much forward to meeting you for further discussion about the research.

Yours, sincerely,

FENG Yan 


\section{Research on 'Teacher career motivation and professional development in special and inclusive education In China'}

\section{Dear Sir/Madam:}

I am FENG Yan. This research of "Teacher career motivation and professional development in special and inclusive education in China" is for my PhD study in Education in the University of Northampton, the UK. As I am also a lecturer in the School of Foreign Languages of Shaoxing University, I wish to conduct the research in some schools in Shaoxing.

The research will take place in the course of May 2007 to December 2007. During the period, I would be collecting data from teachers to investigate teachers' career motivation and their professional development in special and inclusive education. The purpose of the research is to identify the incentive value teachers attach to their choice of the profession and their perspectives on their career development in special and inclusive education. The research also tends to study the relationship between teachers' initial career motivation and their motivation for continuing professional development by examining their knowledge and understanding of, and their attitudes towards special and inclusive education.

A questionnaire survey will be administrated to teachers on their voluntary participation. The questionnaire represents an early stage of data collection which will guide me in further investigation by interviewing with teachers. I would also like to observe some classes and scrutinize your school documents on staff professional qualifications and professional development. In order to gather feedback on the research instruments, I would like to pilot the questionnaire survey, the interview and observation schedules. If you could kindly support me by reading the questions and sending your comments back to me before March 5 , 2007 on the above mentioned, I would be highly grateful. With your feedback, I can modify the questions as appropriate.

The research findings can be used in school decision-making, in practice and for academic purposes only. The Ethical Code will be strictly followed (Please refer to the signed Ethical Code attached to this letter).

Your co-operation in providing some feedback will be greatly appreciated. Should you require further information related to any aspect of this research, please do feel free to contact me at:

\section{FENG Yan}

Centre for Special Needs Education and Research

University of Northampton

Boughton Green Road

Northampton NN2 7AL, the UK

0044-1604-89-2395

Mary.feng@northampton.ac.uk or: maryfy@hotmail.com

Or:

FENG Yan

School of Foreign Languages

Shaoxing University

508 Huancheng West Road, Shaoxing, Zhejiang, 312000, China

Tel: 0575-88347378 (office) 
Email: maryfy@hotmail.com

Thank you very much in advance for your support. I am looking very much forward to your reply.

Yours, sincerely,

FENG Yan 


\section{The letter to student teachers:}

\section{Research on "Teacher career motivation and professional development in special and inclusive education in China"}

Dear student,

I am FENG Yan. This research of "Teacher career motivation and professional development in special and inclusive education in China" is for my PhD study in Education in the University of Northampton, the UK. As I am also a lecturer in the School of Foreign Languages of Shaoxing University, I wish to conduct the research to the fourth year student teachers in the university including yourself if I could get your kind consent.

The purpose of the research on student teachers is to identify the incentive value student teachers attach to their choice of the profession and their perspectives on special and inclusive education. The research also tends to study the relationship between student teachers' initial career motivation by examining their knowledge and understanding of, and their attitudes towards special and inclusive education. The research will take place in May 2007. A questionnaire survey will be administrated on your voluntary participation.

The research findings will be used in university decision-making, in practice and for academic purposes only. The Ethical Code will be strictly followed (Please refer to the signed Ethical Code attached to this letter).

To support me in my academic study and also to reflect on your perceptions and perspectives concerning your career motivation for special and inclusive education, I would be most grateful if you could participate in this research by spending just a few minutes to complete this questionnaire. Once completed, please return it to the dean's secretary of your school before May 28, 2007. Should you require further information related to any aspect of this research, please do feel free to contact me at:

FENG Yan

Centre for Special Needs Education and Research

School of Education

University of Northampton

Boughton Green Road

Northampton NN2 7AL, the UK

Tel: 0044-1604-89-2395 (office)

Email: maryfy@hotmail.com

Or:

FENG Yan

School of Foreign Languages

Shaoxing University

508 Huancheng West Road, Shaoxing, Zhejlang, 312000, China

Tel: 0575-88347378 (office)

Email: maryfy@hotmail.com

Thank you very much in advance for your support. Best wishes for your studies and your career.

Yours, sincerely,

FENG Yan 


\section{The letter to the teachers of the schools:}

\section{Research on 'Teacher career motivation and professlonal development in special and inclusive education In China'}

Dear Sir/Madam,

I am FENG Yan. This research of "Teacher career motivation and professional development in special and inclusive education in China" is for my PhD study in Education in the University of Northampton, the UK. As I am also a lecturer in the School of Foreign Languages of Shaoxing University, I wish to conduct the research in some schools in Shaoxing including yours. I have got the consent from your headteacher. I would be most grateful if I could get your kind consent as well.

The research will take place in the course of May 2007 to December 2007. During the period, I would be collecting data to investigate teachers' career motivation and their professional development in special and inclusive education. The purpose of the research is to identify the incentive value teachers attach to their choice of the profession and their perspectives on their career development in special and inclusive education. The research also tends to study the relationship between teachers' initial career motivation and their motivation for continuing professional development by examining their knowledge and understanding of, and their attitudes towards special and inclusive education.

A questionnaire survey will be administrated on your voluntary participation. The questionnaire represents an early stage of data collection which will guide me in further investigation by interviewing with teachers. I would also like to observe some classes for better understanding of the research topic.

The research findings can be used in your school decision-making, in practice and for academic purposes only. The Ethical Code will be strictly followed (Please refer to the signed Ethical Code attached to this letter).

To support me in my academic study and also to reflect on your perceptions and perspectives concerning your career motivation and professional development in special and inclusive education, I would be most grateful if you could participate in this research and spend just a few minutes to complete this questionnaire. Once completed, please return it to the head of your school before May 21, 2007.

If you would like to be interviewed, please kindly sign your name and provide me with your contact details at the bottom of this letter so that I can arrange the time and venue with you for the interview. Your co-operation will be greatly appreciated. Should you require further information related to any aspect of this research, please do feel free to contact me at:

\section{FENG Yan}

Centre for Special Needs Education and Research

School of Education, University of Northampton

Boughton Green Road

Northampton NN2 7AL, the UK

Tel: 0044-1604-89-2395 (office)

Email: maryfy@hotmail.com

Or: FENG Yan

School of Foreign Languages

Shaoxing University 
508 Huancheng West Road, Shaoxing, Zhejiang, 312000, China

Tel: 0575-88347378 (office)

Email: maryfy@hotmail.com

Thank you very much in advance for your support. I am looking very much forward to meeting you for further discussion about the research.

Yours, sincerely,

FENG Yan

Interest in the interview:

I would like to be interviewed.

My preferred time:

My name:

My signature:

My contact details: Tel:

Email: 


\section{Appendix V}

\section{Ethical Code of the research}

\section{'Teacher career motivation and professional development in special and inclusive education In China'}

\section{PhD research to be conducted from September 2006 to September 2009}

This Code is informed by the principles established in the revised Ethical Guidelines for Educational Research (2004) Issued by the British Educational Research Association (BERA). It is also informed by the Research Ethics Committee Guidance of the University of Northampton. Meanwhile, the researcher will work in accordance with the ethical guidelines for conducting educational research in China. She will also abide by the research norms and values as commonly practiced by education professionals in China.

The researcher recognises the rights of all professional colleagues and students who participate in the research to have their confidentiality protected at all times. Participants in the research have a right to withdraw from the process at any time and will be informed of this right. Voluntary informed consent will be sought before any forms of research are conducted with any respondent as part of the research process. In the case of the teachers from mainstream and special schools, the consent will be sought from their head-teachers prior to the research and subsequently from the teachers themselves. In the case of the university students, the consent will be sought through the deans of the schools as well. Students have the right to refuse participation and will not be pressured or coerced into taking part in the research.

The researcher is under an obligation to describe accurately, truthfully and fairly any information obtained during the course of the research. The identity of the participants will remain anonymous and confidential throughout the research process and in the report of the thesis. The information collected will be for academic purposes only. It will not be given to any third party.

The research report in thesis form will be made available in both paper and electronic format to the head-teachers of the participating schools and the university on the completion of the study. This thesis will also be made available to the local educational authority as required. Once agreed, no part of this ethical statement may be changed or modified without justification and recourse to discussion with all interested parties.

Name of the researcher:

Signature of the researcher:

Date of the signature:

BERA (2004) Revised Ethical Guidelines for Educational Research (2004). Southwell: British Educational Research Association.

Research Ethics Committee (2006) Research Ethics Committee Guldance of the University of Northampton. Northampton: The University of Northampton.

Available online at:

http://www2.northampton.ac.uk/portal/page/portal/knowledgeexchange/homepa ge/GradSchool/student-toolkit\#EthicalApproval. [Accessed March 20 2007]. 


\section{Appendix VI}

\section{Teacher career motivation and professional development in speclal and inclusive education in China}

Questionnaire for teachers in mainstream and special schools

There are three parts in this questionnaire.

\section{Part I: Basic information}

Please tick the appropriate letter from A.B.C. or D.

1. I have been teaching for (我做教师已有几年了):
A. 2-5 years
B. $5-10$ years
C. $10-15$ years
D. more than 15 years

2. My last degree is (我最后的学历是) :
A. diploma (大专)
B. bachelor degree (本科)
C. Master's degree (研究生) D. others, please specify (其他: 请说明)

\section{Part II: Statements}

This part is for you to rate on a scale 1 to 4 the following aspects of your choice by highlighting the appropriate number. For the Items from 1-22, you are expected to highlight only one each.

4 = strongly agree（非常同意）

3= agree (同意)

$2=$ disagree (不同意)

1 = strongly disagree（非常不同意）

\section{Example（范例）}

$43 z 1$

Now, please highlight your response.

1. I like to be a teacher in a mainstream school.

我喜欢做一个普通学校的老师。

\begin{tabular}{|llll}
\hline 4 & 3 & 2 & 1 \\
\hline
\end{tabular}

2. I would like to teach children with special needs in a special school.

我想成为一个特殊学校教特教生的老师。

3. I would like to teach children with special needs in a mainstream school. 我想成为一个普通学校教特殊孩子的老师。

4. I would like to choose other professions than teaching if possible.

可能的话我想选择一个教师以外的职业。

5. The years' experience in the mainstream school has prepared me to teach in a special school.

这些年在普通学校的经验已让我具备做好一个特殊学校老师的资格。

6. The years' experience has prepared me well to teach children with special needs in a mainstream school.

多年的教学经历让我具备在显通学校做一个特教或全纳老师的资格。

$\begin{array}{llll}4 & 3 & 2 & 1\end{array}$ 
21. I am suffering from the stress related to my work at school. 我深感学校工作的压力。

$$
\begin{array}{llll}
4 & 3 & 2 & 1
\end{array}
$$

\section{1}

22. I have a good balance of life and work.

我能很好地平衡工作和生活。

\begin{tabular}{|llll}
\hline 4 & 3 & 2 & 1 \\
\hline
\end{tabular}

$\begin{array}{llll}4 & 3 & 2 & 1\end{array}$

\section{Part III: Questions}

Please answer the following questions on the sheet attached.

1. Why did you choose to be a teacher?

你为何选择做老师?

2. Have you ever regretted your cholce? Why or why not?

你对你的选择后悔过吗? 为什么?

3. How do you understand special education?

你如何看待特殊教育?

4. How do you understand inclusive education?

你如何看待全纳教育?

5. Do you have any comments on speclal and inclusive education in China? 你对我国的特殊与全纳教育有何评论?

\section{Thank you very much for your help!}


Teacher career motivation and professional development in special and inclusive education in China

Questionnaire for student teachers graduating In July 2007

There are two parts in this questionnaire.

Part I: Statements

This part is for you to rate on a scale 1 to 4 the following aspects of your choice by highlighting the appropriate number. For the items from 1-13, you are expected to highlight only one each.

4 = strongly agree (非常同意)

3= agree (同意)

$2=$ disagree (不同意)

1 = strongly disagree（非常不同意）

Example（范例）

$\begin{array}{llll}4 & 3 & 2 & 1\end{array}$

\section{Now please highlight your response.}

1. I would like to be a teacher in a mainstream school. 我想成为一个普通学校的老师。

2. I would like to be a teacher in a special school. 我想成为一个特殊学校的老师。

3. I would like to choose other professions than teaching. 我想选择一个教师以外的职业。

$\begin{array}{llll}4 & 3 & 2 & 1\end{array}$

4. The four-year's learning in the university has prepared me well to teach in a mainstream school.

4年的大学学习已让我具备做好一个普通学校老师的资格。

5. The four-year's learning in the university has prepared me well to teach in a special school or inclusive school.

4年的大学学习已让我具备做好一个特殊或全纳学校老师的资格.

6. I would like to teach children with special needs in a mainstream school. 我想成为一个㫮通学校教特殊孩子的老师。

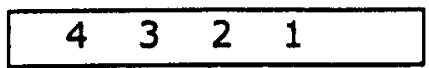

7. I am satisfied with the course offered by the university on special and inclusive education.

我对大学的特殊与全纳教育课程很满意。

8. I am satisfied with the library resources in the university on special and inclusive education.

我对大学图书馆里的特珠与全纳教育资料很满意。

9. I would like to learn more about special and inclusive education. 


\section{Appendix VII}

\section{Interview Schedules}

\section{Teacher career motivation and professional development in special and inclusive education In China}

\section{Interview questions for teachers in mainstream schools}

\section{Part I: Teacher career motivation}

1. Would you please tell me how long you have been teaching?

2. Why did you choose to be a teacher?

3. Did anybody influence you in your choice?

4. Do you think it is the right choice for you?

5. Have you ever regretted your choice?

If yes, why?

If no, what are the things you enjoy about teaching? Could you please give me some examples?

6. People choose to be teachers for various reasons. What do you think are the three most important reasons for their choice?

\section{Part II: Initial teacher education}

1. Do you think the training you have had has prepared you well to meet the needs of all the children in your class?

If yes, what are the good things about the training?

If no, what do you think could have been improved in the training programmes?

2 . Do you think the training you have received has helped you meet the needs of most of the children?

If no, does the inadequate training have an impact on your motivation as a teacher?

If yes, can you please tell me briefly why you think the training is so helpful?

\section{Part III: Teachers' perceptions of special and inclusive education}

1. What do you understand by the term of special education?

2. Does the term inclusive education mean anything to you?

3. Are you aware there are schools specifically for children with special needs?

If yes, do you think these schools are a good idea for those children with special educational needs?

If no, where do you think they should be educated?

4. Do you think mainstream schools should take in all children regardless of their needs or abilities?

If yes, what are the challenges you think teachers will face in having children with special educational needs in their classes?

If no, where do you think they should be educated?

5. Do you think it is appropriate to place these children in your class?

If no, why?

If yes, What impact do you think it will have on your class/classes to have children with special educational needs?

6. Will it have an impact on your motivation to be a teacher to have children with special educational needs in your class? Why?

7. Would you choose to teach in a special school?

If yes, what motivates you to work in special schools?

If no, what do you think motivates other teachers to work in special schools?

\section{Part IV: Professional development}

1. How do you think the role of in-service training in teachers' professional development? 
2. Does your school attach importance to in-service training?

If yes, in what ways teachers are encouraged to continue their further education? If not, what do you think are the reasons for this?

3. Have you received any in-service training since you joined the school?

If yes, would you please say something about it?

If no, do you feel the need of the continuing professional development?

If no, why?

If yes, what kind of training model would you like to have? (e.g., school-based training, full-time, part-time, short term, long term, degree education, conferences, seminars, lectures, etc.)

4. What kind of training do you think is most needed for you at present? (e.g., theories in education, research capacity building, subject-based knowledge, teaching methodology, ICT skills, class management, interpersonal communication skills, etc.)

5. Would you be prepared to pay for the training?

If yes, why do you want to do this?

If no, who do you think should pay for teacher professional development?

6. Do you think the availabllity of professional development opportunities will have an impact on your motivation in your career? Why? 


\section{Teacher career motivation and professional development in special and inclusive education in China}

\section{Questions for teachers in special schools}

\section{Part I: Teacher career motivation}

1. Would you please tell me how long you have been teaching?

2. Why did you choose to be a teacher in the special school?

3. Did anybody influence you in your choice?

4. Do you think it is the right choice for you?

5. Have you ever regretted your choice?

If yes, why?

If no, what are the things you enjoy about teaching? Could you please give me some examples?

6 . People choose to be teachers in special school for various reasons. What do you think are the three most important reasons for their choice?

\section{Part II: Initial teacher education}

1. Do you think the training you have had has prepared you well to meet the needs of all the children in your class?

If yes, what are the good things about the training?

If no, what do you think could have been improved in the training programmes?

2. Do you think the training you have received has helped you meet the needs of all the children?

If no, does the inadequate training have an impact on your motivation as a teacher?

If yes, can you please tell me briefly why you think the training is so helpful?

\section{Part III: Teachers' perceptions of special and inclusive education}

1. What do you understand by the term of special education?

2. Does the term inclusive education mean anything to you?

3. Do you think special schools are a good idea for those children with special educational needs?

If no, where do you think they should be educated?

4. Do you think mainstream schools should take in all children regardless of their needs or abilities?

If yes, what are the challenges you think teachers will face in having children with special educational needs in their classes?

If no, where do you think they should be educated?

5. If you could choose freely, would you like to teach in a mainstream school or special school? Why?

a) What motivates you to have the intention to work in a mainstream school?

b) What do you think are the reasons for mainstream school teachers not to be motivated in working in special schools?

7. How do you think special school teachers are perceived?

a) How do you feel about that?

\section{Part IV: Professional development}

1. How do you think the role of in-service training in teachers' professional development?

2. Does your school attach importance to in-service training?

If yes, in what ways teachers are encouraged to continue their further education?

If not, what do you think are the reasons for this?

3. Have you received any in-service training since you joined the school?

If yes, would you please say something about it?

If no, do you feel the need of the continuing professional development?

If no, why? 
If yes, what kind of training model would you like to have? (e.g., school-based training, full-time, part-time, short-term, long term, degree education, conferences, seminars, lectures, etc.)

4. What kind of training do you think is most needed for you at present? (e.g., theories in education, research capacity building, subject-based knowledge, teaching methodology, ICT skills, class management, interpersonal communication skills, etc.)

5. Would you be prepared to pay for the training?

If yes, why do you want to do this?

If no, who do you think should pay for teacher professional development?

6. Do you think the availability of professional development opportunities will have an impact on your motivation in your career? Why? 


\section{Appendix VIII}

\section{Observation schedule}

Teachers' career motivation and professional development in special and Inclusive education in China

\section{Observation type: non-participant observation}

Important notes:

- Purpose of the observation made clear to the teacher being observed prior to the observation

- Informed consent

- Discuss with the teacher about the observation outcome

- Provide comments and/or suggestions

\section{Part I: Basic information}

- Time:

- Name of the school:

- School type:

- Class:

- Subject being taught in class:

- Number of students:

- Method of observation: qualitative

- Name of the teacher:

- Any support from other professionals in class:

- Professional qualification of the teacher:

- Teaching experiences of the teacher:

\section{Part II: Observation focus}

- The number of students, if any, with special educational needs in the class

- Teacher's attitudes towards students with special educational needs (e.g., body language, teaching instructions, etc.)

- Teacher's classroom management skills

- The impact of the student/students with special educational needs on the class (e.g., on other students, on teaching, etc.)

- How the teacher manages the challenges, if any?

- Is the teacher motivated in teaching the student/students with SEN?

- Class interaction between the teacher and the students, and students with themselves in general

- Teaching effectiveness (general impression)

\section{Part III: General observation}

- Critical event, If any

- What led up to the event?

- What happened?

- What was the outcome?

- Any questions were raised concerning teacher career motivation, knowledge and understanding of special and Inclusive education, and professional development? 


\section{Appendix IX}

\section{Interview scripts}

The interview with the teacher from the special school for children with speech and hearing impairments (Case I: Ms. Shao Yang, pseudonym)

Question: How long have you been teaching?

ST-10 I came here in 1978. I have been here for almost 30 years.

Q: $\quad$ Why did you choose to come to this school?

ST-10 To be quite honest, this has to do with my parents. My parents are both deaf and dumb. They worked here. We [brothers and sisters] grew up in this school. We ate and lived with the students here. Then I went to the countryside to work when I graduated from junior middle school [the then government's policy for school leavers]. When my father retired, I was given a job opportunity. The then educational bureau asked me where I would like to be placed: mainstream schools or kindergartens... which one I would choose. At that time, though I was 20 years old, I was very naive. I thought... if I went to work in other places, I thought I would feel unfamiliar with the situation there and I was afraid. I went to the countryside according to the government's order after I finished my junior middle school. I did not even go to senior middle school before I was asked to go and work in the countryside. Since I was given a teaching position, comparatively... I knew myself well how much knowledge I had. I did not dare to go to other schools. I thought I'd better stay in this school since I knew the school well and it would be a piece of cake for me to teach here.

Q: Oh, your parents were both teachers here in this school?!

ST-10 No, my mother was not. My father was.

Q: $\quad$ So you came to work in this school right before your father's retirement?

ST-10 Yes. He spent all his life in this school. He is almost the founder of the school.

Q: $\quad$ Right. So you had special feeling towards this school?

ST-10 Yes.

Q: What did your father say when you chose to work in this school?

ST-10 My father? Oh my father supported me. At that time, I was the only one among my siblings to work in this line. Now my elder sister and younger sister are both working in the sign language service centre.

Q: $\quad$ Oh, so they are both working in special service for the disabled?

ST-10 Yes. I am the third child, I have a brother, and they 
are doing much better work than I am. Comparatively, I am not as good.

Q:

Why do you think so?

There are reasons. In soclety, they are with adult visual and speech impaired people. They are good at sign language. In school, I am with children in their first and second grades. Because sign language for young children is comparatively easier and not systematic, very soon I found I decreased in my skill of using sign language. I became worse as I made no progress.

Q: $\quad$ So you mean your father does not have visual and speech problems...

ST-10 No, he does.

Q:

But how could he teach?

ST-10 Well, he studied in other places. He learned some knowledge and he taught students.

Q: What about your mother? Does she have visual and/or speech impairments?

ST-10 Yes.

Q:

Well, you do not have...

Well, they had the problems after their birth. It was not innate.

Q: $\quad$ Your famlly is very special. You are all working in special education.

ST-10 Yes. My brother used to work in workers' union. He studied law and now he is a lawyer for people with sensory impairments.

Q: $\quad$ It is a very special family. Have you ever thought of leaving this school during the long years?

ST-10 No. as I have told you, I am not capable of doing things I am not familiar with or good at. I do not have enough confidence to work on other professions. Instead of working on that kind of jobs, I'd prefer working on something I am good at and doing it well. I have never thought of leaving this school. Even my husband is like me. One year, he was asked to teach in a mainstream school. The school had assigned their dally work for him and his name was already in their staff list. But he did not leave the school. He likes the work and does research in this line.

Q: $\quad$ I am looking forward to interviewing him after this.

ST-10 He is good.

Q:

So you and your husband never thought of leaving the school?

ST-10 Because I am so famillar with the students, I know their personalities, their characteristics and their thoughts. Generally speaking, I fit the job, teaching 
here.

Q: $\quad$ Have you been sent somewhere for training, during all these years, in a university or somewhere?

ST-10 No. No. I do not have a chance. I have done some self-study and I have now a certificate from a junior teachers' college and a diploma from a distance learning college. For teaching skills, I learned from teaching experience. I had been to some schools to observe some classes with other colleagues. I do not need any training in sign language. So I did not have chances to be trained.

Q: $\quad$ After all these years, do you feel that it is more difficult to teach children today than the ones years ago?

ST-10 It has been for 30 years now since I started teaching. I used to teach children from Grade 1 and then upgraded with them. Now I am teaching vocational students. As long as I know the sign language, I can teach them. As far as their academic knowledge is concerned, the students are comparatively slow. They are not very good students. Our school educates children for 9 years. If they are good enough after 9 years, they can go to other schools, for example to Hangzhou, to vocational schools. The rest are not good ones. They can not get enrolled in other schools. We help them to learn sign language. In 2007, one class of vocational students graduated from this school. There were quite a few students. We chose some textbooks for vocational training. We could not adopt the full curriculum. They could not understand...

Q: $\quad$ What is your understanding of special education after all the years' teaching? The current situation in China?

ST-10 I can not talk big. I can only give simple comments. I may not hit the point. From my point of view, I would say that the people who are doing research are not familiar with special education. They do not have our experiences. They do not know us well. Their research, how should I put it? They present research findings to please the government or praise the situation and sometimes they try to match us with the standards of teaching in mainstream schools. Maybe it is because of my standard, or my personality, I think it is because their research capacity which made them do so. I actually know this. I am too timid to express myself and I can not express myself well. So I have not said much. Whatever they [the researchers] want to say, let them say it. Whatever you [the school] want me to do and I will do it. I accept whatever you want me to do. Only I will make adjustment in my own teaching.

Q: $\quad$ In other countries, students with special educational needs can study with other children in mainstream schools. What do you think of this?

ST-10 It is 'Learning in Regular classrooms'. I do not think it 
is a right thing to do in China. It would not work. In other countries, a student will have a teacher with him to translate for him. Here, schools can not afford to have this service. Special educational needs will not fit the context in mainstream schools. There are no teachers there who know how to help them. Honestly, even in our school, young teachers are not good at sign language. Sign language can be difficult. Sometimes you can not express the meaning of it. You have to try to understand. You can teach certain signs to the students. But sometimes it is the context, the atmosphere, the situation, the facial expressions...Children with impairments can not understand all these. Sometimes, we complain that students are getting even worse these years. I am teaching the vocational class. I did not teach them when they were young. So when I had to teach them, I felt really difficult to communicate with them. We could not make each other understood. They did not know how to make sign language properly. The good thing is that they are older. So I had to train them bit by bit. I can change them a bit. But it is very difficult to make the whole change. Years ago, in this school, we had training class for new teachers. We had a young teacher study group. They had little or no learning in their colleges before they came to our school. I have just read an article in a special education journal that a class of sign language interpreters had just graduated from Zhongzhou University. But sign language is more than just signs. The interesting thing is, once in a competition, I got $2^{\text {nd }}$ award in Chinese sign language while young teachers got $1^{\text {st }}$ award. They just memorised the signs. Incredible.

Q: $\quad$ You have strong motivation working in this school. What is your opinion on those who came to work in this school and then for different reasons, left the schools for mainstream ones?

ST-10 There are not many cases like this in this school. For a period, there were things like this. They had their husbands in other cities. So they transferred their work place. The real transfers, the ones like you said, happened to three teachers. They are now working in mainstream schools in the city. One of them came to work in the same year with me and we taught the same grade. The other two are in ...Primary School. Their transfers were normal, understandable. You know, working in this special school, if you are a young man, you may have problem finding a wife and for females, for some reason... they left. In the recent few years, things are becoming better. Last year or the year before last, a couple of years ago, a leader from the local education authority came to this school. He said: What can a special school for sensory impaired children do? All you need to do is to make sure that students are safe in the school. This really hurt our 
feelings. In fact it is extremely difficult to work here, to teach well and the achlevement is very difficult to be shown or measured. We can not show that. For one child to write a sentence to his parents, we have to do a great deal of work. But what does this mean to others? The society does not really understand us. The support is far from enough. However, the leader [local educational authority] was not happy, either. As we have less number of students and we have more teachers (compare with mainstream student-teacher ratio), the education authority had to allocate money to us, the money from the government. He was simple minded. And he thought why we were not able to teach these children well. He wondered what we were doing here, whether we had been trying hard enough. He looked down upon us. In other countries, it is quite different. Generally speaking, we felt bad. In fact, sometimes we can not actually show the evidence when we want to be promoted. Young teachers... not many people have been transferred.

Q:

ST-10

Q:

ST-10

Q:

ST-10

Q: $\quad$ You have never regretted?

ST-10 I have frustrations but I am not regretted. Now I do not care.

Q:

Do you want to have training for professional development?

Well, not now. I am in poor health. I have some tumor. I will not try too hard. When I first came, I did not know anything. We were like monks who became monks in their later life. We had no chance for training. We could only ask senior teachers. But many of them did not know as they themselves came here from mainstream schools and they had no experience themselves at all. I asked my father how I should teach. In Hangzhou [the capital city of the province], there is a special school. Sometimes we went there to work with the colleagues on teaching plans, a day trip, you know. About 20 years ago, there were some chances of going to Beijing for training during summer holiday. 2 teachers were sent there for the training. When it was almost my turn, this training was canceled (laugh).

So you missed the chance...

Yes. And I never have got any chances since then.

You had never had full-time training?

No. No. Not at all. A few years ago, we sent some young teachers to Shanghai No. 4 Special School for sensory Impaired children for a month's training. The new batch of teachers who came here just these years has not yet had any chance for training. Limited chances for special schools, you know.

Do you know why people choose to teach in special schools? 
The situation has changed a bit. Now for one teaching place, for example, P.E. or Computer Technology, we have about 10 applicants. It is terribly difficult to find a job nowadays for newly graduates. So some people have to try their lack in special schools. Or maybe they think they can get better pay, or they can just come for a while and then change...

Q:

Can you address the needs of children in your class

Q: Yes, most of the time.

You mentioned about inclusive education, you thought it was not practical?

No. It is a good thing but we do not have the resources. There are examples. Some parents would not like to tell mainstream schools that their children had impairments. When the children reached Grade 6 , they just sat in the corner of the classroom. When other students got into junior middle schools, those children could not get admitted. It is really sad. They had to come back to our school.

Q:

How many students are there in your class?

When I started teaching, I had 24 students. Some did not want to come, so I had 22,21 students. No we have less number of students, more than 10 students. The smallest number is 6 in one class. Things have been changing. In other cities nearby, there used to be special schools like ours. Now ours is the only one. We normally recruit about 10 students each year. In Shangyu [a nearby city], they only recruit students every other year. So we have enough students. If there are more demands, we can recruit more. I had one student, he could speak, but he was mentally retarded.

Q:

So you use the national curriculum for special schools?

ST-10 Yes. But we follow provincial level curriculum basically. The good students graduated from 9 years' study are like ordinary children in Grade 4 in primary schools. 
The interview with the teacher from a mainstream school (Case II: Ms. Zhu Zheng, pseudonym)

$\begin{array}{ll}\text { Question: } & \text { How long have you been teaching? } \\ \text { MT-5 } & 25 \text { years } \\ \text { Q: } & \text { Why did you choose to be a teacher? } \\ \text { MT-5 } & \begin{array}{l}\text { My parents were soldiers. They wanted me to be either } \\ \text { a teacher or a doctor. I chose to be a teacher. }\end{array} \\ \text { Q: } & \text { Do you like to be a teacher? } \\ \text { MT-5 } & \text { Yes. } \\ \text { Q: } & \begin{array}{l}\text { Is this a right choice for you? } \\ \text { MT-5 }\end{array} \\ & \begin{array}{l}\text { For the first three years, I thought it was a wrong } \\ \text { choice. I even wanted to change the profession for the } \\ \text { first two years. But at that time, it was not easy to } \\ \text { change professions. It is different now. Now people can } \\ \text { have many changes in their profession. }\end{array}\end{array}$

Q:

Have you regretted your choice after that?

MT-5

No. If I could choose again, I would choose to be a teacher.

Q:

What makes you so happy to be in teaching?

MT-5

The students. They came to see me after their graduation. I taught in a senior middle school for 20 years. I liked it. That year when I gave birth to my daughter, I was hospitalised. The ward was on the second floor. The flowers from my students were put from the first floor to the second floor. People were surprised to see this and I was greatly moved. I felt it was glorious to be a teacher. I think I am a millionaire spiritually.

Q: $\quad$ People choose to be teachers for various reasons. What do you think are the three most important reasons for people to choose the profession?

MT-5 The exam scores, people from rural areas, or the family economic background. Some might not like it at the beginning. But once they went for school placement, they could communicate with students, they would like it. And some like to have holidays. My daughter also wants to be a teacher. She wants to be a teacher in special education.

Q: Do you think the training you had in the university has prepared you to meet the needs of most of the students in your class?

MT-5 No, far from enough.

Q: $\quad$ With all the years' achlevement and experience, do you have any suggestions for the teacher education institutions or universities for the improvement of training rogrammes?

MT-5 They should have some practical modules, for instance, to ask student teachers to stand at the teaching 
platform. Sometimes, it is not the knowledge but other things which make a good teacher. Students can be given some classroom cases for analysis, how to deal with problems in the classroom, how to make students like your teaching...

Q:

MT-5

Q:

MT-5

Q:

MT-5

Q:

MT-5

Q:

MT-5

Q:

MT-5

Q:

MT-5

Q:

MT-5

So the inadequate training, does that have any impact on your motivation for teaching?

No. Not really. This made me to be a good teacher. It took me two years to adjust myself in teaching. I learned a lot from other teachers.

How much do you know about special education?

I did not know until I went to England and learned that with you. For inclusive education, I think students should have equal opportunities for education. I read ...'s books. We always say that every child can learn. In England, they are working towards it. But in China, it is not yet so. I learned how people in England are doing, anyway.

Do you think it is a good idea for children with special educational needs to study in mainstream schools?

Yes, it is. In inclusive education, we can include some children with mild disabilities.

Should it include all the children with diverse special educational needs?

Yes. Some facilities, some specialists are needed. Those students should go to special schools.

As a headteacher, do you think inclusive education will bring challenges to teachers?

Yes. A lot. They have to change their perceptions, attitudes. They need to have a loving heart. They need to learn the ideas of inclusive education. The things we have learned in England. They need to be trained. Most of our teachers here do not have any knowledge about special education, not al all, to be honest.

Do you think to have children with special educational needs in your classroom is appropriate?

Yes.

What impact will that have on your teaching?

Of course, it will. If the child with disabilities can study well, he can be a good example for other students. There must be a lot for each other to learn. Some children can be physically disabled. But they are not splritually disabled. While others, who are very selfcentered. They are from only-child families. They do not know how to care for other people.

Do you think it will influence your choice of being a teacher to have children with speclal educational needs in your class?

No. No. 
Q:

Q:

MT-5

Q:

MT-5

Q:

MT-5

Q:

MT-5

Q:

MT-5

Q:

MT-5

Why?

I chose to be a teacher. I love children. I should help them. If they make progress, I will be very happy. Years ago, there was a student in Senior Two [senior middle school, second year]. Something happened to his family. So he jumped from a building and got disabled. He was in my class. So I asked my students to help him to move up and down the floors to our classroom. Because of him, my class became united. They organised themselves in groups and took turns to help him. But later the student could not catch up with his peers in his study as he had very low self-esteems. Even parents of other students complained that their children spent too much time on the student and it influenced their academic study. The students had to take part in the national entrance exams. They [parents] jointly wrote letters to the headteacher. They wanted me to leave the class. They thought that for this student, we had spent too much time on him. So the student did not even dare to ask for help to go to the toilet later on. He left our class soon. It was ten years ago. Maybe things have been better today.

Do you think so?

I think it will be better. I am still wondering why the parents reacted like that at that time. I think it will be better now.

Would you like to be a teacher in a special school?

Yes. No hesitation.

Why?

Maybe it is because of the learning in England, because of Professor... because of you. In the special schools, I feel like helping them.

Why do you think teachers choose to work in special schools?

They want to help people. They love them. I do not actually know them. Their sympathy towards the students...

What do you think of them?

I respect them. They should be paid more. They have a lot of patience. If I am going to work there, I have a lot to learn from them.

What is your opinion of professlonal development?

You know me well about my professional development. As for the teachers in my school, you will have chances to listen to them... 


\section{Appendix $X$ \\ Class observation notes (all names are pseudonymous)}

\section{Open class: school based professional development}

Time: 10:00-10:45 a.m.

School type: XX Forelgn Languages School (an independent mainstream school)

Class: Junior 2

Subject: English

No. of students: 42

Teacher: Helen, female (Pseudonym)

Teaching experience: 7 years

Education background: graduated with a bachelor degree from a teachers' college in Hunan Province

Notes: The teacher was from Hunan Province, a disadvantaged province in terms of economic development. With the reform and opening policy, many people from that province moved to provinces on the Eastern part of China to seek job opportunities. Zhejiang Province, the province the research was being conducted was one of them. Normally people from disadvantaged provinces have to make extra efforts in their work to compete with those who were advantaged in terms of social relations, network or local language, to say the least.

Attendants: Besides the students, seven teachers of English from the same school together with the deputy headteacher who was also a teacher of English attended the class.

Purpose of the session: This was part of the staff professional development scheme of the school. According to the school, each term, some teachers were selected to teach classes open to their colleagues of the same subject or year group. Sometimes, teachers from other local schools came as well. For this class, the school used the normal teaching hour to ask the teacher observed to demonstrate her teaching to her colleagues.

This session known as 'Public Session' or 'Open Class'(Gongkai Ke in Chinese) is a typical model of school-based professional development. Normally, teachers were chosen to demonstrate his or her teaching effectiveness to others. It was considered an honour to the teacher selected. He or she would then be given feedback from colleagues after the session. It is very common that these same teachers would be asked to demonstrate their teaching for the inspectors from different educational levels. Their teaching is very often regarded as criteria of quality of teaching of the school. In this school, some innovative teaching methods were being advocated upon the time of the field work of my study. The school specially organised this session for at least two reasons: First, the school wanted to show me that school-based professional development model worked well for the teachers. Second, the school wanted to demonstrate that the teachers there were experimenting new methods in English teaching with a focus on the interactive part from the students in class activities. The school claimed that they attached great importance to teaching and teacher development. But being an independent school, the school did not have enough budget (not willing to budget) to be used for the training of teachers. Class observation was seen as a very effective and economic way of training for teachers.

The purpose of the observation: I would like to observe how an intrinsically motivated teacher (according to the deputy headteacher of the school) teaches her class with the innovative teaching methods advocated by the school. I was recommended to observe Helen's class by the Deputy Headteacher, Jenny. 
According to Jenny, Helen was going to give a model lesson to other teachers in her department so that they could learn from each other. This is a kind of schoolbased training for professional development advocated by Jenny since the past few years.

According to the informal conversation with Helen during the break prior to her teaching, I got to know that she liked the subject she was teaching. She liked to be with children. She was quite happy to be a teacher. She was quite honourd that she would be teaching the same class (same content) again before her colleagues in a week's time. To her, it was a try lesson. She found this kind of teaching quite challenging as not all her colleagues would be supportive. Since it was an honour to be nominated, in the school environment where competition was anywhere anytime, 'some might challenge her by finding fault in her teaching to make her feel bad' [her own words]. This was actually the difficult part of the teaching and could be stressful to the teachers if they were not able to take the negative feedback from their colleagues positively. However, she commented that 'the experience could be a positive one if the colleagues could point out some room for improvement in my teaching'. Anyhow, she said she was quite nervous about the teaching (open class).

Observation in class: Helen did not seem to be nervous in class the researcher observed. In fact, I was quite impressed by her oral English and her methods in involving students in a range of class activities. Room for improvement is as follows:

First, there were some mistakes in her pronunciation when she asked students to read after her some new words of the lesson, which I shared with her right after class. Second, some activities were quite time consuming without clear instruction. For example, she asked the students to pronounce the new words repeatedly, which to some students was quite boring. However, as the students were aware that their deputy headteacher was also in the class with other teachers, they participated in the activities. As an observer, I could sense the feeling of passiveness from the students' body languages. Obviously, Helen was preoccupied by those students sitting in the front rows of the classroom who showed their great enthusiasm. Still others, for example, two boys sitting at the rear of the classroom pretended not to show the feeling and interacted with the teacher actively. This might have to do with my presence as they kept looking at me who happened to be sitting very close to them.

Overall impression: As an independent school, this class size is much smaller than the classes in most of the mainstream schools in the research area. The students could understand their teacher when she taught in English. Most of the students read out loud when asked to. They participated actively in class. 


\section{Class observation: One teaching fits all?}

Time: 2:00-2:45 p.m.

School: XX Primary School (a special school for pupils with learning difficulties)

Class: Primary 5

Teacher: Wang, Male

Teaching experience: 5 years ( 4 years' in a mainstream primary and one year in the special school)

Professional qualification: the teacher graduated from a teachers' college with no formal training on special and inclusive education before he took the job in the special school.

Motivation in teaching in the special school: His previous school merged with another school. He lost his job and found one in this special school. To him, it is a job.

Subject: PE

Class size: 14

Students: 10 boys, 4 girls.

Age: vary from about 12 to 15

Learning difficulties: Down Syndromes, Autism, so I was told by the class teacher. Although I was no expert in diagnosing the diverse difficulties of the students, I believed there might be a spectrum of autistic disorder. The teacher admitted that he did not know much about students' difficulties. He only knew that they were all mentally retarded.

Venue: school playground

\section{Notes:}

1. I asked the Deputy Headteacher whether I could be allowed to observe some classes. I got the consent. I was asked to be the teaching assistant for the PE teacher as that day the assistant was not available. I was told that my 'help' would be much appreciated. I was quite happy to do that, although I was not prepared for this. I introduced myself to the PE teacher and talked with him before class to ask if I needed to prepare anything before class. I also asked the teacher about the pupils. But to my surprise, the PE teacher did not know them very well. According to him, he was covering another teacher that day. He said they were all mentally retarded. I asked the PE teacher whether he knew what specific difficulties the pupils had, he only named two, which were Down Syndromes and autism. He further said that children with Down Syndromes have an international face which makes them very identical. He remarked, 'This is how I was told after I came to work in the school to identify those children'. For the rest, autism seemed to be the word for him which could describe all the other children with certain mental problems.

2. The teacher asked all the pupils to take a chair with them to the playground. They all did so without asking for a reason. I was quite surprised at this. The teacher asked them to stand on the chairs. He threw a basketball to one pupil and asked the pupil to throw it back to him. As all the pupils were standing on the chairs, the distance between the teacher and the pupils when he threw the ball to them was quite short. The reason for doing that was to train them to be brave. Some had problems climbing onto the chairs. The teacher helped them. One boy asked me to stand behind him for protection. He held one of my hands so tight as he was scared. He hurt my hand a bit. I did not let go because I knew he wanted me at that time. When it was his turn to catch the ball, he only used one hand. He kept telling me: hold my hand, hold my hand. He was about 13. If he was placed in mainstream school, I would not be able to know that he had learning difficulties. He looked like an ordinary boy his age. But only when he had problem standing on the chair, I knew he actually had some mental problems. 
Those who could stand onto the chair by themselves laughed at the boy when they saw him so scared of standing at the chair. They tried to show him that they could even stand on one foot. This embarrassed the boy which made him even more scared. The teacher asked others not to laugh at the boy. But they would not listen. Because I was new to them, as I anticipated, my attendance disturbed the class, to some extent. In the whole class, I was quite a distraction to them. Instead of listening to the teacher's instructions, some students kept looking at me most of the time with smiles which I was not famillar with and to be very honest, I was a bit scared. They did not care who I was. One boy called me aunt. The rest started to call me aunt as well. It was not the formal greeting. In fact, they kept calling me aunt. To be polite, I greeted back.

The teacher was very patient in teaching. He had to catch the ball from a distance from time to time as the students did not throw the ball back to him as expected. One student did not understand what the word 'throw' meant. The teacher had to demonstrate a couple of times. The student did not learn. He was laughed by other students every time he tried to 'throw' the ball. Most of the students enjoyed being in the open (it was nice that afternoon). They shared laughters and they played the ball in a way fit for children 5-6 years old. It was very difficult for the teacher to draw everyone's attention. The teacher kept whistling while the students ignored his instruction. An autistic boy about 15 kept smiling to me and asked me where I lived. I told him the first few times but later I stopped answering his questions but told him to listen to the teacher's instructions. Later in the class, I had to avoid his looks. I was scared inwardly wondering why he needed my address. When the class was over, the boy who was afraid of standing on the chair still held my hand tight until I took him to his classroom. It seemed to me that he was very proud of himself in front of other students as I was with him most of the time during the class. He gave me a feeling that, despite of being laughed at in class for not being able to stand on the chair all by himself, having me with him made him happy. In fact, during the class, another child would like me to protect her as well. Once she almost fell of the chair. The teacher did not see her as he was collecting the ball. I wanted to help her. But the boy held my hand so tight that I was unable to reach her who was quite a distance from me and the boy. She helped herself eventually with much effort. I could tell she was disappointed.

\section{Comments:}

This is the first PE lesson I had with children with mental problems. I wonder if the teacher did the right thing by asking all the children to stand on the chair. He asked all the children to play the same game regardless of their abilities. He might argue that they should be trained to be brave. But when the rest of the class laughed at he boy, I felt really bad. I was asking myself if the boy were placed in a mainstream school, would he be able to cope with the task? Or he could just watch his peers play? If he was laughed (if not bullied) in a special school, he would certainly be bullied in a mainstream school. Other children might not think their laugh actually hurt the boy. They probably thought it was quite funny or, the boy was so stupid. As they did not know why the boy was that much scared, they would only think that he was so silly and he was such a coward. 


\section{Class observation: Motivation vs, experience}

Time: 11:00-11:45

School: A special school for visual and audio impairment

Class: Primary 2

Class size: 8

Learning difficulties: audio impairment

Teacher: Miss Shan

Teaching experience: one year teaching experience in the school

Professional qualification: The teacher graduated from a three year teachers' training programme on Chinese language in 2006 from a normal university.

Subject: Chinese

Observers: the researcher and the deputy Headteacher

\section{Notes:}

1. The teacher graduated in 2006. She had learned no relative courses about special education before she came to apply to teach in this special school. I asked her about her motivation in coming to this school. She said that it was very difficult to find a job in other schools in the city. Since she used to be interested in sign language, she applied to work here. She was given a class of primary first year to teach Chinese without any formal training. Obviously, she had great difficulty in meet the challenges. The deputy headteacher who herself had experienced this about 20 years ago when she first started working in this school, helped her a lot as her learning mentor.

2. When I asked for permission to observe classes, the Deputy Headteacher specially recommended me to observe this class with her for the reason that she wanted to show me how fast a teacher without any knowledge of special education could learn from teaching practice. If Interpreted in other way, this was the chance for me to know that school-based training model could work for newly qualified teachers, even with no prior knowledge about special education. According to her, as long as one had a heart of love for children with special educational needs and the patience in teaching, they could succeed in teaching. The deputy Headteacher thought that the young teacher was quite an example. In fact, she remembered herself years ago in the same situation: not knowing what to do with a class of children who could barely speak. She said she learned sign language by being with the children. In other words, children taught her how to use sign language. That was how she asked the young teacher to do. The young teacher did not let her down. She was quite motivated and learned very fast.

3. As an observer with limited knowledge about sign language myself, I could not tell whether the gestures or the languages they used in teaching were the standard ones in China. For example, as long as teachers use mandarin Chinese, they can teach in every classroom in China. I wonder if this is the same case for sing language. Anyhow, I saw the teacher and the children could communicate well. For the whole period, the teacher taught the children two sentences: The button of grandma's shirt is off. The grandma is fixing the button. She spoke very loudly with gestures and other body languages. The children seemed to be able to understand her and followed her. As I was sitting at the back of the classroom, I could not see their mouths. I assumed that they were reading correctly as the teacher kept praising them. But honestly all I could hear was some noise. For the whole class, I could not hear any child pronounce the two sentences identically. The teacher used a shirt, a button to make them understand better. She repeated the sentences in the whole class. She asked the children questions to check their understanding. Questions like: whose button is gone? Whose shirt is it? Who is fixing the button? The children gave different answers. The teacher used many 
methods to make them understand the sentences. She asked them to read the sentences one by one. For some, I could not hear even a noise. For one boy who was the best (I was then told) in class, he felt proud of himself as he had many chances of answering the teacher's questions. He turned back to us and smiled to the Deputy Headteacher every time he answered the questions, no matter whether he did it right or wrong.

4. When the young teacher found some activity did not work, she looked at the Deputy Headteacher. The Deputy Headteacher told the young teacher to try certain method which she thought might be useful in that particular situation. The young teacher quickly adjusted her teaching accordingly. So in that sense, it was not a class for showing the visitors. It was a real teaching practice.

The children were very polite to me and to the Deputy Headteacher. They smiled to us and gathered us chairs to use from the next classroom. I was moved by this special greeting from the children. After class, I talked a bit with the teacher. She was very nervous. She kept explaining to me that she had just started her teaching last year and she still had a lot to learn from other teachers. I gave her positive feedback and told her that she would soon be experienced in teaching children in this school. When she heard this, she felt much better. She told me that she graduated from the university where I went for my bachelor degree (but hers was a three year programme). I asked her if she had learned anything about special education in her training. The answer was negative. We both felt that it was not good to graduate from a teachers' training programme without knowing anything about special education. Or it was not right for the university not to include any module or courses in the curriculum.

When I asked her if she would like to have some training, she was very positive. But then she added that the school would not be able to support her at the moment because she was new and the training was normally provided to good or experienced teachers so that they would have a chance to win some competition for the school. She said she would like to learn to develop. But if she had to pay money for the training herself, she would not do that as she could not afford it. Since the school would only give her help by providing some experienced teachers to mentor her, she said that was the best she could hope to have at present.

Young and inexperienced as she was, I felt she did a good job in her teaching. I realised that it was really not easy to teach children with special educational needs. Teachers need great patience. Given that I have years of teaching experiences, I understand that it is so different teaching in special schools. I start to appreciate the concerns by mainstream school teachers researched that it was not that they did not want to include children in their mainstream schools or they did not want to teach in special schools. It was the knowledge of and skills for special education which prevented them from holding positive attitudes towards special and inclusive education. 


\section{Class observation: Give me three days to see}

Time: 10:00-10:45

School: A special school for visual and hearing impairments

Class: Junior 2

Class size: 19,9 boys 10 girls

Learning difficulties: audio impairment

Teacher: Ms Ying, Deputy Headteacher

Teaching experiences: 19 years in the special school

Professional qualification: the teacher graduated from a three-year's teacher training programme of a junior teachers' college

Subject: Chinese

\section{Notes:}

1. The Deputy Headteacher did not know that I would be sitting in her class that day. Knowing that I was coming for class observation whilst one of her teachers to be observed was for some reason not ready to be observed, the Deputy Headteacher asked if I wanted to be in her class instead. I accepted the Invitation and followed her to the class. So the text she was teaching was not just purposely chosen to impress me. But it happened to be a text about Helen Keller, a wellchosen one for students with hearing impairment. She asked the students to read the text one paragraph after another. After reading, she asked the students some questions to check their understanding. Then she asked them to read the whole text again. She read with them. The students read out loud. I tried to tell what they were reading, but I could not really understand them if I did not hear the teacher read out loud with the students. She used sign languages while she read.

2. If the method were for students in mainstream schools, I would think the method was a very boring one for such a topic. At least, it was very traditional way of teaching: reading and questions. But for teaching students who could hardly speak, I do not know what method would be better. Besides, I found that some questions set students thinking of themselves. Questions like: 'what do you think you would feel if you were Helen Keller'? She further commented: 'Helen Keller could not see anything. If you think you are unfortunate to have speech difficulties, what about her? She made such great achievement in her life despite of the difficulties. So you should all learn from her and work hard. In the future, you can also make great achievement and contribute yourselves to the country. Compare with Helen, you are so lucky...'I was moved by her words. Compare with the children, we are so lucky to be able to hear and speak. I think the teacher used the words to encourage the students to be positive in their life, to be courageous to overcome all kinds of challenges and difficulties in the future. Therefore, the teaching was not just the teaching of a text. She was actually teaching them to have positive attitudes for life.

3. In class, she wrote some sentences on a small blackboard and analysed some words and phrases. The 45 minutes went fast. Most of the time, it was the reading. Although I could not quite understand them, I noticed that they all paused at certain place. It meant that they were all reading at the same pace. For this class, I sat at the right side of the front. So I could see the students' faces. My presence did not attract too much of their attention as they were reading attentively. At certain points, some students became excited. They were eager to answer questions and make comments. I could easlly tell from the highly raised hands and their facial expressions. However, there were two silent boy students sitting in the first row together. They did not have text books with them. One of them kept looking out of the window whlle the other one looked at the other students. It seemed that he was quite amused when they got excited by some 
scenarios. The teacher obvious knew all these. She did not even say a word. I guessed the two of them must be the 'integrated' children in the special school. They were disaffected by such a touch story of Helen Keller. They must have missed more than that. Unfortunately, I was unable to check with the teacher for the reason as I had to move on to the next class while the teacher was answering some students' questions. Later I found that the two boys never learned in classes. They had mental retardation other than speech and hearing impairments. But they were quiet. So they were allowed to upgrade with the rest.

4. My overall impression of the lesson is that: if it were not a story about Helen Keller, if it were not the lesson in a special school, then I would say this teaching method was very much out of date. In other words, it was very boring. It was the way I used to learn in my middle school years. If teachers from mainstream schools come to observe the class, they would think it was quite easy to teach in a special school. However, I did see how much attention the students paid during the lesson (most of the students but the two), how much they had learned judging from their facial expressions, how much they have enjoyed the lesson judging from the active involvement by the students. I had an in-depth interview with the Deputy Headteacher after the lesson. 


\section{Appendix XI}

\section{Data: An example of motivational change according to the SDT theory}

Teaching as a career has been influenced by the changing nature of work and the society. Dornyei (2001:165) defines teaching as a profession whose energy is supplied from intrinsic motives. He states that there are some damaging elements which weaken and destroy the intrinsic character of teacher motivation. It also shifts in assumptions about career structures. In Day and. Kington's words (2008:8), 'Change affects teachers' work, but also how teachers feel about their work'. Other research (e.g., Stempien and Loeb, 2002) finds that working with gifted and talented students predicts high job satisfaction, whereas working with students who had learning difficulties was associated with low job satisfaction.

Over half of the student teachers were extrinsically motivated $(N=217)$ with a contrast to about $72 \%$ of mainstream school teachers and about $76 \%$ of special school teachers. A few special school teachers claimed in the interviews that they were intrinsically motivated by the time of the research. The following accounts were articulated by a teacher in a special school. She had a strong intrinsic motivation for teaching in general but was amotivated to teach in special schools as she was assigned to a special school without her knowledge. However, she witnessed the change in herself after years' experiences. This is complicated in that the teacher had her original intrinsic motivation changed to great amotivation and back to more autonomous regulation which could be a mixture of extrinsic and intrinsic motivation (Deci and Ryan, 2002). I would consider this change as a natural reaction caused by the negative social image of special teachers. As she stayed along in the school, her initial intrinsic motivation overcame her self perception of special teachers and enabled her to have altruistic motivation in her career.

When I was in primary school, I repeated Grade 1 as I was poor in health. My family was poor and my parents were busy. So we children were dressed in shabby clothes. My teacher looked down upon me. I was not happy and I would not accept the attitude from the teacher. I decided to study hard. At the end of the first term, nobody got marks as good as mine. At that time, they chose model students according to the marks. So I was chosen. The second term, we had a new teacher. That teacher was especially kind to me. So I determined to be a teacher. I wanted to be a teacher who would never judge their students according to the clothes they wear, or the familles they are from. I would love my students with all my heart. So now in my class, I love each and very one of them. When they do things wrongly, I would only blame them in my heart that they did that.

My teachers in my junior years were good ones and I am lucky that all my teachers were good ones later in my study life. But the first teacher I had had great impact on me and later, when I finished my junior middle school, I applied to study in junior teachers' college and I decided to be a teacher and a good teacher. That is why I am now a teacher.

I-ST-22

Interviewer: Why did you choose this school [the special school], then?

Intervlewee: I should say that I did not know I should teach here. When I got the offer, I did not even know the school. I was very surprised. My mother was also surprised. I asked why I should go to this school for children with speech impairment. I tried to figure it out and told my mother that it must be the training course which ran in that school for newly qualified teachers. At that time, my mother used some relations to get me into another school. I could have four choices of going to mainstream schools. I felt quite secured and I believed that I would teach in a good school. But my documents were not distributed to the four schools. The local education bureau kept the documents. I was asked to come to this school. 
Interviewer: Have you ever thought of leaving the school?

Interviewee: Yes, I did. In the first year, I tried very hard to leave the school. I almost succeeded by using relations. But I changed my mind. I told myself to try to work here. Later I got used to it and later I did not want to leave.

As shown clearly, the teacher owed this change to their experiences working in special schools, above all, to the recent increased priority attached to special education which reflects broader economic, social and political changes. 


\section{Appendix XII}

\section{The implications from the ethical issues in the current study}

I have discussed some cross cultural ethical dilemmas I encountered as a research student in the UK conducting research, interpretative in nature, in special and inclusive school settings In China. Serious consideration was taken in the whole process to avoid the challenging ethical issues. The issues described in this thesis have culture-specific implications for future national or International research of this nature to be conducted in China. Meanwhile, implications can also be drawn for researching education in a wider world, especially international comparative in nature.

First of all, researchers need to regularly reflect on their work so as to develop their understanding of the ethical implications associated with social and educational investigation across countries and cultures in an effort to construct knowledge whilst remain ethical. They should be sensitive to and aware of special cultural, legal or social contexts in which research is to be conducted. A common theme to suggestions for handling ethical dilemmas in research is the notion (Burgess, 1989) that there is no 'solution' to the problems identified by researchers. In addition, codes are not universally applicable to all circumstances but have to be interpreted in relation to the projects on which researchers work. There is a need to be sensitive to the cultural context in which research is conducted (Simons \& Usher 2000). However, this does not mean that cultural practices must be accepted uncritically.

Moreover, a distinction can be drawn between moral principles and moral rules. Generally principles include: maximising good, minimising harm, pursuing the truth and respecting persons (Clark 1995), Implying that subjects enter research projects voluntarily, understanding the nature of the study and the dangers and obligations involved. Ethical guidelines help ensure that participants are not exposed to risks greater than the gains they might derive. Their identities should be protected so that information collected does not harm or embarrass in any way (Bogdan and Biklen, 1992). In specific, the particular procedures for obtaining voluntary informed consent in economically developing countries may need to be tailored to local custom and culture (Halasa, 1998), even though I share the view that the principle of informed consent applies throughout the world.

For example, although signed forms make it easy to audit informed consent, written consents may be impossible to seek in some areas because participants may be illiterate (Halasa 1998). In that case, informed consent does not ensure that a participant understands the proposed research. In some contexts, this can be viewed as the lack of involvement in educational research where voices are encouraged from key stakeholders. Or, signing a form may be considered as dangerous for social or political reasons. Democratic principles and values had a strong impact on the passive involvement of participants, who either felt obliged, reluctant or de-motivated to provide data for the studies under the pressure from top-down decisions. It may be difficult to identify the members of the community who should be consulted, and to determine the level of authority researchers have to approach potential participants. However, such consultations can be helpful in improving both the informed consent process and the overall research design to avold dilemmas.

Besides, recurring ethical issues related to analysis in qualitative studies suggest analysis-related implications. Additional ethical issues need to be considered (Trahar, 2006) by researchers engaging in narrative enquiry, particularly where cultural contexts have a significant impact on the research. The combination of 
methods for this study provides opportunities to examine how narrative enquiry as a methodology is applied in a range of real world situations. In an attempt to describe and interpret some human phenomenon in the words of selected individuals for this qualitative study, I found it was not always easy to be clear from biases, presuppositions, or mis-interpretations.

For example, the strict adherence to ethical guidelines and UK codes of practice may be in danger of reducing the quality of samples and data. In China, the concept of 'losing face' through admitting ignorance of a subject or appearing less than competent might have led to some guarded responses from the participants (Clough, 2004). In my study, occasionally, I found difficulties in keeping the right balance between the protection of the participants' rights and the generation of valid data. In data analysis, specific ethical issues like confidentiality and anonymity, subjectivity and bias are inevitable. They float beneath the surface of what I did. Issues like privacy, confidentiality, anonymity, and research quality, data ownership and the use of the results all have clear implications for analysis and the quality of conclusions. These, as criticized by Miles and Huberman (1994), have typically received too little public attention within and beyond the research community. Acknowledgement of bias in fact helps to unmask any bias that is implicit in those views and to provide a way of responding critically and sensitively to the research being conducted.

Universality is a feature of an ethical code which compels every person to recognise universal rights for all persons as a constant norm (Evans and Jakupec 1996). This study implies that ethical guidelines need to be formulated to illuminate research in areas where guidelines do not exist (Evans and Jakupec 1996). More flexible ethical guidelines which take into consideration of the contextual related ethical issues should be applied as and when appropriate. As reported in Chapter Eight, ethical guidelines are yet to be formulated and applied within the context of the study for conducting research in special and inclusive education in China. Dilemmas arose out of the conflicts between accepted ethical guidelines which I, as an international student studying in a university in the UK, was obliged to abide by and the research conventions in my home context which has not as yet recognised the essential features of such ethical guidelines.

In particular, within China, it is important to obtain informed consent from different educational levels and stakeholders. Whilst the researcher should take every practicable measure to ensure the confidentiality and anonymity of research participants, $s /$ he should also take care not to give unrealistic assurances or guarantees of confidentiality in a situation where central control may make exceptional demands upon them in terms of access to data. Research participants with easily identifiable characteristics or positions within an organisation should be reminded that it may be difficult to disguise their identity totally without distorting the data (Halasa 1998). Above all, the consent-seeking process should be appropriate to the cultural context and to individual needs. Professionals should respect the limits of participants' understanding and capacity to deal with difficult information and situations.

In my research practice, I applied the guldelines from the UK research system which created additional ethical concerns and practical difficulties. Ethical issues encountered in conducting this study were addressed with great effort. Dealing with ethical issues effectively involved heightened awareness and negotiation in order to address ethical dilemmas, rather than the application of simplistic rules. Future research should draw attention to the delicate counterbalancing of ethical principles (Gorard, 2002) and seek 'solutions' to the dilemmas facing many international research students. With the research experience, I would recommend that researchers make themselves aware of special cultural, legal or 
social considerations in the host countries in which they are operating (Feng and Jament, 2008). 


\section{References}

Addison, R. and Brundrett, M. (2008) Motivation and demotivation of teachers in primary schools: the challenge of change. Education 3-13, 36 (1), 79-94.

Ainscow, M. (1998) Would it work in theory? Arguments for practitioner research and theorising in the special needs field. In: I. Clark, A. Dyson and A. Millward (eds.) Theorising Special Education. London: Routledge.

Ainscow, M. (1999) Understanding the Development of Inclusive Schools. London: RoutledgeFalmer.

Ainscow, M. (2005) Develop inclusive education systems: what are the levers for change? Journal of Educational Change, 6 (2), 109-124.

Ainscow, M. (2008) Making sure that every child matters: towards a methodology for enhancing equity within education systems. In: C. Forlin (ed.) Catering for Learners with Diverse Needs: An Asian-Pacific Focus. Hong Kong: Institute of Education.

Ainscow, M., Booth, T. and Dyson, A. (2006a) Inclusion and the standards agenda: negotiating policy pressures in England. International Journal of Inclusive Education, 10 (4-5), 295-308.

Ainscow, M., Booth, T. and Dyson, A. (2006b) Improving Schools, Developing Inclusion. London: Routledge.

Ainscow, M., Farrell, P. and Tweddle, D. (2000) Developing policies for inclusive education: a study of the role of local education authorities. International Journal of Inclusive Education, 4 (3), 211-229.

Ali, M., Mustapha, R. and Jelas, Z. (2006) An empirical study on teachers' perceptions towards inclusive education in Malaysia. International Journal of Special Education, 21 (3), 36-44.

Alred, G., Byram, M. and Fleming, M. (eds.) (2003) Intercultural Experience and Education. Clevedon: Multilingual Matters.

Al-Zyoudi, M. (2006) Teachers' attitudes towards inclusive education in Jordanian schools. International Journal of Special Education, 21 (2), 55-62.

Anthony, G. and Ord, K. (2008) Change of career secondary teachers: motivations, expectations and intentions. Asia-Pacific Journal of Teacher Education, 36 (4), 359-376.

Anttonen, S. (1999) The trouble of social constructivism (I). Paper presented at the European Conference on Educational Research, Lahtl, Finland, September 2225. Available online at:

http://www.leeds.ac.uk/educol/documents/00001349.htm. [Accessed February 20, 2007].

Armstrong, F. and Moore, M. (eds.) (2004) Action Research for Inclusive Education: Changing Places, Changing Practices, Changing Minds. London and New York: RoutledgeFalmer.

Arthur, L., Marland, H., Pill, A. and Rea, T. (2006) Postgraduate Professional Development for teachers: motivational and inhibiting factors affecting the 
completion of awards. Journal of In-Service Education, 32 (2), 201-219.

Avramidis, E. and Norwich, B. (2002) Teachers' attitudes towards integration/inclusion: a review of the literature. European Journal of Special Needs Education, 17 (2), 129-147.

Ballard, K. (1999) International voices: an introduction. In: K. Ballard (ed.) Inclusive Education: International Voices on Disability and Justice. London: Falmer Press.

Barton, L. (2003) Inclusive Education and Teacher Education: A Basis of Hope or a Discourse of Delusion? London: University of London.

BBC News (2008) Population. Available online at:

http://news.bbc.co.uk/1/shared/spl/hi/in depth/china modern/html/2.stm [Accessed July18 2008].

Bassey, M. (1999) Case Study Research in Educational Settings. Buckingham: Open University Press.

Beale, B. Cole, R. Hillege, S., McMaster, R. and Nagy, S. (2004) Impact of indepth interviews on the interviewer: roller coaster ride. Nursing and Health Sciences, 6 (2), 141-147.

Becker, G. (1964) Human Capitol: A Theoretical and Empirical Analysis with Special Reference to Education. Princeton: Princeton University Press.

Bell, J. (1999) Doing Your Research Project: A Guide for First-Time Researchers in Education and Social Science. ( $3^{\text {rd }}$ ed.) Milton Keynes: Open University Press.

Bell, J. (2002) Narrative inquiry: more than just telling stories. TESOL Quarterly, $36,207-213$.

Bennell, P. and Akyeampong, K. (2007) Teacher motivation in Sub-Saharan Africa and South Asia. Researching the Issues, 71, Department for International Development.

British Educational Research Association (BERA) (2004) Revised Ethical Guidelines for Educational Research. Nottingham: British Educational Research Association.

Berry, R. (2008) Novice teachers' conceptions of fairness in inclusive classrooms. Teaching and Teacher Education, 24 (5), 1149-1159.

Billig, M., Condor, S., Edwards, D., Gane, M., Middleton, D. and Radley, A. (1988) Ideological dilemmas: a social psychology of everyday thinking. Bristol, Sage, cited in: Nilholm, C. (2006) Special education, Inclusion and democracy. European Journal of Special Needs Education, 21 (4), 431-445.

Black-Hawkins, K., Florian, L. and Rouse, M. (2007) Achievement and Inclusion in Schools. London: Routledge

Blake, C. and Monahan, E. (2007) Rethinking teacher preparation for EBD students: towards a partnership model. British Journal of Support for Learning, 22 $(2), 60-65$.

Boe, E. (2006) Long-term trends in the national demand, supply and shortage of special education teachers. The Journal of Special Education, 40 (3), 138-150. 
Bogdan, R. and Knopp, B. (1992) Qualitative Research for Education: An Introduction to Theory and Methods. Boston: Allyn and Bacon.

Booth, T. (1983) Integrating special education. In: T. Booth and P. Potts (eds.) Integrating Special Education. Oxford: Basil Blackwell.

Booth, T. (1996) A perspective on inclusion from England. Cambridge Journal of Education, 26 (1), 87-101.

Booth, T. and Ainscow, M. (eds.) (1998) From Them to Us: An International Study of Inclusion in Education. London: Routledge.

Booth, T., Ainscow, M. and Dyson, A. (1998) England: inclusion and exclusion in a competitive system. In: T. Booth and M. Ainscow (eds.) From Them to Us: An International Study of Inclusion in Education. London: Routledge.

Booth, T., Nes, K. and Stromastad, M. (eds.) (2003) Developing Inclusive Teacher Education.London:Routledge/Falmer.

Bray, M. (1998) Financing education in developing Asia: themes, tensions, and policies. International Journal of Educational Research, 29 (7), 627-642.

Bray, M. and Gui, Q. (2001) Comparative education in greater China: contexts, characteristics, contrasts and contributions. Comparative Education, 37 (4), 451473.

Brighouse, T. and Woods, D. (1999) How to Improve Your School. London: Routledge.

Brookhart, S. and Freeman, D. (1992) Characteristics of entering teacher candidates. Review of Educational Research, 62, 37-60.

Broom, A. (2005) Using qualitative interviews in CAM research: a guide to study design, data collection and data analysis. Complementary Therapies in Medicine, 13 (1), 65-73.

Broomfield, C. (2006) PGCE secondary trainee teachers and effective behaviour management: an evaluation and commentary. Support for Learning, 21 (4) 188193.

Brown, A. and Dowling, P. (1998) Doing Research/Reading Research. London: Falmer Press.

Brown, K., Welsh, L., Hill, K. and Cipko, J. (2008) The efficacy of embedding special education instruction in teacher preparation programmes in the United States. Teaching and Teacher Education, 24 (8), 2087-2094.

Brownell, M., Ross, D., Colon, E. and McCallum, C. (2005) Critical features of special education teacher preparation: a comparison with general teacher education. The Journal of Special Education, 38 (4), 242-252.

Bryman, A. and Burgess, R. (1994a) Developments in qualitative data analysis: an introduction. In: A. Bryman and R. Burgess (eds.) Analysing Qualitative Data. London: Routledge.

Bryman, A. and Burgess, R. (1994b) Reflections on qualitative data analysis. In: A. Bryman and R. Burgess (eds.) Analysing Qualitative Data. London: Routledge. 
Bryman, A. (2008) Social Research Methods (3rd ed.). Oxford: Oxford University Press.

Burgess, R. (1984) In the Field: An Introduction to Field Research. London: Allen \& Unwin.

Burgess, R. (ed.) (1989) The Ethics of Educational Research. London: FalmerPress.

Cameron, M., Baker, R. and Lovett, S. (2006) Teachers of Promise: Getting Started in Teaching: Phase One Overview. Wellington: New Zealand Council for Educational Research.

Cameron, M., Berger, J., Lovett, S. and Baker, R. (2007) Early career teachers' opportunities for professional learning: impacts on teaching practice, job satisfaction, motivation, and career decisions. Paper presented at British Education Research Association Annual Conference, Institute of Education, London, the UK, $7^{\text {th }}$ September. Available online at:

http://www.nzcer.org.nz/pdfs/15677.pdf. [Accessed August 24, 2008].

Carlberg, C. and Kavale, K. (1980) The efficacy of special versus regular class placement for exceptional children: a meta-analysis. The Journal of Special Education, 14 (3), 295-309.

Chapman, D., Snyder, C. and Burchfield, S. (1993) Teacher incentives in the third World. Teaching and Teacher Education, 9 (3), 301-316.

Chapman, D. and Adams, D. (1998) The quality of education In Asia: the perennial priority. International Journal of Educational Research, 29 (7), 643-665.

Chen, A.Y., Lim, C.P. and Gopinathan, S. (2003) The recruitment and preparation of teachers. In: J. Keeves and R. Watanabe (eds.) International Handbook of Educational Research in the Asia-pacific Region. Dordrecht: Kluwer Academic Publishers.

Chen, S.R. (BBC News, 16 January 2009) China rural-urban wage gap widens http://news.bbc,co.uk/1/hi/world/asia-pacific/7833779.stm. [Accessed on January 17 2009].

Chen, Y.Y. (1990) A few problems in teacher training in special education. A report of study commissioned by the Teacher Education Bureau of the State Education Commission. Cited in: Potts, P. (1995) Reforming special education In China. In: P. Potts, F. Armstrong and M. Masterton (eds.) Equality and Diversity in Education (2): National and International Contexts. London: Routledge and the Open University.

Chen, Y.Y. (2005) Emerging patterns of Inclusive education In China. Paper presented at the International Special and Inclusive Education Congress (ISEC) University of Strathclyde, Glasgow, Scotland, $1^{\text {st }}-4^{\text {th }}$ August.

Chen, Y.Y. (1996) Making special education compulsory and inclusive In China. Cambridge Journal of Education, 26 (1), 47-57.

Chen, Y.Y. and Hua, G.D. (1998) A Trial of Inclusion for Special Needs Children: Successful Experience from the Countryside. Beijing: Education and Science Publishing House. 
Cheng, K.M. (1990) The culture of schooling in East Asia. In: N. Entwistle (ed.) Handbook of Educational Ideas and Practices. London: Routledge.

Chinese National Commission for UNESCO (2004) Education development in China Available from:

http://www.ibe.unesco,org/International/ICE47/English/Natreps/reports/china oc r.pdf [Accessed July 20, 2007].

Chih, H. (2007) Using software to open up the 'black box' of qualitative data analysis in evaluations: the experience of a multi-site team using NUD*IST Version 6. Evaluation, 13 (1), 110-120. SAGE Publications Disability Rights Commission, UK

Chong, S., Forlin, C. and Au, M.L. (2007) The influence of an inclusive education course on attitude change of pre-service secondary teachers in Hong Kong. AsiaPacific Journal of Teacher Education, 35 (2), 161-179.

Chuene, K., Lubben, F. and Newson, G. (1999) The views of pre-service and novice teachers on mathematics teaching in South Africa related to their educational experience. Educational Research, 41 (1), 23-34.

Clandinin, D. and Connelly, F. (1990) Stories of experience and narrative inquiry. Educational Researcher, 19 (5), 2-14.

Clandinin, D. and Connelly, F. (1996) Teacher professional knowledge landscapes: teacher stories, stories of teachers, school stories and stories of schools. Educational Researcher, 25 (3), 24-30.

Clandinin, D. and Connelly, F. (2000) Narrative Inquiry: Experience and Story in Qualitative Research. San Francisco: Jossey-Bass Inc.

Clark, J. (1995) Ethical and Political Issues in Qualitative Research from a Philosophical Point of View. Paper presented at the Annual Conference of the American Educational Research Association, San Francisco.

Clough, P. (2004) Theft and ethics in life portrayal: Lolly: the final story. International Journal of Qualitative Studies in Education, 17 (3), 371-382.

Clough, P. and Barton, L. (eds.) (1998) Articulating with Difficulty: Research Voices in Inclusive Education. London: Paul Chapman Publishing Ltd.

Clough, P. and Garner, P. (2003) Special educational needs and inclusive education: origins and current issues. In: S. Bartlett and D. Burton (eds.) Education Studies. London: Sage.

Cochran-Smith, M. (2004) Walking the road: race, diversity and social justice in teacher education. Multicultural Education Series, New York: Teachers College, Columbia University.

Cohen, L., Manion, L. and Morrison, K. (2000) Research Methods in Education. London: Routledge/Falmer.

Cohen, L., Manion, L. and Morrison, K. (2007) Research Methods in Education (6 ${ }^{\text {th }}$ ed.) London: Routledge.

Connelly, F. and Clandinin, D. (1990) Stories of experience and narrative inquiry. Educational Researcher, 19 (5), 2-14. 
Coocican, H. (1992) Research Methods and Statistics in Psychology. London: Hodder and Stoughton.

Cooman, R., Gieter, S., Pepermans, R., Du Bois, C., Caers, R. and Jegers, M. (2007) Graduate teacher motivation for choosing a job in education. International Journal for Educational Vocational Guidance, 7 (2), 123-136.

Cortazzi, M. and Jin, L.X. (2001) Large classes in China: 'good' teachers and interaction. In: D. Watkins and J. Biggs (eds.) Teaching the Chinese Learner: Psychological and Pedagogical Perspectives. Hong Kong: University of Hong Kong.

Creed, P. and Wong, O.Y. (2006) Reliability and validity of a Chinese version of the career: decision-making difficulties questionnaire. International Journal for Educational and Vocational Guidance, 6, 47-63.

Creswell, J. (1994) Research Design. London: Sage Publications.

Creswell, J. (1998) Qualitative Inquiry and Research Design: Choosing among the Five Decisions. California: Sage.

Creswell, J. (2008) Research Design: Qualitative, Quantitative, and Mixed Methods Approaches (3rd ed.). London: SAGE Publications.

Croll, P. and Moses, D. (2000) Ideologies and utopias: education professionals' views of inclusion. European Journal of Special Needs Education, 15 (1), 1-12.

Crossley, M. and Holmes, K. (2001) Challenges for educational research: international development, partnerships and capacity building in small states. Oxford Review of Education, 27 (3), 395-409.

Crossley, M. and Jarvis, P. (2001) Context matters. Comparative Education, 37 (4), 405-408.

Crossley, M. and Watson, K. (2003) Comparative and International Research in Education: Globalisation, Context and Difference. London: RoutledgeFalmer. Centre for Special and Inclusive Education CSIE (2000) Index for Inclusion. Bristol: Centre for Studies on Inclusive Education.

Cunningham, M. and Oliver, C. (2007) Insider views of the status of teachers and the teaching profession, paper presented at British Educational Research Association Annual Conference, Institute of Education, London, the UK, September 6-9.

Curtis, S., Gesler, W., Smith, G. and Washburn, S. (2000) Approaches to sampling and case selection in qualitative research: examples in the geography of health. Social Science and Medicine, 50 (7-8), 1001-1014.

Czaja, R. and Blair, J. (1996) Designing Surveys: A Guide to Decisions and Procedures. Thousand Oaks: Pine Forge.

Darling-Hammond, L. (1997) Doing What Matters Most: Investing in Quality Teaching. New York: National Commission on Teaching \& America's Future.

Darling-Hammond, L. and Sykes, G. (1999) Teaching as the Learning Profession: Handbook of Policy and Practice. San Francisco: Jossey-Bass. 
Darling-Hammond, L., Chung, R. and Frelow, F. (2002) Variation in teacher preparation: how well do different pathways prepare teachers to teach? Journal of Teacher Education, 53 (4), 286-302.

Dart, G. (2006) 'My eyes went wide open' - an evaluation of the special needs education awareness course at Molepolole College of Education, Botswana. British Journal of Special Education, 33 (3), 130-138.

Davies, J. and Garner, P. (1997) At the Crossroads: Special Educational Needs and Teacher Education. London: David Fulton.

Day, C. (1999) Developing Teachers: The Challenges of Life Long Learning. London: Falmer Press.

Day, C. (2004) A Passion for Teaching. London: RoutledgeFalmer.

Day, C. and Sachs, J. (2005) Professionalism, performativity and empowerment: discourses in the politics, policies and purposes of continuing professional development. In: C. Day and J. Sachs (eds.) International Handbook on the Continuing Professional Development of Teachers. Buckingham: Open University Press.

Day, C. and Kington, A. (2008) Identity, well-being and effectiveness: the emotional contexts of teaching. Pedagogy, Culture and Society, 16 (1), 7-23.

Deci, E. (1971) Effects of externally mediated rewards on intrinsic motivation. Journal of Personality and Social Psychology, 18 (1), 105-115.

Deci, E. (1975) Intrinsic Motivation. New York: Plenum Press.

Deci, E. and Ryan, R. (1985) Intrinsic Motivation and Self-Determination in Human Behaviour. New York: Plenum Press.

Deci, E. and Ryan, R. (2007) Facilitating optimal motivation and psychological well-being across life's domains. Canadian Psychology, 49 (1), 14-23.

Deci, E. and Ryan, R. (2008) Self-determination theory: a macro-theory of human motivation, development, and health. Canadian Psychology, 49 (3), 182-185.

Deng, M. (2005) A comparative study between rural and urban primary schools on teachers' teaching adjustment strategies in mainstreaming classes. Chinese Journal of Special Education, 58 (4), 65-70.

Deng, M. and Manset, G. (2000) Analysis of the 'learning in regular classrooms' movement in China. Mental Retardation, 38 (2), 124-130.

Deng, M., Poon-McBrayer, K. and Farnsworth, E. (2001) The development of special education in China: a socio-cultural review. Remedial and Special Education, 22 (5), 288-298.

Deng, M. and Holdsworth, J. (2007) From unconsclous to conscious inclusion: meeting special education needs in West China. Disability and Society, 22 (5), 507-522.

Deng, M. and Guo, L. (2007) Local special education administrators' understanding of inclusive education in China. International Journal of Educational Development, 27 (6), 697-707. 
Department for Education and Employment (DfEE) (2000) Professional Development: Support for Teaching and Learning. London: DfEE.

DiCicco-Bloom, B. and Crabtree, B. (2006) The qualitative research Interview. Medical Education, 40 (4), 314-321.

Ding, Y., Gerken, K., Vandyke, D. and Xiao, F. (2006) Parents and special education teachers' perspectives on implementing individualized instruction in P.R. China: an empirical and socio-cultural approach. International Journal of Special Education, 21(3), 138-150.

Dornyei, Z. (2001) Motivation Strategies in the Language Classroom. Cambridge: Cambridge University Press.

Doveston, M. and Keenaghan, M. (2006) Growing talent for inclusion: using an appreciative inquiry approach into investigating classroom dynamics. Journal of Research in Special Educational Needs, 6 (3), 153-165.

Dowson, C. (2007) Developing inclusive schools in Hong Kong. In: S. Phillipson (ed.) Learning Diversity in the Chinese Classroom. Hong Kong: Hong Kong University Press

Edmonds, S., Sharp, C. and Benefield, P. (2002) Recruitment to and Retention on Initial Teacher Training: A Systematic Review. Slough: NFER.

Elliott, J. (2005) Using Narrative in Social Research: Qualitative and Quantitative Approaches. London: Sage.

Ellsworth, N. and Zhang, C. (2007) Progress and challenges in China's special education development: observations, reflections and recommendations. Remedial and Special Education, 28 (1), 58-64.

Erickson, F. (1986) Qualitative methods in research on teaching. In: M. Wittrock (ed.) Handbook of Research on Teaching. New York: Macmillan.

Evans, L. (1999) Managing to Motivate: A Guide for School Leaders. London: Cassell.

Evans, L. (2000) The effects of educational change on morale, job satisfaction and motivation. Journal of Educational Change, 1 (2), 173-192.

Evans, L. (2002) What is teacher development? Oxford Review of Education, 28 (1), 123-137.

Evans, L. (2008) Professionalism, professionality and the development of education professionals. British Journal of Educational Studies, 56 (1), 20-38.

Evans, J. and Lunt, I. (2002) Inclusive education: are there limits? European Journal of Special Education, 17 (1), 1-14.

Evans, T. and Jakupec, V. (1996) Research ethics in open and distance education: context, principles and issues. Distance Education, 17 (1), 72-94.

European Agency for Development in Special Needs Education (EADSNE) (2005) Inclusive Education and Classroom Practice in Secondary Education. Middelfart: EADSNE. 
Fairbrother, G. (2005) Comparison to what end? Maximizing the potential of comparative education research. Comparative Education, 41 (1), 5-24.

Fairclough, N. (1992) Discourse and Social Change. Cambridge: Polity.

Fang, J.M. (2000) Review and prospect of special education research in China. Chinese Journal of Special Education, 25 (1), 2-4.

Farrell, P. (2000) The impact of research on developments in inclusive education. International Journal of Inclusive Education, 4 (2), 153-162.

Farrell, P. (2001) Special education in the last twenty years: have things really got better? British Journal of Special Education, 28 (1), 3-9.

Farrell, P and Ainscow, M. (2002) Making special education inclusive: mapping the issues. In: P. Farrell and M. Ainscow (eds.) (2002) Making Special Education Inclusive: From Research to Practice. London: David Fulton Publishers.

Farrell, P., Dyson, A., Polat, F., Hutcheson, G. and Gallannaugh, F. (2007) SEN inclusion and pupil achievement in English schools. Journal of Research in Special Educational Needs, 7 (3), 172-178.

Faulkner, M. (1996) What do we want from CPD? British Journal of Administrative Management, July/August, p. 30

Feng, Y. (2007) Listening to the voices of children: the impact of parental and school expectations on children's emotional well-being in China. Paper presented at the British Educational Research Association (BERA) National Conference, Institute of Education, the UK, $5^{\text {th }}-8^{\text {th }}$ September. Available on line at: http://www.leeds.ac.uk/educol/documents/168283.htm. [Accessed November 25, 2008].

Feng, Y. and Jament, J. (2007) Doing educational research in developing countries: challenges and opportunities. In: C. Corcoran, E. Gardiner, N. MaCnab, and W. Milner (eds.) Understanding education research: principles and practice. Birmingham: The University of Birmingham.

Feng, Y. and Jament, J. (2008) Integrated but not included: exploring quiet disaffection in mainstream schools in China and India. The International Journal on School Disaffection, 6 (1), 12-18.

Feng, Y and Jament, J. (2008) Can ethical guidelines be international?: Students' dilemmas researching education in China and India. Research Intelligence of British Educational Research Association (BERA) September, Issue 104, 24-25.

Feng, Y. and Yu, L.P. (2008) Teacher voices from China: the Impact of crosscultural experiences on EFL teachers' motivation for professional development. Paper presented at Asia Pacific Educational Research Association (APERA) Conference, Institute of Education, Nanyang Technological University, Singapore, November 26-28.

Feng, W., Pei, P. and Cao, Y. (2008) A comparative study of personality characteristics between special education teachers and elite teachers in general schools. Chinese Journal of Special Education, 96 (6), 58-62.

Ferguson, D. (2008) International trends in inclusive education: the continuing 
challenges to teach each one and everyone. European Journal of Special Needs Education, 23 (2), 109-120.

Fish, J. (1989) What Is Special Education? Milton Keynes: Open University Press.

Florian, L. (1998) Inclusive practice: what, why and how? In: C. Tilstone, L. Florian and R. Rose (eds.) Promoting Inclusive Practice. London: Routledge.

Florian, L. (ed.) (2007) The SAGE Handbook of Special Education. London: SAGE Publications.

Florian, L. (2009) Preparing teachers to work in 'schools for all'. Teaching and Teacher Education, 25 (4), 533-534.

Forlin, C., Au, M. and Chong, S. (2008) Teachers attitudes, perceptions and concerns about inclusive education in the Asia-Pacific reglon. In: $\mathrm{C}$, Forlin and J, Ming-Gon (eds.) Reform, Inclusion and Teacher Education: Towards a New Era of Special Education in the Asia Pacific Region. London: Routledge

Forlin, C. (2008) Education reform for inclusion in the Asia-Pacific region: what about teacher education? In: C. Forlin and M.G. Lian (eds.) Reform, Inclusion and Teacher Education: Towards a New Era of Special Education in the Asia-Pacific Region. London: Routledge.

Forlin, C. and Lian, M.G. (eds.) (2008) Reform, Inclusion and Teacher Education: Towards a New Era of Special Education in the Asia-Pacific Region. London: Routledge.

Forrester, G., Motteram, G. and Liu, B.X. (2006) Transforming Chinese teachers' thinking, learning and understanding via e-learning. Journal of Education for Teaching, 32 (2), 197-212.

Frase, L. (1992) Maximizing People Power in Schools: Motivating and Managing Teachers and Staff. Newbury Park: Corwin Press.

Fraser, C., Kennedy, A., Reid, L. and Mckinney, S. (2007) Teachers' continuing professional development: contested concepts, understandings and models. Journal of In-service Education, 33 (2), 153-169.

Friedman, A. and Phillips, M. (2004) Continuing professional development: developing a vision. Journal of Education and Work, 17 (3), 361-376.

Friedman, A., Durkin, C., Phillips, M. and Davies, K. (2000) Continuing Professional Development in the UK: Policies and Programmes. Bristol: Parn.

Gagne, M. and Deci, E. (2005) Self-determination theory and work motivation. Journal of Organizational Behaviour, 26 (4), 331-362.

Gan, Z.L. (2004) An Investigation of the current situation of special education teachers in Fujian Province. Chinese Journal of Special Education, 46 (4), 74-78.

Gao, S. (1999) Current issues in teacher education In China. Paper presented at the Annual Meeting of the Comparative and International Education Society. Toronto, Ontario, Canada.

Gao, X.S. (2008) Teachers' professional vulnerability and cultural tradition: a Chinese paradox. Teaching and Teacher Education, 24 (1), 154-165. 
Gargiulo, R. (2008) Special Education in Contemporary Society: An Introduction to Exceptionality. London: Sage Publications.

Garner, P. (1996) Students' views on special needs courses in initial teacher education. British Journal of Special Education, 23 (4), 176-179.

Garner, P. (1999) By the book: twenty-five years of writing about special education. British Journal of Special Education, 26 (1), 61-64.

Garner, P. (2000) Mainstream teachers and inclusion: a chronic case of Nimsa (not in my subject area)? Paper presented at International Special Education Congress (ISEC): Including the Excluded. University of Manchester, the UK, 24-28 July.

Garner, P. (2001) Goodbye Mr Chips: special needs, inclusive education and the deceit of initial teacher training. In: T. O'Brien (ed.) Enabling Inclusion: Blue Skies...Dark Clouds? London: The Stationery Office.

Garner, P. (2000) Vision or revision? Conflicting ideologies in the English education system. In: K. Mazurek, M. Winzer, and C. Majorek (eds.) Education in a Global Society: A Comparative Perspective. Boston: Allyn and Bacon.

Garner, P. (2006) Redefining professional development: responding to the needs of teachers. LEARN, Journal of the Irish Learning Support Association, Dublin, 28, 17-25.

Garner, P. and Davies, J. (1997) At the Crossroad: Special Educational Needs and Teacher Education. London: Taylor and Francis.

Gergen, K. (1995) Social construction and the educational process. In: L. Steffe and J. Gale (eds.) Constructivism in Education. New Jersey: Lawrence Erlbaum Associates, Inc.

Gergen, K. (2001) Social Construction in Context. London: Sage Publishers.

Ginzberg, E., Ginsburg, S. Axelrad, S. and Herma, J. (1951) Occupational Choice: An Approach to a General Theory. New York: Columbia University Press. Available online at: http://www.questia.com/PM. ast?a $=0 \& d=11909810$.

[Accessed November 16, 2008].

Gilbert, J. (1995) Studies and fields: directions of research in science education. Studies in Science Education, 25 (1), 173-197.

Gilbert, J. and Swift, D. (1985) Towards a Lakatosian analysis of the Plagetian and alternative conceptions research programmes. Science Education, 69, 681-696.

Gopinathan, S. and Sharpe, L. (2002) The teacher is the key: professionalism and the strategic state. In: E. Thomas (ed.) Teacher Education: Dilemmas and Prospects: World Year Book of Education. London: Kogan Page.

Gorard, S. (2002) Ethics and equity: pursuing the perspective of non-participants. Social Research Update, 39, 1-4.

Gorard, S. and Taylor, C. (2004) Combining Methods in Educational and Social Research. Maidenhead: Open University Press. 
Gorard, S. (2005) Current contexts for research in educational leadership and management. Educational Management Administration and Leadership, 33 (2), 155-164.

Gorard, S., See, B.H., Smith, E. and White, P. (2006) Teacher Supply: the Key Issues. London: Continuum.

Gorard, S., See, B.H., Smith, E. and White, P. (2007) What can we do to strengthen the teacher workforce? International Journal of Lifelong Education, 26 (4), 419-437.

Gorard, S. and Sundaram, V. (2008) Equity and its relationship to citizenship education. In: J. Arthur, I. Davies and C. Hahn (eds.) The Sage Handbook of Education for Citizenship and Democracy. London: Sage

Gredler, M. and Clayton-Shields, C. (2008) Vygotsky's Legacy: A Foundation for Research and Practice. New York: Guilford Press.

Griffiths, M. (1998) Educational Research for Social Justice: Getting off the Fence. Buckingham: Open University Press.

Grinyer, A. (2002) The anonymity of research participants: assumptions, ethics and practicalities. Social Research Update, 36, 1-4.

Grosvenor, I. and Rose, R. (2001) Questionnaires. In: R. Rose and I. Grosvenor (eds.) Doing Research in Special Education: Ideas into Practice. London: David Fulton Publishers.

Gu, M.Y. (2006) The reform and development in teacher education in China. In: N.Z. Zhou (ed.) An International Perspective on Teacher Education: Teacher Education Reform, Teacher Professional Standard and School-Based Teacher Development. Shanghai: East China Normal University Press.

Gu, Q. (2007) Teacher Development: Knowledge and Context. London: Continuum International Publishing Group.

Guay, F., Ratelle, C. and Chanal, J. (2008) Optimal learning in optimal contexts: the role of self-determination in education. Canadian Psychology, 49 (3), 233240.

Guo, H.Y. and Shi, C.X. (2004) Special education student teachers' attitudes towards special education in Hebei Province. Chinese Journal of Special Education, $52(10), 74-77$.

Guo, Y.G. and Lanham, M.D. (2005) Asia's Educational Edge: Current Achievements in Japan, Korea, Taiwan, China, and India. Lanham: Lexington Books.

Guo, L.L. (2008) Current situation of job burnout and its relationship with job characteristics in special education on teachers. Chinese Journal of Special Education, 91 (1), 22-27.

Halasa K. (1998) Annotated bibllography: ethics in educational research. Australian Association for Research in Education (AARE). Available online at: http://www.aare, edu.au/ethics/aareethc.htm[accessed 20 April 2008].

Hall, D. and Langton, B. (2006) Perceptions of the Status of Teachers. Wellington: 
New Zealand Teachers Council and the Ministry of Education. Hannum, E. and Wang, M.Y. (2006) Geography and educational inequality in China. China Economic Review, 17 (3), 253-265.

Hardman, M. (2009) Redesigning the preparation of all teachers within the framework of an integrated program model. Teaching and Teacher Education, 25 (4), 583-587.

Hargreaves, A. (1998) The emotional practice of teaching. Teaching and Teacher Education, 14 (8), 835-854.

Hargreaves, A. (2000) Mixed emotions: teachers' perceptions of their interactions with students. Teaching and Teacher Education, 16 (8), 811-826.

Hargreaves, A. and Fullan, M. (1992) Understanding Teacher Development. New York: Teachers College Press.

Hargreaves, L. (2007) How can the status of teachers and the teaching profession be improved. Paper presented at British Educational Research Association (BERA) Annual Conference, Institute of Education, London, the UK, September, 5-8.

Hausstatter, R. (2007) Students' reasons for studying special needs education: challenges facing inclusive education. Teacher Development, 11 (1), 45-57.

Hawley, W. (1985) Designing and implementing performance-based career ladder plans. Educational Leadership, 43 (3), 57-61.

Hayes, D. (2003) Emotional preparation for teaching: a case study about trainee teachers in England. Teacher Development, 7 (2), 153-171.

Hayhoe, R. (2004) Ten lives in mine: Creating portraits of influential Chinese educators. International Journal of Educational Research, 41 (4-5), 324-338.

Heath, S., Charles, V., Crow, G. and Wiles, R. (2007) Informed consent, gatekeepers and go-betweens: negotiating consent in child-and youth-oriented institutions. British Educational Research Journal, 33 (3), 403-417.

Herzberg, F. (1966)Work and the Nature of Man. Cleveland: World Publishing.

Herzberg, F., Mausner, B. and Snyderman, B. (1993) The Motivation to Work. New Jersey: Transaction Publishers.

Hitchcock, G and Hughes, D. (1995) Research and the Teacher: A Qualitative Introduction to School-Based Research ( $2^{\text {nd }}$ ed.) London: Routledge.

Hodkinson, A. (2005) Conceptions and misconceptions of inclusive education: a critical examination of final-year trainees' knowledge and understanding of inclusion. Research in Education, 73, May,15-28.

Hoyle, E. (1975) Professionality, professionalism and control in teaching. In: V. Houghton, D. McHugh and C. Morgan (eds.) Management in Education: the Management of Organisations and Individuals. Ward Lock Educational in association with Open University Press.

Hu, G.W. (2005) Professional development of secondary EFL teachers: lessons from China. The Teachers College Record, 107 (4), 654-705. 
Hu, X., Chen, G. and Lew, M. (1994) The creation of career counseling in the People's republic of China. Psychology-A Quarterly Journal of Human Behaviour, $31(3 / 4), 37-44$.

Huang, R.J. and Bao, J.S. (2006) Towards a model for teacher professional development in China: introducing Kell. Journal of Mathematics Teacher Education, 9 (3), 279-298.

Hughes, J. and Manuel, J. (2006) 'It has always been my dream': exploring preservice teachers' motivations for choosing to teach. Teacher Development, 10 (1), 5-24.

Hung, F.S., Chung, Y.P. and Ho, E.S. (2000) To work or to continue education? The choice of senior secondary students in Shenzhen, China. Higher Education, 39 (4), 455-467.

Hunt, P. and Goetz, L. (1997) Research on inclusive educational programs, practices, and outcomes for students with severe disabilities. The Journal of Special Education, 31 (1), 3-29.

Hustler, D., McNamara, O., Jarvis, J., Londra, M., Campbell, A. and Howson, J. (2003) Teachers' Perceptions of Continuing Professional Development Research Report RR429: Norwich: Department for Education and Skills, ISBN 184185006 6, Avallable online at:

http://www.dcsf.gov.uk/research/data/uploadfiles/RR429.pdf. [Accessed September 21, 2008].

Hutton, J., Eccles, M. and Grimshaw, J. (2008) Ethical issues in implementation research: a discussion of the problems in achieving informed consent. Implementation Science, 52 (3), 1-8.

International Labour Organization (2007) CEART: Geneva, Avallable online at: http://www.ilo.org/public/english/dialogue/sector/techmeet/cearto6/ceartr.pdf [Accessed August 18, 2008].

Jiang, Y.E., Wang, H. and Fan, L.L. (2008) Presentation and strategies on special education teachers in Jiangsu province. Chinese Journal of Special Education, 98 (8), 45-48.

Johnson, S. (1986) Incentives for teachers: what motivates? what matters? Educational Administration Quarterly, 22 (3), 54-79.

Johnston, B. (1997) Do EFL teachers have careers? TESOL Quarterly, 31 (4), 681 712.

Joint ILO/UNESCO (2006) Committee of Experts on the Application of the Recommendations concerning. Teaching Personnel Report, Ninth Session.

Jordan, A. and Stanovich, P. (2003) Teachers' personal epistemological beliefs about students with disabilities as indictors of effective teaching practices. Journal of Research in Special Educational Needs. 3 (1). Avallable online at: http://www.nasen.uk.com/ejournal/ejprinter.php?id=000059000184,php[Accessed June 17, 2007].

Jordan, A., Schwartz, E. and McGhie-Richmond, D. (2009) Preparing teachers for inclusive classrooms. Teaching and Teacher Education, 25 (4), 535-542. 
Judge, S. and Oreshkina, M. (2004) Special education teacher preparation in Belgium, Russia, and United States: A Comparative Study. Teacher Education and Special Education, 27 (3), 240-250.

Kalyanpur, M. (2008) Equality, quality and quantity: challenges in inclusive education policy and service provision in India. International Journal of Inclusive Education, 12 (3), 243-262.

Kane, R., and Mallon, M. (2006) Perceptions of Teachers and Teaching. Wellington: Ministry of Education and New Zealand Teachers Council.

Katsiyannis, A., Zhang, D. and Conroy, M. (2003) Availability of special education teachers. Remedial and Special Education, 24 (4), 246-253.

Kearns, H. and Shevlin, M. (2006) Initial teacher preparation for special educational needs: policy and practice in the North and South of Ireland. Teacher Development, 10 (1), 25-42.

Kennedy, A. (2005) Models of continuing professional development (CPD): a framework for analysis. Journal of In-Service Education, 31 (2), 235-250.

Khatib, J. (2007) A survey of general education teachers' knowledge of learning disabilities in Jordan. International Journal of Special Education, 22 (1), 72-76.

King, K. and Buchert, L. (eds.) (1999) Changing International Aid to Education. Global Patterns and National Contexts. Paris: UNESCO Publishing/NORRAG.

Kirk, J. and Miller, M. (1986) Reliability and Validity in Qualitative Research. Beverly Hills: Sage.

Klassen, R., Chong, W.H., Huan, V., Wong, I., Kates, A. and Hannok, W. (2008) Motivation beliefs of secondary school teachers in Canada and Singapore: a mixed methods study. Teaching and Teacher Education, 24 (7), 1919-1934.

Kniveton, B. (2004) The influences and motivations on which students based their choice of career. Research in Education, 72, November, 47-59.

Koutrouba, K., Vamvakari, M. and Steliou, M. (2006) Factors correlated with teachers' attitudes towards the inclusion of students with special educational needs in Cyprus. European Journal of Special Needs Education, 21 (4), 381-394.

Kukla, A. (2000) Social Construction and the Philosophy of Science. London: Routledge.

Kuyuni, A. and Desai, I. (2007) Principals and teachers' attitudes and knowledge of inclusive education as predictors of effective teaching practices in Ghana. Journal of Research in Special Educational Needs, 7 (2), $104-113$.

Kyriacou, C., Hultgren, Ã. and Stephens, P. (1999) Student teachers' motivation to become a secondary school teacher in England and Norway. Teacher Development, 3 (3), 373-381.

Lambe, J. (2007) Northern Ireland student teachers' changing attltudes towards inclusive education during initial teacher education. International Journal of Special Education, 22 (1), 59-71.

Lambe, J. and Bones, R. (2006) Student teachers' perceptions about inclusive 
classroom teaching in Northern Ireland prior to teaching practice experience. European Journal of Special Needs Education, 21 (2), 167-186.

Lambe, J. and Bones, R. (2008) The impact of a special school placement on student teacher beliefs about inclusive education in Northern Ireland. British Journal of Special Education, 35 (2), 108-116.

Lamie, J. (2006) Teacher education and training in China: evaluating change with Chinese lecturers of English. Journal of In-service Education, 32 (1), 63-84.

Lent, R., Brown, S. and Hackett, G. (1996) Career development from a sociocognitive perspective. In: D. Brown, and L. Brooks (eds.) Career Choice and Development. San Francisco: Jossey-Bass.

Leyser, Y., Kapperman, G. and Keller, R. (1994) Teacher attitudes toward mainstreaming: a cross-cultural study in six nations. European Journal of Special Needs Education, 9 (1), 1-15.

Li, D.F. (1999) Modernization and teacher education in China. Teaching and Teacher Education, 15 (2), 179-192.

Li, F.L., Morgana, W. and Ding, X.H. (2008) The expansion of higher education, employment and over-education in China. International Journal of Educational Development, 28 (6), 687- 697.

Lim, L. and Tan, J. (2004) Learning and diversity. In: L. Lim and M. Quah (eds.) Educating Learners with Diverse Abilities. Singapore: McGraw Hill.

Lin, J. and Zhang, Y. (2006) Educational expansion and shortages In secondary schools in China: the bottle neck syndrome. Journal of Contemporary China, 15 (47), 255-274.

Lin, S.X. (2000) Survey of research on special education in mainland China in the 1990s. Chinese Journal of Special Education, 27 (3), 1-4.

Lindsay, G. (1997) Are we ready for inclusion? In: G. Lindsay and D. Thompson (eds.) Values into Practice in Special Education. London: Fulton.

Liu, C.L., Du, X.X. and Yao, J. (2000) A study of regular primary school teachers' acceptance of special needs children. Chinese Journal of Special Education, 27 (3), 32-37.

Liu, Q.L. and Wang, H. (2006) Four problems of special education in China. Chinese Journal of Special Education, 71 (5), 33-36.

Liu, T. and LI, K.W. (2006) Disparity in factor contributions between coastal and inner provinces in post-reform China. China Economic Review, 17 (4), 449-470.

Liu, Y. and Xiao, F. (2005) On the issues of teacher education in special education. Teacher Education Study, 17 (4), 47-51.

Liu, Z.Q. (2008) Human capital externalities and rural-urban migration; evidence from rural China. China Economic Review, 19 (3), 521-535.

Livneh, C. and Livneh, H. (1999) Continuing professional education among educators: predictors of participation In learning activities. Adult Education Quarterly, 49 (2), 91-106. 
Loreman, T., Sharma, U., Forlin, C. and Earle, C. (2005) Pre-service teachers' attitudes and concerns regarding inclusive education. Paper presented at the International Special and Inclusive Education Congress (ISEC) University of Strathclyde, Glasgow, Scotland, $1^{\text {st }}-4^{\text {th }}$ August.

Lowes L. and Gill, P. (2006) Participants' experiences of being interviewed about an emotive topic. Journal of Advanced Nursing, 55 (5), 587-595.

Luo, F. (2000) The analysis of definition development of special education for thirty years. Chinese Journal of Special Education, 25 (1), 5-7.

Maandag, D., Deinum, J., Hofman, W. and Buitink, J. (2007) Teacher education in schools: an international comparison. European Journal of Teacher Education, 30 (2), 151-173.

Malmberg, L. (2006) Goal-orientation and teacher motivation among teacher applicants and student teachers. Teaching and Teacher Education, 22 (1), 58-76.

Martinez, R. (2003) Impact of a graduate class on attitudes toward inclusion, perceived teaching efficacy and knowledge about adapting instruction for children with disabilities in inclusive settings. Teacher Development, 7 (3), 473-494.

Maslow, A. (1943) A theory of human motivation. Psychological Review, 50, 370396. Available online at: http://psychclassics.yorku.ca/Maslow/motivation.htm [Accessed March 2007].

Mason, J. (1994) Linking qualitative and quantitative data analysis. In: A. Bryman and R. Burgess (eds.) Analysing Qualitative Data. London: Routledge.

Mason, J. (1996) Qualitative Researching. London: Sage Publications.

Mason, J. (2002) Qualitative Researching (2 ${ }^{\text {nd }}$ ed.). London : Sage.

Mau, W.C. (2000) Cultural differences in career decision-making styles and selfefficacy. Journal of Vocational Behavior, 57 (3), 365-378.

Maxwell, J. (1996) Qualitative Research Design: An Interactive Approach. Thousand Oaks: Sage Publications.

Maxwell, J. A. (1992) Understanding and validity in qualitative research. Harvard Educational Review, 62 (3), 279-300.

McCabe, H. (2008) Effective teacher training at the autism Institute in the People's Republic of China. Teacher Education and Special Education, 31 (2), 103 117.

McCarthy, J. (2006) Revisiting constructivism. LEARN Journal of the Irish Learning Support Association, 28, 26-35.

McCormack, A., Gore, J. and Thomas, K. (2006) Early teacher professional learning. Asia-Pacific Journal of Teacher Education, 34 (1), 95-113.

Mcleskey, F. and Ross, D. (2004) The politics of teacher education in the new millennium: implications for special education teacher educators. Teacher Education and Special Education, 27 (4), 342-349. 
McLoughlin, C., Zhou, Z. and Clark, E. (2005) Reflections on the development and status of comtemporary special education services in China. Psychology in the Schools, 42 (3), 273-283.

McMahon, M. (1997) Social constructivism and World Wide Web: a paradigm for learning. ASCILITE Proceedings, 411-417.

Meijer, C. (2003) (ed.) Inclusive Education and Classroom Practices. Middlefart: European Agency for Development in Special Needs Education.

Meijer, C., Soriano, V. and Watkins, A. (2003) Special Needs Education in Europe: Thematic Publication. Middelfart: European Agency for Development in Special Needs Education.

Merriam, S. (1998) Qualitative Research and Case Study: Applications in Education, Revised and Expanded from Case Study Research in Education. San Francisco: Jossey-Bass.

Merriam, S. (1988) Case Study Research in Education. San Francisco: Jossey Bass.

Miles, M. and Huberman, A. (1984) Qualitative Data Analysis: A Sourcebook of New Methods. Beverly Hills: SAGE Publications

Miles, M. and Huberman, A. (1994) Qualitative Data Analysis: An Expanded Sourcebook. London: SAGE Publications

Miller, W. Crabtree, B. (1999) The dance of interpretation. In: B. Carbtree and W. Miller (eds.) Doing Qualitative Research. Thousands Oaks, California: Sage.

Ministry of Education of China (1986) The Law of 9 Years' Compulsory Education of the People Republic of China. Available online at: http://www.moe.edu.cn [Accessed April 2, 2006]

Ministry of Education of China (2003) Full-time Teachers in Special Education Schools Broken down by Rank and Age. Available online at:

http://www. moe.edu.cn/edoas/website 18/level3.jsp?tablename $=10628 \mathrm{infold}=14$ $\underline{302}$ [Accessed April 2, 2006].

Ministry of Education of China (2005) 2004 National Statistical Bulletin Report on the Development of Education Work. Available online at:

http://www.edu.cn/20050728/3144984.shtml [Accessed December 15, 2008].

Ministry of Education of China (1993) Outlines for Education Reform and Development. Available online at:

Http://www.moe.edu.cn/edoas/website18/info1428.htm [Accessed on October $20,2006]$.

Ministry of Education of China (2001) The Guidelines on Curriculum Reform of Basic Education (for experiment). Beijing: Ministry of Education, China. Avallable from: http://www.moe.edu.cn/edoas/website18/info732,htm [Accessed April 2, 2006].

Ministry of Education of Finland (1993) Comprehensive School Act. Helsinki: Ministry of Education.

Mitchell, D. (2004) General introduction. In: D. Mitchell (ed.) Special Educational 
Needs and Inclusive Education: Systems and Contexts. London: Taylor and Francis.

Mitchell, D. (2005) Sixteen propositions on the contexts of inclusive education. In: D. Mitchell (ed.) Contexualising Inclusive Education: Evaluating Old and New International Perspectives. London: Routledge.

Mitchell, D. and Desai, I. (2005) Diverse socio-cultural contexts for inclusive education in Asia. In: D. Mitchell (ed.) Contexualising Inclusive Education: Evaluating Old and New International Perspectives. London: Routledge.

Mittler, P. (2000) Working towards Inclusive Education. London: David Fulton. Moran, A. (2007) Embracing inclusive teacher education. European Journal of Teacher Education, 30 (2), 119-134.

National People's Congress of China (1990) Law of the People's Republic of China on the Protection of Disabled Persons. Beijing: Legal System Publishers.

National People's Congress of China (1993) The Teacher Act. Beijing: Legal System Publishers.

National People's Congress of China (1994) The Education Act for the Disabled. Beijing: National People's Congress.

National People's Congress of China (1995) The Education Act. Beijing: Legal System Publishers.

National People's Congress of China (2006) The Compulsory Educational Laws of the People Republic of China (revised). Beijing: National People's Congress.

New statistical Yearbooks (2008) Basic Statistics on Special Education. Beijing: China Statistics Press. Available online at:

http://www.sei.gov.cn/hgji/yearbook/2008/left.htm. [Accessed on January 10 2009].

Nilholm, C. (2006) Special education, inclusion and democracy. European Journal of Special Needs Education, 21 (4), 431- 445.

Norwich, B. (2008a) Dilemmas of Difference, Inclusion and Disability: International Perspectives and Future Directions. London: Routledge.

Norwich, B. (2008b) What future for speclal schools and inclusion? Conceptual and professional perspectives. British Journal of Special Education, 35 (3), 136143.

Nunan, D. (2001) Is language teaching a profession? TESOL in Context, 11 (1), August. Available online at: http://www,tesol.org.au/docs/572edited.pdf [Accessed May 17, 2008].

Nunkoosing, K. (2005) The problems with interviews. Qualitative Health Research, 15 (5), 698-706.

Oancea, A. (2005) Criticisms of educational research: key topics and levels of analysis. British Educational Research Journal, 31 (2), 157-183.

Ocloo, M. and Subbey, M. (2008) Perception of basic education school teachers 
towards inclusive education in the Hohoe District of Ghana. International Journal of Inclusive Education, 12 (5-6), 639-650.

Oppenheim, A. (1992) Questionnaire Design, Interviewing and Attitude Measurement. London: Printer.

Organisation for Economic Co-operation and Development/World Education Indicators (OECD/WEI) (2005) Education trends in perspective analysis of the World Education Indicators. Available online at:

http://www.uis.unesco.org/TEMPLATE/pdf/wei/WEI2005.pdf, [Accessed July 23, 2008].

Organisation for Economic Co-operation and Development /World Education Indicators (OECD/WEI) (2005) Education Trends in Perspective Analysis of the World Education Indicators. Available online at:

http://www.uis.unesco.org/TEMPLATE/pdf/wei/WEI2005.pdf. [Accessed July 23, 2008].

Oyserman, D., Coon, H. and Kemmelmeier, M. (2002) Rethinking individualism and collectivism: evaluation of theoretical assumptions and meta-analyses. Psychological Bulletin, 128 (1), 3 -72.

Paine, L. (1991) Reforming teachers: the organization, reproduction and transformation of teaching. In: I. Epstein (ed.) Chinese Education: Problems, Policies and Prospects. New York: Garland.

Paine, L. and Fang, Y.P. (2006) Reform as hybrid model of teaching and teacher development in China. International Journal of Educational Research, 45 (4-5), 279-289.

Paine, L. and Fang, Y.P. (2007) Dilemmas in reforming China's teaching: assuring quality in professional development. In: M. Tatto (ed.) Reforming Teaching Globally. Oxford Studies in Comparative Education: Symposium Books.

Pang, Y.H. and Richey, D. (2006a) The development of special education in China. International Journal of Special Education, 21 (1), 77-86.

Pang, Y.H. and Richey, D. (2006b) China's challenge for the future: familycentredness in early children special education. The Journal of the International Association of Special Education, 7 (1), 11-21.

Patton, M. (2002) Qualitative Evaluation and Research Methods. Thousand Oaks: Sage Publications.

Payne, R. (2005) Special education teacher shortage: barriers or lack of preparation? International Journal of Special Education, 20 (1), 88-91.

Pelletier, L., Se'guin-Le'vesque, C. and Legault, L. (2002) Pressure from above and pressure from below as determinants of teachers' motivation and teaching behaviour. Journal of Educational Psychology, 94 (1), 186-196.

Peng, X.G. (2003) The study on teachers' attitude towards integration handicapped students. Chinese Journal of Special Education, 38 (2), 10-15.

Phillips, D. and Ochs, K. (2003) Processes of policy borrowing in education: some explanatory and analytical Devices. Comparative Education, 39 (4), 451-461. 
Piao, Y.Q. (1992) Introduction to Special Education. Beijlng: China: Huaxia Press. Piao, Y.Q. (1995) Study of Special Education. Fujian: Fujian Education Publishing House.

Pijl, S. (2007) Introduction: the social position of pupils with special needs in regular education. European Journal of Special Needs Education, 22 (1), 1-5.

Pijl, S., Meijer, C. and Hegarty, S. (1997) Inclusive Education: A Global Agenda. London: Routledge.

Pion, G.M., Smith, D.D. and Tyler, N.C. (2003) Career choice of recent doctorates in special education: their implications for addressing faculty shortage. Teacher Education and Special Education, 26 (3), 182-194.

Poland, B. (2002) Transcription quality. In: J. Gubrium and J. Holstein (eds.) Handbook of Interview Research. Thousands Oak: Sage.

Porter, L. and Lawler, E. (1968) Managerial Attitudes and Performance. Homewood: Irwin-Dorsey.

Potts, P. (1995) Reforming special education in China. In: P. Potts, F. Armstrong and M. Masterton (eds.) Equality and Diversity in Education (2): National and International Contexts. London: Routledge and the Open University.

Potts, P. (2000) A Western perspective on inclusion in Chinese urban educational settings. International Journal of Inclusive Education, 4 (4), 301-313.

Potts, P. (2003) Modernising Education in Britain and China: Comparative Perspectives on Excellence and Social Inclusion. London: RoutledgeFalmer.

Prawatt, R. and Floden, R. (1994) Philosophical perspective on constructivist views of learning. Educational Psychology, 29 (1), 37-48.

Priyadharshini, E. and Robinson-Pant, A. (2003) The attractions of teaching: an investigation into why people change careers to teach. Journal of Education for Teaching, 29 (2), 95-112.

Punch, M. (1986) The politics and ethics of fieldwork: muddy boots and grubby hands. Qualitative Research Methods. Series No. 3, California: Sage Publications.

Punch, K. (2003) Survey Research: The Basics. London: Sage.

Punch, K. (2005) Introduction to Social Research: Quantitative and Qualitative Approaches (2nd ed.). London: SAGE.

Qian, T. (1994) Adult education in China: policies and practice in the 1980 s. Review of Policy Research, 13 (3-4), 391-414.

Qian, Z.L. and Liu, W. (2002) Beljing Normal University and special education in China. Teacher Education Research, 14 (4), 44-47.

Reeve, J. (2002) Self-determination theory applied to educational settings. In: E. Deci and R. Ryan (eds.) Handbook of Self-Determination Research. Rochester: University of Rochester Press.

Reid, I. and Caudwell, J. (1997) Why did secondary PGCE students choose teaching as a career? Research in Education, 58, 46 -58. 
Reiss, S. (2000) Who Am I? The 16 Basic Desires That Motivate Our Actions and Define Our Personalities. New York: Tarcher/Putnum.

Reiss, S. (2004) Multifaceted nature of intrinsic motivation: the theory of 16 basic desires. Review of General Psychology, 8 (3), 179-193.

Richards, G. and Clough, P. (2004) ITE students' attitudes to Inclusion. Research in Education, 72, 77-86.

Richards, J. Nunan, D. (1990) Second Language Teacher Education. Cambridge: Cambridge University Press.

Richards, J. and Farrell, T. (2005) Professional Development for Language Teachers: Strategies for Teacher Learning. Cambridge: Cambridge University Press.

Richardson, P. and Watt, H. (2005) 'I've decided to become a teacher': influences on career change. Teacher and Teacher Education, 21 (5), 475-489.

Richardson, P. and Watt, H. (2006) Who chooses teaching and why? Profiling characteristics and motivations across three Australian universities. Asia-Pacific Journal of Teacher Education, 34 (1), 27-56.

Rinke, C. (2008) Understanding teachers' careers: linking professional life to professional path. Educational Research Review, 3 (1), 1-13.

Robinson, B. and Yi, W.W. (2008) The role and status of non-governmental ('daike') teachers in China's rural education. International Journal of Educational Development, 28 (1), 35-54.

Robson, C. (2002) Real World Research (2 ${ }^{\text {nd }}$ ed.). Oxford: Blackwell.

Rose, R. and Grosvenor, I. (2001) Interviews. In: R. Rose and I. Grosvenor (eds.) Doing Research in Special Education: Ideas into Practice. London: David Fulton Publishers.

Rose, R. (2002) Including pupils with special educational needs: beyond rhetoric and towards an understanding of effective classroom practice. Westminster Studies in Education, 25 (1), 67-76.

Rose, R. (2000) Creating the Conditions for Inclusion in Primary Schools in the UK. Paper presented at the International Special Education Congress, University of Manchester, the UK, $24^{\text {th }}-28^{\text {th }}$ July.

Rose, R. (2007) Reinterpreting inclusion: putting participation at the heart of the agenda. LEARN, Journal of the Irish Learning Support Association, 29, 26-32.

Rose, R. (2003) Inclusive education and pupils with special educational needs: rights, responsibilities and pragmatics. Inaugural professorial lecture presented at the University of Northampton.

Rose, R. and Jones, K. (2007) The efficacy of a volunteer mentoring scheme in supporting young people at risk. Emotional and Behavioural Difficulties, 12 (1), 314.

Rose, R., Smith, A. and Feng, Y. (2009) Supporting pupils and families: a case 
study of two English extended secondary schools. British Educational Leadership, Management and Administration Society (BELMAS), 23(2), 57-62.

Rouse, M. and Florian, L. (1997) Inclusive education in the market-place. International Journal of Inclusive Education, 1 (4), 323-336.

Ryan, R. and Brown, K. (2005) Legislating competence: the motivational impact of high stakes testing as an educational reform. In: C. Dweck and A. Elliot (eds.) Handbook of Competence. New York: Guilford Press.

Ryan, R. and Deci, E. (2000a) Intrinsic and extrinsic motivations: classic definitions and new directions. Contemporary Educational Psychology, 25 (1), 5467.

Ryan, R. and Deci, E. (2000b) Self-determination theory and the facilitation of intrinsic motivation, social development and well-being. American Psychologist, $55(1), 68-78$.

Ryan, R. and Deci, E. (2002) Overview of self-determination theory: an organismic dialectical perspective. In: E. Decl, and R. Ryan, (eds.) Handbook of Self-Determination Research. The University of Rochester Press.

Schon, D. (1983) The Reflective Practitioner: How Professionals Think in Action. USA: Basic Books.

Scott, C., Cox, S. and Dinham, S. (1999) The occupational motivation, satisfaction and health of English school teachers. Educational Psychology, 19 (3), 287-308.

Seale, C. (2004) Analysing qualitative data. In: C. Seale (ed.) Social Research Methods. London: Routledge.

Sebba, J. and Ainscow, M. (1996) International development in inclusive schooling: mapping the issues. Cambridge Journal of Education, 26 (1), 5-19.

Sharma, U., Forlin, C., Loreman, T. and Earle, C. (2006) Pre-service teachers' attitudes, concerns and sentiments about inclusive education: an international comparison of the novice pre-service teachers. International Journal of Special Education, 21(2), 80-93.

Shevlin, M. and Rose, R. (eds.) (2003) Encouraging Voices: Respecting the Insights of Young People Who Have Been Marginalised. Dublin: National Disability Authority

Shi, X.G. and Englert, P. (2008) Reform of teacher education in China. Journal of Education for Teaching, 34 (4), 347-359.

Silverman, D. (2001) Interpreting Qualitative Data: Methods for Analysing Talk, Text and Interaction ( $2^{\text {nd }}$ ed.). London: Sage.

Simina V. and Hamel M. (2005) CASLA through a social constructivist perspective: Web-Quest in project-driven language learning. ReCALL, 17 (2), 217-228.

Sin, K. (2004) Catering for students' different needs in teacher training. Special Education Forum, 7 (1), 102-109. 
Sinclair, C. (2008) Initial and changing student teacher motivation and commitment to teaching. Asia-Pacific Journal of Teacher Education, 36 (2), 79 104.

Siniscalco, M. (2002) A Statistical Profile of the Teaching Profession. International Labour Office, Geneva, United Nations Educational, Scientific and Cultural Organization, Paris, ISBN 92-2-113115-7.

Slee, R. (ed.) (1993) Is There a Desk with My Name on It? The Politics of Integration. London: The Falmer Press.

Slee, R. (2001) Inclusion in practice: does practice make perfect? Educational Review, 53 (2), 113-123.

Slee, R. (2005) Education and the politics of recognition: inclusive education-an Australian snapshot. In: D. Mitchell (ed.) Contexualising Inclusive Education: Evaluating Old and New International Perspectives. London: Routledge.

Slee, R. (2006) Limits to and possibilities for educational reform. International Journal of Inclusive Education, 10 (2-3), 109-119.

Smith, C. and Gillespie, M. (2007) Research on professional development and teacher change: implications for adult basic education. In: J. Comings, B. Garner and C. Smith (eds.) Review of Adult Learning and Literacy (vol. 7): Connecting Research, Policy and Practice. London: Routledge.

Smith, C. and Varma, V. (eds.) (1996) A Handbook of Teacher Development. Aldershot: Arena.

Smith, D., Pion, G., Tyler, N. and Gilmore, R. (2003) Doctoral Programs In Special Education: The Nation's Supplier. Teacher Education and Special Education, 26 (3), 172-182.

Song, H.Z. (2008) Sleeping giant: Chinese teacher education system past, present and future (I). On the Horizon, 16 (3), 137-142. Emerald Group Publishing Limited.

Song, M. and Xu, J.C. (2006) Study of teacher's work related stress in the special education field (review). Chinese Journal of Rehabilitation Theory Practice, 12 (12), 1083-1085.

Spear, M., Gould, K. and Lee, B. (2000) Who Would Be a Teacher? A Review of Factors Motivating and De-motivating Prospective and Practising Teachers. Slough: NFER.

Spittle, M., Jackson, K. and Casey, M. (2009) Applying self-determination theory to understand the motivation for becoming a physical education teacher. Teaching and Teacher Education, 25 (1), 190-197.

SSA. (2007) Inclusive Education in SSA (online). Available from: http://ssa.nic.in/childspl/overview\%200n\%20inclusive $\% 20$ education.pdf[Accesse d on April 15, 2008].

State Council of China (1996) The Outline of the $9^{\text {th }}$ Five Year National Development Plan for the Disabled (1996-2000). Beijing: Huaxia Press.

Stempien, L. and Loeb, R. (2002) Differences in job satisfaction between general 
education and special education teachers: implications for retention. Remedial and Special Education, 23 (5), 258-267.

Stout, R. (1996) Staff development policy: fuzzy choices in an imperfect market. Education Policy Analysis Archives, 4 (2). ISSN 1068-2341Retrieved March 31, 2006, Available online from: http://epaa.asu.edu/epaa/v4n2,html. [Accessed October 23, 2008].

Strauss, A. (1987) Qualitative Analysis for Social Scientists. Cambridge: Cambridge University Press.

Strauss A. and Corbin, J. (1990) Basics of Qualitative Research: Grounded Theory Procedures and Techniques. Newbury Park, CA: Sage.

Su, L. (1993) The Handbook of Learning in Regular Classrooms for Children with Visual Impairments. Beijing: Huaxia Press.

Su, Z.X. (1997) Teaching as a profession and as a career: minority candidates' perspectives. Teaching and Teacher Education, 13 (3), 325-340.

Symeonidou, S. and Phtiaka, H. (2009) Using teachers' prior knowledge, attitudes and beliefs to develop in-service teacher education courses for inclusion. Teaching and Teacher Education, 25 (4), 543-550.

Tatto, M. (2007) International comparisons and the global reform of teaching. In: M. Tatto (ed.) Reforming Teaching Globally. Oxford Studies in Comparative Education: Symposium Books.

Tatto, M. and Plank, D. (2007) Conclusion: the dynamics of global teaching reform. In: M. Tatto (ed.) Reforming Teaching Globally. Oxford Studies in Comparative Education: Symposium Books.

Tesch, R (1990) Qualitative Research: Analysis Types and Software Tools. New York: The Falmer Press.

Thomas, G. and Loxley, A. (2007) Deconstructing Special Education and Constructing Inclusion. Buckingham: Open University Press.

Thomas, G., Walker, D. and Webb, J. (1998) The Making of the Inclusive School. London: Routledge.

Tilstone, C., Florian, L. and Rose, R. (eds.) (1998) Promoting Inclusive Practice. London: Routledge.

Tilstone, C. (2003) Professional development of staff: steps towards developing policies. In: $C$, Tilstone and $R$, Rose (eds.) Strategies to Promote Inc/usive Practice. London: Routledge

Tilstone, C. and Rose, R. (eds.) (2003) Strategies to Promote Inclusive Practice. London: Routledgefalmer.

Tinker, A. and Coomber, V. (2004) University Research Ethics Committees: Their Role, Remit and Conduct. London: King's College.

Trahar, S. (ed.) (2006) Narrative research on learning: comparative and international perspectives. Bristol Papers in Education, Oxford: Symposium Books. 
Tyler, N., Smith, D. and Pion, G. (2003) Doctorial students In special education: characteristics and career aspirations. Teacher Education and Special Education, 26 (3), 194-206.

United Nations Educational, Scientific and Cultural Organisation (UNESCO, 1990) World Declaration on Education for All and Framework for Actions to Meet Basic Learning Needs (Jomtien, Thailand). Paris: UNESCO.

United Nations Educational, Scientific and Cultural Organisation (UNESCO, 1994) The Salamanca Statement and Framework for Action on Special Needs Education, Paris: UNESCO.

United Nations Educational, Scientific and Cultural Organisation (UNESCO, 1998) From Special Needs Education to Education for All: Discussion Paper for the International Consultative Forum on Education for All. Paris: UNESCO.

United Nations Educational, Scientific and Cultural Organisation (UNESCO, 2000) Education for All: Meeting our Collective Commitments. The Dakar Framework for Action. Paris: UNESCO

United Nations Educational, Scientific and Cultural organization (UNESCO, 2001) The Open File on Inclusive Education. Paris: UNESCO.

United Nations Educational, Scientific and Cultural Organisation (UNESCO, 2005) Education for All (EFA) Global Monitoring Report- The Quality Imperative. Paris: Author. Cited in Singal, N. (2006) Inclusive education in India: international concept, national interpretation. International Journal of Disability, Development and Education. 53 (3), 351-369.

United Nations Educational, Scientific and Cultural Organisation (UNESCO/UIS, 2006a) Teacher Supply and Demand in East Asia and the Pacific,Available online at:

http://www, uis.unesco.org/TEMPLATE/pdf/Teachers2006/Regional Profiles/RegPro file EAsiaPacific.pdf [accessed June 20, 2008].

United Nations Educational, Scientific and Cultural Organisation (UNESCO, 2006b) Guidebook for Planning Education in Emergencies and Reconstruction: Teacher Motivation, Compensation and Work Conditions. Paris, Available online at: http://www.unesco.org/ilep, [Accessed August 10, 2008].

United Nations Educational, Scientific and Cultural Organisation (UNESCO, 2007) The Global Action Plan: Improving Support to Countries in Achieving the Goals of Education For All. Available online at:

http://www.unesco.org/education/GAP/GAP v04.pdf [Accessed February 13 2009].

United Nations Educational, Scientific and Cultural Organisation (UNESCO, 2008) Education for All: Global Monitoring Report. Available online at:

http://unesdoc.unesco.org/images/0015/001548/154820e,pdf. [Accessed November 28 2008].

United Nations Educational, Scientific and Cultural Organisation (UNESCO, 2008) Education for All: Will We Make It (Summary) Global Monitoring Report. Available online at: http://unesdoc.unesco.org/images/0015/001548/154820e.pdf

[Accessed December 12, 2008]. 
United Nations (1993) Standard Rules on the Equalisation of Opportunities for Persons with Disability. New York: United Nations.

United Nations (1993) Conventions on Children's Rights. New York: United Nations.

Vallerand, R. (2000) Deci and Ryan's self-determination theory: a view from the hierarchical model of intrinsic and extrinsic motivation. Psychological Inquiry, 11 (4), 312-318.

Vallerand, R., Pelletier, L., Blais, M., Briere, N., Senecal, C. and Vallieres, E. (1992) The academic motivation scale: a measure of intrinsic motivation, extrinsic motivation, and amotivation in education. Education and Psychological Measurement, 52, 1003-1017.

Vallerand, R. and Ratelle, C. (2002) Intrinsic and extrinsic motivation: A hierarchical model. In: E. Deci, and R. Ryan (eds.) Handbook of SelfDetermination Research. New York: The University of Rochester Press.

Vallerand, R., Pelletier, L. and Koestner, R. (2008) Reflections on selfdetermination theory. Canadian Psychology, 49 (3), 257-262.

Vaughn, S., Schumm, J. and Sinagub, J. (1996) Focus Group Interviews in Education and Psychology. Thousand Oaks: SAGE Publications.

Villegas-Reimers, E. (2003) Teacher Professional Development: An International Review of the Literature. Paris: UNESCO International Institute for Educational Planning.

Vroom, V. (1964) Work and Motivation. New York: Wiley.

Vulliamy, G. (1990a) The potential of qualitative educational research strategies in developing countries. In: G. Vulliamy, K. Lewin and D. Stephens (eds.) Doing Educational Research in Developing Countries: Qualitative Strategies. London: The Falmer Press.

Vulliamy, G.. (1990b) Research processes: postscript. In: G. Vulliamy, K. Lewin and D. Stephens (eds.) Doing Educational Research in Developing Countries: Qualitative Strategies. London: The Falmer Press.

Vulliamy, G., Lewin, K. and Stephens, D. (1990) Doing Educational Research in Developing Countries: Qualitative Strategies. London: RoutledgeFalmer.

Vulliamy, G. and Webb, R. (eds.) (1992) Teacher Research and Special Educational Needs. London: David Fulton.

Wan, L.L., Wang, H.P., Du, X.X. and Chen, R.E (2008) An investigation into special education teachers' professionalization in Shanghal. Chinese Journal of Special Education, 98 (8), 49-53.

Wan, Y.M. and Peterson, M. (2007) A case study of a merger in Chinese higher education: the motives, processes, and outcomes. International Journal of Educational Development, 27 (6), 683-696.

Wang, H. (2006) An investigation report on problems in compulsory education development for special children in China. Chinese Journal of Special Education, 76 (10), 3-9. 
Wang, H. (2007) The Current research situations and developmental trends of educational diagnosis and assessment for children with special needs in China. Chinese Journal of Special Education, 88 (10), 14-20.

Wang, H.Y. (2008) Preparing teachers to work with young children with disabilities. In: C, Forlin and J, Ming-Gon (eds.) Reform, Inclusion and Teacher Education: Towards a New Era of Special Education in the Asia Pacific Region. London: Routledge.

Wang, J.P. (2004) The teacher education in China: its status quo, problems and tendency. Teacher Education Research, 16 (5), 3-12.

Wang, M.R. (1988) The social context of adult education in China. New Directions for Continuing Education, 37, Spring, 5-11.

Wang, Y., Gu, D.Q. and Chen, Y.Q. (2004) Discussion about advanced teacher's training in the field of special education. Teacher Education Research, 16 (4), 5560.

Warnock, H.M. (1978) Special Educational Needs: Report of the Committee of Enquiry into the Education of Handicapped Children and Young People. London: Her Majesty's Stationery Office.

Wasburn-Moses, L. (2008) Satisfaction among current doctoral students in special education. Remedial and Special Education, 29 (5), 259-268.

Watson, K. (ed.) (2001) Doing Comparative Education Research: Issues and problems. Oxford: Symposium Books.

Watts, A. and Sultana, R. (2004) Career guidance policies in 37 countries: contrasts and common themes. International Journal for Educational and Vocational Guidance 4 (2-3), 105-122.

Watt, H. and Richardson, P. (2007) Motivational factors influencing teaching as a career choice: development and validation of the FIT-Choice scale. The Journal of Experimental Education, 75 (3), 167-202.

Watt, H. and Richardson, P. (2008) Motivations, perceptions, and aspirations concerning teaching as a career for different types of beginning teachers. Learning and Instruction, 18 (5), 408-428.

Webster, L. and Mertova, P. (2007) Using Narrative Inquiry as a Research Method: An Introduction to Using Critical Event Narrative Analysis in Research on Learning and Teaching. London: Routledge.

Wedell, K. (2008) Confusion about inclusion: patching up or system change. British Journal of Special Education, 35 (3), 127 - 135.

Wei, X.M. and Yuan, W.D. (2000) Mainstream primary teachers and special school teachers' attitudes towards inclusion of children with special needs in mainstream schools. Chinese Journal of Special Education, 27 (3), 31-33.

Wen, W., Xie, W.H. and LI, L.F. (2007) Changes to the higher education structure of a transitional society: a case study of China. Paper presented at the British Educational Research Association Annual Conference, Institute of Education, London, the Uk September 5-8. 
Wigfield, A. and Eccles, J. (2000) Expectancy-value theory of achievement motivation. Contemporary Educational Psychology, 25 (1), 68-81.

Wilczenski, F. (1992) Measuring attitudes towards inclusive education. Psychology in the Schools, 29 (4), 306-312.

Wilczenski, F. (1995) Development of a scale to measure attitudes towards inclusive education. Educational and Psychological Measurement, 55 (2), 291299.

Wingfield-Hayes, R. (BBC News, March 2006) China's rural millions left behind. Beijing, 13:17 GMT http://news.bbc.co.uk/1/hi/world/asia-pacific/4782194.stm [Accessed July 18 2008].

Wragg, E. (1994) An Introduction to Classroom Observation. London: Routledge.

Wu, C.Y. (2005) Changing concepts: the prerequisite of the implementation of inclusive education. Chinese Journal of Special Education, 58 (4), 60-64.

Wu, Z.J. (2004) Being, understanding and naming: teachers' life and work in harmony. International Journal of Educational Research, 41 (4-5), 307-323

Wu, Z.J. (2005) Teachers'Knowing in Curriculum Change. Beijing: Foreign Language and Research Press.

Xiao, F. (2005) Mainstreaming in China: history, actuality and perspectives. Chinese Journal of Special Education, 57 (3), 3-7.

Xu, S.J. and Connelly, M. (2009) Narrative inquiry for teacher education and development: focus on English as foreign language in China. Teaching and Teacher Education, 25 (2), 219-227.

Xu, J.C. (2008) Meeting new challenges of special education In China. In: C. Forlin and M.J. Lian (eds.) Reform, Inclusion and Teacher Education. London:

Routledge.

Yang, H.L. and Wang, H.B. (1994) Special education in China. Journal of Special Education, 28 (1), 93-105.

Yang, D.P. and Wu, J.Q. (1999) Some issues in the reform and development of teacher education and training in China. Teacher Development, 3 (2), 157-172.

Yang, R. (2000) Tensions between the global and the local; a comparative illustration of the reorganization of China's higher education in the 1950 s and 1990s. Higher Education, 39 (3), 319-337.

Yang, S.H. (2008) Narrative of a cross-cultural language teaching experience: Conflicts between theory and practice. Teaching and Teacher Education, 24 (6), 1564-1572.

Yin, R. (1993) Applications of Case Study Research. London: Sage.

Yong, B. (1995) Teacher trainees' motives for entering into a teaching Career in Brunei Darussalam. Teaching and Teacher Education, 11 (3), 275-280. 
Young, B. (1995) Career plans and work perceptions of pre-service teachers. Teaching and Teacher Education, 11 (3), 281-292.

Younger, M., Brindley, S., Pedder, D. and Hagger, H. (2004) Starting points: student teachers' reasons for becoming teachers and their preconceptions of what this will mean. European Journal of Teacher Education, 27 (3), 245-264.

Yu, S.H. (2008) The present situation and future development of the special education teacher certification system in Shanghai. Chinese Journal of Special Education, $96(6)$, 52-57.

Yuen, M. and Westwood, P. (2001) Integrating students with special needs in Hong Kong secondary schools: teachers' attitude and their possible relationship to guidance training. International Journal of Special Education, 16 (2), 69-84.

Zhang, N.S. and Chen, G.H. (2002) A review of integration: the attitudes of primary teacher toward students with special need 'learning in regular schools'. Chinese Journal of Special Education, 34 (2), 1-6.

Zhang, Q.Y. and Watkins, D. (2007) Conceptions of a good tertiary EFL teacher in China. TESOL Quarterly, 41(4), 781-790.

Zhang, W. (2001) Rethinking regional disparity in China. Economics of Planning, $34(1-2), 113-138$.

Zhang, W.Y., Hu, X. and Pope, M. (2002) The evolution of career guidance and counseling in the People's Republic of China. The Career Development Quarterly, $50(3), 226-236$.

Zhang, W. and Pope, M. (1997) History of career counseling in USA, China, and Hong Kong. In: W. Evraiff (ed.) Proceedings of the Sixth International Counseling Conference. Beijing: Beijing Normal University Press.

Zhao, Y., Zhang, G.M., Yang, W.Z., Kirkland, D., Han, X. and Zhang, J.W. (2008) A comparative study of educational research in China and the United States. Asia Pacific Journal of Education, 28 (1), 1-17.

Zhou, J. and Reed, L. (2005) Chinese government documents on teacher education since the 1980s. Journal of Education for Teaching, 31 (3), 201-213.

Zuo, R.Y. and Wang, W.H. (2008) Deficiency and Improvement of pre-school teachers' professional quality from the perspective of inclusive education. Chinese Journal of Special Education, 96 (6), 8-12. 